Universidade de São Paulo

Instituto de Astronomia, Geofísica e Ciências Atmosféricas

Departamento de Astronomia

Vinicius Moris Placco

\title{
Busca por Estrelas Muito Pobres em Metais Baseada no Enriquecimento em Carbono
}

São Paulo 

Vinicius Moris Placco

\section{Busca por Estrelas Muito Pobres em Metais Baseada no Enriquecimento em Carbono}

Tese apresentada ao Departamento de Astronomia do Instituto de Astronomia, Geofísica e Ciências Atmosféricas da Universidade de São Paulo como requisito parcial para a obtenção do título de Doutor em Ciências.

Área de Concentração: Astronomia Orientadora: Prof. ${ }^{a}$ Dr. ${ }^{a}$ Silvia Rossi

São Paulo 

Ao dia de amanhã 



\section{Agradecimentos}

À Carol, por todo o amor, dedicação e por sempre entender que as minhas ausências iriam contribuir para o meu crescimento pessoal e profissional;

Aos meus pais, Sylvio e Inez, e irmãos, Matheus e Juliana, que apoiaram as minhas escolhas desde o curso de Física e acreditaram no meu potencial;

À Silvia Rossi, por me apresentar às estrelas pobres em metais, pela orientação desde o trabalho de graduação e pela orientação "não-científica" durante esses anos de convivência;

Aos pesquisadores: Timothy C. Beers, pelo exemplo de pesquisador e pelas valiosas dicas que enriqueceram meu trabalho. Seu entusiasmo pelas estrelas pobres em metais mostrado em nossas conversas me fez querer continuar neste caminho; Norbert Christlieb, por ceder a base de dados para este trabalho, por toda a ajuda com a seleção e inspeção visual dos espectros, e por me receber em seu instituto; Young S. Lee, Catherine Kennedy, Thirupathi Sivarani, Dieter Reimers e Lutz Wisotzki, pela co-autoria nos artigos;

Aos colegas: "Dotô" Alessandro Pereira Moisés, pelo grande auxílio com a revisão gramatical do texto, e ao sempre guerreiro Tiago "Zé Colméia" Mendes de Almeida, que dividiu sala comigo por um bom tempo e me aguentou quase um mês na Índia. Agradeço também aos dois pelo companheirismo e co-autoria do blog Café com Ciência; Alan Alves Brito, pela leitura criteriosa dos meus textos e pelas dicas valiosas em meus projetos futuros; Felipe Santos, Oscar Cavichia e Márcio Avellar, pela força nos estudos de final de semana para o exame de qualificação. Além disso, agradeço novamente ao Oscar pela coautoria do IAGTESE, template para $\mathrm{LT}_{\mathrm{E} X}$ que foi utilizado para redigir esta tese e muitas outras dissertações e teses no IAG; Rodrigo Holanda, Gleidson Gomes da Silva, Marcus Vinicius, Raimundo Lopes, Rafael Kimura, Rafael Santucci, Alan Alves do Carmo, Douglas Augusto de Barros, José Fernando de Jesus, Gustavo Rocha, Rodrigo Vieira e Victor Hugo, 
companheiros de bandejão e frequentadores eventuais do cafézinho da F-312. Não poderia deixar de agradecer também aos colegas da graduação em física (Monstros) e aos meus amigos desde sempre: Bola, Capixaba, HT e Montanha;

Aos Professores: Dra. Beatriz Barbuy pela relatoria deste trabalho, Dr. Jacques Lépine por ministrar a disciplina Estrutura da Galáxia, Dra. Cláudia Mendes de Oliveira e Dra. Sandra dos Anjos pela orientação no estágio supervisionado em ensino do PAE;

Às "meninas" da secretaria (Marina, Regina, Cida e Conceição), ao pessoal da informática (Marco, Luís, Ulisses e Patrícia), à Irene (que sempre manteve a sala impecável) e a todo o pessoal da limpeza, segurança e administração do IAG, que sempre proporcionaram um ambiente favorável para fazer pesquisa;

À Ana, ao Celso e à Camila, que sempre me recebem muito bem em sua casa e me fazem sentir como parte da família;

À FAPESP, pelo apoio financeiro, sob o projeto $\mathrm{n}^{\mathrm{o}}$ : 2007/04356-3;

À CAPES (Coordenação de Aperfeiçoamento de Pessoal de Nível Superior), MSU (Michigan State University), JINA (Joint Institute for Nuclear Astrophysics), Universität Heidelberg, IIA (Indian Institute of Astrophysics) e IAU (International Astronomical Union), pelo apoio financeiro em estágios e conferências;

À corrida, que me faz acordar todos os dias às 5 h da manhã, me traz saúde, disposição e com certeza me ajudou a vencer a maratona da pós-graduação.

Esta tese foi escrita em IATEX com a classe IAGTESE, para teses e dissertações do IAG. 
"O teu começo vem de muito longe.

O teu fim termina no teu começo.

Contempla-te em redor.

Compara.

Tudo é o mesmo.

Tudo é sem mudança.

Só as cores e as linhas mudaram. Que importa as cores, para o Senhor da Luz?

Dentro das cores a luz é a mesma. Que importa as linhas, para o Senhor do Ritmo?

Dentro das linhas o ritmo é igual.

Os outros vêem com os olhos ensombrados.

Que o mundo perturbou,

Com as novas formas.

Com as novas tintas.

Tu verás com os teus olhos.

Em Sabedoria.

E verás muito além."

Cecília Meireles - Cântico XXI

"If you are not prepared to be wrong, you will never come up with anything original."

Ken Robinson 



\section{Resumo}

O principal objetivo deste trabalho é mostrar que é possível buscar por estrelas pobres em metais a partir da premissa de que uma grande fração destas será rica em carbono. Essa hipótese ainda não havia sido verificada pois muitas das chamadas estrelas CEMP (Carbon Enhanced Metal-Poor) foram negligenciadas em estudos anteriores devido à forma como foram executadas as buscas por estas estrelas. Estes objetos são importantes pois assumem o papel de registros fósseis das primeiras gerações estelares, uma vez que retêm em suas atmosferas informações vitais acerca da composição química do meio em que foram geradas. Por não apresentarem bandas moleculares intensas de carbono em seus espectros, muitas dessas estrelas não foram selecionadas para estudos em média/alta resolução.

Este trabalho fornece, a partir do estudo da parte estelar do HES (Hamburg/ESO Survey), dois novos índices de linha para a região da banda G (4304A). Estes, pelo fato de possuírem uma largura de banda de $200 \AA$, conseguem superar falhas dos índices anteriormente definidos e representam com fidelidade as principais características desta região.

Após uma análise detalhada da base de dados, e do cálculo dos novos índices de linha para todos os objetos disponíveis, foram identificadas 132 novas estrelas pobres em metais, sendo que $51 \%$ destas possuem metalicidades abaixo de $[\mathrm{Fe} / \mathrm{H}]<-1.0$ e apresentam consideráveis enriquecimentos em carbono $([\mathrm{C} / \mathrm{Fe}]>+0.5)$. Já para as estrelas encontradas com $[\mathrm{Fe} / \mathrm{H}]<-2.5$, a fração de estrelas com abundâncias de carbono $[\mathrm{C} / \mathrm{Fe}]>+1.0$ chega a 80\%. Estimativas de abundâncias de elementos químicos tais como bário e estrôncio revelam que, mesmo com parâmetros atmosféricos e abundâncias de carbono semelhantes, as estrelas analisadas por este trabalho possuem mais de um tipo de cenário possível para sua formação. Finalmente, este trabalho contribui também com uma lista de 6123 candidatas a estrelas CEMP inéditas na literatura. 



\section{Abstract}

The main goal of this work is to show that is possible to search for metal-poor stars based on the premise that a large fraction of these will be carbon-rich. This hypothesis had not yet been verified because many of the so-called CEMP (Carbon Enhanced Metal-Poor) stars were neglected in previous studies due to the design of the search for metal-poor stars with carbon enhancements. Those objects play a major role as fossil records of the very first generation of stars, since they carry in their atmospheres vital informations concerning the chemical composition of the medium where they were formed. By not showing strong carbon molecular bands in their spectra, many of those stars were not selected for follow-up studies in medium/high resolution.

This work provides, based on the study of the stellar part of the HES (Hamburg/ESO Survey), two new line indices for the G band (4304 $\AA$ ) that, by having a line band of $200 \AA$, can overcome the flaws of the previously defined indices and also truly represent the main features of this region.

After an extensive analysis of the database and the calculation of the line indices for all the available objects, 132 new metal-poor stars were identified with the SOAR telescope, being that $51 \%$ of those stars with $[\mathrm{Fe} / \mathrm{H}]<-1.0$ present considerable carbon enhancements $([\mathrm{C} / \mathrm{Fe}]>+0.5)$. For the observed stars with $[\mathrm{Fe} / \mathrm{H}]<-2.5$, the fraction of objects with $[\mathrm{C} / \mathrm{Fe}]>+1.0$ rises up to $80 \%$. Abundance estimates for barium and strontium show that, even with similar atmospheric parameters and carbon abundances, the stars analyzed in this work have more than one possible formation scenario. Finally, this work also contributes with a 6123 CEMP star candidate list of unpublished objects. 



\section{Lista de Figuras}

1.1 Comportamento da linha K do Ca II em função da metalicidade. . . . . . . 28

1.2 Painel superior: (1) surveys de grande abertura (p. ex., HK, HES) que fornecem as estrelas candidatas a pobres em metais. Painel central: (2) seleção das candidatas via follow-up de espectroscopia em média resolução. Painel inferior: (3) espectroscopia em alta resolução das candidatas confirmadas como estrelas pobres em metais. Figura adaptada de Christlieb (2003). . . 30

1.3 Diferentes graus de enriquecimento em carbono. . . . . . . . . . . . . . . 33

1.4 Comportamento das abundâncias de carbono e bário em função da metalicidade para as estrelas do HERES. Figura adaptada de Placco (2007). . . .

2.1 Exemplo de cálculo de GPHES. O valor do índice é dado pela área em verde, delimitada pelo ajuste linear entre os valores centrais das bandas laterais. Também é mostrada a linha K do Ca II. O eixo de comprimento de onda está colocado partindo do vermelho para o azul, como apresentado nos espectros originais do HES. . . . . . . . . . . . . . . . . . .

2.2 Exemplo da nova definição do índice para a banda $\mathrm{G}$ do $\mathrm{CH}$. A linha preta cheia mostra o ajuste de contínuo aplicado às estrelas neste trabalho. Também é mostrada a comparação entre o índice GPHES (área em verde) e o novo índice GPE (área em vermelho). As setas representam os valores centrais das bandas laterais utilizadas para o ajuste do contínuo de GPHES. Também é mostrada a linha K do Ca II. O eixo de comprimento de onda está colocado partindo do vermelho para o azul, como apresentado nos espectros originais do HES. . . . . . . . . . . . . . . . 
2.3 Definição do índice EGP. A área delimitada em vermelho representa a banda lateral e a área em verde representa a banda da linha. Também é mostrada a linha K do CaII. O eixo de comprimento de onda está colocado partindo do vermelho para o azul, como apresentado nos espectros originais do HES.

2.4 Comportamento da abundância de carbono dos objetos da base de dados SAGA em função dos índices de linha GPE e EGP. . . . . . . . . . . . . . 50

2.5 Comportamento da abundância de carbono dos objetos da base de dados SAGA em função da metalicidade para dois intervalos do índice GPE. . . .

3.1 Painel superior: Placa digitalizada do Digitized Sky Survey I. Painel inferior: Placa de prisma-objetivo digitalizada do HES referente ao mesmo campo do painel superior. . . . . . . . . . . . . . . . . . .

3.2 Painel esquerdo: Comparação entre o volume do céu observado pelos dois surveys. Painel direito: área de cobertura do HES (áreas delimitadas) em comparação com os locais onde se encontram as candidatas a estrelas pobres em metais descobertas pelo survey HK. Figura retirada de Christlieb (2003). 55

3.3 Distribuição dos índices de linha e cor para a subamostra de teste do HES. 58

3.4 Comportamento do índice KPHES em função dos parâmetros calculados pelas equações 3.1 e 3.2. O tamanho dos pontos é proporcional ao valor do índice GPHES. . . . . . . . . . . . . . . . . . . . . . 59

3.5 Distribuição dos novos índices de linha. . . . . . . . . . . . . . . . 62

3.6 Distribuição dos novos índices de linha em função do índice de cor $(\mathrm{J}-\mathrm{K})_{0}$. 63

4.1 Distribuição do índice GPE em função de $(\mathrm{J}-\mathrm{K})_{0}$, para as 85894 candidatas (pontos cinzas) e estrelas de Aoki et al. (2007) (círculos pretos). A linha sólida horizontal mostra o limite para GPE. . . . . . . . . . . . . . .

4.2 Comparação entre o índice GPHES previamente calculado para as estrelas do HES e o novo índice GPE. Os círculos pretos em destaque são as estrelas de Aoki et al. (2007) . . . . . . . . . . . . . . . . . . . 
4.3 Painel superior: seção da placa fotográfica do DSS-I, centralizada no objeto de interesse. Painel central: placa de prisma objetivo digitalizada do HES. Painel inferior: espectro extraído da estrela de interesse. As linhas verticais identificam as linhas H e K do Ca II (próximas a $4000 \AA$ ) e a região da banda G (próxima a $4300 \AA)$. . . . . . . . . . . . . . . . . . . 70

4.4 Exemplos de objetos que caracterizam as classes descritas na Tabela 4.2. . 72

4.5 Diagrama índice-cor para as estrelas que foram submetidas à inspeção visual, divididas de acordo com as classes definidas na Tabela 4.3. As estrelas presentes em Aoki et al. (2007) estão representadas pelos símbolos em verde. 74

4.6 Paineis superiores: Ajustes polinomiais para valores constantes de metalicidade, baseados em Christlieb et al. (2008). Paineis inferiores: Critério de seleção para eliminar estrelas com a linha K do CaII intensa (mpcc). Os pontos pretos representam as estrelas onde a linha K do Ca II encontra-se ausente (mpca), fraca (mpcb) ou não encontrada (unid). Os pontos cinzas representam as estrelas mpcc, e são selecionadas aquelas que se encontram abaixo da linha $[\mathrm{Fe} / \mathrm{H}] \leq-2.0$ para ao menos um dos índices de cor. . . . . 76

4.7 Exemplo de candidatas à estrelas CEMP observadas segundo o novo critério de índice de linha. Os espectros foram tomados com o espectrógrafo Goodman no telescópio SOAR. . . . . . . . . . . . . . .

4.8 Exemplo do procedimento adotado pelo SSPP para o cálculo dos parâmetros atmosféricos para 5 das 132 candidatas a estrelas CEMP. Da esquerda para a direita são exibidos: o espectro original, a região das linha do Ca II, com os ajustes por síntese espectral e os espectros com o contínuo subtraído. . .

4.9 Distribuição de $T_{\text {eff }}$ e $\log g$ para as 132 candidatas observadas com o SOAR. 88

4.10 Distribuição de metalicidades para as 132 candidatas observadas com o SOAR. As setas indicam os locais dos picos em $[\mathrm{Fe} / \mathrm{H}]$ para a distribuição observada, que encontram-se próximos àqueles associados pelo trabalho de Carollo et al. (2007) às populações do halo externo $(\mathrm{OH} ;[\mathrm{Fe} / \mathrm{H}]=-2.2)$, halo interno $(\mathrm{IH} ;[\mathrm{Fe} / \mathrm{H}]=-1.6)$, disco espesso pobre em metal (MWTD; $[\mathrm{Fe} / \mathrm{H}]=-1.3)$ e disco espesso canônico $(\mathrm{TD} ;[\mathrm{Fe} / \mathrm{H}]=-0.6) . . .$. 
4.11 Comportamento da metalicidade em função do índice GPE para as candidatas observadas e para as estrelas CEMP de Aoki et al. (2007). . . . . . . 90

4.12 Determinação da abundância de carbono para uma das estrelas da subamostra. O painel superior mostra parte do espectro original (em preto) sobreposto por um espectro sintético (em vermelho) com os parâmetros atmosféricos listados e $[\mathrm{C} / \mathrm{Fe}]=0.0$. O painel central mostra a região ao redor da banda $G$, com uma linha vermelha mostrando o melhor ajuste. A linha verde representa a divisão entre o espectro original e o espectro sintético, que deve apresentar valores próximos de 1.0 para um ajuste considerado satisfatório. O painel inferior mostra o resultado do melhor ajuste com o valor listado de $[\mathrm{C} / \mathrm{H}] . \ldots \ldots \ldots \ldots \ldots$

4.13 Comportamento da metalicidade com a abundância de carbono $[\mathrm{C} / \mathrm{Fe}]$ para as candidatas observadas e para as estrelas presentes em Aoki et al. (2007). As flechas representam os limites superiores. As linhas pontilhadas mostram

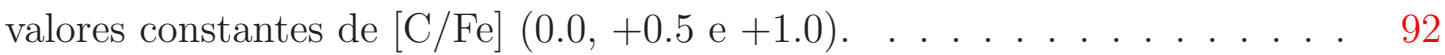

4.14 Exemplo de identificação das linhas de $\operatorname{Sr}(4077 \AA)$ e Ba $(4554 \AA)$. . . . . . 94

4.15 Comportamento das abundâncias estimadas dos elementos Ba e Sr em função da metalicidade. As linhas pontilhadas mostram valores constantes das

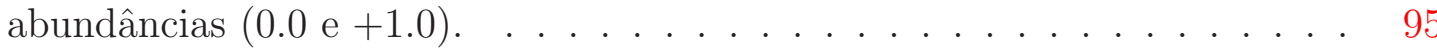

4.16 Distribuição das abundâncias de carbono em relação ao bário. O tamanho dos pontos indica a escala de metalicidade. As áreas delimitadas representam as definições das classes de estrelas CEMP presentes na Tabela 1.2. As linhas pontilhadas mostram valores constantes de $[\mathrm{C} / \mathrm{Fe}](0.0,+0.5 \mathrm{e}+1.0) .96$

4.17 Critério de seleção para estrelas ricas em carbono no plano dos índices $\mathrm{C}_{2} \mathrm{e}$ CN. As linhas tracejadas delimitam a área de ocorrência das estrelas ricas em carbono segundo Christlieb et al. (2001). . . . . . . . . . . . . . . . . 98

4.18 Estrela EMP HE 1045+0226 observada neste trabalho. Em destaque estão a linha K do Ca II e a banda G do CH. . . . . . . . . . . . . . . . . . . 99

4.19 Estrelas CEMP inéditas na literatura observadas com o SOAR. . . . . . . 100 
5.1 Painel superior: exemplo de fonte brilhante saturada. Painel inferior: exemplo de espectro não saturado. Note a diferença na ordem de grandeza no eixo $y$, que representa as contagens. . . . . . . . . . . . .

5.2 Distribuição dos índices de linha GPE e EGP para os objetos da segunda subamostra, divididos por tipo de fonte. A escala do eixo y é dada em frequência relativa, para facilitar a visualização. . . . . . . . . . . . . . 108

5.3 Comportamento da magnitude B em função da magnitude interna spcmag. 109

5.4 Histogramas normalizados para correção do índice GPE, divididos em intervalos de spcmag. . . . . . . . . . . . . . . . . . .

5.5 Histogramas normalizados para correção do índice EGP, divididos em intervalos de spcmag. . . . . . . . . . . . . . . . . . . . . 112

5.6 Ajustes polinomiais para as correções de saturação dos índices de linha. 114

5.7 Distribuição dos índices de linha corrigidos da segunda subamostra. . . . . 116

5.8 Comportamento do índice GPE em função de $(\mathrm{J}-\mathrm{K})_{0}$ para os dados da segunda subamostra, separados em dois intervalos de EGP. Os círculos pretos mostram os dados de Aoki et al. (2007). . . . . . . . . . . . . 117

5.9 Distribuição dos índices de linha GPE e EGP para os dados da segunda subamostra. As linhas pretas mostram os limites definidos para a inspeção visual das candidatas a estrelas CEMP. Os círculos pretos mostram os dados de Aoki et al. (2007) . . . . . . . . . . . . . . . . . . .

5.10 Comportamento dos índices de linha para os objetos inspecionados da segunda subamostra, divididos de acordo com as classes da Tabela 4.3. . . .

5.11 Comportamento do índice GPE em função da cor $(\mathrm{J}-\mathrm{K})_{0}$. Os símbolos utilizados são os mesmos exibidos na Figura 5.10. . . . . . . . . . . .

5.12 Candidatas selecionadas por inspeção visual da segunda subamostra do HES. Os painéis superiores mostram estrelas com bandas moleculares de carbono intensas $(f h l c)$. Nos painéis centrais e inferiores estão exibidas, respectivamente, estrelas com a linha K do Ca II fraca (mpca) e intensa ( mpcc). Também estão identificadas as principais linhas características de cada espectro.

A.1 Espectros das estrelas observadas com o SOAR (1). 
A.2 Espectros das estrelas observadas com o SOAR (2) . . . . . . . . . . . 152

A.3 Espectros das estrelas observadas com o SOAR (3) . . . . . . . . . . . 153

A.4 Espectros das estrelas observadas com o SOAR (4). . . . . . . . . . . . 154

A.5 Espectros das estrelas observadas com o SOAR (5). . . . . . . . . . . 155

A.6 Espectros das estrelas observadas com o SOAR (6) . . . . . . . . . . . 156

A.7 Espectros das estrelas observadas com o SOAR (7) . . . . . . . . . . 157

A.8 Espectros das estrelas observadas com o SOAR (8). . . . . . . . . . 158

A.9 Espectros das estrelas observadas com o SOAR (9). . . . . . . . . . . . . 159

A.10 Espectros das estrelas observadas com o SOAR (10) . . . . . . . . . . . . . 160

A.11 Espectros das estrelas observadas com o SOAR (11). . . . . . . . . . . . 161

A.12 Espectros das estrelas observadas com o SOAR (12) . . . . . . . . . . . . 162

A.13 Espectros das estrelas observadas com o SOAR (13). . . . . . . . . . . . 163

A.14 Espectros das estrelas observadas com o SOAR (14). . . . . . . . . . . . 164

B.1 Fluxograma de cálculo dos índices GPE e EGP . . . . . . . . . . . 165 


\section{Lista de Tabelas}

1.1 Nomenclatura para metalicidade (Beers e Christlieb, 2005) . . . . . . . . . . 29

1.2 Classificação de estrelas pobres em metais enriquecidas em carbono. . . . . 35

2.1 Definições dos principais índices de linha da banda $\mathrm{G}$ do $\mathrm{CH}$ encontrados na literatura. Os valores são mostrados em A. . . . . . . . . . . . . . . . . 44

4.1 Parâmetros das estrelas CEMP de Aoki et al. (2007) utilizados neste trabalho. 66

4.2 Descrição das classes utilizadas na inspeção visual. . . . . . . . . . . . . . . 71

4.3 Distribuição das candidatas selecionadas via inspeção visual. . . . . . . . . . 71

4.4 Parâmetros estelares e índices de linha $(\AA)$ para as candidatas observadas. $\quad 78$

4.4 Parâmetros estelares e índices de linha $(\AA)$ para as candidatas observadas. $\quad 79$

4.4 Parâmetros estelares e índices de linha $(\AA)$ para as candidatas observadas. $\quad 80$

4.4 Parâmetros estelares e índices de linha $(\AA)$ para as candidatas observadas. 81

4.5 Parâmetros atmosféricos e $[\mathrm{C} / \mathrm{Fe}]$ para as candidatas observadas. . . . . . 83

4.5 Parâmetros atmosféricos e $[\mathrm{C} / \mathrm{Fe}]$ para as candidatas observadas. . . . . . 84

4.5 Parâmetros atmosféricos e $[\mathrm{C} / \mathrm{Fe}]$ para as candidatas observadas. . . . . . 85

4.5 Parâmetros atmosféricos e [C/Fe] para as candidatas observadas. . . . . . 86

4.6 Critérios de seleção para estrelas ricas em carbono (Christlieb et al., 2001). 98

5.1 Parâmetros adotados para as correções de saturação. . . . . . . . . . . . 113

5.2 Distribuição das candidatas selecionadas via inspeção visual. . . . . . . . . 119

5.3 Comparação dos resultados das inspeções visuais. . . . . . . . . . . . . . . 123

C.1 Objetos inéditos selecionados neste trabalho. O índice GPE é dado em A. 176

C.1 Objetos inéditos selecionados neste trabalho. O índice GPE é dado em $\AA . \quad 177$ 
C.1 Objetos inéditos selecionados neste trabalho. O índice GPE é dado em A. 178

C.1 Objetos inéditos selecionados neste trabalho. O índice GPE é dado em $\AA$.

C.1 Objetos inéditos selecionados neste trabalho. O índice GPE é dado em A. 180

C.1 Objetos inéditos selecionados neste trabalho. O índice GPE é dado em A. 181

C.1 Objetos inéditos selecionados neste trabalho. O índice GPE é dado em A. 182

C.1 Objetos inéditos selecionados neste trabalho. O índice GPE é dado em $\AA$.

C.1 Objetos inéditos selecionados neste trabalho. O índice GPE é dado em A. 184

C.1 Objetos inéditos selecionados neste trabalho. O índice GPE é dado em $\AA$.

C.1 Objetos inéditos selecionados neste trabalho. O índice GPE é dado em A. 186

C.1 Objetos inéditos selecionados neste trabalho. O índice GPE é dado em A. 187

C.1 Objetos inéditos selecionados neste trabalho. O índice GPE é dado em $\AA$.

C.1 Objetos inéditos selecionados neste trabalho. O índice GPE é dado em A. 189

C.1 Objetos inéditos selecionados neste trabalho. O índice GPE é dado em A. 190 


\section{Sumário}

1. Introdução . . . . . . . . . . . . . . . . . . . . . . . . . . 23

1.1 Cenário Atual . . . . . . . . . . . . . . . . . . . . . . 24

1.2 Busca por Estrelas Pobres em Metais . . . . . . . . . . . . . . . . . . . . . 27

1.3 Estrelas Pobres em Metais Enriquecidas em Carbono . . . . . . . . . . . . 31

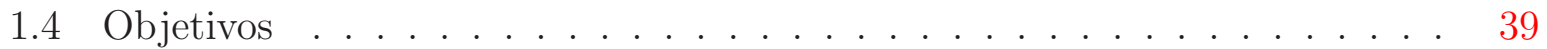

2. Novos Índices de Linha para a Banda $G$ do $C H$. . . . . . . . . . . . . . . . . . 43

2.1 Por que procurar novos Índices para o Carbono? . . . . . . . . . . . . . . . 44

2.2 GPE - Ajuste de Contínuo . . . . . . . . . . . . . . . . 46

2.3 EGP - Razão entre Fluxos . . . . . . . . . . . . . . . . . . . . . . . . . 48

2.4 Teste com a Base de Dados SAGA . . . . . . . . . . . . . . . 50

3. Base de Dados . . . . . . . . . . . . . . . . . . . . . . . . . . . . . . . . 53

3.1 O Hamburg/ESO Survey . . . . . . . . . . . . . . . . . . . . . . 53

3.2 Caracterização da Amostra . . . . . . . . . . . . . . . . . . . . . . 56

$3.2 .1 \quad$ Análise Exploratória . . . . . . . . . . . . . 56

3.2.2 Cálculo dos Índices GPE e EGP para as Estrelas do HES . . . . . . 60

4. Primeira Subamostra . . . . . . . . . . . . . . . . . . . . 65

4.1 Seleção de Candidatas a Estrelas CEMP . . . . . . . . . . . . . . . . 65

4.1 Restrições à Base de Dados . . . . . . . . . . . . . . . . . . . . 67

4.1 .2 Inspeção Visual . . . . . . . . . . . . . . . . . . . . . . . . . . . . . 69

4.1.3 Seleção no Plano Cor vs. Índice de Linha . . . . . . . . . . . . . . . 74 
4.2 Validação das Candidatas a Estrelas CEMP . . . . . . . . . . . . . 76

4.2.1 Observações Espectroscópicas em Média Resolução ...... 77

4.2.2 Parâmetros Atmosféricos e Abundâncias de Carbono . . . . . . . . 82

4.3 Estimativas para Abundâncias de $\mathrm{Ba}$ e $\mathrm{Sr}$. . . . . . . . . . . . . . . 93

4.4 Discussão . . . . . . . . . . . . . . . . . . . . . . . . . 96

5. Segunda Subamostra . . . . . . . . . . . . . . . . . . . . . . 103

5.1 Restrições à Base de Dados . . . . . . . . . . . . . . . . . . . 104

5.1.1 Estrelas - Source type: STARS . . . . . . . . . . . . . . . 104

5.1.2 Fontes brilhantes - Source type: BRIGHT . . . . . . . . . . . . 105

5.1 .3 Comportamento dos Índices de Linha . . . . . . . . . . . . . . . . . 106

5.2 Correções de Saturação para Fontes Brilhantes . . . . . . . . . . . . . . . . 109

5.3 Critério de seleção baseado nos índices GPE e EGP . . . . . . . . . . . . . 116

5.4 Inspeção Visual . . . . . . . . . . . . . . . . . . . . . . . . . . . . . . . 119

5.5 Discussão . . . . . . . . . . . . . . . . . . . . . . . . . . 122

6. Conclusões . . . . . . . . . . . . . . . . . . . . . . . . . 127

6.1 Principais Resultados . . . . . . . . . . . . . . . 127

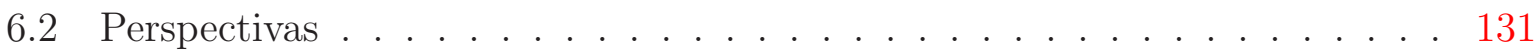

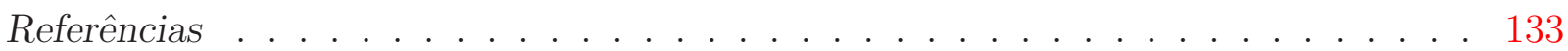

$\begin{array}{ll}\text { Apêndice } & 149\end{array}$

A. Estrelas Observadas com o SOAR . . . . . . . . . . . . . . . . 151

B. Código Fonte para Cálculo dos Índices de Linha . . . . . . . . . . . . . . . . . . 165

C. Objetos Inéditos Classificados por Inspeção Visual . . . . . . . . . . . . . . . . . 175 
Capítulo 1

\section{Introdução}

Um dos grandes desafios da astrofísica moderna é compreender a origem dos elementos químicos. Para responder tal questão, deve-se explorar o laboratório mais espetacular providenciado pela natureza: as estrelas nascidas nos primórdios da história do Universo, e mais especificamente da Via Láctea. Estes objetos retêm em suas atmosferas informações acerca das abundâncias químicas ligadas diretamente aos eventos responsáveis pela formação dos primeiros elementos.

Durante a última metade do século passado, astrônomos prosseguiram metodicamente desde o reconhecimento inicial de estrelas com metalicidades significativamente menores que o Sol (Chamberlain e Aller, 1951), até chegarem a reunir amostras compostas por milhares de estrelas com metalicidades inferiores a 1\% da abundância solar. O survey HK de Beers e colaboradores (Beers et al., 1985, 1992), por exemplo, identificou 1000 estrelas $\operatorname{com}[\mathrm{Fe} / \mathrm{H}]^{1}<-2.0, \sim 100 \mathrm{com}[\mathrm{Fe} / \mathrm{H}]<-3.0$ além de alguns objetos com abundâncias $[\mathrm{Fe} / \mathrm{H}] \sim-4.0$, que na época acreditava-se ser o limite de deficiência em metais da Galáxia.

O sucesso do survey HK inspirou uma expansão da busca por estrelas de metalicidade extremamente baixa. Por exemplo, pode-se citar o HES (Hamburg/ESO Survey - Reimers, 1990; Christlieb, 2003; Christlieb et al., 2008), que fez crescer exponencialmente o número de estrelas com $[\mathrm{Fe} / \mathrm{H}]<-2.0$, quando comparado ao número de estrelas identificadas anteriormente pelo survey HK. Além disso, durante esta nova campanha observacional, foram encontradas as estrelas mais deficientes em metais conhecidas até o momento: HE 01075240, com $[\mathrm{Fe} / \mathrm{H}]=-5.2$ (Christlieb et al., 2002; Bessell et al., 2004), HE 1327-2326, com $[\mathrm{Fe} / \mathrm{H}]=-5.4$ (Frebel et al., 2005) e HE 0557-4840, com $[\mathrm{Fe} / \mathrm{H}]=-4.75$ (Norris et al., 2007).

\footnotetext{
${ }^{1}[\mathrm{~A} / \mathrm{B}]=\log \left(N_{A} / N_{B}\right)_{\star}-\log \left(N_{A} / N_{B}\right)_{\odot}$, onde $N$ refere-se às abundâncias por número de átomos de um dado elemento e os índices referem-se à estrela $(\star)$ e ao Sol $(\odot)$
} 


\subsection{Cenário Atual}

Nos dias de hoje, sabe-se que estrelas com atmosferas cujas abundâncias metálicas são substancialmente menores que sua contrapartida solar fornecem subsídios fundamentais para estudos em física e astrofísica. Dentre os principais temas, pode-se destacar:

- A natureza do Big Bang: teorias de nucleossíntese do Big Bang (BBN - Big Bang Nucleosynthesis), aliadas à densidade de bárions obtida pelo WMAP (Wilkinson Microwave Anisotropy Probe - Dunkley et al., 2009), predizem a abundância primordial do elemento químico lítio após os primeiros minutos da criação do Universo. No entanto, existem discrepâncias entre estes valores e aqueles inferidos através do estudo de estrelas pobres em metais (ver, por exemplo, Asplund et al., 2006; Aoki et al., 2009; García Pérez et al., 2009), o que sugere que diferentes abordagens, tanto em teorias de BBN quanto nos mecanismos que podem ocorrer no interior estelar (Piau et al., 2006; Meléndez et al., 2009; Spite e Spite, 2010), devem ser utilizadas.

- A origem das Primeiras Estrelas: modelos atuais e limites observacionais sugerem que a formação estelar teve início não mais que algumas dezenas de milhões de anos após o Big Bang (início da época da reionização - Miralda-Escudé, 2003; Raue et al., 2009) e, muito provavelmente, foi responsável pela produção dos primeiros elementos mais pesados que o Li. O sítio dessa primeira produção de elementos químicos provavelmente está associado a explosões de estrelas de alta massa formadas em um ambiente pobre em metais (Bromm e Larson, 2004). Estes objetos de tempo de vida curto podem ter fornecido para o meio interestelar as primeiras sementes de elementos pesados, o que influencia fortemente a história da evolução química da Via Láctea (Ballero et al., 2006) assim como a formação das gerações estelares subsequentes.

- A primeira função de massa (First Mass Function - FMF): a distribuição de massas com a qual as estrelas se formaram durante a história do Universo é um parâmetro de fundamental importância para modelos de evolução de galáxias. Embora a função de massa inicial (Initial Mass Function - IMF) observada hoje pareça ser bem descrita por leis de potência (Salpeter, 1955; Miller e Scalo, 1979; Scalo, 1998), é muito provável que ela seja muito diferente da FMF, associada com as primeiras formações estelares no Universo. Dadas as características dos objetos extremamente pobres em 
metais, sugere-se que a FMF para metalicidades próximas de zero fosse inclinada à formação de objetos de alta massa (de População III - Tumlinson, 2007). Estudos detalhados de padrões de abundâncias elementais em estrelas de baixa metalicidade (ver, por exemplo, os trabalhos de Barklem et al., 2005; Jonsell et al., 2006; Placco, 2007; Bonifacio et al., 2009; Roederer et al., 2009) constituem uma das várias metodologias pelas quais pode-se inferir os principais parâmetros da FMF.

- O comportamento da função de distribuição de metalicidades (Metallicity Distribution Function - MDF) do halo Galáctico: amostras de estrelas pobres em metais como a dos recém compilados SEGUE 1 e 2 (Sloan Extension for Galactic Exploration and Understanding - Yanny et al., 2009), que são surveys complementares do SDSS (Sloan Digital Sky Survey - York et al., 2000), tornaram possível confrontar a distribuição observada de metalicidades com modelos detalhados de evolução química galáctica (como, por exemplo, o modelo de duplo infall proposto por Chiappini et al., 1997). Além disso, a partir da análise da MDF em função de grandezas cinemáticas e dinâmicas, é possível inferir a presença de uma variedade de componentes estruturais na Galáxia (Carollo et al., 2007), como o halo interno e o halo externo. Esses componentes exibem perfis de densidades espaciais, órbitas estelares e metalicidades distintos, que corroboram com a hipótese de que tais estruturas possuem diferentes histórias de formação (Beers, 2009) e devem ser construídos separadamente em um modelo de evolução para a Via Láctea.

- Predições de produção de elementos químicos por explosões de supernovas: o padrão de abundâncias químicas formado em uma explosão de supernova fornece parâmetros de entrada essenciais para modelos teóricos computacionais de evolução estelar (Nomoto et al., 2006). A partir do estudo dessas abundâncias em estrelas pobres em metais (que, presumivelmente, não sofreram poluição de gerações estelares posteriores), é possível restringir o intervalo de massas das estrelas progenitoras das supernovas (Qian e Wasserburg, 2003), bem como associar tais objetos aos seus prováveis sítios de formação, e assim inferir características importantes tanto da população estelar que deu origem a essas estrelas pobres em metais quanto da evolução química da Galáxia (Wanajo e Ishimaru, 2006). 
- Os locais de produção de elementos formados por captura de nêutrons: elementos além do pico do Fe (A 60) são formados principalmente por captura de nêutrons (processo-s e processo-r - ver Burbidge et al., 1957, para uma descrição detalhada destes processos) em vários sítios astrofísicos. Modelos do processo-s (por exemplo Kappeler et al., 1989), no qual as escalas de tempo para captura de nêutrons por sementes do pico do Fe são maiores que o tempo requerido para o decaimento beta, podem ser comparados com abundâncias observadas em estrelas pobres em metais com massas entre 1.0 e $4.0 \mathrm{M}_{\odot}$ (Herwig, 2005), quando estas se encontram no ramo assimptótico das gigantes (AGB - Asymptotic Giant Branch). Nesta fase ocorrem sucessivos pulsos térmicos e episódios de mistura de material da superfície com as camadas mais internas da estrela, fazendo com que os elementos formados pelo processo-s possam ser detectados. Da mesma forma, a compreensão da natureza do processo-r, onde as capturas de nêutrons ocorrem mais rapidamente que o decaimento beta, pode ser testada pelo confronto das predições dos modelos (Qian, 2005) com as abundâncias de elementos pesados observadas em estrelas muito pobres em metais (por exemplo Depagne et al., 2002; Sivarani et al., 2006; Cowan et al., 2008).

- Estudo das origens dos elementos carbono, nitrogênio e oxigênio: as sequências de reações químicas básicas para a formação de C, N e O são bem compreendidas atualmente. Entretanto, os locais astrofísicos onde essas reações ocorrem e quais dominaram durante a história do Universo são objetos de estudo, uma vez que a presença de elementos como C e O aumenta significativamente com a diminuição da metalicidade (Rossi et al., 1999) em estrelas de baixa massa. Somente certos ambientes astrofísicos alcançam temperaturas e pressões suficientes para que tais reações aconteçam. Aparentemente, uma série de cenários pode contribuir, desde sistemas binários formados por estrelas de massas baixas e intermediárias (Herwig, 2004), até possíveis mecanismos de produção intrínsecos ainda não descobertos. De qualquer forma, alguns cenários propostos são mais eficientes que outros, e operam em diferentes épocas. Diante disso, restam as estrelas de baixa massa com longos tempos de vida, que são registros fósseis da formação dos primeiros elementos químicos (Salvadori et al., 2007), por serem formadas a partir de um gás poluído pela explosão de estrelas de alta massa e preservarem o resultado da nucleossíntese em suas atmosferas. 


\subsection{Busca por Estrelas Pobres em Metais}

Como visto acima, informações sobre o período de transição de uma IMF que forma uma maior quantidade de estrelas primordiais de alta massa para uma que forme as primeiras estrelas pobres em metais de baixa massa é de vital importância para o entendimento dos processos de formação das primeiras galáxias e da Via Láctea. Infelizmente, a população de estrelas pobres em metais conhecida ainda não é grande o bastante para determinar empiricamente a metalicidade crítica das primeiras estrelas de baixa massa (Tumlinson, 2006, 2007; Salvadori et al., 2007). Dessa forma, deve-se continuar a busca iniciada nos surveys HK, HES e SDSS por estrelas pobres em metais.

Uma das claras evidências que corrobora com a busca pelo maior número possível de estrelas pobres em metais é a existência de um hiato entre $-5.0 \leq[\mathrm{Fe} / \mathrm{H}] \leq-4.0$. Segundo alguns autores (Shigeyama et al., 2003; Karlsson, 2006), esta ausência de objetos poderia ser resultado de um processo astrofísico ainda não compreendido que operaria nessa faixa de enriquecimento em metais. Porém, com a descoberta de HE 0557-4840 $([\mathrm{Fe} / \mathrm{H}]=-4.75$ - Norris et al., 2007), que apresenta comportamento semelhante às estrelas com $[\mathrm{Fe} / \mathrm{H}]<-5.0$, essa hipótese foi descartada. Todavia, antes da execução de tais surveys para a busca desses objetos, fez-se necessário o desenvolvimento de um método de identificação de estrelas candidatas a pobres em metais a partir de espectros em baixa resolução. Para tanto, foi utilizada a intensidade de uma linha espectral específica encontrada nesses espectros, e que tem uma relação diretamente proporcional com a quantidade de metais na estrela: a linha K do Ca II, em $3933 \AA$ (Beers et al., 1985). A Figura 1.1 mostra o comportamento desta linha em função da metalicidade para três estrelas pobres em metais observadas pelo HES, onde é possível notar o efeito mencionado acima.

Assim, utilizando a linha K do Ca II como indicador de metalicidade, o trabalho pioneiro de Beers et al. (1985) identificou 134 estrelas candidatas a pobres em metais. A esta lista foram adicionadas mais 1044 objetos através do trabalho posterior de Beers et al. (1992). Com o crescente número de objetos observados, fez-se necessário o desenvolvimento de uma série de índices de linha (KP - Beers et al., 1999) para obter estimativas de [Fe/H] em baixa resolução. No entanto, dadas as características evolutivas dos objetos (desde estrelas anãs até gigantes), foi inserida uma dependência da metalicidade com a temperatura, através de índices de cor (mais detalhes em Beers et al., 1999; Rossi et al., 2005, e Seção 3.2.1 desta 


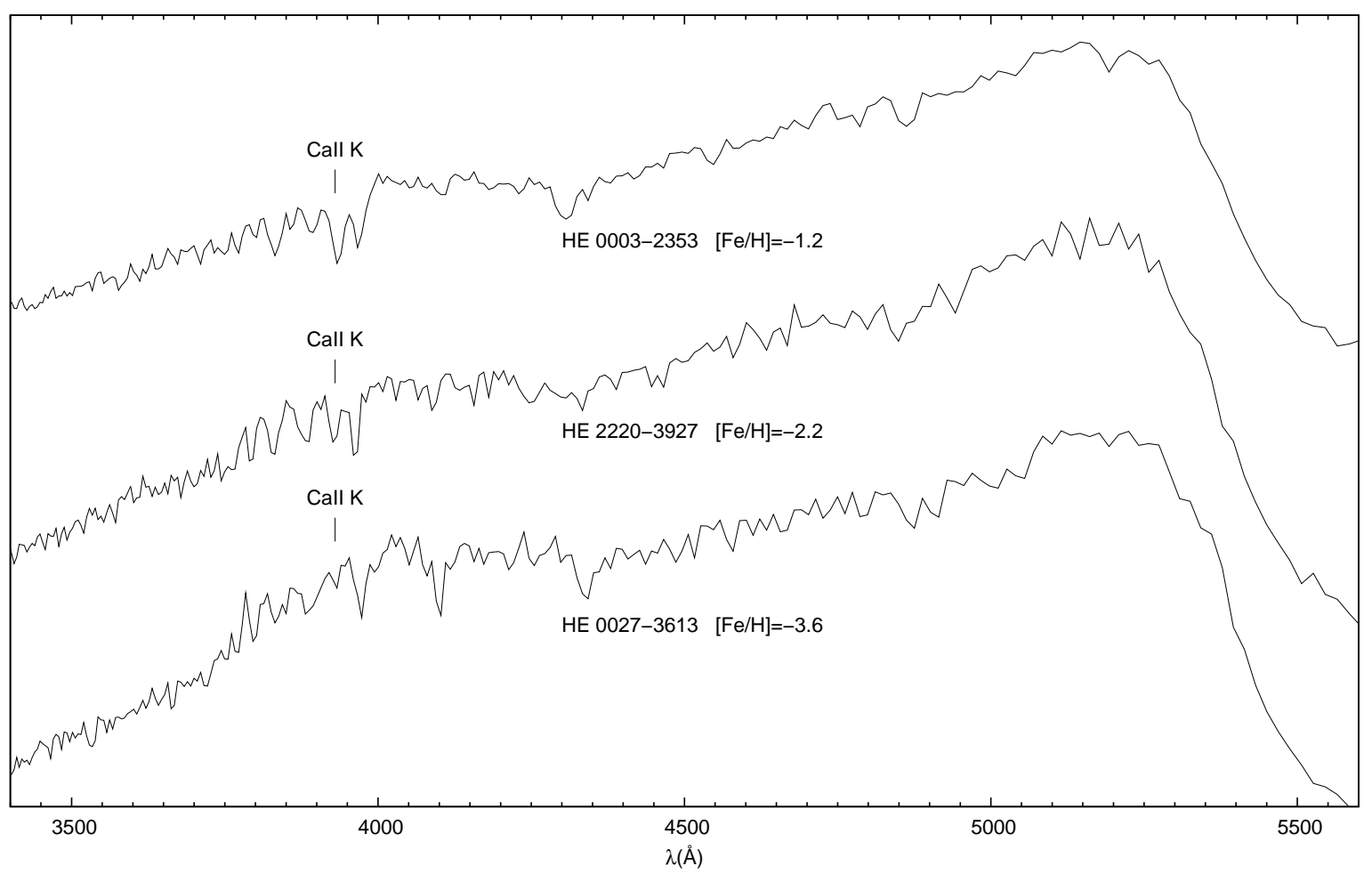

Figura 1.1: Comportamento da linha K do Ca II em função da metalicidade.

tese). Mais recentemente, com o intuito de facilitar e uniformizar a classificação de estrelas pobres em metais, Beers e Christlieb (2005) propuseram uma nomenclatura baseada na metalicidade, listada na Tabela 1.1.

Uma vez observadas em baixa resolução, é necessário realizar procedimentos adicionais para confirmar o status "pobre em metais" e classificar os objetos de acordo com a taxonomia da Tabela 1.1, bem como obter abundâncias elementais de outros elementos de interesse, como por exemplo, carbono, lítio e elementos formados por captura de nêutrons.

Geralmente, o processo envolve três passos observacionais (ver Figura 1.2): (1) um survey de grande abertura (chamado de wide-angle survey) deve ser levado a cabo e as estrelas candidatas a pobres em metais devem ser selecionadas (utilizando, por exemplo, os métodos citados acima); (2) observações espectroscópicas subsequentes (chamadas observações de follow-up) em resolução moderada das candidatas são necessárias para validar as estrelas pobres em metais genuínas entre elas (por exemplo, Placco et al., 2010a); (3) espectroscopia de alta resolução das candidatas mais interessantes encontradas no passo (2) (por exemplo, Frebel et al., 2007). 
Tabela 1.1 - Nomenclatura para metalicidade (Beers e Christlieb, 2005).

\begin{tabular}{cccc}
\hline \hline$[\mathrm{Fe} / \mathrm{H}]$ & Classificação & Termo Original & Sigla \\
\hline$\sim 0.0$ & Abundância Solar & Solar & - \\
$<-1.0$ & Pobre em Metais & Metal-Poor & MP \\
$<-2.0$ & Muito Pobre em Metais & Very Metal-Poor & VMP \\
$<-3.0$ & Extremamente Pobre em Metais & Extremely Metal-Poor & EMP \\
$<-4.0$ & Ultra Pobre em Metais & Ultra Metal-Poor & UMP \\
$<-5.0$ & Hiper Pobre em Metais & Hyper Metal-Poor & HMP \\
$<-6.0$ & Mega Pobre em Metais & Mega Metal-Poor & MMP \\
\hline
\end{tabular}

O passo (1) pode ser obtido de diferentes maneiras. Por exemplo, (a) com surveys colorimétricos : Du et al. (2004) descrevem o uso de um sistema de filtros com 15 bandas internediárias (sistema BATC) para obtenção aproximada de metalicidades para uma amostra de anãs num raio de 5 kpc do plano galáctico; o SDSS gerou o maior catálogo de fotometria bem calibrada para estrelas da Galáxia utilizando o sistema ugriz (ver, por exemplo, Ivezić et al., 2004); (b) surveys de movimentos próprios: catálogo STARNET (Röser, 1996), catálogo SuperCOSMOS (Hambly et al., 2001), o survey Northern Proper Motion Survey (Hanson et al., 2004), o Southern Proper Motion Survey (Girard et al., 2004) e o catálogo Astrográfico US Naval Observatory CCD (Zacharias et al., 2004). Entretanto, os surveys espectroscópicos (survey HK e HES) são muito mais eficientes para se descobrir grandes amostras de estrelas genuinamente pobres em metais entre as candidatas selecionadas. Eles ainda têm a vantagem adicional de que as amostras são obtidas sem viés cinemático, o que não é o caso das amostras selecionadas através dos movimentos próprios.

A partir do esforço observacional obtido até o momento, a era dos grandes surveys para estrelas da Galáxia deu um salto considerável desde o início desta década, e ainda está em curso. Um dos investimentos mais ambiciosos dos últimos anos foi o SDSS, com medidas astrométricas precisas obtidas para todas as estrelas detectadas (e não saturadas), que foram comparadas com scans de placas fotográficas de gerações anteriores de observações feitas entre os anos de 1950 e 1990 (Munn et al., 2004). Além disso, a partir de suas extensões SDSS-II, SEGUE-1, SEGUE-2 (mencionadas anteriormente) e o RAVE (RAdial Velocity Experiment - Zwitter et al., 2008; Fulbright et al., 2010), o número de estrelas 


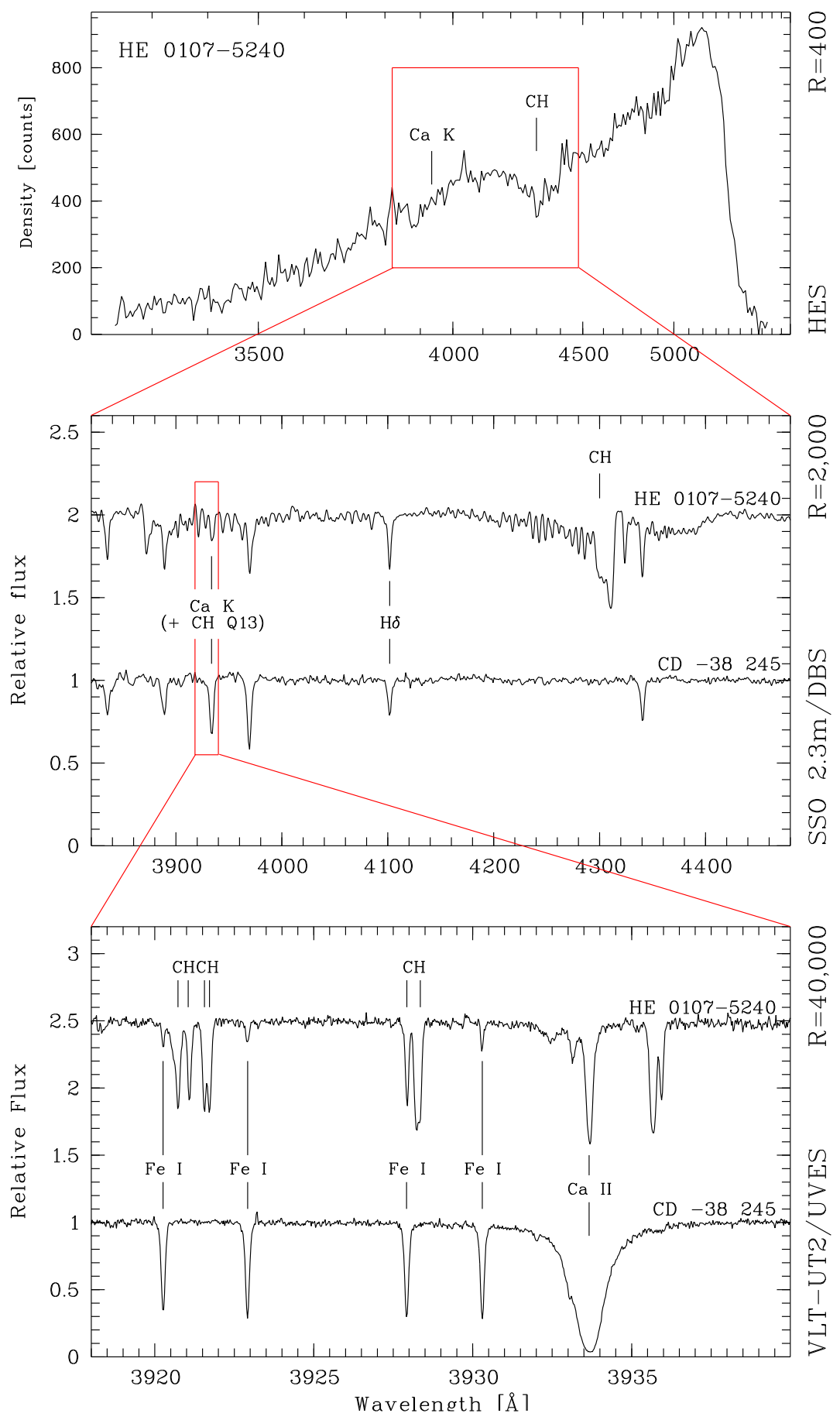

Figura 1.2: Painel superior: (1) surveys de grande abertura (p. ex., HK, HES) que fornecem as estrelas candidatas a pobres em metais. Painel central: (2) seleção das candidatas via follow-up de espectroscopia em média resolução. Painel inferior: (3) espectroscopia em alta resolução das candidatas confirmadas como estrelas pobres em metais. Figura adaptada de Christlieb (2003). 
com informações espectroscópicas detalhadas passará de um milhão de objetos, com o objetivo principal de amostrar todas as populações estelares presentes na Galáxia. Este número é (para estrelas VMP e EMP) no mínimo uma ordem de grandeza maior que aquele fornecido pela combinação dos surveys HK e HES (Beers, 2009). Com a publicação do DR7 (Data Release 7 - Abazajian et al., 2009) do SDSS, aumentou-se consideravelmente a estatística para estrelas pobres em metais, que contribuiu significativamente para o estudo dos diversos componentes estelares da Via Láctea (Carollo et al., 2010).

\subsection{Estrelas Pobres em Metais Enriquecidas em Carbono}

A recente explosão de informações provenientes de estudos espectroscópicos em alta resolução de estrelas pobres em metais na Galáxia está remodelando a compreensão da natureza dos processos nucleossintéticos que ocorreram durante as primeiras gerações estelares. Um dos aspectos mais interessantes inserido neste contexto são as observações detalhadas de follow-up de estrelas que exibem grandes sobreabundâncias de carbono $(+0.5<[\mathrm{C} / \mathrm{Fe}]<+4.0)$, comum entre estrelas pobres em metais (Beers e Christlieb, 2005).

Recentemente foi constatado que uma grande fração, em torno de 20\%, das estrelas com metalicidades $[\mathrm{Fe} / \mathrm{H}]<-2.0$ exibem consideráveis enriquecimentos em carbono ([C/Fe]>+1.0 ; Lucatello et al., 2006). A fração destas estrelas, também chamadas de CEMP (Carbon Enhanced Metal-Poor), aumenta para $30 \%$ se $[\mathrm{Fe} / \mathrm{H}]<-3.0,40 \%$ para $[\mathrm{Fe} / \mathrm{H}]<-3.5$ e $100 \%$ para $[\mathrm{Fe} / \mathrm{H}]<-4.0$ (ver, por exemplo, Christlieb et al., 2002; Frebel et al., 2005; Norris et al., 2007). No entanto, também existem estudos mais recentes (e.g. Cohen et al., 2005; Frebel et al., 2006) que reivindicam que esta fração (especificamente para $[\mathrm{Fe} / \mathrm{H}]<-2.0)$ é, de fato, ainda menor (9\% e 14\%, respectivamente). Este impasse é uma das motivações principais para se obter determinações confiáveis, tanto de metalicidade quanto de abundâncias de carbono, para um grande número de estrelas. Ademais, a identificação de estrelas CEMP (em particular as mais brilhantes), tem um papel fundamental em trabalhos teóricos sobre o assunto (Herwig, 2004; Campbell e Lattanzio, 2008; Lau et al., 2009). Ao fornecer suporte às observações espectroscópicas em alta resolução, necessárias para determinação dos padrões de abundâncias de outros elementos (por exemplo aqueles formados por processo-s e processo-r - Barklem et al., 2005), pode-se testar sítios astrofísicos possivelmente associados com a produção de carbono. 
A maioria das estrelas CEMP conhecidas até o presente foram originalmente identificadas como candidatas a pobres em metais através de surveys de prisma objetivo ${ }^{2}$, tais como o survey HK (Beers et al., 1985, 1992) e o HES (Christlieb, 2003; Christlieb et al., 2008). Ambos os surveys basearam-se na intensidade e presença (ou ausência) das linhas de Ca II em espectros de baixa resolução. Nos últimos anos (Goswami et al., 2006; Marsteller, 2007), espectroscopia em média resolução para a maioria desses objetos tem sido obtida. A inspeção destes dados observacionais indicam que ao menos $50 \%$ desses alvos são consistentes com a identificação de estrelas CEMP, enquanto o restante é composto, em sua maioria, por estrelas ricas em carbono de metalicidade solar.

No entanto, estas amostras de estrelas ricas em carbono foram selecionadas com base na soma de linhas moleculares de carbono, tais como $\mathrm{CN}, \mathrm{C}_{2}$, e $\mathrm{CH}$, que introduz um viés para estrelas com menores temperaturas. Estrelas CEMP com temperaturas efetivas acima de $\sim 5500 \mathrm{~K}$ frequentemente exibem intensidade incomum apenas na região da banda $\mathrm{G}$ do CH (4300 A), e muito provavelmente foram negligenciadas nas seleções anteriores. Uma vez que, até o momento, as estrelas CEMP foram descobertas através da seleção de estrelas pobres em metais, foi introduzido um viés em $[\mathrm{Fe} / \mathrm{H}]<-2.5$ nas amostras de estrelas ricas em carbono; portanto, é mister ampliar o intervalo de metalicidades para tais objetos, afim de encontrar estrelas em uma faixa maior de valores.

A Figura 1.3 mostra parte dos espectros de três objetos do HES com abundâncias de carbono determinadas a partir de estudos em alta resolução. Para a estrela HE 0025-3355 (abundância de carbono solar), nota-se a presença de algumas linhas da série de Balmer do hidrogênio, e nenhuma linha intensa de carbono. Já a estrela HE 2204-4058, mesmo apresentando um índice de cor $(\mathrm{B}-\mathrm{V})$ baixo (o que indica alta temperatura), possui a banda $\mathrm{G}$ do $\mathrm{CH}$ proeminente, e uma abundância de carbono 20 vezes maior do que a do Sol. Este é um exemplo claro de objeto que seria negligenciado em uma busca por estrelas ricas em carbono baseada, por exemplo, na intensidade das linhas moleculares de CN. Buscas como esta (ver, por exemplo, Christlieb et al., 2001), selecionam objetos similares à HE 2134-3940 (parte inferior da Figura 1.3), que é uma estrela de menor temperatura e que apresenta intensas bandas moleculares de carbono.

\footnotetext{
${ }^{2}$ A luz proveniente das estrelas observadas por esses surveys é espalhada por um prisma e posteriormente é coletada em uma placa fotográfica.
} 


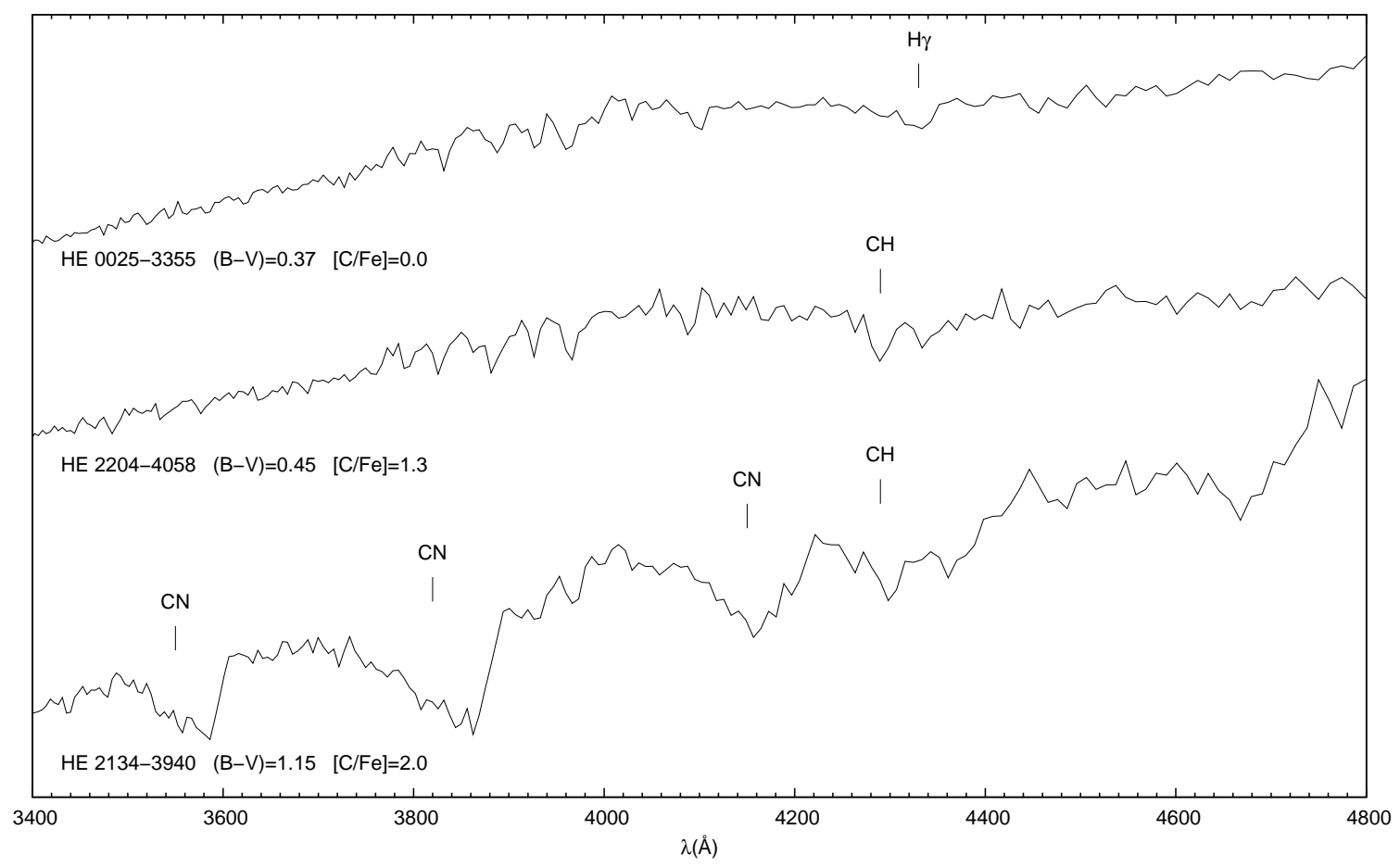

Figura 1.3: Diferentes graus de enriquecimento em carbono.

Para a maioria das estrelas CEMP existe uma clara correlação entre o enriquecimento em carbono e a presença de elementos formados por processo-s em sobreabundância, tal como o bário (estrelas CEMP-s - ver Beers e Christlieb, 2005, e Tabela 1.2). Este comportamento é consistente com a hipótese de que estes enriquecimentos (tanto para o carbono quanto para os elementos do processo-s) ocorrem devido a processos nucleosintéticos em atividade durante o estágio evolutivo do ramo assimptótico das gigantes (asymptotic giant-branch - AGB, ver Herwig, 2005, para uma discussão detalhada), tanto pela estrela propriamente dita (o que deve ser raro, mas veja Masseron et al., 2006, para possíveis cenários) como por uma companheira binária já extinta, que transferiu material para a componente observada do sistema binário (Stancliffe e Glebbeek, 2008).

No entanto, estudos recentes (por exemplo Aoki et al., 2007) mostraram que esta correlação entre enriquecimento em carbono e sobreabundância em elementos do processo-s não persiste mais (ou, pelo menos, é de natureza distinta) para estrelas com $[\mathrm{Fe} / \mathrm{H}]<-2.7$, incluindo todas as estrelas mais pobres em metais observadas até o momento: HE 0107$5240([\mathrm{Fe} / \mathrm{H}]=-5.3), \mathrm{HE} 1327-2326([\mathrm{Fe} / \mathrm{H}]=-5.4)$ e HE $0557-4840([\mathrm{Fe} / \mathrm{H}]=-4.75)$. Estes objetos são classificados como CEMP-no (o que indica a ausência do enriquecimento em 


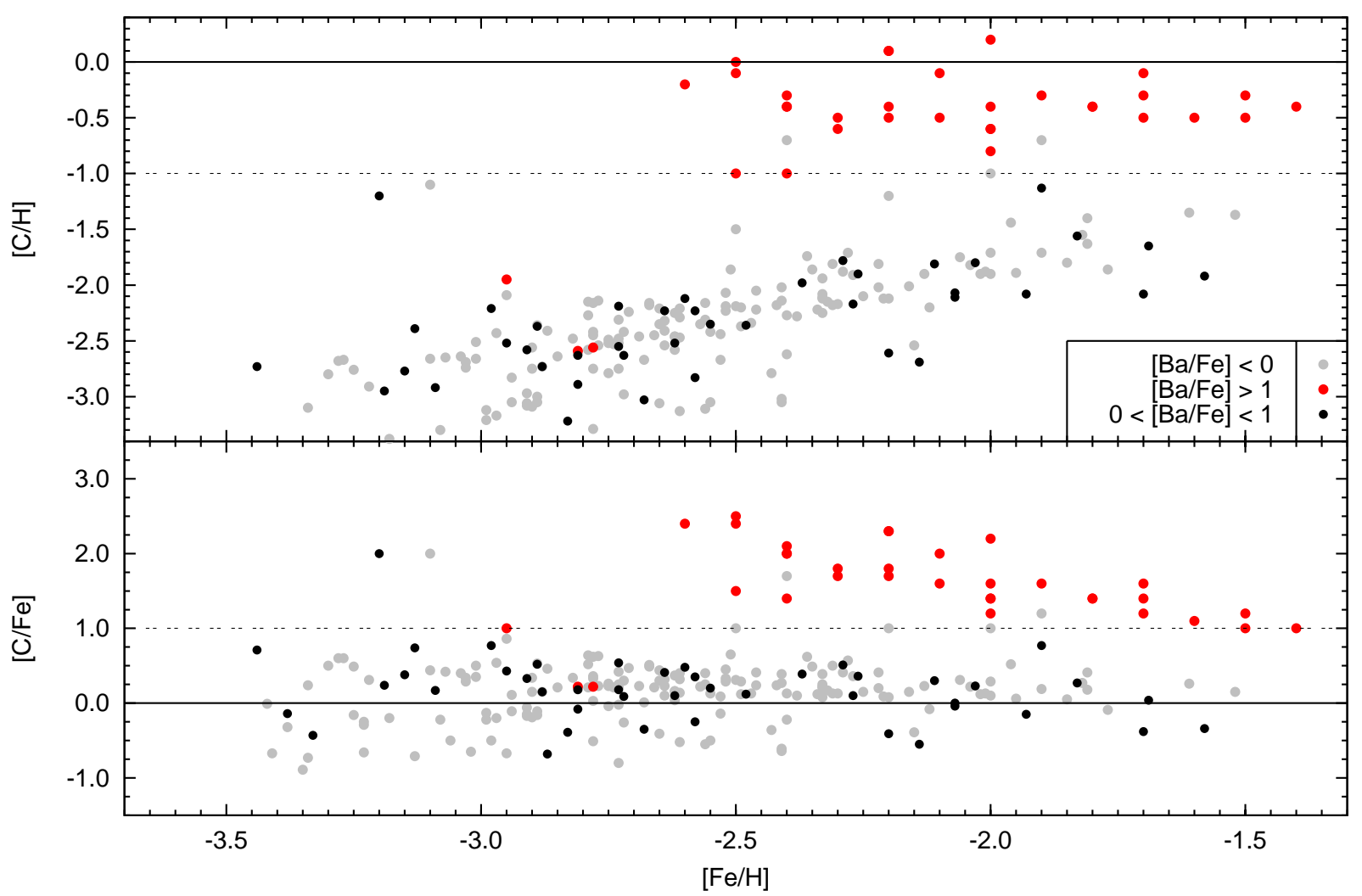

Figura 1.4: Comportamento das abundâncias de carbono e bário em função da metalicidade para as estrelas do HERES. Figura adaptada de Placco (2007).

elementos formados pelo processo-s - Tabela 1.2) e, juntamente com as demais classes propostas por Beers e Christlieb (2005), sugerem que uma série de mecanismos distintos para a produção de carbono deve ter tido seu papel no universo primordial.

A Figura 1.4 mostra o comportamento da abundância de carbono e bário ([C/Fe], $[\mathrm{C} / \mathrm{H}]$ e $[\mathrm{Ba} / \mathrm{Fe}]$ ) em função da metalicidade, para as estrelas do HERES (Hamburg ESO R-process Enhanced Star survey - Christlieb et al., 2004; Barklem et al., 2005; Jonsell et al., 2006; Placco, 2007). Para [Fe/H] $\gtrsim-2.7$, é possível distinguir de forma bastante clara dois regimes: estrelas ricas em carbono que possuem, em sua maioria, sobreabundâncias de bário $([\mathrm{C} / \mathrm{Fe}]>1.0$ e $[\mathrm{Ba} / \mathrm{Fe}]>1.0$ - estrelas $\mathrm{CEMP}-\mathrm{s})$ e estrelas com abundâncias de carbono próximas do valor solar que não são enriquecidas em Ba. Essa divisão apoia as hipóteses levantadas por Aoki et al. (2007) e, além disso, o valor -2.7 para metalicidade também pode ser utilizado como limite para o início da operação do processo-s na Galáxia (Sivarani et al., 2006). A distribuição das abundâncias de C e Ba torna-se distinta para o regime com 
$[\mathrm{Fe} / \mathrm{H}]<-2.7$. Nesta faixa de metalicidades pode-se observar alguns objetos condizentes com a definição de estrelas CEMP-no, comportamento semelhante ao das estrelas mais pobres em metais citadas anteriormente.

Além disso, devido ao viés de seleção em metalicidade mencionado acima, muitas das estrelas CEMP conhecidas até o momento podem estar associadas com a população do chamado halo externo, que exibe um pico na distribuição de metalicidade em $[\mathrm{Fe} / \mathrm{H}] \sim-2.2$ (Carollo et al., 2007). Demais estrelas CEMP provavelmente estão associadas com as populações do halo interno (com MDF centrada em $[\mathrm{Fe} / \mathrm{H}] \sim-1.6$ ) e do disco espesso pobre em metais $([\mathrm{Fe} / \mathrm{H}] \sim-1.3)$, cujas distribuições estendem-se até metalicidades mais elevadas. Dessa forma, é necessário aumentar o número de estrelas pertencentes a essas diversas populações, com o intuito de investigar possíveis diferenças em suas origens (por exemplo, Frebel et al., 2006; Tumlinson, 2007).

Tabela 1.2 - Classificação de estrelas pobres em metais enriquecidas em carbono.

\begin{tabular}{cccc}
\hline \hline Sigla & \multicolumn{3}{c}{ Critério de Classificação } \\
\hline CEMP & {$[\mathrm{C} / \mathrm{Fe}]>+1.0$} & & \\
CEMP-r & {$[\mathrm{C} / \mathrm{Fe}]>+1.0$} & e & {$[\mathrm{Eu} / \mathrm{Fe}]>0.0$} \\
CEMP-s & {$[\mathrm{C} / \mathrm{Fe}]>+1.0-[\mathrm{Ba} / \mathrm{Fe}]>+1.0$} & e & {$[\mathrm{Ba} / \mathrm{Eu}]>+0.5$} \\
CEMP-r $/ \mathrm{s}$ & {$[\mathrm{C} / \mathrm{Fe}]>+1.0$} & e & $0.0 \leq[\mathrm{Ba} / \mathrm{Eu}] \leq+0.5$ \\
CEMP-no & {$[\mathrm{C} / \mathrm{Fe}]>+1.0$} & e & {$[\mathrm{Ba} / \mathrm{Fe}]<0.0$} \\
\hline
\end{tabular}

Entretanto, a visão desses primeiros períodos não está totalmente clara devido a uma série de "peculiariedades" nas abundâncias de elementos químicos observadas nas estrelas mais deficientes em metais. Entre as mais interessantes, podem-se destacar as observações que mostram um excesso de carbono $(+0.5 \leq[\mathrm{C} / \mathrm{Fe}] \leq+4.0)$ em uma grande fração de estrelas pobres em metais. Para a maioria das estrelas enriquecidas em carbono estudadas até o momento, incluindo anãs e gigantes de População I, as chamadas estrelas de bário e as estrelas $\mathrm{CH}$ pobres em metais (até $[\mathrm{Fe} / \mathrm{H}] \sim-2.5$ ), existe uma clara correlação entre o enriquecimento em carbono e a presença de elementos formados por processo-s. Isso sugere que o enriquecimento e/ou produção desses elementos muito provavelmente ocorreu durante o presente (ou prévio) estágio evolutivo do ramo assimptótico das gigantes, ou na própria estrela ou em sua companheira binária atualmente já extinta. 
Porém, análises espectroscópicas de alta resolução de estrelas enriquecidas em carbono com $[\mathrm{Fe} / \mathrm{H}] \leq-2.5$ revelam (como citado anteriormente) que estrelas individuais apresentam diferenças em seus padrões de abundâncias que sugerem origens muito diferentes para as primeiras gerações de estrelas nascidas na Galáxia. Por exemplo, Aoki et al. (2007), em um estudo detalhado de 26 recém descobertas estrelas pobres em metais e enriquecidas em carbono (CEMP), mostraram que muitas das estrelas com $[\mathrm{Fe} / \mathrm{H}]<-2.5$ não apresentam evidência de operação do processo-s. Além disso, as estrelas mais pobres em metais conhecidas até hoje, as hiper pobres em metais HE 0107-5240 (Christlieb et al., 2002) e HE 1327-2326 (Frebel et al., 2005), ambas com $[\mathrm{Fe} / \mathrm{H}]<-5.0$, também não exibem a presença de elementos formados por processo-s. Deve-se notar que essas estrelas exibem razões de abundância de carbono (tanto quanto de $\mathrm{N}$ e O) que variam de algumas centenas a muitos milhares de vezes as razões solares, um padrão compartilhado por algumas outras estrelas com [Fe/H] extremamente baixa (por exemplo, CS 22949-037: Depagne et al., 2002; Norris et al., 2002); (CS 29498-043: Aoki et al., 2002); (HE 0557-4840: Norris et al., 2007). Beers e Christlieb (2005) notaram que 5 em 12 estrelas $(\sim 40 \%)$ com $[\mathrm{Fe} / \mathrm{H}]<-3.5$, para as quais existe análise publicada de abundâncias baseada em espectroscopia de alta resolução, exibem $[\mathrm{C} / \mathrm{Fe}]>+1.0$.

O carbono é um dos elementos mais comuns na natureza e desempenha um papel vital em diferentes contextos astrofísicos importantes, tanto dentro quanto fora de estrelas, como no enriquecimento primordial do meio interestelar. Exemplos de estrelas enriquecidas em carbono podem ser encontrados em todo o diagrama HR. Os espectros de estrelas enriquecidas em carbono são impressionantes porque (dependendo da temperatura e do grau de enriquecimento em carbono) eles exibem bandas de absorção de $\mathrm{C}_{2}$, $\mathrm{CN}$ e $\mathrm{CH}$ bastante proeminentes na região do visível (ver Figura 1.3). A presença dessas bandas no espectro depende do equilíbrio molecular na estrela, devido à forte ligação da molécula $\mathrm{CO}$, a saber: se $\mathrm{A}(\mathrm{C})<\mathrm{A}(\mathrm{O})$ (onde $\mathrm{A}(\mathrm{X})$ é a abundância por número), a maior parte do carbono está presa à molécula de $\mathrm{CO}$ e outros compostos de oxigênio estão presentes; se $\mathrm{A}(\mathrm{C})>\mathrm{A}(\mathrm{O})$, o oxigênio está, em sua maior parte, preso na molécula de $\mathrm{CO}$ e algumas características espectrais de compostos de oxigênio (por exemplo, água e TiO) estão ausentes, enquanto os de carbono encontram-se presentes (em particular $\mathrm{C}_{2}$ ). Nos primórdios da formação da Galáxia, a abundância média de oxigênio, $\mathrm{A}(\mathrm{O})$, era muito mais baixa que atualmente. 
Portanto, uma fonte primária extra de carbono foi capaz de produzir estrelas enriquecidas em carbono facilmente. Convencionalmente, estrelas carbonadas são aquelas que exibem $[\mathrm{C} / \mathrm{O}]>0.0$ na escala antiga de abundâncias (Grevesse e Sauval, 1998). Para fins de futuras discussões, todas as estrelas de carbono são consideradas estrelas enriquecidas em carbono, mas nem todas referidas como enriquecidas em carbono se adequam à definição usual de estrelas carbonadas, porque mede-se o enriquecimento de carbono em relação ao ferro ao invés do oxigênio.

À medida em que mais informações observacionais são coletadas e modelos de evolução desenvolvidos, fica mais claro que o enriquecimento de carbono em estrelas pobres em metais não pode ser atribuído a um único processo, como no caso da maior parte das estrelas mais deficientes nas populações das componentes do halo e disco espesso. Essas estrelas deveriam ser velhas e ter massas inferiores à solar. Mesmo quando na fase AGB não se espera que elas tragam grandes quantidades de carbono de seus interiores para a superfície (através dos processos de dragagem - dredge-up), ao contrário de estrelas AGB de População I observadas hoje em dia. Dessa forma, pode-se concluir que a sobreabundância de carbono presente nas atmosferas dessas estrelas de baixa massa não é devida a processos intrínsecos que ocorreram em seu interior.

Além disso, no extenso catálogo de estrelas pobres em metais de Beers e colaboradores (Beers et al., 1985, 1992), no mínimo 10-15\% das estrelas do survey com $[\mathrm{Fe} / \mathrm{H}] \leq-2.0$ exibem $[\mathrm{C} / \mathrm{Fe}] \geq+1.0$; essa fração aumenta para $25 \%$ da amostra quando se considera objetos com $[\mathrm{Fe} / \mathrm{H}] \leq-3.0$ (Norris et al., 1997; Rossi et al., 2005; Frebel et al., 2006). A análise recente de Lucatello et al. (2006), realizada com as estrelas do HERES, sugere que a fração de estrelas CEMP com $[\mathrm{Fe} / \mathrm{H}] \leq-2.0$ e $[\mathrm{C} / \mathrm{Fe}] \geq+1.0$ é $\sim 20 \%$, no mínimo. Por comparação, estrelas carbonadas de População I constituem menos de $1 \%$ das estrelas do disco com temperaturas e gravidades similares (Luck e Bond, 1991). Deve-se notar, no entanto, que o resultado encontrado em Luck e Bond (1991) é baseado em uma amostra muito menor de estrelas, o que confirma a necessidade de obter estatística de qualidade para estrelas enriquecidas em carbono.

No intervalo de metalicidades $-4.0 \leq[\mathrm{Fe} / \mathrm{H}] \leq-2.0$ existe um limite superior para o enriquecimento de carbono, em $[\mathrm{C} / \mathrm{H}] \sim-0.5$ (Rossi et al., 1999; Ryan, 2003; Lucatello et al., 2006). Isso imediatamente sugere que, em alguma época remota no Universo, uma 
significativa fração de carbono foi produzida, por uma ou mais das seguintes fontes: (1) um mecanismo primordial a partir de progenitores estelares de alta massa, (2) produção interna intrínseca por estrelas de baixa massa com $[\mathrm{Fe} / \mathrm{H}]$ extremamente baixo, ou (3) produção extrínseca de carbono por estrelas de massa intermediária, as quais podem ser importantes fábricas de carbono durante seus estágios AGB, seguido por transferência de massa para a companheira de mais baixa massa sobrevivente. É também possível que todas as três fontes tenham desempenhado seus papéis. Beers e Christlieb (2005) discutem essas alternativas com maiores detalhes.

Muitas das estrelas CEMP também exibem uma grande sobreabundância de elementos químicos formados por captura de nêutrons. Dois exemplos são: a bem conhecida estrela enriquecida em processo-r CS 22892-052 ([Fe/H] $=-3.1$, $[\mathrm{Eu} / \mathrm{Fe}]=+1.7$; Sneden et al., 1996, 2003) e LP 625-44, uma estrela que mostra elementos formados por processo-s que superam os valores do Sol por fatores maiores que $250([\mathrm{Fe} / \mathrm{H}]=-2.7,[\mathrm{Ba} / \mathrm{Fe}]=+2.4$; Aoki et al., 2000). Johnson e Bolte (2002) relatam sobre uma estrela (CS 22183-015) com claro enriquecimento por processo-s mesmo em uma metalicidade muito baixa de $[\mathrm{Fe} / \mathrm{H}]=-3.1$. Recentemente, uma nova classe de CEMP que exibe sobreabundância de elementos formados tanto por processo-s quanto por processo-r foi identificada (por exemplo, Barbuy et al., 1997; Hill et al., 2000; Lucatello et al., 2003; Goswami et al., 2006; Jonsell et al., 2006; Allen e Barbuy, 2006) - essas estrelas também exibem frequentemente sobreabundância de $\mathrm{Pb}$. Finalmente, estrelas CEMP que não apresentam evidência de presença de elementos formados por processos de captura de nêutrons também têm sido identificadas (Aoki et al., 2002; Ryan et al., 2005; Aoki et al., 2006; Frebel et al., 2007).

Até bem recentemente, todas as estrelas de carbono conhecidas eram gigantes. A descoberta de uma estrela rica em carbono com movimento próprio grande, G77-61 (Dahn et al., 1977), a qual tem que ser uma estrela de classe V (sequência principal), foi uma surpresa. Observações subsequentes (Dearborn et al., 1986) mostraram que ela tinha uma companheira anã branca. Essa estrela é também de interesse por apresentar uma metalicidade bem baixa. Plez e Cohen (2005) mostraram que G77-61 tem $[\mathrm{Fe} / \mathrm{H}]=-4.0$, o que a coloca no grupo das estrelas com mais baixas metalicidades que se conhecem. Em seguida, Margon et al. (2002), Downes et al. (2004) e Knapp et al. (2006) identificaram mais de 600 estrelas com enriquecimento suficiente em carbono para exibirem as bandas de Swan de 
$\mathrm{C}_{2}$ nas observações espectroscópicas do SDSS. Mais da metade desses objetos são confirmadamente estrelas de sequência principal considerando-se suas propriedades cinemáticas. As cores dessas estrelas sugerem que elas coincidem com tipos espectrais desde $\mathrm{M}$ até $\mathrm{F} / \mathrm{G}$ ou mesmo tipo A, embora a maioria deste último tipo seja muito provavelmente composta por anãs brancas ricas em carbono peculiares (Knapp et al., 2006).

O SDSS contribuiu até o momento com $95 \%$ de todas as estrelas de carbono anãs, e correções de completeza indicam que a maioria das estrelas de carbono de alta latitude são anãs ao invés de gigantes (ver Green, 1992; Margon et al., 2002). Uma hipótese de primeira ordem seria que estrelas de carbono geradas por transferência de massa a partir de uma companheira seriam espalhadas igualmente através de todos os tipos evolutivos, enquanto estrelas de carbono intrínsecas geradas por dragagem interna deveriam ocorrer somente em gigantes. Para isso, o(s) processo(s) que produz(em) anãs carbonadas deve(m) ser bastante eficiente(s) a fim de que elas superem em número as gigantes (mesmo considerando os diferentes volumes amostrados por essas estrelas de luminosidades tão diferentes).

Embora as estrelas de carbono tenham sido reconhecidas como uma classe distinta de objetos astrofísicos por mais de um século, somente nos últimos anos percebeu-se que o enriquecimento em carbono é dominante em estrelas de, essencialmente, todos os tipos espectrais. Só recentemente que ficou reconhecida a marcante diversidade de padrões de abundâncias elementais associados a sua presença. Uma vez obtida uma amostra de objetos com características bem definidas (parâmetros atmosféricos e abundâncias de carbono), é possível reunir informação estatística/observacional necessária para quantificar esses fenômenos de enriquecimento, e ligá-los ao conhecimento crescente (com base nas observações do Universo em altos redshifts e nas primeiras gerações de estrelas) das origens dos elementos químicos.

\subsection{Objetivos}

O principal objetivo deste trabalho é demonstrar a eficácia de procurar estrelas CEMP de metalicidade intermediária, através do uso de um nova abordagem para sua identificação. A inclusão de candidatas a estrelas CEMP com temperaturas maiores (que não exibem bandas de $\mathrm{CN}$ e $\mathrm{C}_{2}$ ) também possibilita investigar as relações entre os níveis de carbono observados e o estágio evolutivo (Lucatello et al., 2006). Também deve ser levado 
em conta o fato de que provavelmente o inventário de estrelas ultra- $([\mathrm{Fe} / \mathrm{H}]<-4.0)$ e hiper$([\mathrm{Fe} / \mathrm{H}]<-5.0)$ pobres em metais ainda está incompleto. Mesmo que alguns desses objetos extremos eventualmente não apresentem enriquecimento em carbono, este trabalho utiliza os dados disponíveis como suporte para a procura de candidatas que satisfaçam os critérios estabelecidos. Algumas dessas estrelas com $[\mathrm{Fe} / \mathrm{H}]<-4.0$ podem ter sido negligenciadas em buscas anteriores devido a espectros com baixa razão sinal-ruído na região da linha $\mathrm{K}$ do Ca II nas placas fotográficas de prisma objetivo (ver Christlieb et al., 2008, para um procedimento alternativo para superar este problema). No entanto, estas estrelas podem ser rastreadas pela presença de uma intensa banda $\mathrm{G}$ do $\mathrm{CH}$, que é comumente associada às estrelas mais deficientes em metais.

Dessa forma é possível obter estimativas tanto da frequência como do grau de enriquecimento em carbono em certos intervalos específicos de índice de cor e metalicidade, para cobrir diferentes estágios evolutivos, incluindo anãs, subgigantes e estrelas em várias posições ao longo do ramo das gigantes. Assim, pode-se conhecer a frequência de estrelas com enriquecimento de carbono em diferentes faixas (por exemplo, $[\mathrm{C} / \mathrm{Fe}] \geq+0.5$ ), e explorar o nível de dependência entre o grau de enriquecimento em carbono com o estágio evolutivo. Essas frequências e graus de enriquecimento em carbono podem ser utilizados para restringir modelos teóricos, com o objetivo de acessar os modos dominantes que devem ser levados em conta em prescrições de evolução química galáctica.

Uma lista de estrelas do HES com linhas de carbono intensas foi previamente reunida por Christlieb et al. (2001). Os espectros para a maior parte desses objetos têm sido obtidos nos últimos anos. A inspeção desses dados indica que pelo menos $50 \%$ dos alvos são consistentes com a identificação de estrelas CEMP, enquanto os outros são estrelas ricas em carbono com abundância aproximadamente solar. Entretanto, essa lista prévia foi reunida com base na soma de linhas de carbono molecular, tais como $\mathrm{CN}, \mathrm{C}_{2}$ e $\mathrm{CH}$, as quais dão muita ênfase às estrelas mais frias na amostra. Estrelas CEMP com temperaturas efetivas mais altas que $\sim 5500 \mathrm{~K}$, frequentemente, mostram apenas uma excepcional intensidade em uma única característica, a banda G em $4300 \AA$ e, portanto, podem ter sido omitidas no catálogo anterior.

Assim, faz-se necessário o desenvolvimento de um método que possa levar em conta essa característica marcante das estrelas ricas em carbono com temperaturas mais eleva- 
das. Para tanto, é preciso dispor de uma amostra significativamente grande de espectros digitalizados, como a do HES, e propor uma nova forma de selecionar objetos de interesse. Além disso, pode-se utilizar como base auxiliar para esta tarefa os índices de linha recém compilados (KPHES e GPHES - ver definições em Christlieb et al., 2008, e no Capítulo 2 desta tese) e informações colorimétricas do 2MASS (The Two Micron All Sky Survey Skrutskie et al., 2006) para compor uma lista de estrelas que exibam uma forte banda G. Em seguida, subamostras selecionadas são observadas em média resolução com o telescópio $\mathrm{SOAR}^{3}$ de $4.1 \mathrm{~m}$, com o intuito de demonstrar a eficácia da procura por estrelas adicionais de baixa metalicidade, baseada na premissa de que a maior parte delas será, além de pobre em metal, fortemente enriquecida em carbono.

Este trabalho está estruturado da seguinte forma: no Capítulo 2 são apresentadas as novas definições dos índices de linha para a banda $\mathrm{G}$ do $\mathrm{CH}$, bem como as melhorias propostas em relação aos índices previamente utilizados; o Capítulo 3 descreve as principais características do HES. Além disso, é feita uma análise exploratória e são apresentados os cálculos dos novos índices de linha para a base de dados; a análise completa da primeira e segunda subamostras de dados do HES, baseadas nos novos índices de linha desenvolvidos, encontram-se, respectivamente, nos Capítulo 4 e 5; as conclusões e perspectivas deste trabalho são delineadas no Capítulo 6.

\footnotetext{
${ }^{3}$ Southern Astrophysics Research Telescope.
} 


\section{Capítulo 2}

\section{Novos Índices de Linha para a Banda G do CH}

Um dos objetivos deste trabalho é determinar um conjunto de índices de linha que possam descrever fidedignamente não apenas a banda $\mathrm{G}$ do $\mathrm{CH}$, mas também definir um intervalo em comprimento de onda que inclua as asas da região que são afetadas por outras bandas de carbono, tais como $\mathrm{C}_{2}$ e $\mathrm{CN}$, e que ocorrem eventualmente até em estrelas CEMP mais quentes, com $(\mathrm{J}-\mathrm{K})_{0} \leq 0.3$. Uma vez que estes índices consigam capturar toda a informação contida na banda G, é necessário desenvolver um procedimento de calibração em função de parâmetros conhecidos (como por exemplo [C/Fe]) e confirmados por estudos em alta resolução.

A "régua padrão" utilizada ao longo deste trabalho é composta de uma amostra de 26 estrelas do HES. Estas estrelas são pobres em metais e ricas em carbono, e foram analisadas em alta resolução por Aoki et al. (2007). Esta amostra foi escolhida pois a base de dados do HES contém espectros em baixa resolução para todos estes objetos. Desta forma, é possível comparar o comportamento dos novos índices (calculados na mesma resolução dos demais objetos da base de dados) com a abundância em carbono medida em alta resolução. O objetivo, nesse caso, não é encontrar valores de $[\mathrm{C} / \mathrm{Fe}]$ diretamente a partir de um índice de linha, mas distinguir o comportamento de estrelas enriquecidas e não enriquecidas em carbono. Assim, uma calibração da forma $[\mathrm{C} / \mathrm{Fe}]=f($ índice de linha) não é suficiente nesse caso, pois não leva em conta parâmetros importantes como a temperatura do objeto.

A calibração dos índices pode ser feita, por exemplo, em um diagrama índice de linha vs. indice de cor, sendo que a utilização da cor do objeto representa uma escala de temperatura, uma vez que este trabalho visa identificar estrelas ricas em carbono que não satisfazem as restrições impostas por Christlieb et al. (2001) que impõe um viés em 
$T_{\text {eff }}$ ao selecionar estrelas ricas em carbono apenas em função de índices moleculares. Assim, dentro de uma região específica do diagrama (por exemplo $0.2 \leq(\mathrm{J}-\mathrm{K})_{0} \leq 0.8$, equivalente a $T_{\text {eff }} \sim 4500$ - 5500K - Aoki et al., 2007), a expectativa é a de que as estrelas confirmadamente CEMP comportem-se de forma distinta das demais, fornecendo assim uma região com maior probabilidade de ocorrência deste tipo de objeto.

\subsection{Por que procurar novos Índices para o Carbono?}

Até o momento, análises em baixa e média resolução na região da banda $\mathrm{G}$ do $\mathrm{CH}$ utilizavam-se do índice GP (com largura de banda de $15 \AA$ - definido por Beers et al., 1999) para estimar o conteúdo de carbono na estrela; um índice similar foi originalmente definido por Beers et al. (1985), anteriormente à constatação de que estrelas pobres em metais poderiam exibir altos enriquecimentos em carbono.

O índice GP é uma pseudo largura equivalente que mede o contraste entre o espectro observado e o nível do contínuo na região da banda G. Este índice é quantificado através do cálculo da área de uma banda de $15 \AA$ de largura (centrada em $4304 \AA$ ), delimitada por um pseudo contínuo. Este, por sua vez, é calculado através de um ajuste linear entre os valores centrais de duas bandas laterais, tanto na região azul quanto na região vermelha do espectro. A Tabela 2.1 lista os intervalos de comprimento de onda para alguns dos índices de linha da banda $G$ encontrados na literatura.

Tabela 2.1 - Definições dos principais índices de linha da banda G do CH encontrados na literatura. Os valores são mostrados em $\AA$.

\begin{tabular}{lcccr}
\hline \hline Índice & Banda azul & Banda da linha & Banda vermelha & Referência \\
\hline GP & $4247.0-4267.0$ & $4297.5-4312.5$ & $4362.0-4372.0$ & Beers et al. (1999) \\
GPHES & $4246.0-4255.0$ & $4281.0-4307.0$ & $4446.0-4612.0$ & Christlieb et al. (2008) \\
GPE & $\ldots$ & $4200.0-4400.0$ & $\ldots$ & Placco et al. (2010a) \\
\hline
\end{tabular}

A necessidade de um novo índice para esta região é clara e se mostra evidente em estudos recentes (por exemplo Rossi et al., 2005; Christlieb et al., 2008) pelo fato de que uma largura de banda de $15 \AA$ não consegue capturar todo o fluxo absorvido pelo carbono molecular na região da banda G do CH. Além disso, o índice GP sofre de contaminação 
em suas bandas laterais quando uma estrela é particularmente rica em carbono, ou em baixas temperaturas efetivas, pelo fato de que um ajuste linear nesta região subestima severamente a posição do contínuo para estes objetos ${ }^{1}$.

No trabalho de Christlieb et al. (2008) é apresentado um novo índice de linha para a banda $G$, a ser utilizado nos espectros escaneados do HES, chamado GPHES, com uma largura de banda de $26 \AA$, calibrado para estar em uma escala de valores similares aos do índice GP. No entanto, como pode ser visto na Figura 2.1, mesmo este novo (e mais largo) índice não é suficiente para capturar toda a informação proveniente da banda G, principalmente para as estrelas com enriquecimentos mais extremos identificadas pelo HES.

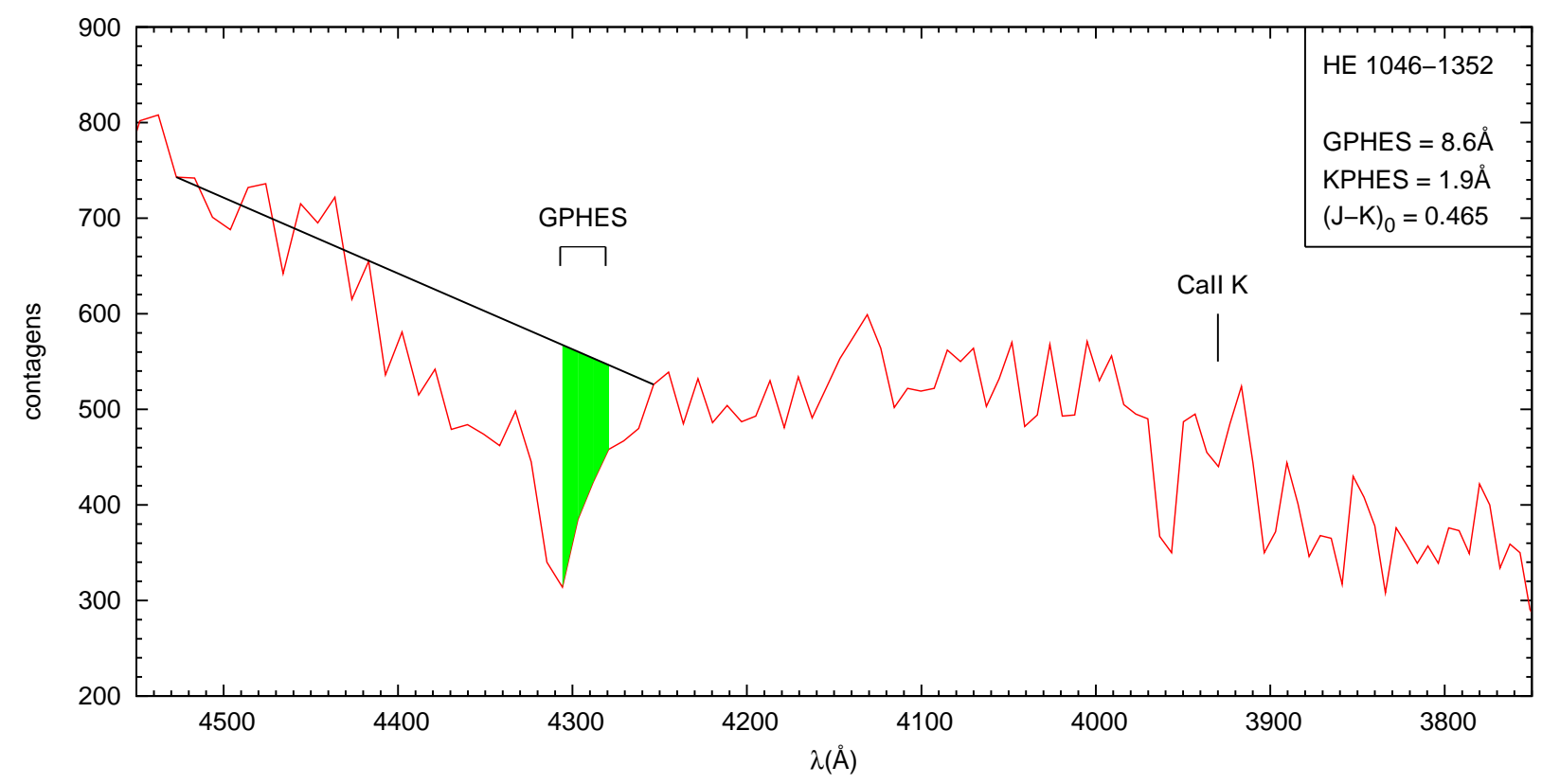

Figura 2.1: Exemplo de cálculo de GPHES. O valor do índice é dado pela área em verde, delimitada pelo ajuste linear entre os valores centrais das bandas laterais. Também é mostrada a linha K do Ca II. O eixo de comprimento de onda está colocado partindo do vermelho para o azul, como apresentado nos espectros originais do HES.

Novos índices para esta característica em particular dos espectros devem cobrir não somente a banda G "clássica" (centrada em $4304 \AA$ A), mas também a porção do espectro que se estende na direção das asas desta região, que também pode ser afetada por outras espécies moleculares de carbono. É importante notar que, caso uma estrela não apresente alta abundância de carbono (uma banda G não pronunciada) os novos índice permane-

\footnotetext{
${ }^{1}$ Por exemplo, Figuras 1(h) e 2(d) de Rossi et al. (2005)
} 
cerão válidos, pois, ainda assim, fora desta região não haverá fluxo proveniente de outros elementos (exceto pela linha de Balmer $\mathrm{H} \gamma$ em $4340 \AA$ - veja discussão a seguir), que sejam suficientes para contaminar os resultados.

É possível identificar alguns exemplos de espectros fortemente afetados pela banda $G$ do CH no trabalho de Rossi et al. (2005). Nota-se a dificuldade de obter toda a informação na região da banda $\mathrm{G}$ com a utilização de um índice com largura de banda muito estreita (15 A). Além disso, para algumas estrelas, o índice GP pode saturar, perdendo-se então a informação para o restante da região. Portanto, os novos índices devem cobrir pelo menos a região entre 4200-4400 . O fato da linha de Balmer $\mathrm{H} \gamma$ estar presente em $4340 \AA$ não é um empecilho, já que esta linha também se encontra presente em estrelas "normais" (pobres em carbono) e possui proporcionalidade similar com a temperatura. Porém, como é mostrado no Capítulo 4 desta tese, é muito importante observar o intervalo de temperatura considerado, pois a amostra pode ser contaminada por estrelas quentes com fortes linhas de hidrogênio (por exemplo, estrelas de tipo espectral A).

\subsection{GPE - Ajuste de Contínuo}

Pelo exposto acima, conclui-se que a formulação para a determinação de um índice de linha da banda $\mathrm{G}$ deve abranger uma área maior dentro desta região além de evitar o cálculo do contínuo pelos métodos comumente utilizados. Assim, o índice GPE (GPHES Extended) é definido da seguinte forma:

$$
\operatorname{GPE}(\AA)=\int_{4200}^{4400}\left(1-\frac{S(\lambda)}{C(\lambda)}\right) d \lambda,
$$

onde $S(\lambda)$ representa o espectro observado e $C(\lambda)$ é o ajuste local para o contínuo. Esta definição é similar àquela de Cardiel et al. (1998), mas neste caso o nível do contínuo do espectro não é estimado por interpolação linear entre as bandas laterais (como é o caso de GP e GPHES), uma vez que a região próxima à banda G pode ser afetada pela presença de outras moléculas associadas ao carbono, como visto acima, e comprometer a determinação do valor do índice. Foram feitas diversas tentativas de ajuste de contínuo, incluindo formulações alternativas às adotadas para GP e GPHES. A escolha final é baseada nas técnicas empregadas pelo SSPP (SEGUE Stellar Parameter Pipeline - ver Lee 
et al., 2008; Allende Prieto et al., 2008, para uma descrição detalhada do procedimento), otimizada para a resolução dos espectros da base de dados do HES.

Através da inspeção visual de uma série de espectros de estrelas CEMP, definiu-se que o intervalo mais eficiente para o novo índice deve, de fato, cobrir a região entre 4200-4400 $\mathrm{A}$. Esta largura de banda impõe às determinações de GPE um intervalo de valores pelo menos uma ordem de grandeza maior do que o dos índices GP e GPHES. Isto é importante para minimizar os erros associados às medidas (ver detalhes na Seção 4.1.1, Figura 4.2).

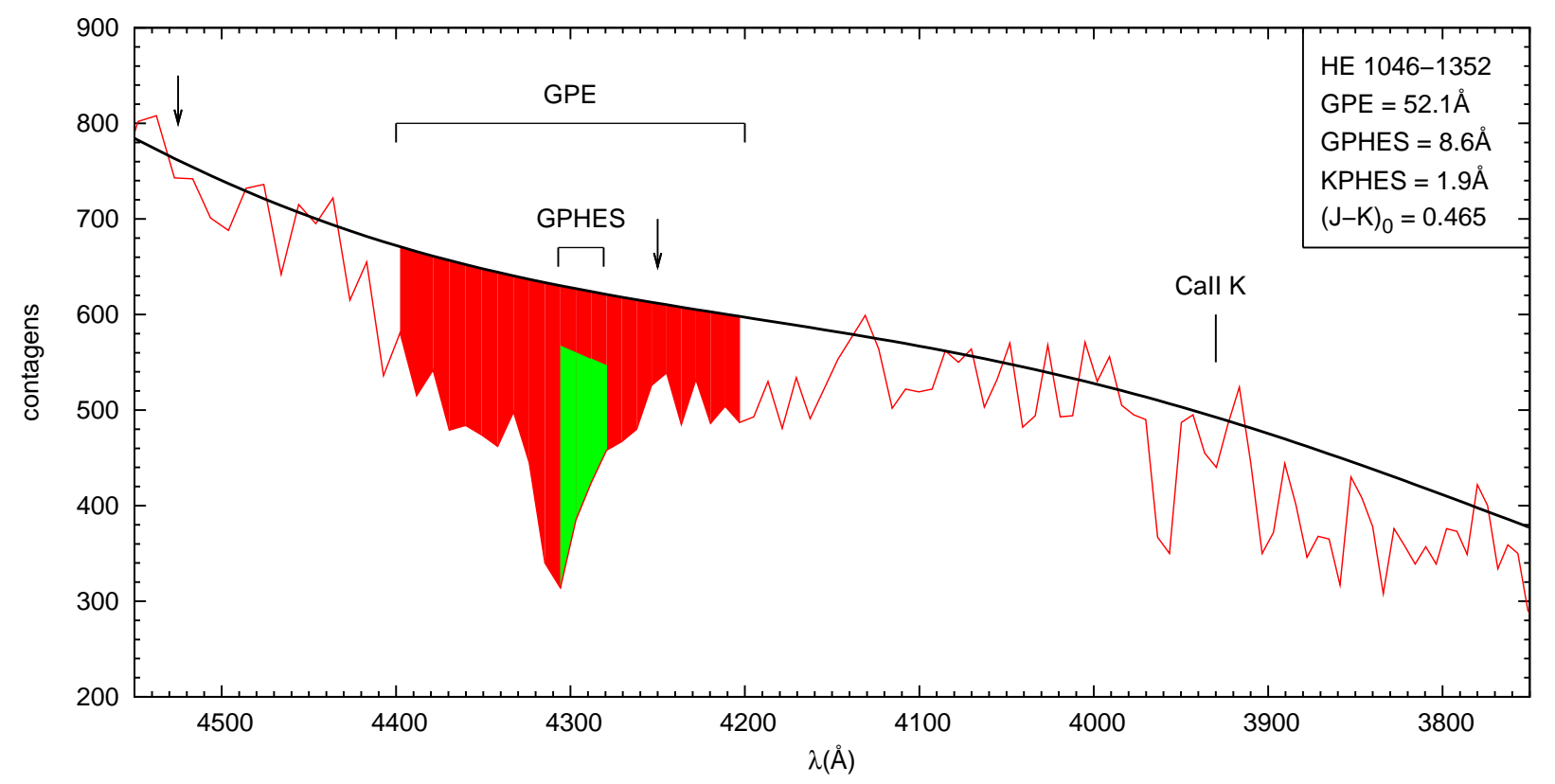

Figura 2.2: Exemplo da nova definição do índice para a banda G do CH. A linha preta cheia mostra o ajuste de contínuo aplicado às estrelas neste trabalho. Também é mostrada a comparação entre o índice GPHES (área em verde) e o novo índice GPE (área em vermelho). As setas representam os valores centrais das bandas laterais utilizadas para o ajuste do contínuo de GPHES. Também é mostrada a linha K do Ca II. O eixo de comprimento de onda está colocado partindo do vermelho para o azul, como apresentado nos espectros originais do HES.

A Figura 2.2 mostra o espectro extraído das placas fotográficas escaneadas do HES de uma estrela enriquecida em carbono típica (fria). A área estreita ao redor de $4300 \AA$ mostra a localização do índice GPHES (ver também Figura 2.1), que é mais largo (e um pouco deslocado para a região azul) do que o índice GP. A banda da linha do novo índice GPE está representada pela região de $200 \AA$ de largura ao redor da mesma região. É possível concluir através da inspeção da Figura 2.2 que o índice GPHES é, de fato, muito 
estreito para ser representativo da força do toda a banda $G$, sendo que suas bandas laterais (cujos valores centrais estão representados pelas setas da Figura 2.2) também sofrem de contaminação. Comentários similares também se aplicam ao índice GP que, como pode ser visto na Tabela 2.1, possui uma largura de linha ainda menor que a do índice GPHES.

Como visto acima, o novo índice GPE também inclui a linha de Balmer H $\gamma$ em $4340 \AA$, o que não configura um problema, pois esta linha também é encontrada em estrelas com abundâncias de carbono próximas da solar; sua intensidade deve variar com a temperatura da mesma forma tanto para estrelas ricas em carbono quanto para estrelas com $[\mathrm{C} / \mathrm{Fe}] \leq 0.0$. Na definição do GPE, a forma do contínuo possui um papel importantíssimo, uma vez que este deve ser bem ajustado ao longo de toda a região de interesse, e não simplesmente estimado por interpolação em bandas laterais isoladas.

\subsection{EGP - Razão entre Fluxos}

Além do índice GPE, procurou-se também uma forma alternativa de medir a contribuição da banda $\mathrm{G}$ do $\mathrm{CH}$ para o fluxo total da estrela, porém sem depender da determinação do contínuo. Tal índice alternativo foi calculado utilizando-se uma definição semelhante à proposta por Smith e Norris (1983) e modificada por Morrison et al. (2003). Utilizando os mesmos argumentos mostrados acima para justificar a largura de $200 \AA$ do índice GPE, a largura da linha de banda nesse caso também terá este valor.

O índice EGP consiste de uma razão entre fluxos, integrados em intervalos definidos para as bandas da linha e para a região do vermelho, que pode ser escrito como:

$$
\operatorname{EGP}(\text { magnitude })=-2.5 \log \left[\frac{\int_{4200}^{4400} I_{\lambda} \cdot d \lambda}{\int_{4425}^{4520} I_{\lambda} \cdot d \lambda}\right] \approx-2.5 \log \left[\frac{\sum_{n=1}^{k} I_{\lambda_{n}} \cdot \Delta \lambda}{\sum_{m=1}^{k} I_{\lambda_{m}} \cdot \Delta \lambda}\right],
$$

onde $I_{\lambda_{n}}$ e $I_{\lambda_{m}}$ são os valores de fluxo medido (em contagens) para as bandas da linha e no vermelho, respectivamente e $\Delta \lambda$ refere-se à resolução do espectro, em $\AA$. A definição em Morrison et al. (2003) utiliza uma banda na região do vermelho e outra em comprimentos de onda na região do azul. Pelo fato de existir, para os objetos mais frios, bandas de CN na parte azul proposta para o novo índice (em $3883 \AA$ e $4216 \AA$ ), as estimativas para o contínuo não são satisfatórias. Então, usa-se apenas a razão entre o fluxo integrado na linha (200 A de largura; 4200-4400 ̊) e o fluxo integrado na banda vermelha (4425-4520 $)$. 


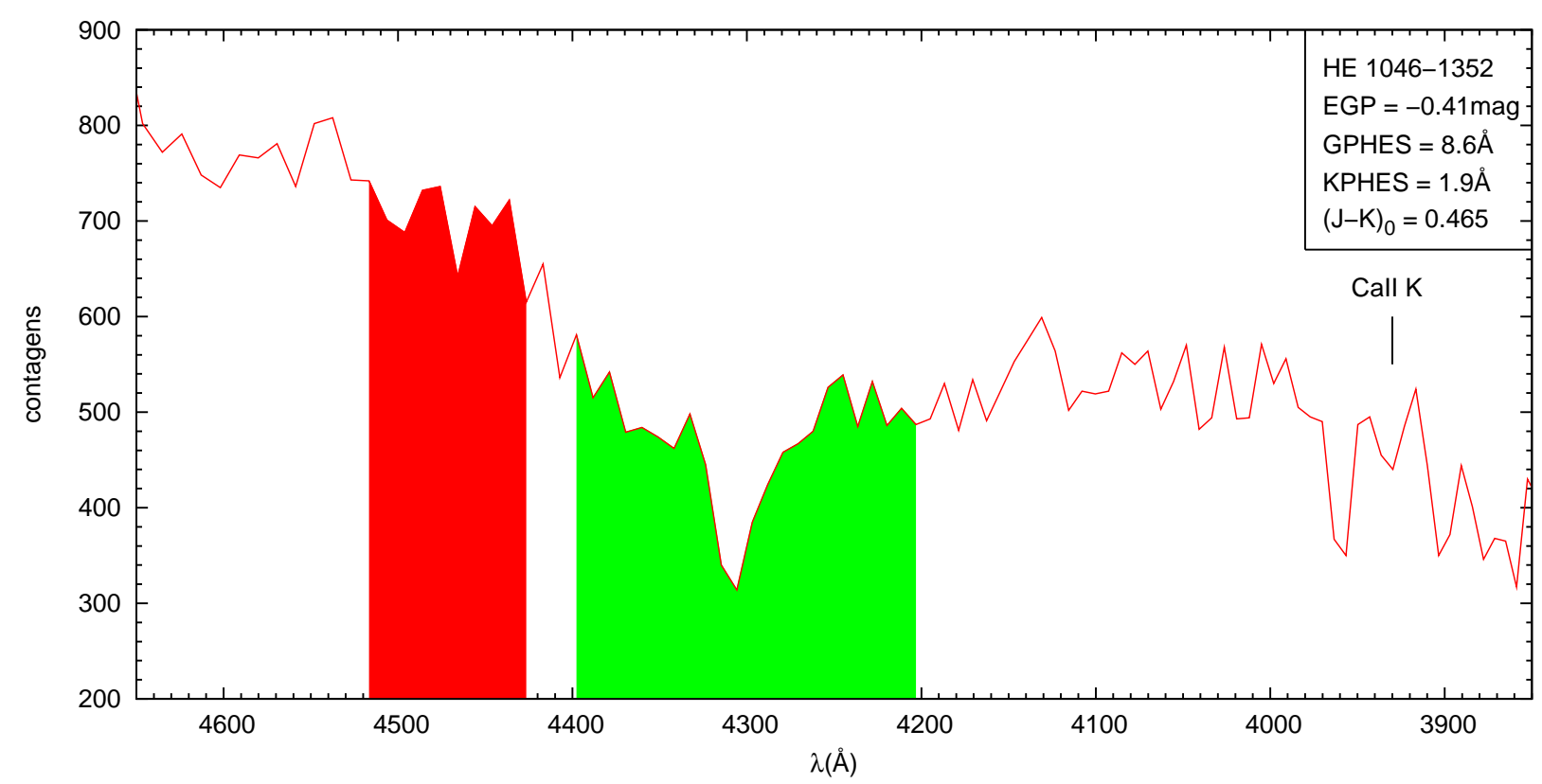

Figura 2.3: Definição do índice EGP. A área delimitada em vermelho representa a banda lateral e a área em verde representa a banda da linha. Também é mostrada a linha K do Ca II. O eixo de comprimento de onda está colocado partindo do vermelho para o azul, como apresentado nos espectros originais do HES.

A Figura 2.3 mostra os intervalos de comprimento de onda de definição do índice EGP. É importante lembrar que, diferentemente do índice GPE, o EGP depende essencialmente da profundidade da banda $\mathrm{G}$ e da diferença dos fluxos entre esta e a região contígua na parte vermelha do espectro, ou seja, o rebaixamento do contínuo causado pela presença da banda $\mathrm{G}$ irá afetar também a banda lateral, e manterá o contraste entre os fluxos. Isso não ocorre no caso do índice GPE, pois nele o contínuo é estimado a partir de todo o intervalo de comprimento de onda do espectro, o que pode superestimar o nível do contínuo e por consequência o valor do índice.

Além disso, pelas características logarítmicas da Equação 2.2, é possível notar que o índice EGP possui um intervalo dinâmico menor do que aquele do índice GPE. Este fato não configura o mesmo problema apresentado pelos índices GP e GPHES pois o índice EGP não utiliza interpolação das bandas laterais para estimar o contínuo e, como será mostrado do Capítulo 5, este será utilizado como um índice auxiliar ao GPE. 


\subsection{Teste com a Base de Dados SAGA}

Para fazer um primeiro teste do comportamento dos novos índices de linha descritos acima, foi utilizada a base de dados SAGA (Stellar Abundances for Galactic Archeology - Suda et al., 2008). Esta base de dados é uma compilação de abundâncias retiradas da literatura referentes a estrelas pobres em metais, que inclui tanto estrelas do survey $\mathrm{HK}$ quanto do HES. Foram extraídos da base SAGA parâmetros para 257 objetos do HES e, no caso de múltiplas referências para um mesmo objeto, foi escolhido o conjunto de medidas mais recente (ou com maior resolução, para referências de mesmo ano de publicação).

Assim, a partir dos identificadores dos objetos, foi possível extrair da base de dados do HES os espectros em baixa resolução das estrelas selecionadas e calcular os dois índices. A Figura 2.4 mostra o comportamento dos novos índices de linha em função dos valores de abundância de carbono extraídos da base SAGA.

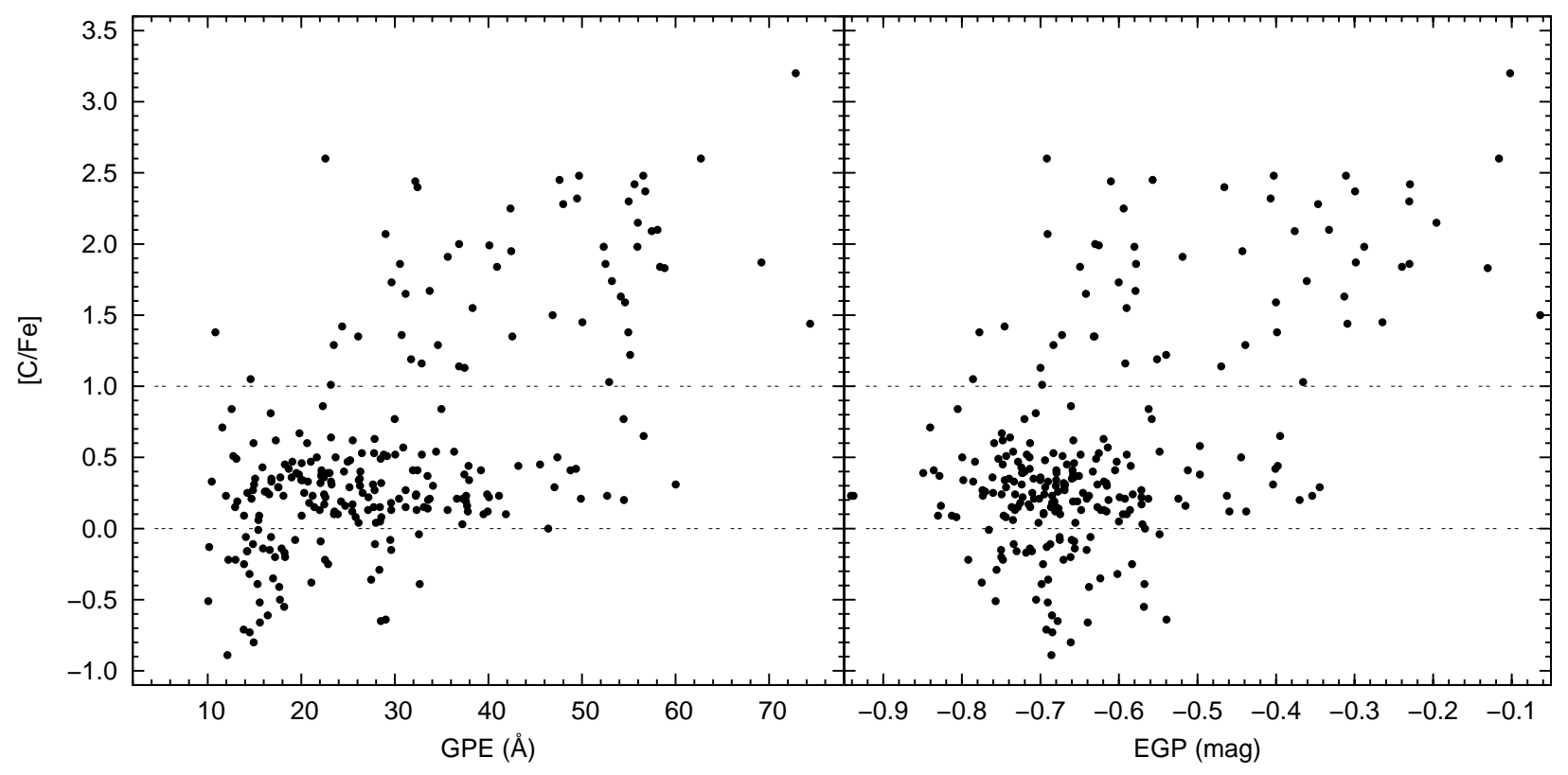

Figura 2.4: Comportamento da abundância de carbono dos objetos da base de dados SAGA em função dos índices de linha GPE e EGP.

Nota-se que, para os regimes onde $[\mathrm{C} / \mathrm{Fe}]>+1.0$, os valores dos índices tendem a crescer com o aumento da abundância de carbono, mostrando que o índice captura com sucesso a informação contida na banda G. Porém, a presença de objetos com altos valores para os índices e baixos valores de $[\mathrm{C} / \mathrm{Fe}]$ sugere que existe alguma contaminação no espectro 
que mascara o comportamento da banda G. Esta contaminação é atribuída, como visto acima, à linha $\mathrm{H} \gamma$ em 4340 Å. Dessa forma, para as estrelas com abundâncias de carbono intermediárias, é necessário introduzir uma nova variável que descreva essa dependência.

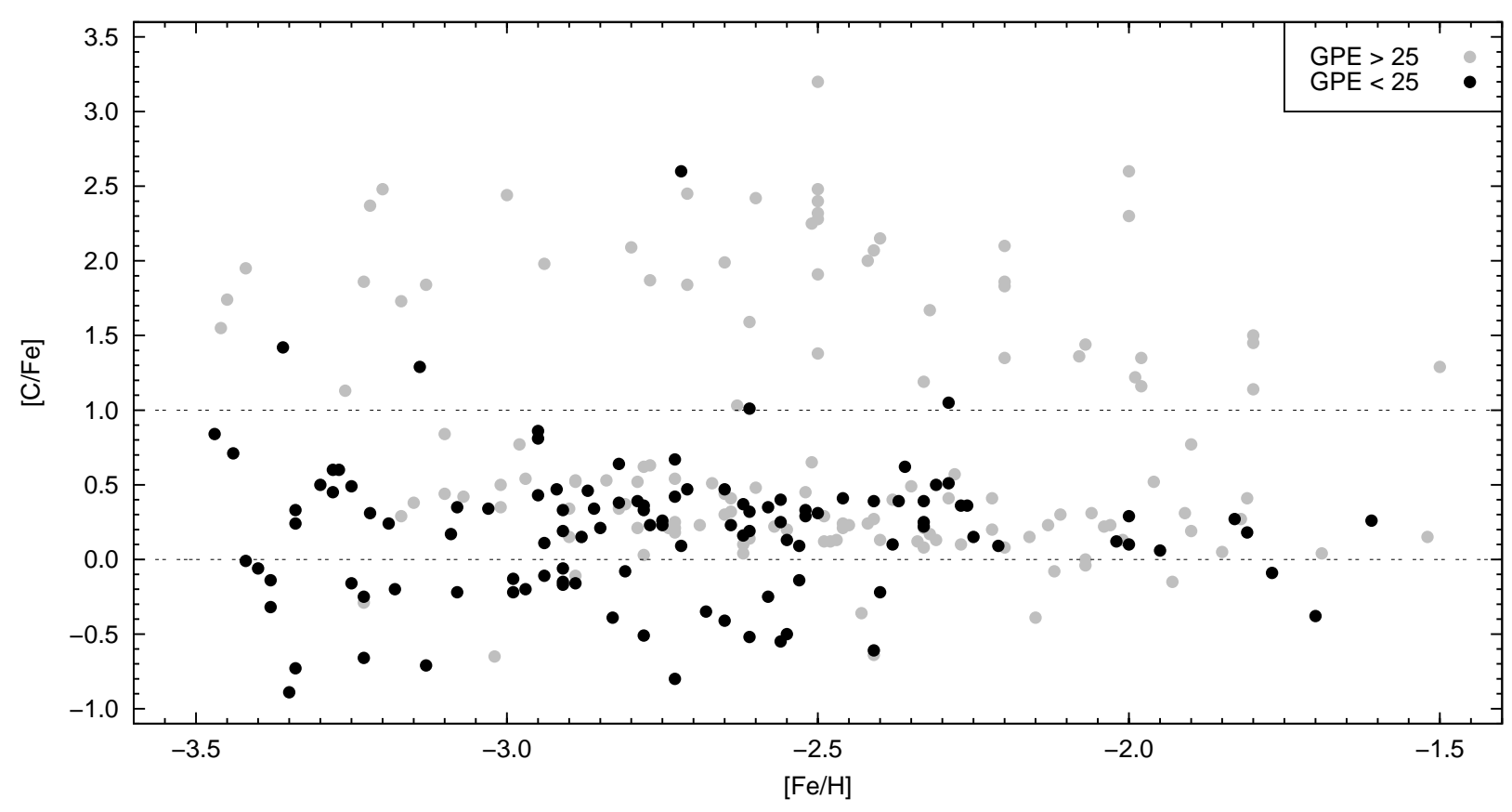

Figura 2.5: Comportamento da abundância de carbono dos objetos da base de dados SAGA em função da metalicidade para dois intervalos do índice GPE.

Ainda de acordo com a Figura 2.4, nota-se que grande parte das estrelas CEMP possui GPE $\gtrsim 25$, mas ainda assim existe um grupo de estrelas com abundâncias intermediárias de carbono $([\mathrm{C} / \mathrm{Fe}] \sim+0.5)$ que possuem valores de GPE semelhantes aos das estrelas mais enriquecidas. A Figura 2.5 mostra o comportamento da abundância de carbono em função da metalicidade, para objetos com valores de GPE maiores e menores que $25 \AA$. A atribuição desta primeira restrição em GPE tem apenas caráter exploratório, ou seja, o número 25 foi escolhido apenas para tentar separar regimes de abundância de carbono.

Outrossim, a Figura 2.5 apresenta dois pontos interessantes: (i) com exceção de alguns objetos com $[\mathrm{C} / \mathrm{Fe}] \sim+1.0$, a maioria das estrelas com valores de GPE menores que 25 possuem $[\mathrm{C} / \mathrm{Fe}]<+1.0$, ou seja, estrelas com mesmo valor de $[\mathrm{C} / \mathrm{Fe}]$ e valores discrepantes de GPE provavelmente possuem (como será visto no Capítulo 4) temperaturas distintas; (ii) o índice obteve a informação contida na banda G para as estrelas CEMP independentemente do valor de $[\mathrm{Fe} / \mathrm{H}]$, ou seja, o índice GPE (e, por conseguinte, EGP) não introduz 
o viés para baixas metalicidades presente nas buscas que utilizam o índice $\mathrm{KP}^{2}$.

Vale lembrar que a base de dados SAGA é uma compilação de vários estudos da literatura, que utilizam diferentes métodos para a determinação de metalicidades e abundâncias de carbono. Dessa forma, espera-se que parte das discrepâncias encontradas seja devido a esses métodos distintos de análise. Por conseguinte, como será visto no Capítulo 4, é necessário recorrer a uma amostra homogênea de estrelas CEMP para estabelecer restrições coerentes aos índices de linha.

\footnotetext{
${ }^{2}$ Ver Seção 1.2 para mais detalhes.
} 
Capítulo 3

\section{Base de Dados}

\subsection{O Hamburg/ESO Survey}

O HES (Hamburg/ESO Survey - Reimers, 1990; Reimers e Wisotzki, 1997; Wisotzki et al., 2000) foi o primeiro survey dedicado à observação de quasares a cobrir todo o céu do Hemisfério Sul. Inicialmente, de maneira oposta ao survey HK, o HES não foi desenhado para observação de objetos estelares próximos. Segundo Reimers (1990), os principais objetivos desta campanha observacional eram:

- Encontrar QSO's (Quasi-stellar object) brilhantes $(\mathrm{B}<17.5)$, apropriados para estudos de linhas em absorção com o VLT (Very Large Telescope);

- Identificar linhas de visada não afetadas pelo meio intergaláctico em redshifts de até $z=3$, adequados para espectroscopia em comprimentos de onda de repouso no ultravioleta extremo (100-1200 ̊) utilizando o HST (Hubble Space Telescope), em particular a linha em $304 \AA$ do He II;

- Aumentar a base de dados de lentes gravitacionais conhecidas e;

- Estudar a parte brilhante da função de luminosidade dos quasares.

Porém, dadas as características desse survey de prisma objetivo (com resolução espectral de $15 \AA$ para a linha K do CaII), esperava-se encontrar espécies interessantes de estrelas, tais como estrelas do halo pobres em metais, estrelas de carbono, variáveis cataclísmicas, anãs brancas, estrelas do ramo horizontal entre outras (ver Christlieb et al., 2008, e referências nele contidas), como subproduto. 
A parte espectroscópica do HES teve início em 1990. O survey de prisma objetivo foi conduzido com o auxílio do telescópio ESO Schmidt de 1m localizado em La Silla Chile, sendo que os espectros referentes à parte estelar foram digitalizados e reduzidos no Observatório de Hamburgo (Hamburger Sternwarte). Com uma área efetiva de $6726 \mathrm{deg}^{2}$, o survey cobriu toda a porção extragaláctica $\left(|b|>30^{\circ}\right)$ sul $\left(\delta<-2.5^{\circ}\right)$ do céu.
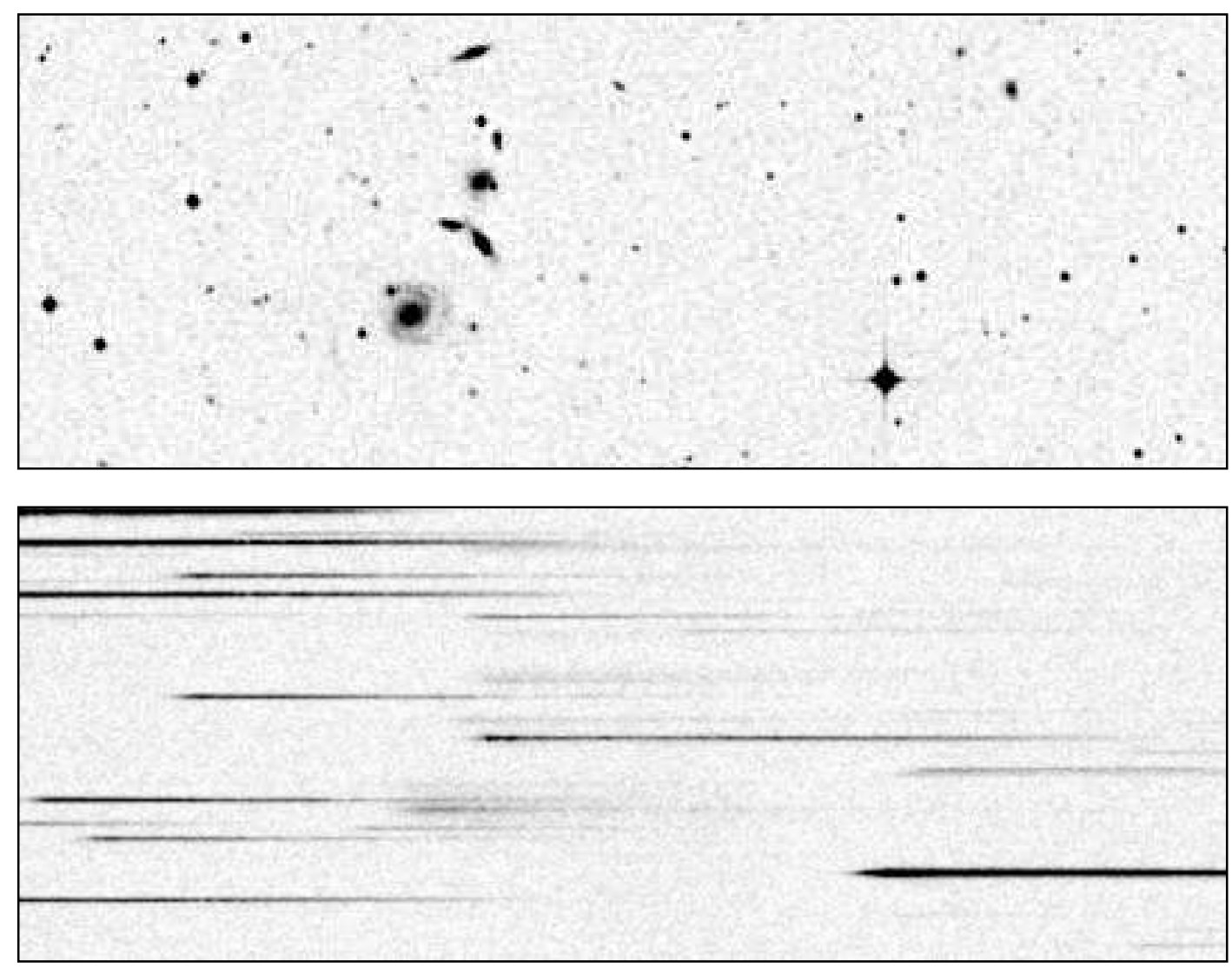

Figura 3.1: Painel superior: Placa digitalizada do Digitized Sky Survey I. Painel inferior:

Placa de prisma-objetivo digitalizada do HES referente ao mesmo campo do painel superior.

A Figura 3.1 mostra, em seu painel superior, uma das placas do DSS-I (Digitized Sky Survey I) utilizadas para comparação com as placas de prisma objetivo digitalizadas do HES (exemplo no painel inferior da figura). Para a extração automática dos espectros referentes à parte estelar, foram feitas comparações das posições de cada objeto na placa do DSS-I com seu equivalente na placa digitalizada do HES. O trabalho desenvolvido nesta tese faz uso dos espectros estelares digitalizados a partir destas placas e que foram cedidos pelo Dr. Norbert Christlieb (comunicação particular). 
O trabalho de Christlieb et al. (2008) utilizou a parte estelar do HES para aumentar o número de estrelas pobres em metais conhecidas por um fator 3-5 vezes (comparado com o survey $\mathrm{HK}$ ), principalmente devido às maiores magnitudes atingidas $(\mathrm{B} \sim 17.5$ mag), o que permite a observação de objetos cada vez mais distantes e/ou menos luminosos. A Figura 3.2 mostra a diferença de cobertura do céu entre os dois surveys citados acima.
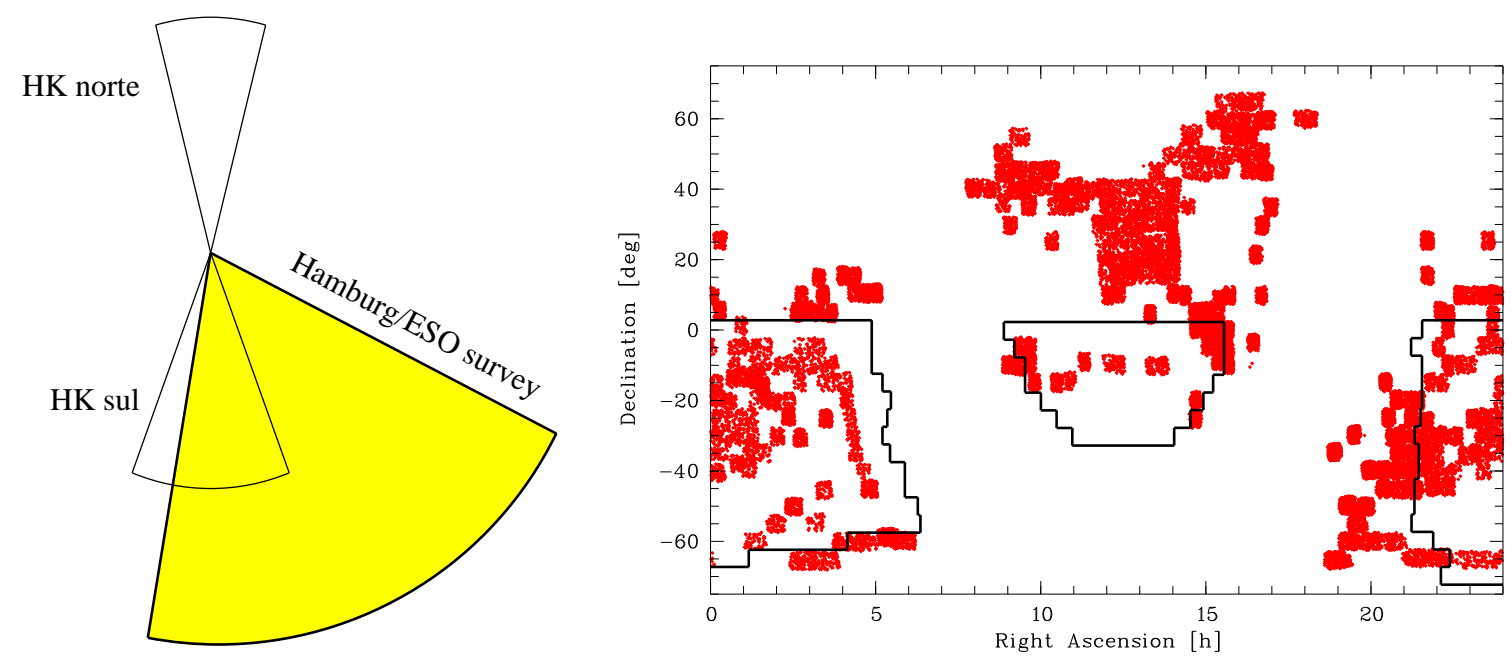

Figura 3.2: Painel esquerdo: Comparação entre o volume do céu observado pelos dois surveys. Painel direito: área de cobertura do HES (áreas delimitadas) em comparação com os locais onde se encontram as candidatas a estrelas pobres em metais descobertas pelo survey HK. Figura retirada de Christlieb (2003).

Neste ínterim, o volume total de objetos observados aumentou em quase uma ordem de grandeza. Porém, observações de follow-up ainda não foram obtidas para todos os objetos mais interessantes identificados até o momento pelo HES. A cobertura em comprimento de onda do survey encontra-se no intervalo 3200 - $5300 \AA$, que inclui a linha K de Ca II (3933 A, utilizada para estimativas de [Fe/H] - ver Beers et al., 1999; Rossi et al., 2005) e a banda $\mathrm{G}$ do $\mathrm{CH}(\sim 4300 \AA$ - para estimativas de $[\mathrm{C} / \mathrm{Fe}])$.

O trabalho apresentado nesta tese, e de outras investigações que ainda estão em curso, fizeram uso da base de dados estelar completa do HES, composta por 4404908 objetos. A principal motivação encontrada para se trabalhar com a base supracitada é o fato de que é mais confiável trabalhar com uma amostra única e homogênea, o que permite testar as novas definições dos índices de linha GPE e EGP (Seções 2.2 e 2.3, respectivamente), e ainda assim possuir um número relevante de candidatas para futuras análises. Outro ponto importante reside no fato de que o HES possui uma série de estudos em média e 
alta resolução de estrelas CEMP publicados (tais como Barklem et al., 2005; Lucatello et al., 2006; Aoki et al., 2007; Schuler et al., 2008; Schörck et al., 2009), que podem ser utilizados para comparação, uma vez que todos os objetos encontrados nestes estudos possuem espectros em baixa resolução na base de dados do HES.

\subsection{Caracterização da Amostra}

A matriz completa de dados do HES possui 4404908 linhas e 80 colunas, perfazendo um total $~ 352$ milhões de células contendo informações sobre os objetos. Sendo assim, foi necessário utilizar uma ferramenta robusta que pudesse não só carregar os dados, mas também aplicar filtros, fazer seleções, adicionar/excluir/editar informações se necessário, indexar buscas utilizando texto e fazer consultas complexas. Para tanto, utilizou-se o sistema gerenciador de banco de dados de código aberto Postgre $S Q L$, desenvolvido na Universidade de Berkeley, EUA.

Dessa forma, foi possível inserir os novos índices GPE e EGP posteriormente, uma vez que estes ainda não faziam parte da base de dados original. Outrossim, a formatação proposta para a base de dados facilita a interação com outros programas, como por exemplo o conjunto de pacotes IRAF (Image Reduction and Analysis Facility - Tody, 1986), utilizado para extração e calibração dos espectros do HES.

Algumas das informações presentes na base de dados são: ascensão reta e declinação (J2000), latitude e longitude galácticas, número, quadrante e identificadores das placas fotográficas observadas no HES (ver Figura 3.1), fotometria nas bandas UBV (extraída do HES) e JHK (extraída do 2MASS) com seus respectivos erros, correções de avermelhamento (baseadas nos mapas de Schlegel et al., 1998), índices de cor intrínsecos, índices de linha (KPHES, GPHES, $\mathrm{CN}_{1}, \mathrm{CN}_{3}, \mathrm{C}_{1}, \mathrm{C}_{2}$ ), indicadores do $2 \mathrm{MASS}$ (relacionados à qualidade da fotometria e localização de fontes próximas), razão sinal/ruído $(\mathrm{S} / \mathrm{N})$ por pixel em diferentes regiões dos espectros observados, entre outras. Também estão disponíveis os espectros em baixa resolução para todos os objetos.

\subsubsection{Análise Exploratória}

Antes de proceder com o cálculo dos índices GPE e EGP para toda a base de dados do HES, foi realizada uma análise exploratória utilizando as informações de índices de 
linha KPHES e GPHES e o índice de cor $(\mathrm{J}-\mathrm{K})_{0}{ }^{1}$ disponíveis para cada objeto. Como visto no Capítulo 1 (e na Figura 1.1), a linha K (3933 A) do Ca II é um forte indicador de metalicidade em espectros de baixa resolução. Dessa forma, através da seleção em KPHES, é possível separar estrelas candidatas a pobres em metais (ver, por exemplo Christlieb et al., 2008). A linha H (3968 ̊) do Ca II não pode ser utilizada para análise, pois sofre contaminação pela linha $\mathrm{H} \epsilon(3970 \AA)$ da série de Balmer do hidrogênio. Esse efeito torna-se cada vez mais pronunciado com o aumento da temperatura, o que inviabiliza sua utilização como indicador de metalicidade.

O primeiro conjunto de restrições para os parâmetros é:

- KPHES > 0.0 (para estimativa de $[\mathrm{Fe} / \mathrm{H}])$;

- $0.0<$ GPHES $\leq 20.0$ (para estimativa de $[\mathrm{C} / \mathrm{Fe}]$ );

- $(\mathrm{J}-\mathrm{K})_{0} \neq-9.99$ (objetos sem fotometria JHK foram excluídos);

- ph_qual $=\{\mathrm{ABC}\}\{\mathrm{ABC}\}\{\mathrm{ABC}\}$ (flags do 2MASS que selecionam objetos com razão sinal/ruído maior que 5 na região da linha $\mathrm{K}$ do Ca II).

Este conjunto de restrições fornece 4178412 objetos, cujas distribuições das variáveis KPHES, GPHES e $(\mathrm{J}-\mathrm{K})_{0}$ são mostradas na Figura 3.3. Nota-se que o valor mais frequente para a variável KPHES fica próximo de 9.5 (linhas de Ca II proeminentes), onde existe um corte na escala, introduzido artificialmente na amostra devido a problemas de saturação. Já o índice GPHES possui uma distribuição mais simétrica, com valor médio próximo a 5.0 e, para o índice de cor $(\mathrm{J}-\mathrm{K})_{0}$, nota-se um deslocamento da distribuição para valores maiores que 0.4, indicando que grande parte da amostra é constituída de estrelas mais avermelhadas, de População II.

Os índices de linha fornecem quantidades não físicas que descrevem características presentes nos espectros. É necessário então "traduzir" essa informação em termos de parâmetros físicos conhecidos. Pode-se estimar as grandezas $[\mathrm{Fe} / \mathrm{H}]$ e $[\mathrm{C} / \mathrm{Fe}]$ através das calibrações propostas por Rossi et al. (2005). Este trabalho fornece equações que utilizam os índices KP e GP e o índice de cor $(\mathrm{J}-\mathrm{K})_{0}$ para estimar a metalicidade e a abundância de carbono, e que são escritas da seguinte forma:

\footnotetext{
${ }^{1}$ Refere-se ao índice de cor corrigido pelo avermelhamento
} 

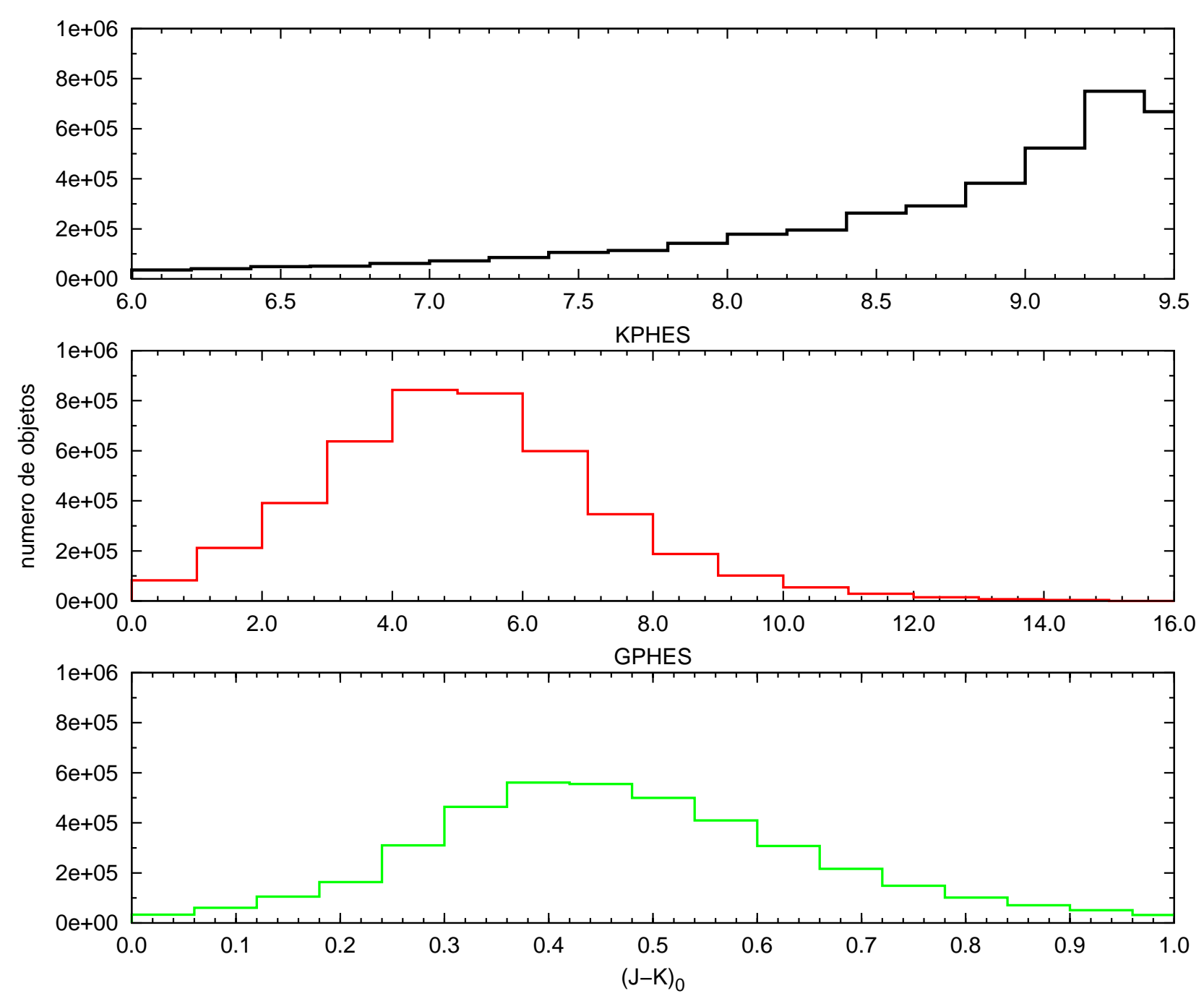

Figura 3.3: Distribuição dos índices de linha e cor para a subamostra de teste do HES.

$$
\begin{array}{r}
{[\mathrm{Fe} / \mathrm{H}]=-1.27-1.56 \cdot \mathrm{LKP}+3.09 \cdot \mathrm{LKP}^{2}-4.04 \cdot(\mathrm{J}-\mathrm{K})_{0}} \\
{[\mathrm{C} / \mathrm{Fe}]=1.70-3.40 \cdot \mathrm{LKP}+1.99 \cdot \mathrm{LGP},}
\end{array}
$$

onde LKP e LGP são os logarítmos de KPHES e GPHES na base 10, respectivamente. É importante notar que as relações originais propostas por Rossi et al. (2005) utilizam as grandezas KP e GP, distintas daquelas do HES, que foram definidas posteriormente devido à baixa resolução espectral alcançada pelo survey (ver Christlieb et al., 2008, para maiores detalhes). Mesmo assim, dadas as características logarítmicas das Equações $3.1 \mathrm{e}$ 3.2, conclui-se que pequenas diferenças nos índices não acarretam grandes incertezas nos valores finais de $[\mathrm{Fe} / \mathrm{H}]$ e $[\mathrm{C} / \mathrm{Fe}]$. Além disso, essas determinações foram utilizadas apenas 
para uma descrição geral do comportamento da amostra selecionada.

A relação entre as estimativas de metalicidade e abundância de carbono é mostrada na Figura 3.4. Além da dispersão das duas variáveis, foi introduzida uma escala de cor (referente aos valores do índice KPHES) e uma escala de tamanho dos pontos (referente aos valores de GPHES), que denotam as dependências dos índices nas equações 3.1 e 3.2.

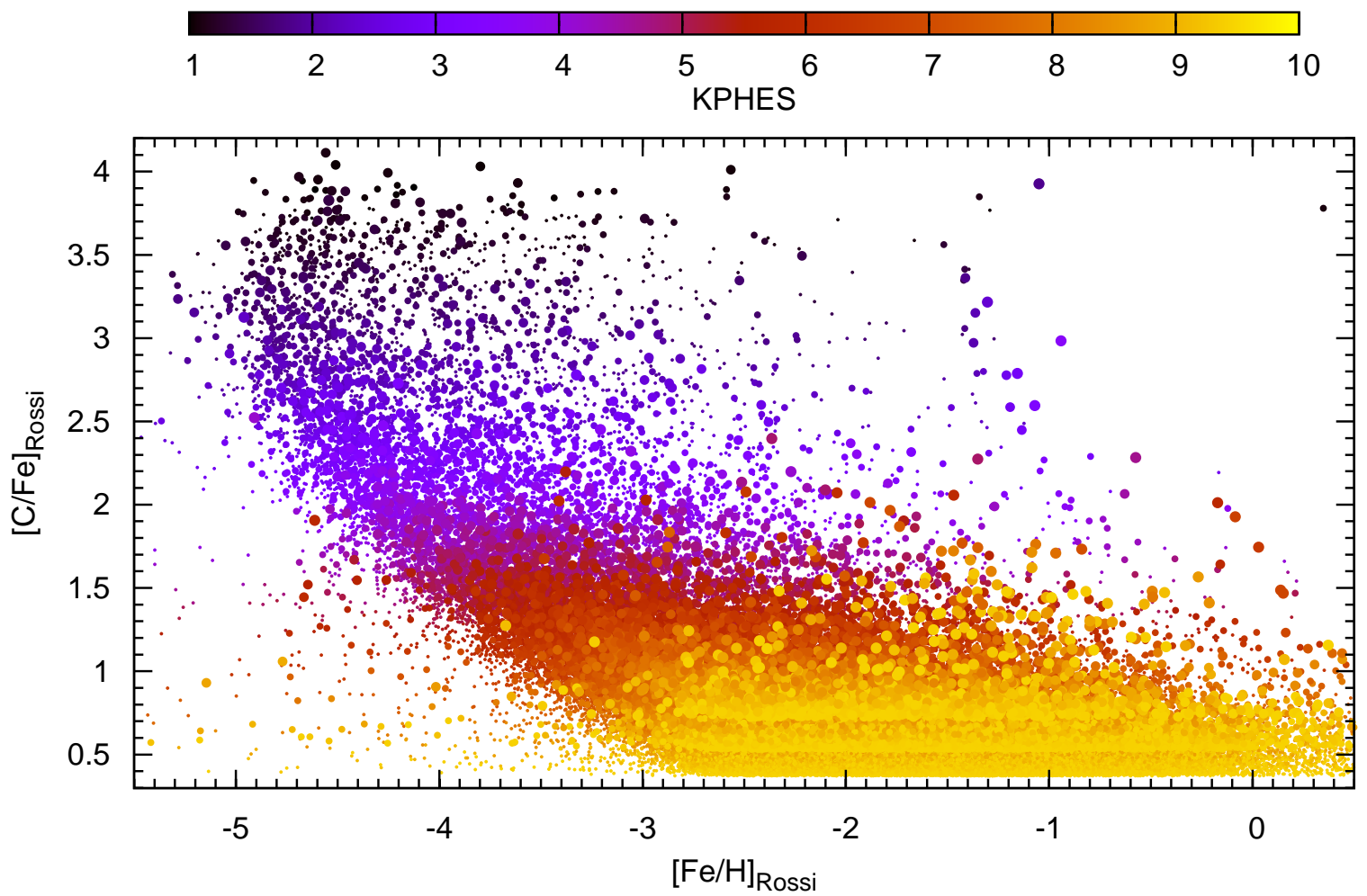

Figura 3.4: Comportamento do índice KPHES em função dos parâmetros calculados pelas equações 3.1 e 3.2. O tamanho dos pontos é proporcional ao valor do índice GPHES.

O cálculo das grandezas $[\mathrm{Fe} / \mathrm{H}]$ e $[\mathrm{C} / \mathrm{Fe}]$ para esses objetos fornece um comportamento global da amostra. Porém, as incertezas associadas aos índices são elevadas e a calibração de Rossi et al. (2005) é válida para um intervalo limitado do espaço de parâmetros. Muitos dos valores apresentados na Figura 3.4, principalmente aqueles associados a menores valores de KPHES e maiores valores de GPHES, provavelmente são resultado de algum erro na determinação deste índice ${ }^{2}$.

\footnotetext{
${ }^{2}$ Vale lembrar que não foi feita nenhuma inspeção visual prévia nos espectros, ou seja, existem valores que podem estar associados a, por exemplo, sobreposição de espectros, defeitos nas placas fotográficas e problemas com a emulsão fotográfica.
} 
O comportamento crescente de $[\mathrm{C} / \mathrm{Fe}]$ com a diminuição da metalicidade é esperado, tanto devido a resultados observacionais (Rossi et al., 1999; Lucatello et al., 2006), quanto ao fato de que as equações 3.1 e 3.2 foram calibradas utilizando estrelas pobres em metais ricas em carbono, o que insere um viés no cálculo para objetos em baixa resolução. Também, ao comparar o número relativo de estrelas em diferentes faixas de metalicidade, não se observa uma diminuição acentuada do número de objetos, fato que contraria as observações (ver Beers e Christlieb, 2005).

Além disso, os índices GP e GPHES, como definidos por Beers et al. (1999) e Christlieb et al. (2008), respectivamente, não fornecem uma representação adequada acerca da sobreabundância de carbono (detalhes no Capítulo 2 desta tese). Isto ocorre principalmente para casos mais extremos onde a influência do carbono afeta uma região mais extendida do espectro, ou seja, estes índices não fornecem toda a informação presente na banda G. Desta forma, fez-se necessário o cálculo dos novos índices de linha GPE e EGP para toda a base de dados, com o intuito de trazer um enfoque distinto no tratamento das estrelas candidatas a CEMP.

\subsubsection{Cálculo dos Índices GPE e EGP para as Estrelas do HES}

Uma vez identificadas as falhas das técnicas anteriormente empregadas na busca por estrelas com enriquecimento em carbono, foram feitos os cálculos dos índices GPE e EGP para toda a base de dados do HES. Os valores foram determinados para todos os espectros disponíveis, independentemente da qualidade dos mesmos. Eventuais problemas com os índices são diagnosticados posteriormente por inspeção visual. Antes dos cálculos dos índices propriamente ditos, realizou-se uma fase de testes com diversas abordagens referentes ao ajuste do contínuo (para o índice GPE - ver Seção 2.2) e à largura de banda na região vermelha do espectro (para o índice EGP - ver Seção 2.3).

Ao todo foram calculados 8809816 índices em um período de aproximadamente 4 meses, utilizando entre 2 e 4 computadores trabalhando em paralelo. As rotinas desenvolvidas para o procedimento foram escritas em shell script, e utilizaram funções internas de um sistema operacional tipo Unix para realizar os cálculos, além dos softwares IRAF, PostgreSQL e IDL (Interactive Data Language - Landsman, 1989). A sequência dos principais procedimentos utilizados é mostrada a seguir. O software e/ou função utilizados em cada 
um dos passos encontra-se entre parênteses:

1. Formatação dos arquivos de dados originais do HES (awk);

2. Leitura da base de dados (PostgreSQL);

3. Introdução de número sequencial de identificação para os objetos (awk);

4. Extração do espectro da base de dados do HES (IRAF);

5. Calibração em comprimento de onda (awk);

6. Determinação do contínuo (IDL);

7. Cálculo dos índices GPE e EGP (bc);

8. Adição dos novos valores à base de dados (PostgreSQL);

9. Visualização da saída (por exemplo Figuras 2.2 e 2.3 - Gnuplot).

A calibração em comprimento de onda foi feita utilizando a seguinte relação (cedida por Norbert Christlieb - comunicação particular) entre a coordenada original dos espectros $(x)$ e o comprimento de onda $(\lambda)$ :

$$
x=-2953.588+8.218377 \cdot 10^{10} \cdot \frac{1}{\lambda^{2}}+7.675455 \cdot 10^{16} \cdot \frac{1}{\lambda^{4}},
$$

onde $x$ é dado em $\mu \mathrm{m}$ e $\lambda$ em $\AA$. Esta calibração foi determinada a partir da comparação entre as placas digitalizadas do HES e das placas do DSS-I (ver Figura 3.1). A precisão desta calibração é de $\pm 13 \AA$ na região da linha $\mathrm{H} \gamma(4340 \AA)$ e $\pm 5 \AA$ em $\lambda=3500 \AA$. A razão sinal/ruído típica dos espectros do HES na região da linha K do Ca II encontra-se no intervalo $5 \leq \mathrm{S} / \mathrm{N} \leq 25$, e o poder resolutor é $R \sim 500$.

No Apêndice B são mostrados o fluxograma que descreve o procedimento adotado e o código fonte de todas as rotinas envolvidas nos cálculos dos índices listadas acima. A Figura 3.5 mostra a relação entre os dois índices para todos ${ }^{3}$ os objetos da amostra. É possível notar que GPE e EGP guardam uma relação diretamente proporcional entre si, advinda do fato de que ambos levam em conta para os cálculos a mesma área ao redor da banda G.

\footnotetext{
${ }^{3}$ Alguns valores da Figura 3.5 foram removidos para adequar a escala e facilitar a visualização.
} 
A principal motivação para se calcular índices que dependem essencialmente de grandezas distintas (contínuo no caso de GPE e razão de fluxos em EGP) é eliminar possíveis tendências introduzidas, por exemplo, pelo cálculo do contínuo além de possuir uma informação independente que possa ajudar na pré-seleção dos objetos, dado o tamanho da amostra. Além disso, também pelo fato de ambos os índices utilizarem a mesma largura de banda, é possível criar filtros que selecionem apenas objetos cujos índices estejam dentro de um certo intervalo de confiança, calibrado através dos valores calculados para estrelas que possuam determinações de [C/Fe] em alta resolução (ver Capítulos 4 e 5 para maiores detalhes). Esse fato ajuda a prevenir contaminações nas subamostras selecionadas, uma vez que não se espera encontrar valores de índices que estejam distantes da tendência apresentada para toda a amostra (por exemplo nas porções superior esquerda e inferior direita da Figura 3.5).

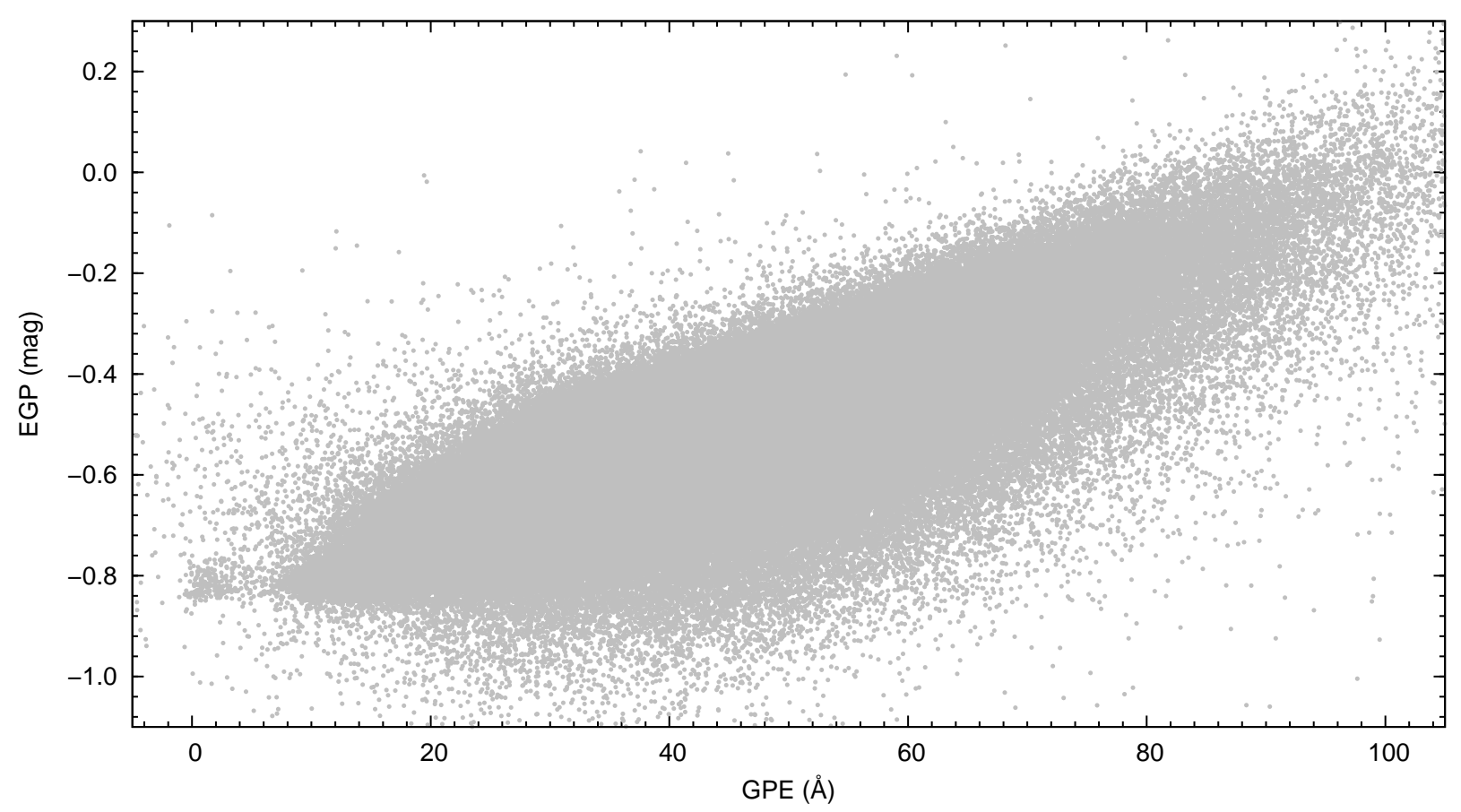

Figura 3.5: Distribuição dos novos índices de linha.

Uma abordagem, válida e factível, que pode ser implementada em uma amostra dessa dimensão seria procurar relações entre os novos índices e a temperatura dos objetos, visto que um dos objetivos deste trabalho é levar em conta as estrelas quentes excluídas da amostra de Christlieb et al. (2001). O índice de cor $(\mathrm{J}-\mathrm{K})_{0}$, obtido pelo 2MASS, foi 
escolhido como representante da escala de temperatura. Este índice é muito menos afetado pelo chamado reddening bias (onde a cor estimada diretamente pelo espectro do HES é avermelhada) do que, por exemplo, a cor (B-V). Porém, como é mostrado na Seção 4.1.3, o índice de cor $(\mathrm{B}-\mathrm{V})$ pode ser utilizado em conjunto com o $(\mathrm{J}-\mathrm{K})_{0}$ para filtrar o excesso de objetos dentro de um determinado intervalo.

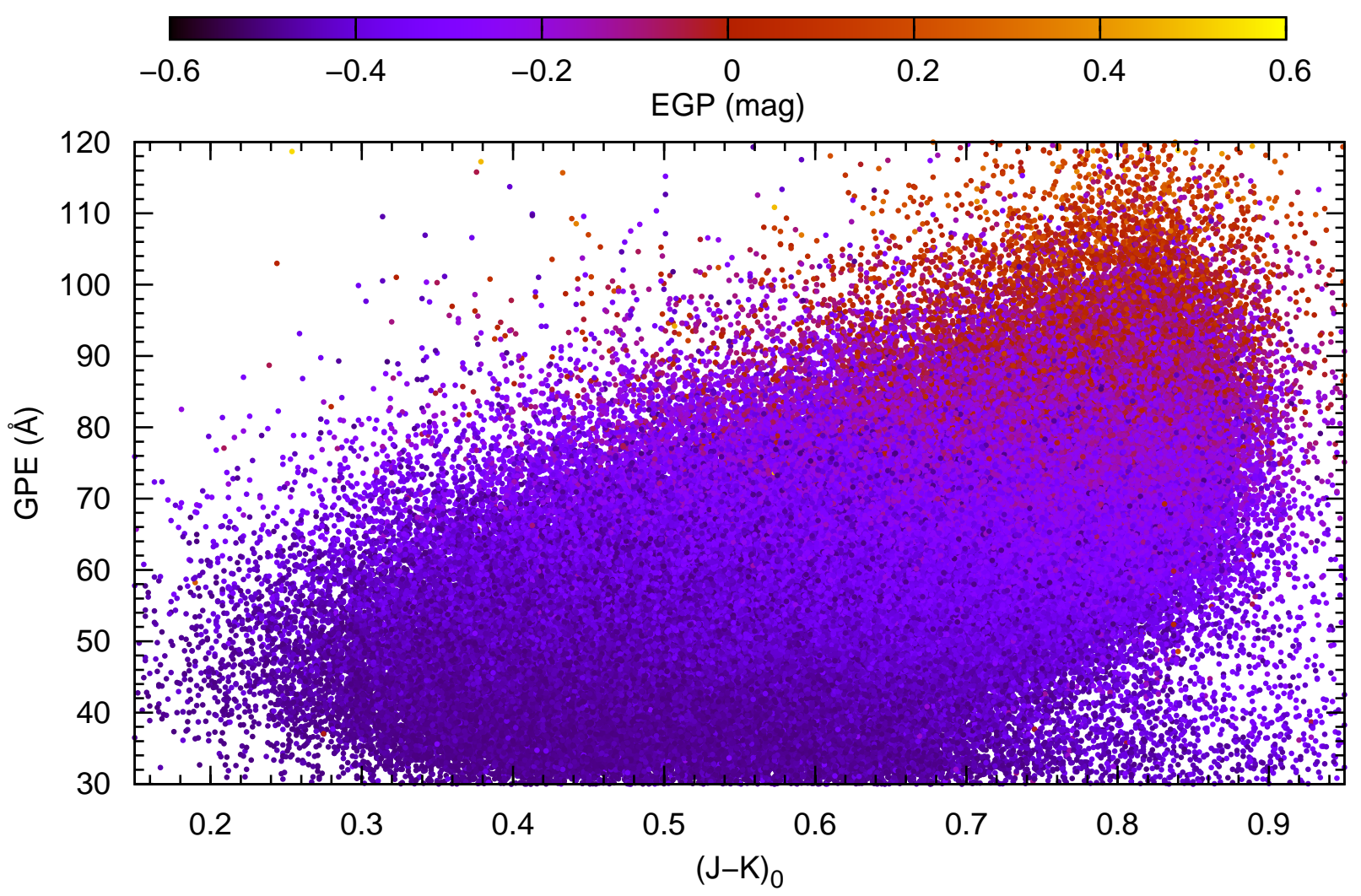

Figura 3.6: Distribuição dos novos índices de linha em função do índice de cor $(\mathrm{J}-\mathrm{K})_{0}$.

A distribuição dos índices GPE e EGP em função da cor $(\mathrm{J}-\mathrm{K})_{0}$ é apresentada na Figura 3.6, onde são mostradas estrelas com fotometria 2MASS, com índices de cor dentro do intervalo $0.1 \leq(\mathrm{J}-\mathrm{K})_{0} \leq 1.1$ e $\mathrm{GPE} \geq 30$ (mais detalhes sobre as restrições adotadas podem ser encontradas na Seção 4.1.1), perfazendo um total de 2334334 objetos. A tendência de crescimento dos valores dos índices é esperada, bem como seu comportamento em função da cor. Valores maiores de $(\mathrm{J}-\mathrm{K})_{0}$ representam objetos com temperaturas menores. Dessa forma, a ocorrência de maiores valores dos índices deveria também aumentar com $(\mathrm{J}-\mathrm{K})_{0}$. Porém, nota-se a presença de objetos na porção superior esquerda da Figura 3.6, o que pode denotar a ocorrência de estrelas CEMP com temperaturas mais elevadas, que são um dos 
alvos deste trabalho. Dado o grande número de pontos, espera-se que quase todo o plano seja preenchido para valores de GPE e $(\mathrm{J}-\mathrm{K})_{0}$ dentro dos intervalos $\left(0.4<(\mathrm{J}-\mathrm{K})_{0}<0.7\right.$ e $40<$ GPE $<80$ ). Porém, esse comportamento pode ser apenas uma consequência do número elevado de pontos. Assim, uma análise mais detalhada se faz necessária, bem como a inspeção visual de parte dos espectros para excluir possíveis erros. 
Capítulo 4

\section{Primeira Subamostra}

O objetivo principal deste estudo piloto (ver Placco et al., 2010a) foi o de testar o índice GPE (descrito em detalhes na Seção 2.2) na base de dados do HES (Capítulo 3), através da comparação da sua eficácia em selecionar estrelas CEMP com a análise em alta resolução disponível (e, por conseguinte, com parâmetros atmosféricos e [C/Fe] determinados; p.e. Aoki et al., 2007). Esta comparação foi feita a partir de espectros em baixa resolução, extraídos seguindo a mesma metodologia que fora utilizada para as estrelas inéditas, estrelas estas cuja identificação foi um dos objetivos deste trabalho, e cuja motivação foi seu uso em futuros surveys dedicados a estrelas CEMP.

Neste Capítulo são descritos todos os procedimentos adotados para testar o índice GPE, desde a seleção de candidatas do HES, passando pelos cálculos dos parâmetros atmosféricos, abundâncias de carbono e estimativas das abundâncias de bário e estrôncio, até a análise dos impactos dessas novas determinações nos cenários propostos para estrelas CEMP.

\subsection{Seleção de Candidatas a Estrelas CEMP}

O primeiro passo foi obter o índice GPE para uma subamostra selecionada de candidatas do HES, bem como para suas contrapartidas em baixa resolução, das estrelas CEMP estudadas por Aoki et al. (2007). O segundo passo foi examinar o comportamento destes objetos em um diagrama GPE vs. $(\mathrm{J}-\mathrm{K})_{0}$, onde a fotometria no infra vermelho próximo foi retirada do 2MASS (Skrutskie et al., 2006). Sabendo que a maioria das estrelas não apresentará sobreabundância em carbono (ou seja, a intensidade da banda G será proporcional à metalicidade), é possível identificar o local de ocorrência das estrelas CEMP considerando que estas apresentam um desvio da tendência associada às estrelas não enriquecidas. 
Para fins de comparação foram calculados, para os espectros em baixa resolução do HES, os índices GPE e EGP das 27 estrelas CEMP presentes no estudo em alta resolução de Aoki et al. (2007). A Tabela 4.1 lista os parâmetros destas estrelas, utilizados ao longo deste Capítulo e do Capítulo 5.

Tabela 4.1 - Parâmetros das estrelas CEMP de Aoki et al. (2007) utilizados neste trabalho.

\begin{tabular}{|c|c|c|c|c|c|c|}
\hline Nome & $(\mathrm{J}-\mathrm{K})_{0}$ & $\operatorname{GPHES}(\AA)$ & $\operatorname{GPE}(\AA)$ & EGP (mag) & {$[\mathrm{Fe} / \mathrm{H}]$} & {$[\mathrm{C} / \mathrm{Fe}$} \\
\hline HE $0131-3953$ & 0.20 & 7.3 & 51.0 & -0.56 & -2.71 & 2.45 \\
\hline HE $0039-2635$ & 0.57 & 6.2 & 40.9 & -0.43 & -2.91 & 2.72 \\
\hline HE $0007-1832$ & 0.25 & 4.1 & 33.7 & -0.61 & -2.65 & 2.55 \\
\hline HE $0202-2204$ & 0.45 & 4.8 & 34.0 & -0.59 & -1.98 & 1.16 \\
\hline HE 0206-1916 & 0.57 & 7.3 & 57.8 & -0.33 & -2.09 & 2.10 \\
\hline HE $0400-2030$ & 0.50 & 5.9 & 38.9 & -0.47 & -1.73 & 1.14 \\
\hline HE 1319-1935 & 0.61 & 9.3 & 50.7 & -0.26 & -1.74 & 1.45 \\
\hline HE $0507-1653$ & 0.54 & 8.1 & 41.6 & -0.37 & -1.38 & 1.29 \\
\hline HE $1005-1439$ & 0.50 & 8.5 & 49.7 & -0.40 & -3.17 & 2.48 \\
\hline HE $1434-1442$ & 0.50 & 8.1 & 43.8 & -0.44 & -2.39 & 1.95 \\
\hline HE $0012-1441$ & 0.61 & 7.2 & 57.1 & -0.40 & -2.52 & 1.59 \\
\hline HE $1523-1155$ & 0.55 & 8.8 & 52.6 & -0.23 & -2.15 & 1.86 \\
\hline HE $0212-0557$ & 0.54 & 7.0 & 54.6 & -0.36 & -2.27 & 1.74 \\
\hline HE $0441-0652$ & 0.58 & 6.1 & 47.0 & -0.51 & -2.47 & 1.38 \\
\hline HE $1157-0518$ & 0.56 & 9.6 & 57.5 & -0.20 & -2.34 & 2.15 \\
\hline HE $1150-0428$ & 0.41 & 8.0 & 57.5 & -0.30 & -3.30 & 2.37 \\
\hline HE $1429-0551$ & 0.64 & 8.1 & 44.9 & -0.35 & -2.47 & 2.28 \\
\hline HE 1528-0409 & 0.51 & 7.1 & 56.6 & -0.23 & -2.61 & 2.42 \\
\hline HE $1410-0004$ & 0.38 & 5.4 & 45.7 & -0.63 & -3.02 & 1.99 \\
\hline HE $1410+0213$ & 0.57 & 5.0 & 30.8 & -0.60 & -2.16 & 1.73 \\
\hline HE $1447+0102$ & 0.50 & 8.7 & 57.9 & -0.31 & -2.47 & 2.48 \\
\hline HE $1443+0113$ & 0.54 & 11.9 & 59.6 & -0.24 & -2.07 & 1.84 \\
\hline HE $2158-0348$ & 0.41 & 10.7 & 71.5 & -0.30 & -2.70 & 1.87 \\
\hline HE 2228-0706 & 0.47 & 7.5 & 48.8 & -0.41 & -2.41 & 2.32 \\
\hline HE $2221-0453$ & 0.66 & 9.9 & 57.7 & -0.08 & -2.22 & 1.83 \\
\hline HE 2232-0603 & 0.04 & 10.4 & 56.2 & -0.54 & -1.85 & 1.22 \\
\hline HE $2330-0555$ & 0.53 & 8.4 & 57.7 & -0.38 & -2.78 & 2.09 \\
\hline
\end{tabular}




\subsubsection{Restrições à Base de Dados}

Para identificar as candidatas a estrelas CEMP, inicialmente foram impostas as seguintes restrições à base de dados do HES:

- ph_qual = AAA (fotometria JHK do 2MASS com precisão <0.11 magnitudes);

- objtype = stars (remove fontes extensas e brilhantes);

- KPHES $<8.0$ (remove estrelas com a linha CaII K muito intensas, independentemente da temperatura efetiva);

- BHES < 15.5 (seleção de objetos para observação com o telescópio SOAR);

- $0.15 \leq(\mathrm{J}-\mathrm{K})_{0} \leq 0.90$ (intervalo de cor adequado para análise de abundâncias).

Este primeiro conjunto de restrições, aplicado à base de dados, gerou uma amostra com 85894 objetos. O índice GPE foi calculado para estes objetos, bem como para os espectros em baixa resolução das estrelas presentes em Aoki et al. (2007), que são de fato estrelas CEMP. A Figura 4.1 mostra a distribuição do índice GPE em função da cor $(\mathrm{J}-\mathrm{K})_{0}$, para a amostra descrita acima e para as estrelas de Aoki et al. (2007). O índice de cor $(\mathrm{J}-\mathrm{K})_{0}$ foi escolhido como indicador de temperatura, pelo fato de que esta última influencia fortemente a intensidade das bandas moleculares de carbono, tais como $\mathrm{CN}, \mathrm{C}_{2}$ e $\mathrm{CH}$, além das linhas da série de Balmer do hidrogênio. O índice de linha é válido pois, para um dado valor de $(\mathrm{J}-\mathrm{K})_{0}$, as estrelas CEMP apresentarão maiores valores de GPE do que as estrelas que não possuem enriquecimento em carbono.

Levando em consideração a localização das estrelas CEMP conhecidas na Figura 4.1, foi determinado um limite inferior para a ocorrência de estrelas enriquecidas em carbono em $\mathrm{GPE}=30 \AA$, o que reduziu o número de candidatas para 6018 estrelas. Foi levantada a possibilidade de que, ao impor tal restrição, potenciais candidatas fossem desprezadas. No entanto, o corte em GPE representa um compromisso entre duas situações antagônicas: (i) um número satisfatório de candidatas a serem exploradas e (ii) o tempo que pode ser dispendido em observações subsequentes. Caso o valor imposto fosse de $35 \AA$, a subamostra contaria com apenas 1883 objetos; ademais, para GPE $=25 \AA$, a subamostra iria conter 26313 objetos, o que impossibilitaria uma inspeção visual. 


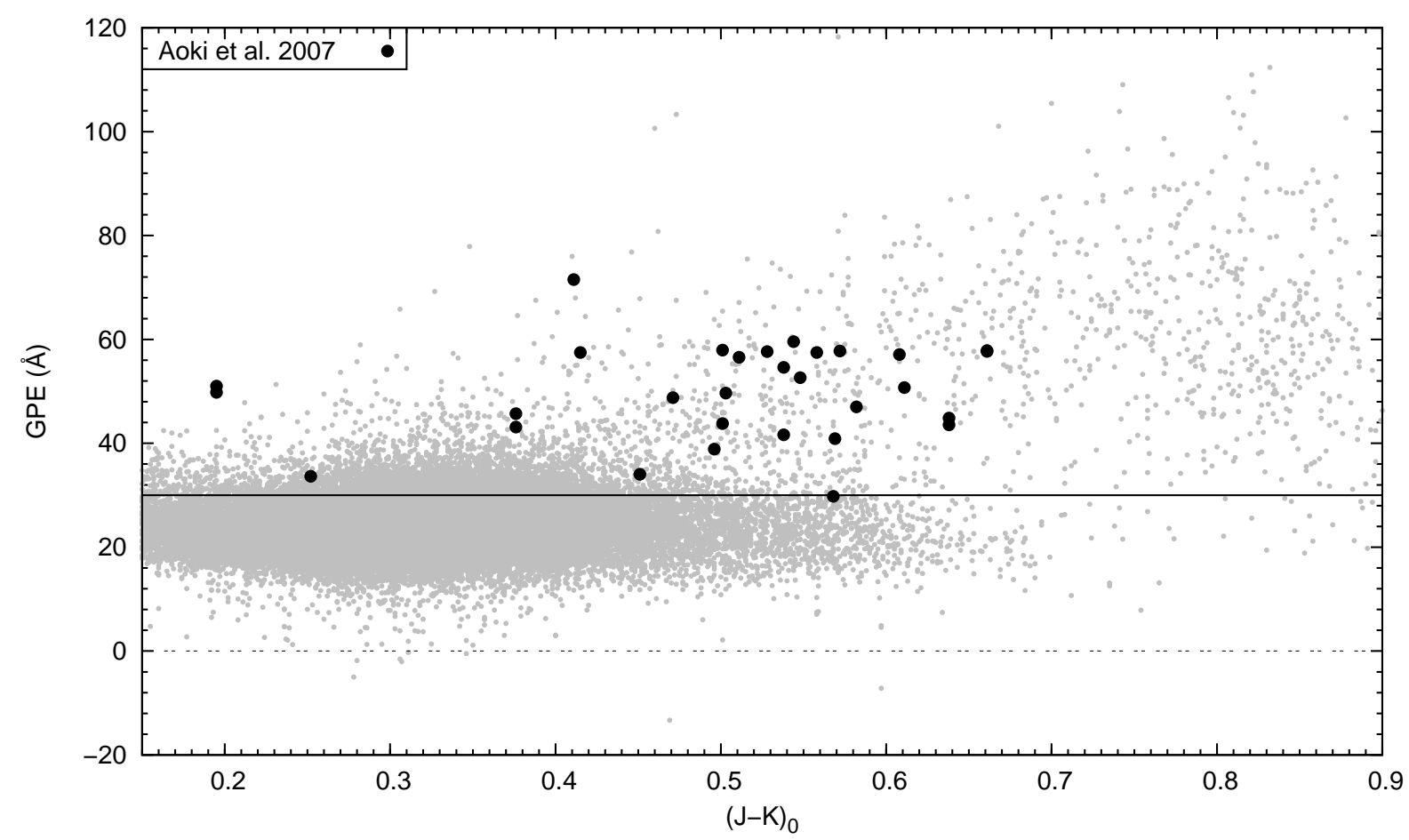

Figura 4.1: Distribuição do índice GPE em função de $(\mathrm{J}-\mathrm{K})_{0}$, para as 85894 candidatas (pontos cinzas) e estrelas de Aoki et al. (2007) (círculos pretos). A linha sólida horizontal mostra o limite para GPE.

Dentre as motivações para a introdução de um novo índice de linha para a banda G do carbono, pode se destacar o fato de que o índice GPHES, previamente calculado para a base de dados do HES, é suscetível à saturação ou à contaminação por fortes bandas moleculares de carbono, devido à forma como é estimado o nível do contínuo (ver Seção 2.1 desta tese). A Figura 4.2 exibe a comparação entre os valores de GPE e GPHES para a primeira subamostra, bem como para as estrelas CEMP de Aoki et al. (2007).

Se ambos os índices descrevessem com sucesso toda a informação contida na banda G, esperaria-se uma relação bem definida entre o comportamento de GPE e GPHES, semelhante ao apresentado pelas estrelas CEMP estudadas em alta resolução. Porém, é possível notar claramente um desvio em relação à tendência linear para valores de GPE acima de $40 \AA$, cujos objetos também possuem valores mais altos de $(\mathrm{J}-\mathrm{K})_{0}$, como visto na Figura 4.1. Então, conclui-se que o novo índice traduz com mais fidelidade a informação contida nesta região do espectro. Além disso, outra vantagem do índice GPE sobre os demais (ver Tabela 2.1), é a de que este possui um intervalo dinâmico muito maior $(200 \AA)$, o que é crucial para minimizar erros nas medidas dos índices de linha. Pequenos erros de 
medida afetam com maior intensidade GPHES do que GPE, tanto por conta da largura de banda de linha quanto da interpolação linear das bandas laterais.

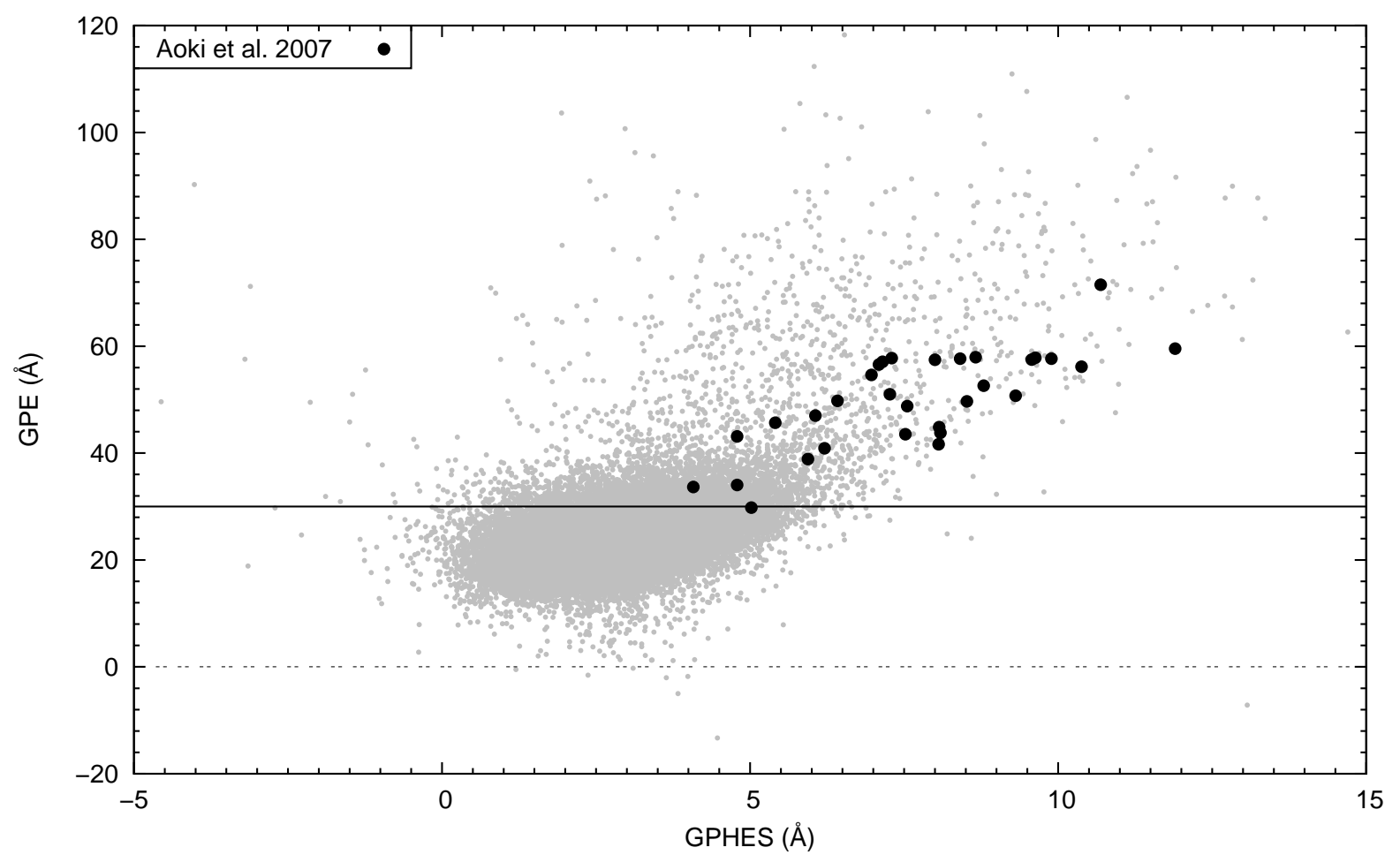

Figura 4.2: Comparação entre o índice GPHES previamente calculado para as estrelas do HES e o novo índice GPE. Os círculos pretos em destaque são as estrelas de Aoki et al. (2007).

É importante salientar que as restrições feitas acima não levam em conta a razão sinal/ruído dos espectros, e nem podem distinguir entre espectros considerados satisfatórios e possíveis erros, atribuídos principalmente à sobreposição de objetos, defeitos nas emulsões das placas fotográficas e artefatos presentes nas medidas. Assim, foi necessária a realização de uma inspeção visual nos espectros para classificar as candidatas selecionadas, como exposto a seguir.

\subsubsection{Inspeção Visual}

Com o intuito de validar os cálculos dos índices de linha para os objetos da primeira subamostra, foi feita a inspeção visual das placas fotográficas digitalizadas do HES que continham as estrelas selecionadas com GPE $\geq 30 \AA$, perfazendo um total de 6018 objetos. Essa inspeção teve como principal objetivo classificar todas as candidatas por meio da intensidade da linha Ca II K, na presença de linhas de hidrogênio da série de Balmer ou 
bandas moleculares de carbono. Além disso, foram filtrados valores espúrios de GPE, que podem ter sido originados por sobreposição de espectros, defeitos na emulssão ou riscos nas placas fotográficas. O procedimento adotado para a inspeção visual seguiu os seguintes passos:

1. Inspeção da placa fotográfica do DSS-I e identificação do objeto de interesse, centralizado na imagem (Painel superior - Figura 4.3);

2. Identificação do espectro da estrela na placa de prisma objetivo digitalizada do HES (Painel central - Figura 4.3);

3. Classificação do objeto a partir da identificação de linhas espectrais e bandas moleculares de interesse (Painel inferior - Figura 4.3).
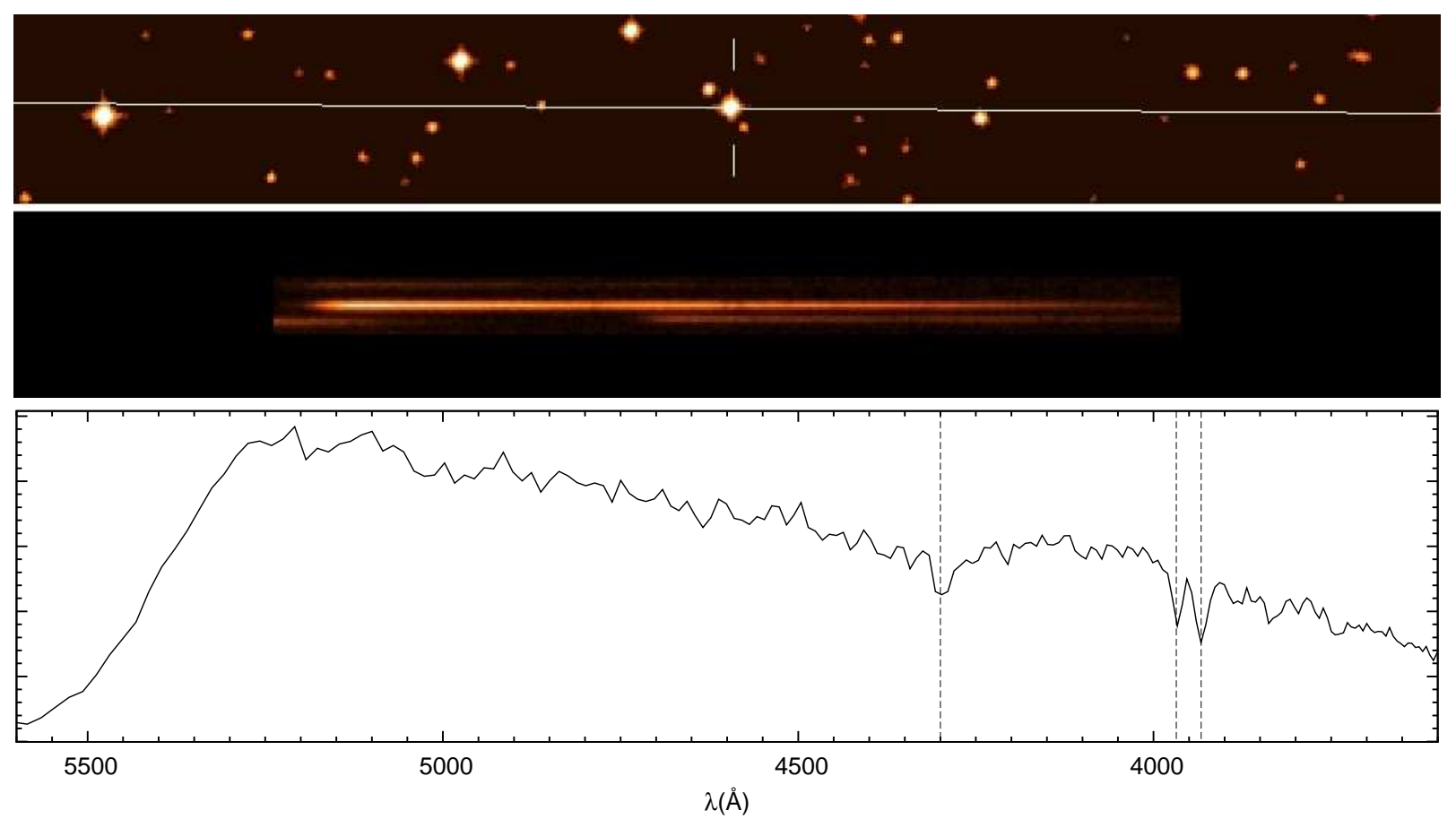

Figura 4.3: Painel superior: seção da placa fotográfica do DSS-I, centralizada no objeto de interesse. Painel central: placa de prisma objetivo digitalizada do HES. Painel inferior: espectro extraído da estrela de interesse. As linhas verticais identificam as linhas H e K do Ca II (próximas a $4000 \AA$ ) e a região da banda G (próxima a $4300 \AA$ ) .

Para cada objeto inspecionado foi associada uma classificação, a qual será utilizada posteriormente para identificar alvos interessantes para observação. As classes utilizadas neste trabalho são descritas na Tabela 4.2: 
Tabela 4.2 - Descrição das classes utilizadas na inspeção visual.

\begin{tabular}{cc|cc}
\hline \hline Classe & Descrição & Classe & Descrição \\
\hline mpca & Linha Ca II K ausente & fhlc & Bandas moleculares de carbono intensas \\
mpcb & Linha Ca II K fraca & unid & Linha Ca II K não encontrada \\
mpcc & Linha Ca II K forte & hbab & Ramo Horizontal/tipo espectral A ou B \\
nois & Baixa razão sinal-ruído & habs & Linhas intensas de H em absorção \\
ovl & Sobreposição de espectros & art & Defeitos nas placas fotográficas \\
\hline
\end{tabular}

A Figura 4.4 mostra exemplos de espectros do HES para cada uma das classes descritas na Tabela 4.2. Além disso, em cada um dos painéis estão destacadas as principais características espectrais utilizadas na classificação dos objetos.

Assim, após aplicar as restrições à base de dados e determinar o valor de GPE para o qual espera-se encontrar candidatas a estrelas CEMP, foi feita a inspeção visual dos 6018 objetos pré-selecionados. A Tabela 4.3 mostra a distribuição das estrelas de acordo com as classes mostradas na Tabela 4.2.

Tabela 4.3 - Distribuição das candidatas selecionadas via inspeção visual.

\begin{tabular}{cc|cc|cc}
\hline \hline Classe & $\mathrm{n}^{\circ}$ de objetos & Classe & $\mathrm{n}^{\circ}$ de objetos & Classe & $\mathrm{n}^{\circ}$ de objetos \\
\hline mpca & 4 & fhlc & 30 & nois & 277 \\
mpcb & 280 & unid & 143 & ovl & 79 \\
mpcc & 4614 & hbab & 218 & art & 123 \\
& & habs & 73 & & \\
\hline
\end{tabular}

Nota-se que a maioria dos espectros apresenta a linha $\mathrm{K}$ do Ca II intensa, sendo que a fração de estrelas com esta linha fraca ou inexistente é bem menor. Esse fato reproduz a forma da distribuição de metalicidade no halo da Galáxia, que mostra uma diminuição considerável do número de objetos com o decréscimo no valor da metalicidade (Beers e Christlieb, 2005). Diferentemente da classe mpca, onde a ausência da linha K do cálcio sugere uma metalicidade muito baixa, nos objetos classificados como unid não é possível identificar as linhas do CaII, pois estes objetos possuem um baixo fluxo na região mais azul do espectro. Porém, ainda assim é possível identificar a banda G. 


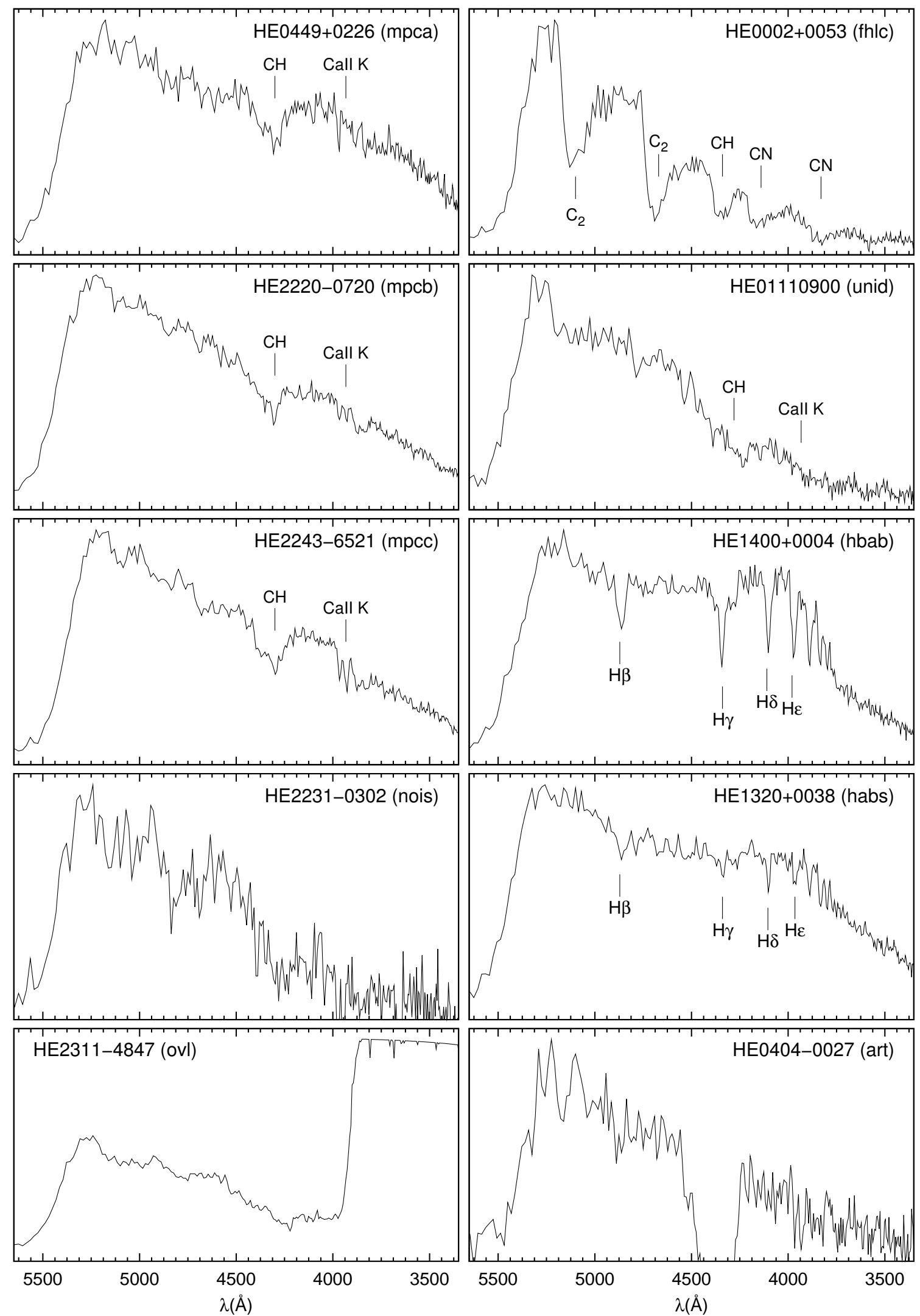

Figura 4.4: Exemplos de objetos que caracterizam as classes descritas na Tabela 4.2. 
Os objetos pertencentes às classes hbab e habs, que possuem linhas de hidrogênio em absorção, representam aproximadamente $5 \%$ do total da subamostra. A diferença principal entre as duas classes está na intensidade da descontinuidade de Balmer, em torno de 3650 Å. Essa descontinuidade consiste em uma queda abrupta na distribuição espectral de energia de uma estrela para comprimentos de onda próximos ao limite da série de Balmer $(\sim 3645 \AA)$, provocada pela absorção do contínuo por átomos de hidrogênio. A descontinuidade de Balmer atinge um máximo para estrelas de tipo A0 quando na sequência principal. Porém, tanto para a classe hbab quanto para a classe habs, a linha $\mathrm{H} \gamma$ em $4340 \AA$ contamina significativamente a região da banda $G$, o que fornece um valor superestimado para o índice GPE.

Em menor número também encontra-se a classe fhlc. Estas estrelas (que apresentam intensas bandas moleculares de carbono) foram pré-selecionadas porque possuem, mesmo com temperaturas menos elevadas, a banda $\mathrm{G}$ pronunciada e uma banda de CN intensa em $4216 \AA$ A. Além disso, esta classe de objetos também preenche os requisitos em magnitude e KPHES. Vale lembrar que estas estrelas não são o foco principal desta análise, e possuem outros métodos de seleção, como por exemplo o de Christlieb et al. (2001). Mesmo assim, espera-se que que estes objetos estejam presentes na subamostra.

Já as classes nois, ovl e art representam os objetos que foram excluídos do restante da análise. Para estas classes, o cálculo do contínuo (e consequentemente o valor do índice) é superestimado devido a, por exemplo, uma superposição de espectros, baixa razão sinal ruído e descontinuidades no espectro, que geram contaminação no índice de linha. A Figura 4.5 mostra o comportamento do índice GPE em função de $(\mathrm{J}-\mathrm{K})_{0}$ para os objetos da Tabela 4.3, com exceção das classes nois, ovl e art.

Ao inspecionar a Figura 4.5, nota-se que a maioria das estrelas localizadas à esquerda - $(\mathrm{J}-\mathrm{K})_{0}<0.3$ - do gráfico exibe linhas intensas de hidrogênio. Esses objetos, como visto acima, representam uma contaminação na amostra, e foram pré-selecionados pois possuem uma proeminente linha $\mathrm{H}_{\gamma}(4340 \AA)$, que contribui significativamente para o índice GPE. Mesmo assim, duas estrelas CEMP de Aoki et al. (2007) encontram-se na região $(\mathrm{J}-\mathrm{K})_{0} \sim 0.2$, porém com valores de GPE significativamente maiores que os demais objetos nesta região. Então, pode-se aumentar a restrição em GPE nesta região ou utilizar (como mostrado no Capítulo 5) o índice EGP como parâmetro auxiliar na pré-seleção de objetos. 


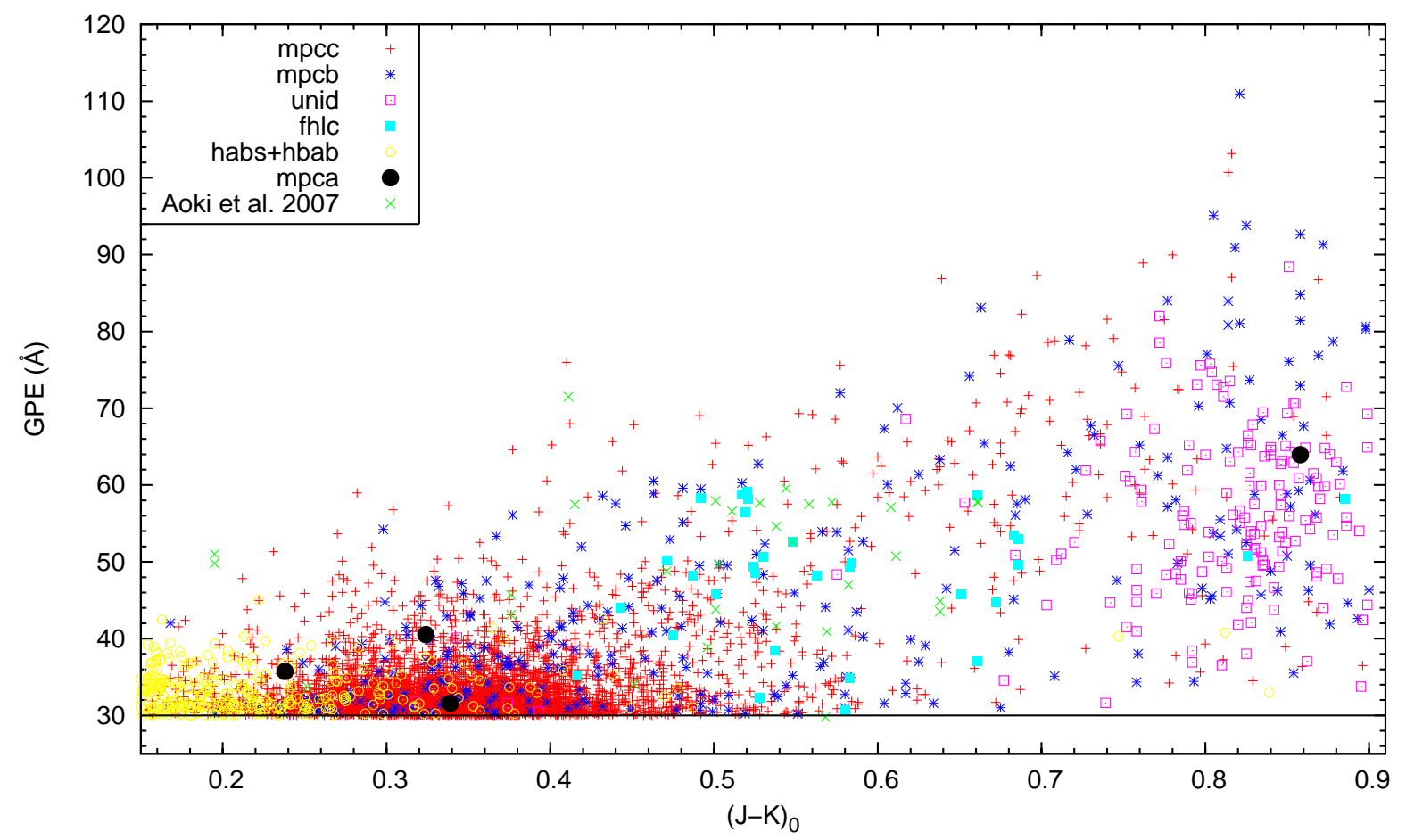

Figura 4.5: Diagrama índice-cor para as estrelas que foram submetidas à inspeção visual, divididas de acordo com as classes definidas na Tabela 4.3. As estrelas presentes em Aoki et al. (2007) estão representadas pelos símbolos em verde.

Já para o restante da distribuição - $(\mathrm{J}-\mathrm{K})_{0}>0.3$, a intensidade desta linha diminui com a temperatura, fazendo com que sua influência deixe de ser limitante para a análise.

Em contrapartida, na região onde concentram-se objetos mais vermelhos - $(\mathrm{J}-\mathrm{K})_{0}>0.7$, observa-se a predominância de objetos da classe unid. Este comportamento é esperado, visto que estes objetos são mais frios $\left(T_{\text {eff }} \sim 4500 \mathrm{~K}\right)$ que os demais. Assim, o sinal proveniente da parte azul do espectro é reduzido, prejudicando a identificação (e medida da intensidade) da linha $\mathrm{K}$ do Ca II.

\subsubsection{Seleção no Plano Cor vs. Índice de Linha}

Uma das dificuldades encontradas no método de seleção descrito na Seção 4.1.2 foi a de que a subamostra é dominada por um grande número de estrelas que apresentam a linha $\mathrm{K}$ do Ca II muito intensa ( $m p c c)$, sendo que muitas delas podem ser mais ricas em metais do que as estrelas CEMP que este trabalho se propôs a identificar. Para reduzir o número desses objetos, foi adotada uma versão menos restritiva do método de seleção proposto por 
Christlieb et al. (2008) no espaço de parâmetros que engloba o índice de linha $\mathrm{KP}^{1}$ e as cores $(\mathrm{J}-\mathrm{K})_{0}$ ou $(\mathrm{B}-\mathrm{V})$.

A partir de um conjunto de valores aleatórios para KP e o índice de cor escolhido, são utilizadas relações semelhantes às descritas em, por exemplo, Rossi et al. (2005), para calcular as metalicidades desta amostra. A seguir, é feita uma regressão polinomial entre os parâmetros para os pares de dados que satisfaçam a restrição imposta para metalicidade. Para a presente subamostra, foi utilizado o valor $[\mathrm{Fe} / \mathrm{H}]=-2.0$, com as seguintes regressões para $(\mathrm{J}-\mathrm{K})_{0}$ e $(\mathrm{B}-\mathrm{V})$, adaptadas de Christlieb et al. (2008):

$$
\begin{aligned}
& \mathrm{KP}([\mathrm{Fe} / \mathrm{H}]=-2.0)=-2.37+14.75 \cdot(\mathrm{J}-\mathrm{K})_{0}+40.39 \cdot(\mathrm{J}-\mathrm{K})_{0}^{2} \\
& -90.64 \cdot(\mathrm{J}-\mathrm{K})_{0}^{3}+51.52 \cdot(\mathrm{J}-\mathrm{K})_{0}^{4} \\
& \mathrm{KP}([\mathrm{Fe} / \mathrm{H}]=-2.0)=18.24-155.03 \cdot(\mathrm{B}-\mathrm{V})+504.44 \cdot(\mathrm{B}-\mathrm{V})^{2} \\
& -683.79 \cdot(\mathrm{B}-\mathrm{V})^{3}+421.71 \cdot(\mathrm{B}-\mathrm{V})^{4}-97.22 \cdot(\mathrm{B}-\mathrm{V})^{5}
\end{aligned}
$$

É importante ressaltar que eventuais erros nas medidas do índice KP permitem (devido ao grande número de candidatas) que muitas estrelas com $-2.0 \leq[\mathrm{Fe} / \mathrm{H}] \leq-1.0$ entrem na amostra. Se o corte de metalicidade imposto estivesse mais próximo de $[\mathrm{Fe} / \mathrm{H}] \sim-1.0$, o número de estrelas com altas abundâncias tornar-se-ia proibitivo. A Figura 4.6 mostra a distribuição das estrelas de classe mpcc para ambas as cores mencionadas acima e suas respectivas regressões associadas à metalicidade constante.

A seleção final das candidatas a estrelas CEMP incluiu todas as estrelas onde: (i) a linha K do Ca II encontrava-se ausente ( $m p c a)$, (ii) fraca $(m p c b)$ ou (iii) não encontrada (unid), (iv) estrelas com bandas de carbono molecular intensas (fhlc) e também (v) as estrelas de classe mpcc que possuissem índice KP abaixo de pelo menos uma das regressões para metalicidade constante (pontos cinzas na Figura 4.6).

Tendo em vista a dimensão do HES e o número de publicações associadas aos seus objetos, foi realizada uma busca detalhada por objetos que já haviam sido alvo de outros estudos (incluindo estrelas pobres em metais e estrelas ricas em carbono conhecidas). Feita a identificação, todos os objetos já publicados foram excluídos, resultando em uma subamostra com 669 candidatas inéditas a estrelas CEMP.

\footnotetext{
${ }^{1} \mathrm{O}$ índice KP, definido por Beers et al. (1999), mede a intensidade da linha K do Ca II.
} 


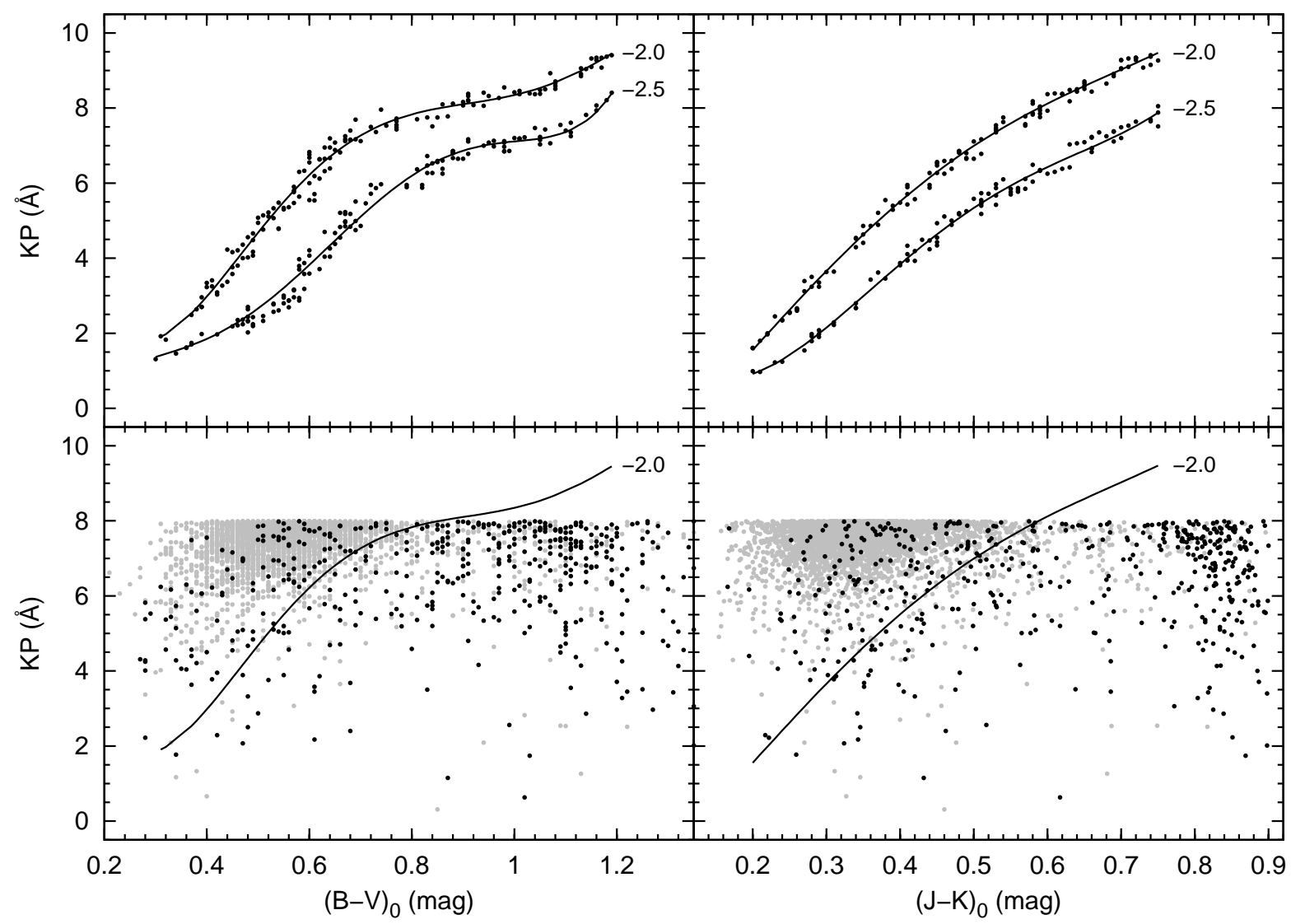

Figura 4.6: Paineis superiores: Ajustes polinomiais para valores constantes de metalicidade, baseados em Christlieb et al. (2008). Paineis inferiores: Critério de seleção para eliminar estrelas com a linha K do Ca II intensa $(m p c c)$. Os pontos pretos representam as estrelas onde a linha K do Ca II encontra-se ausente $(m p c a)$, fraca $(m p c b)$ ou não encontrada (unid). Os pontos cinzas representam as estrelas mpcc, e são selecionadas aquelas que se encontram abaixo da linha $[\mathrm{Fe} / \mathrm{H}] \leq-2.0$ para ao menos um dos índices de cor.

\subsection{Validação das Candidatas a Estrelas CEMP}

Um passo muito importante na seleção de candidatas é a confirmação de seu status de estrela CEMP. Para tanto, foram obtidos um número limitado de espectros em média resolução na faixa óptica do espectro com o telescópio SOAR de 4.1m. Após a observação e redução dos dados, foram obtidas estimativas para os parâmetros atmosféricos e medidas de $[\mathrm{C} / \mathrm{Fe}]$. Detalhes sobre as observações, procedimentos de redução e subsequente análise são fornecidos a seguir. 


\subsubsection{Observações Espectroscópicas em Média Resolução}

A espectrocopia em média resolução de 132 das 669 candidatas a estrelas CEMP selecionadas foi obtida com o espectrógrafo Goodman², acoplado ao telescópio SOAR, entre o segundo semestre 2008 e o segundo semestre de 2009. As observações foram feitas em modo clássico, a partir das salas de observação remota instaladas no Departamento de Astronomia do Instituto de Atronomia, Geofísica e Ciências Atmosféridas da Universidade de São Paulo e no Departamento de Física e Astronomia da Michigan State University, em colaboração com pesquisadores desta instituição.

O espectrógrafo Goodman opera em diversos modos de observação. Para este trabalho, foi utilizada a rede de $6001 \mathrm{~mm}^{-1}$ na configuração azul (intervalo de comprimento de onda: 3550-5500 A), com uma fenda de 1".03, alcançando um poder resolutor $R \sim 1500$ (resolução de $\sim 3.5 \AA$ ). Esta resolução foi escolhida devido à sua similaridade com a resolução dos espectros obtidos pelo SDSS, uma vez que foram utilizadas as mesmas ferramentas para a determinação dos parâmetros atmosféricos (ver Seção 4.2.2 para mais detalhes).

Os procedimentos de calibração incluíram bias, flat-fields e também espectros de lâmpadas de $\mathrm{HgAr}$ e $\mathrm{Cu}$, tomados logo após a observação de cada objeto do programa. Os tempos de exposição para a maioria das estrelas observadas está na faixa de 10-20 minutos (para atingir S/N > 40 na região da banda G). Também foram observadas estrelas-padrão, utilizadas para determinação de velocidades radiais, extraídas do catálogo de Carney e Latham (1986). Tarefas como subtração de bias, correção por flat-fields, extração de espectros, calibração em comprimento de onda e normalização de contínuo foram todas realizadas utilizando os pacotes padrão do IRAF.

A Tabela 4.4 lista, para as candidatas observadas, as coordenadas equatoriais (J2000), magnitude BHES, $(\mathrm{J}-\mathrm{K})_{0}$, GPE, KPHES, GPHES (em $\AA$ ) e a classe designada de acordo com a Tabela 4.2. Os espectros em média resolução para algumas estrelas selecionadas podem ser vistos na Figura 4.7, organizados em ordem crescente de $(J-K)_{0}$. A relação completa dos espectros das 132 candidatas observadas encontra-se no Apêndice A.

\footnotetext{
2 http://www.soartelescope.org/observing/goodman-high-throughput-spectrograph
} 
Tabela 4.4 - Parâmetros estelares e índices de linha $(\AA)$ para as candidatas observadas.

\begin{tabular}{|c|c|c|c|c|c|c|c|c|}
\hline Nome & $\alpha(\mathrm{J} 2000)$ & $\delta(\mathrm{J} 2000)$ & BHES & $(\mathrm{J}-\mathrm{K})_{0}$ & GPE & KPHES & GPHES & Classe \\
\hline HE $0008+0049$ & $00: 11: 10.5$ & $+01: 05: 51$ & 14.5 & 0.58 & 32.0 & 7.2 & 4.7 & mpcb \\
\hline HE $0024-0550$ & $00: 26: 33.7$ & $-05: 33: 35$ & 14.7 & 0.42 & 30.4 & 6.0 & 3.2 & mpcc \\
\hline HE $0034-0011$ & $00: 36: 51.2$ & $+00: 05: 29$ & 15.0 & 0.36 & 29.7 & 5.5 & 5.2 & mpcc \\
\hline HE $0035-5803$ & $00: 37: 27.3$ & $-57: 47: 27$ & 15.0 & 0.36 & 31.3 & 7.4 & 4.1 & mpcc \\
\hline HE $0053-0356$ & $00: 56: 04.7$ & $-03: 40: 40$ & 14.7 & 0.38 & 36.5 & 6.1 & 6.1 & mpcb \\
\hline HE $0058+0141$ & 01:01:16.5 & $+01: 57: 46$ & 15.0 & 0.26 & 28.6 & 6.4 & 2.4 & mpcb \\
\hline HE $0100-4957$ & 01:02:13.8 & $-49: 41: 29$ & 15.0 & 0.58 & 37.8 & 7.7 & 2.8 & mpcc \\
\hline HE $0102-0004$ & 01:05:09.8 & $+00: 11: 38$ & 14.3 & 0.32 & 29.3 & 6.1 & 3.9 & mpcb \\
\hline HE $0118-4834$ & $01: 20: 18.4$ & $-48: 19: 12$ & 14.7 & 0.37 & 37.4 & 5.4 & 5.5 & mpcb \\
\hline HE $0156-5608$ & $01: 58: 38.8$ & $-55: 54: 25$ & 14.9 & 0.49 & 30.7 & 6.8 & 5.0 & mpcc \\
\hline HE $0159-5216$ & 02:01:40.6 & $-52: 02: 15$ & 14.7 & 0.49 & 32.6 & 7.5 & 5.4 & mpcc \\
\hline HE $0214-0818$ & $02: 16: 44.1$ & $-08: 04: 31$ & 14.8 & 0.31 & 32.9 & 6.8 & 4.0 & mpcb \\
\hline HE $0307-5339$ & 03:08:42.2 & $-53: 28: 20$ & 14.9 & 0.44 & 43.5 & 7.3 & 7.6 & mpcb \\
\hline HE $0316-2903$ & $03: 18: 14.7$ & $-28: 52: 51$ & 14.7 & 0.47 & 37.8 & 6.7 & 5.9 & mpcc \\
\hline HE $0320-1242$ & 03:23:07.3 & $-12: 31: 27$ & 15.0 & 0.42 & 38.1 & 6.9 & 3.9 & mpcb \\
\hline HE $0322-3720$ & $03: 24: 27.8$ & $-37: 09: 57$ & 14.2 & 0.62 & 39.9 & 7.9 & 5.5 & mpcb \\
\hline HE $0336-3948$ & 03:38:43.3 & $-39: 38: 22$ & 14.9 & 0.37 & 30.7 & 6.0 & 5.0 & mpcc \\
\hline HE $0340-3933$ & $03: 41: 56.5$ & $-39: 24: 06$ & 14.6 & 0.34 & 33.0 & 6.6 & 4.0 & mpcc \\
\hline HE $0345+0006$ & 03:48:19.4 & $+00: 15: 10$ & 15.1 & 0.53 & 30.6 & 6.6 & 4.0 & mpcc \\
\hline HE $0405-4411$ & 04:07:14.2 & $-44: 03: 53$ & 15.1 & 0.32 & 31.8 & 6.9 & 1.7 & unid \\
\hline HE $0414-4645$ & $04: 16: 10.2$ & $-46: 38: 17$ & 15.1 & 0.34 & 34.1 & 5.7 & 3.4 & mpcc \\
\hline HE $0440-5525$ & 04:42:00.1 & $-55: 19: 30$ & 15.0 & & 32.0 & 6.4 & 4.1 & mpcb \\
\hline HE $0444-3536$ & $04: 46: 39.5$ & $-35: 31: 07$ & 14.7 & 0.49 & 43.2 & 7.7 & 6.3 & mpcc \\
\hline HE $0449-1617$ & 04:52:01.4 & $-16: 12: 11$ & 15.1 & 0.42 & 31.7 & 6.7 & 3.8 & mpcb \\
\hline HE $0451-3127$ & $04: 53: 45.5$ & $-31: 22: 18$ & 15.1 & 0.50 & 30.4 & 6.6 & 4.4 & mpcc \\
\hline HE $0500-5603$ & 05:01:41.2 & $-55: 58: 46$ & 14.7 & 0.80 & 35.6 & 7.9 & 5.8 & mpcc \\
\hline HE $0509-1611$ & 05:11:30.0 & $-16: 07: 43$ & 15.1 & 0.52 & 41.7 & 7.8 & 7.1 & mpcc \\
\hline HE $0511-3411$ & $05: 13: 40.7$ & $-34: 08: 16$ & 15.0 & 0.37 & 33.1 & 6.4 & 4.5 & mpcc \\
\hline HE $0514-5449$ & 05:15:11.9 & $-54: 46: 21$ & 15.0 & 0.31 & 31.0 & 6.3 & 3.2 & mpcb \\
\hline HE $0518-3941$ & $05: 20: 23.1$ & $-39: 38: 18$ & 14.6 & 0.18 & 30.9 & 6.0 & 2.5 & mpcc \\
\hline HE $0535-4842$ & $05: 36: 51.6$ & $-48: 40: 50$ & 14.7 & 0.39 & 30.5 & 7.8 & 5.1 & unid \\
\hline HE $0536-5647$ & 05:37:18.1 & $-56: 46: 08$ & 14.1 & 0.49 & 31.5 & 7.4 & 4.1 & mpcb \\
\hline HE $0537-4849$ & 05:38:39.1 & $-48: 47: 36$ & 14.9 & 0.39 & 30.5 & 7.8 & 4.0 & mpcb \\
\hline HE $0901-0003$ & 09:03:53.6 & $+00: 15: 48$ & 15.1 & 0.43 & 31.1 & 7.5 & 4.6 & mpcc \\
\hline HE 0910-0126 & 09:13:26.1 & $-01: 39: 19$ & 14.8 & 0.26 & 28.8 & 4.5 & 2.9 & mpcb \\
\hline HE $0912+0200$ & $09: 15: 30.1$ & $+01: 47: 29$ & 15.1 & 0.50 & 45.4 & 7.6 & 8.9 & mpcc \\
\hline HE $0918-0156$ & 09:21:06.2 & $-02: 08: 58$ & 15.1 & 0.84 & 53.2 & 7.9 & 7.7 & mpcc \\
\hline HE $0922-0337$ & $09: 25: 15.3$ & $-03: 50: 36$ & 14.7 & 0.61 & 33.3 & 8.0 & 5.1 & mpcc \\
\hline HE $0923-0323$ & 09:26:00.7 & $-03: 36: 57$ & 15.1 & 0.39 & 30.2 & 7.8 & 5.0 & mpcc \\
\hline HE $0928+0003$ & 09:30:33.2 & $+00: 10: 08$ & 14.9 & 0.75 & 68.0 & 7.3 & 8.0 & unid \\
\hline
\end{tabular}


Tabela 4.4 (Continuação)

\begin{tabular}{|c|c|c|c|c|c|c|c|c|}
\hline Nome & $\alpha(\mathrm{J} 2000)$ & $\delta(\mathrm{J} 2000)$ & BHES & $(\mathrm{J}-\mathrm{K})_{0}$ & GPE & KPHES & GPHES & Classe \\
\hline HE $0928+0059$ & 09:31:07.0 & $+00: 46: 43$ & 14.8 & 0.27 & 30.9 & 7.5 & 4.4 & mpcb \\
\hline HE $0933-0733$ & 09:36:09.5 & $-07: 46: 57$ & 15.1 & 0.38 & 41.5 & 7.8 & 6.0 & mpcb \\
\hline HE $0934-1058$ & $09: 36: 33.7$ & $-11: 11: 42$ & 14.9 & 0.67 & 44.8 & 7.9 & 6.1 & fhlc \\
\hline HE $0948+0107$ & $09: 51: 27.8$ & $+00: 53: 21$ & 14.9 & 0.50 & 31.6 & 5.8 & 3.6 & mpcb \\
\hline HE $0948-0234$ & 09:51:09.5 & $-02: 48: 21$ & 15.1 & 0.37 & 34.0 & 7.6 & 4.4 & mpcb \\
\hline HE $0950-0401$ & $09: 52: 43.7$ & $-04: 16: 03$ & 14.1 & 0.34 & 36.3 & 6.4 & 5.7 & mpcb \\
\hline HE $0950-1248$ & 09:53:04.3 & $-13: 03: 07$ & 15.0 & 0.38 & 33.7 & 7.0 & 4.8 & mpcc \\
\hline HE $0951+0114$ & $09: 53: 55.5$ & $+01: 00: 29$ & 14.9 & 0.63 & 59.9 & 7.8 & 5.5 & mpcb \\
\hline HE $1001-1621$ & 10:03:54.8 & $-16: 35: 45$ & 15.0 & 0.40 & 34.4 & 6.2 & 4.5 & mpcc \\
\hline HE $1002-1405$ & 10:04:35.4 & $-14: 19: 54$ & 14.1 & 0.36 & 38.8 & 7.5 & 4.9 & mpcc \\
\hline HE $1007-1524$ & 10:09:38.2 & $-15: 39: 20$ & 15.0 & 0.36 & 32.3 & 6.9 & 4.6 & mpcc \\
\hline HE $1009-1342$ & $10: 12: 10.0$ & $-13: 57: 17$ & 15.0 & 0.85 & 62.7 & 8.0 & 5.5 & unid \\
\hline HE $1009-1613$ & $10: 11: 26.5$ & $-16: 28: 40$ & 14.4 & 0.40 & 39.6 & 7.0 & 6.9 & mpcc \\
\hline HE $1009-1646$ & $10: 12: 11.5$ & $-17: 01: 17$ & 15.1 & 0.40 & 39.2 & 6.6 & 7.5 & mpcc \\
\hline HE $1010-1445$ & $10: 13: 03.8$ & $-15: 00: 51$ & 15.0 & 0.56 & 30.6 & 6.9 & 5.8 & mpcc \\
\hline HE $1022-0730$ & $10: 24: 39.3$ & $-07: 45: 59$ & 14.9 & 0.37 & 30.2 & 7.7 & 5.3 & mpcb \\
\hline HE $1027-1217$ & $10: 29: 29.9$ & $-12: 32: 31$ & 15.1 & 0.43 & 35.2 & 5.4 & 3.1 & mpcb \\
\hline HE $1028-1505$ & $10: 31: 23.4$ & $-15: 20: 46$ & 15.0 & 0.62 & 33.5 & 7.8 & 4.4 & mpcc \\
\hline HE 1039-1019 & $10: 42: 25.4$ & $-10: 34: 51$ & 14.9 & 0.40 & 36.2 & 7.8 & 4.8 & mpcb \\
\hline HE $1045+0226$ & 10:48:03.4 & $+02: 10: 47$ & 15.0 & 0.57 & 53.6 & 7.4 & 8.9 & mpcb \\
\hline HE $1046-1644$ & 10:49:13.4 & $-17: 00: 19$ & 14.7 & 0.55 & 30.2 & 7.0 & 4.4 & mpcb \\
\hline HE 1049-0922 & $10: 52: 26.2$ & $-09: 38: 33$ & 14.7 & 0.58 & 48.4 & 8.0 & 5.5 & unid \\
\hline HE $1049-1025$ & $10: 51: 44.2$ & $-10: 41: 05$ & 14.1 & 0.45 & 54.7 & 7.4 & 9.6 & mpcb \\
\hline HE $1104-0238$ & 11:07:00.4 & $-02: 54: 17$ & 15.0 & 0.90 & 33.8 & 7.9 & 5.5 & unid \\
\hline HE $1110-1625$ & 11:13:05.4 & $-16: 41: 29$ & 15.0 & 0.38 & 33.4 & 6.9 & 5.4 & mpcc \\
\hline HE $1112-0203$ & $11: 14: 48.6$ & $-02: 19: 26$ & 14.2 & 0.83 & 45.3 & 7.9 & 5.9 & unid \\
\hline HE $1125-1343$ & $11: 28: 26.1$ & $-13: 59: 58$ & 15.0 & 0.66 & 36.1 & 7.1 & 5.4 & mpcc \\
\hline HE $1129-1405$ & $11: 32: 19.2$ & $-14: 21: 44$ & 15.1 & 0.48 & 33.0 & 6.5 & 4.9 & mpcc \\
\hline HE $1132-0915$ & $11: 35: 24.9$ & $-09: 32: 33$ & 14.7 & 0.39 & 31.8 & 4.8 & 3.4 & mpcc \\
\hline HE $1133-0802$ & $11: 35: 59.0$ & $-08: 18: 43$ & 14.9 & 0.49 & 40.4 & 8.0 & 7.1 & mpcc \\
\hline HE $1135-0800$ & $11: 38: 23.9$ & $-08: 16: 57$ & 15.1 & 0.54 & 32.7 & 6.0 & 4.9 & mpcb \\
\hline HE $1137-1259$ & $11: 39: 37.2$ & $-13: 15: 52$ & 15.0 & 0.58 & 35.0 & 7.3 & 5.3 & mpcb \\
\hline HE $1142-0637$ & $11: 45: 00.8$ & $-06: 54: 18$ & 14.9 & 0.57 & 34.3 & 7.4 & 3.8 & mpcc \\
\hline HE $1146-1040$ & $11: 49: 24.5$ & $-10: 56: 41$ & 15.0 & 0.50 & 40.9 & 7.6 & 5.4 & mpcc \\
\hline HE $1146-1126$ & 11:49:09.5 & $-11: 43: 02$ & 14.9 & 0.58 & 34.9 & 6.5 & 5.3 & mpcc \\
\hline HE $1147-1057$ & 11:49:33.0 & $-11: 14: 26$ & 15.1 & 0.38 & 33.2 & 5.7 & 4.4 & mpcb \\
\hline HE $1148-1020$ & $11: 51: 11.4$ & $-10: 37: 32$ & 15.0 & 0.41 & 36.2 & 7.7 & 3.6 & mpcb \\
\hline HE $1148-1025$ & $11: 50: 49.8$ & $-10: 41: 42$ & 14.8 & 0.42 & 38.5 & 6.9 & 6.1 & mpcb \\
\hline HE $1212-1123$ & $12: 14: 36.7$ & $-11: 39: 48$ & 15.1 & 0.29 & 31.5 & 6.2 & 3.9 & mpcb \\
\hline HE $1217-1054$ & $12: 19: 56.9$ & $-11: 11: 27$ & 14.9 & 0.55 & 38.3 & 7.6 & 6.0 & mpcc \\
\hline
\end{tabular}


Tabela 4.4 (Continuação)

\begin{tabular}{|c|c|c|c|c|c|c|c|c|}
\hline Nome & $\alpha(\mathrm{J} 2000)$ & $\delta(\mathrm{J} 2000)$ & BHES & $(\mathrm{J}-\mathrm{K})_{0}$ & GPE & KPHES & GPHES & Classe \\
\hline HE $1217-1633$ & $12: 20: 30.2$ & $-16: 49: 44$ & 14.8 & 0.52 & 56.5 & 7.7 & 9.7 & fhlc \\
\hline HE $1222-1631$ & $12: 24: 59.5$ & $-16: 48: 15$ & 14.8 & 0.57 & 34.1 & 7.7 & 5.7 & mpcc \\
\hline HE $1223-0930$ & $12: 26: 01.9$ & $-09: 47: 35$ & 14.5 & 0.50 & 45.8 & 7.4 & 8.2 & fhlc \\
\hline HE $1224-0723$ & $12: 27: 15.1$ & $-07: 40: 21$ & 14.9 & 0.41 & 38.9 & 6.7 & 5.1 & mpcc \\
\hline HE $1224-1043$ & $12: 26: 51.5$ & $-11: 00: 35$ & 14.8 & 0.36 & 33.5 & 4.8 & 2.5 & mpcc \\
\hline HE $1228-0750$ & $12: 31: 30.3$ & $-08: 06: 38$ & 15.0 & 0.30 & 30.3 & 4.8 & 1.9 & mpcb \\
\hline HE $1228-1438$ & $12: 30: 44.6$ & $-14: 55: 05$ & 14.5 & 0.89 & 42.6 & 8.0 & 7.9 & mpcb \\
\hline HE $1231-3136$ & $12: 34: 31.2$ & $-31: 52: 39$ & 15.1 & 0.33 & 30.3 & 5.6 & 2.2 & mpcb \\
\hline HE $1255-2734$ & $12: 58: 18.4$ & $-27: 50: 23$ & 14.3 & 0.43 & 36.8 & 5.6 & 5.9 & mpcc \\
\hline HE $1301+0014$ & $13: 03: 45.8$ & $+00: 01: 28$ & 15.1 & 0.46 & 32.6 & 5.2 & 3.3 & mpcc \\
\hline HE $1301-1405$ & 13:04:03.6 & $-14: 21: 30$ & 15.1 & 0.48 & 34.3 & 6.7 & 4.8 & mpcc \\
\hline HE $1302-0954$ & $13: 04: 58.2$ & $-10: 10: 11$ & 14.5 & 0.49 & 32.8 & 7.4 & 5.1 & $\mathrm{mpcb}$ \\
\hline HE 1311-3002 & $13: 13: 59.7$ & $-30: 18: 21$ & 14.3 & 0.58 & 34.8 & 8.0 & 7.2 & fhlc \\
\hline HE $1320-1130$ & $13: 23: 37.0$ & $-11: 46: 03$ & 15.1 & 0.34 & 34.4 & 7.0 & 4.7 & mpcb \\
\hline HE $1320-1641$ & $13: 23: 11.9$ & $-16: 56: 38$ & 15.0 & 0.87 & 43.5 & 7.9 & 6.9 & mpcc \\
\hline HE $1321-1652$ & $13: 24: 27.3$ & $-17: 07: 48$ & 15.0 & 0.35 & 43.3 & 5.8 & 7.1 & mpcc \\
\hline HE $1343+0137$ & $13: 46: 17.3$ & $+01: 22: 29$ & 15.1 & 0.41 & 28.3 & 5.5 & 2.5 & mpcc \\
\hline HE 1408-0444 & $14: 10: 50.4$ & $-04: 58: 51$ & 14.7 & 0.22 & 31.2 & 2.2 & 2.8 & mpcb \\
\hline HE $1409-1134$ & $14: 11: 43.4$ & $-11: 49: 02$ & 15.0 & 0.36 & 36.4 & 7.9 & 4.3 & mpcb \\
\hline HE $1410-0549$ & $14: 13: 21.7$ & $-06: 03: 33$ & 14.9 & 0.25 & 31.0 & 6.1 & 1.4 & mpcb \\
\hline HE $1414-1644$ & $14: 17: 03.4$ & $-16: 58: 23$ & 14.6 & 0.47 & 32.8 & 6.0 & 4.7 & mpcc \\
\hline HE $1418-1634$ & $14: 20: 51.0$ & $-16: 47: 46$ & 15.1 & 0.54 & 30.5 & 7.0 & 6.1 & mpcc \\
\hline HE $1428-0851$ & 14:30:40.6 & $-09: 05: 09$ & 14.9 & 0.53 & 30.5 & 6.2 & 2.4 & mpcc \\
\hline HE $1430-1518$ & $14: 32: 56.4$ & $-15: 31: 35$ & 14.9 & 0.79 & 45.9 & 7.6 & 10.1 & unid \\
\hline HE $1447-1533$ & $14: 49: 54.5$ & $-15: 46: 22$ & 14.3 & 0.83 & 34.5 & 7.9 & 6.9 & mpcc \\
\hline HE $1448-1406$ & $14: 50: 53.1$ & $-14: 19: 14$ & 14.9 & 0.37 & 30.4 & 5.8 & 2.7 & mpcb \\
\hline HE $1451-0659$ & $14: 54: 03.0$ & $-07: 11: 40$ & 14.5 & 0.63 & 37.0 & 7.9 & 5.6 & mpcb \\
\hline HE $1458-0923$ & 15:00:45.4 & $-09: 35: 49$ & 14.4 & 0.41 & 47.9 & 6.6 & 6.9 & mpcb \\
\hline HE $1458-1022$ & $15: 01: 35.7$ & $-10: 33: 54$ & 14.7 & 0.54 & 30.2 & 7.0 & 5.3 & mpcc \\
\hline HE $1458-1226$ & $15: 01: 32.8$ & $-12: 37: 57$ & 15.1 & 0.47 & 43.5 & 7.4 & 6.9 & mpcc \\
\hline HE $1504-1534$ & $15: 07: 46.2$ & $-15: 45: 31$ & 14.8 & 0.85 & 38.9 & 8.0 & 7.3 & mpcc \\
\hline HE $1505-0826$ & $15: 08: 04.7$ & $-08: 38: 22$ & 14.9 & 0.25 & 32.2 & 7.5 & 3.6 & mpcb \\
\hline HE $1507-1055$ & 15:10:09.9 & $-11: 07: 19$ & 14.9 & 0.80 & 39.3 & 7.8 & 8.8 & mpcc \\
\hline HE $1507-1104$ & $15: 09: 45.4$ & $-11: 16: 09$ & 15.1 & 0.90 & 46.3 & 7.3 & 8.3 & mpcb \\
\hline HE $1512+0149$ & $15: 15: 08.3$ & $+01: 38: 05$ & 15.0 & 0.67 & 54.6 & 7.1 & 8.7 & mpcc \\
\hline HE $1516-0107$ & $15: 18: 54.0$ & $-01: 18: 50$ & 15.0 & 0.43 & 35.1 & 5.0 & 4.5 & mpcb \\
\hline HE 1518-0541 & $15: 21: 20.6$ & $-05: 52: 08$ & 14.1 & 0.54 & 32.4 & 6.8 & 3.5 & mpcb \\
\hline HE $1527-0740$ & $15: 30: 18.5$ & $-07: 50: 50$ & 15.1 & 0.44 & 37.8 & 6.2 & 1.7 & mpcb \\
\hline HE $1529-0838$ & $15: 31: 54.8$ & $-08: 48: 39$ & 15.1 & 0.38 & 36.4 & 7.9 & 4.9 & mpcb \\
\hline HE $2025-5221$ & $20: 29: 38.6$ & $-52: 11: 22$ & 14.8 & 0.39 & 39.1 & 4.7 & 6.1 & mpcc \\
\hline
\end{tabular}


Tabela 4.4 (Continuação)

\begin{tabular}{ccccccccc}
\hline \hline Nome & $\alpha(\mathrm{J} 2000)$ & $\delta(\mathrm{J} 2000)$ & BHES & $(\mathrm{J}-\mathrm{K})_{0}$ & GPE & KPHES & GPHES & Classe \\
\hline HE 2052-5610 & $20: 56: 34.9$ & $-55: 59: 17$ & 15.0 & 0.27 & 39.9 & 6.0 & 7.0 & mpcc \\
HE 2112-5236 & $21: 16: 09.2$ & $-52: 23: 30$ & 14.8 & 0.52 & 43.5 & 7.1 & 7.0 & mpcc \\
HE 2117-6018 & $21: 21: 26.2$ & $-60: 05: 33$ & 15.0 & 0.59 & 31.7 & 6.6 & 4.9 & mpcc \\
HE 2140-4746 & $21: 44: 06.1$ & $-47: 32: 59$ & 14.7 & 0.36 & 30.6 & 5.8 & 3.1 & mpcc \\
HE 2151-0332 & $21: 53: 58.6$ & $-03: 18: 09$ & 15.0 & 0.47 & 40.0 & 5.7 & 5.1 & mpcb \\
HE 2201-1108 & $22: 04: 08.4$ & $-10: 53: 33$ & 15.0 & 0.29 & 39.3 & 6.0 & 4.2 & mpcb \\
HE 2207-0912 & $22: 10: 13.4$ & $-08: 57: 29$ & 15.0 & 0.41 & 36.8 & 4.3 & 1.5 & mpcc \\
HE 2209-1212 & $22: 11: 44.1$ & $-11: 57: 37$ & 14.6 & 0.30 & 39.8 & 5.1 & 4.3 & mpcb \\
HE 2219-1357 & $22: 22: 28.2$ & $-13: 42: 06$ & 14.9 & 0.20 & 30.3 & 4.4 & 2.3 & mpcb \\
HE 2231-0710 & $22: 33: 56.1$ & $-06: 54: 35$ & 14.6 & 0.43 & 57.4 & 1.2 & 7.7 & mpcb \\
HE 2257-5710 & $23: 00: 40.4$ & $-56: 54: 15$ & 14.7 & 0.51 & 31.6 & 6.6 & 5.3 & mpcc \\
HE 2353-5329 & $23: 55: 49.3$ & $-53: 12: 39$ & 13.9 & 0.29 & 33.0 & 4.6 & 4.1 & mpcc \\
\hline
\end{tabular}
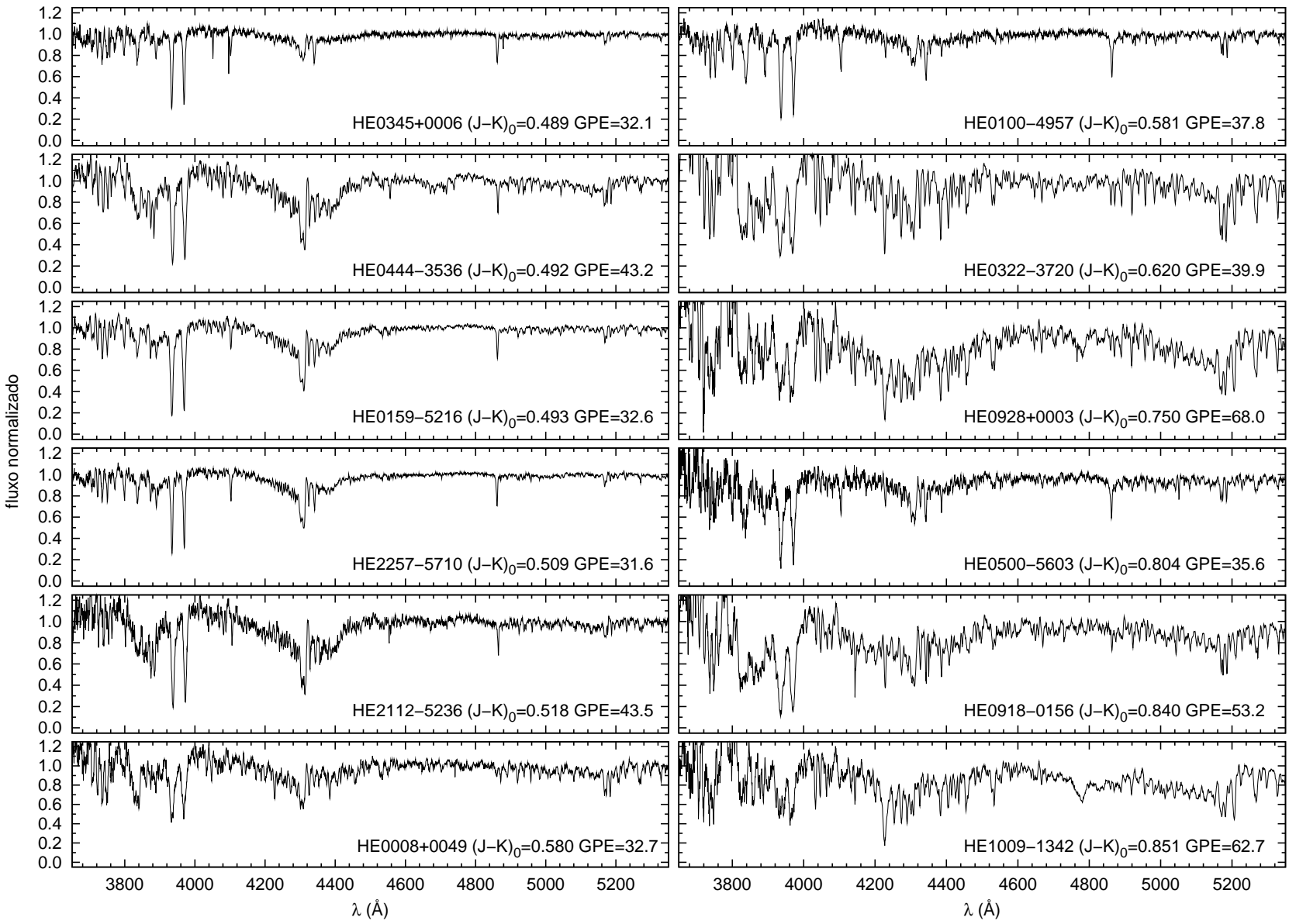

Figura 4.7: Exemplo de candidatas à estrelas CEMP observadas segundo o novo critério de índice de linha. Os espectros foram tomados com o espectrógrafo Goodman no telescópio SOAR. 


\subsubsection{Parâmetros Atmosféricos e Abundâncias de Carbono}

Para obtenção das estimativas dos parâmetros atmosféricos ([Fe/H], $\log g$ e $\left.T_{\text {eff }}\right)$ para as candidatas a estrelas CEMP, foi utilizado o conjunto de rotinas do SSPP (SEGUE Stellar Parameter Pipeline - veja Lee et al., 2008, para uma descrição detalhada do método); os resultados estão listados na Tabela 4.5, juntamente com a velocidade radial e valor do erro associado. As duas últimas colunas referem-se, respectivamente, às abundâncias de carbono e seus respectivos erros, cujo método de cálculo é discutido a seguir.

O SSPP utilizou uma série de rotinas para calcular os parâmetros atmosféricos a partir dos espectros em média resolução do Goodman. Para a determinação da temperatura efetiva foram utilizados três métodos: (i) a partir do índice de cor $(\mathrm{J}-\mathrm{K})_{0}$; (ii) a partir de índices de linha para a série de Balmer do hidrogênio e; (iii) a partir da linha K do Ca II. Já o $\log g$ é calculado através das linhas do Ca I $(4227 \AA)$ e do $\mathrm{MgH}(\sim 5170 \AA)$, e por calibrações com as temperaturas efetivas. A metalicidade, por sua vez, é calculada tanto pelos índices KP (linha K do Ca II, ver Beers et al., 1999, para mais detalhes) quanto por comparações e interpolações com grades de espectros sintéticos da literatura (ver Lee et al., 2008). Após a realização dos cálculos, o SSPP faz uma média dos valores encontrados e, utilizando métodos estatísticos, rejeita valores considerados incompatíveis.

Mesmo assim, foi feita uma inspeção visual nos espectros sintéticos e observados (ver Figura 4.8) com o objetivo de assegurar que os valores utilizados estavam realmente associados aos melhores ajustes. Deste modo, foi constatado que os valores de temperatura que melhor se adequavam à amostra eram aqueles determinados por calibrações utilizando o índice de cor $(\mathrm{J}-\mathrm{K})_{0}$, em oposição aos cálculos feitos à partir das linhas de hidrogênio da série de Balmer, provavelmente relacionado ao intervalo de temperaturas no qual as estrelas da amostra se encontram. Para os valores de $\log g$, foi utilizada a média das determinações para todos os objetos. Isso mostra que os métodos aplicados para os cálculos são satisfatórios para um grande intervalo, englobando tanto estrelas anãs quanto gigantes. Enfim, para a metalicidade, uma fração próxima de $90 \%$ dos objetos utilizou o valor médio das determinações. Alguns objetos, no limite de magnitude imposto para a seleção, possuem espectros com nível de ruído mais elevado que os demais, o que acarretou em incertezas maiores no cálculo das metalicidades. Dessa forma, para estes últimos, o valor final de metalicidade foi determinado a partir da intensidade da linha K do Ca II. 
Tabela 4.5 - Parâmetros atmosféricos e [C/Fe] para as candidatas observadas.

\begin{tabular}{|c|c|c|c|c|c|c|c|}
\hline Nome & $\mathrm{V}(\mathrm{km} / \mathrm{s})$ & $\sigma_{\mathrm{V}}(\mathrm{km} / \mathrm{s})$ & $T_{\text {eff }}(\mathrm{K})$ & $\log g(\operatorname{cgs})$ & {$[\mathrm{Fe} / \mathrm{H}]$} & {$[\mathrm{C} / \mathrm{Fe}]^{\mathrm{a}}$} & $\sigma_{[\mathrm{C} / \mathrm{Fe}]}$ \\
\hline HE $0008+0049$ & -27.6 & 13.3 & 5054 & 4.27 & -1.73 & 0.26 & 0.13 \\
\hline HE $0024-0550$ & 80.6 & 7.2 & 5761 & 4.39 & -1.94 & 0.44 & 0.06 \\
\hline HE $0034-0011$ & -173.0 & 18.3 & 6111 & 4.39 & -2.16 & 1.73 & 0.13 \\
\hline HE $0035-5803$ & 78.7 & 25.7 & 6083 & 4.57 & -0.65 & 1.00 & 0.05 \\
\hline HE $0053-0356$ & -5.8 & 13.6 & 6004 & 4.39 & -1.98 & 1.73 & 0.13 \\
\hline HE $0058+0141$ & 17.1 & 10.5 & 6670 & 4.57 & -0.46 & 0.77 & 0.07 \\
\hline HE $0100-4957$ & 184.2 & 17.2 & 5050 & 2.61 & -2.32 & -0.11 & 0.20 \\
\hline HE $0102-0004$ & -106.2 & 13.2 & 6314 & 3.93 & -2.20 & 1.19 & 0.19 \\
\hline HE $0118-4834$ & -86.0 & 28.0 & 6015 & 4.50 & -2.34 & 2.09 & 0.25 \\
\hline HE $0156-5608$ & 279.0 & 8.1 & 5431 & 4.32 & -2.02 & 0.77 & 0.06 \\
\hline HE $0159-5216$ & 42.3 & 8.0 & 5413 & 3.80 & -1.90 & 0.77 & 0.09 \\
\hline HE $0214-0818$ & 46.6 & 4.7 & 6379 & 4.34 & -1.12 & 1.25 & 0.09 \\
\hline HE $0307-5339$ & 207.5 & 37.1 & 5689 & 4.32 & -1.96 & 1.06 & 0.25 \\
\hline HE $0316-2903$ & 269.3 & 21.4 & 5528 & 4.43 & -2.29 & 1.04 & 0.13 \\
\hline HE $0320-1242$ & 123.8 & 14.3 & 5745 & 4.39 & -0.88 & 0.17 & 0.20 \\
\hline HE $0322-3720$ & -3.5 & 21.3 & 4901 & 4.71 & -0.96 & 0.10 & 0.20 \\
\hline HE $0336-3948$ & 165.3 & 2.7 & 6066 & 4.52 & -0.64 & 0.44 & 0.07 \\
\hline HE $0340-3933$ & -1.1 & 6.2 & 6226 & 4.57 & -0.28 & 0.06 & 0.20 \\
\hline HE $0345+0006$ & 17.2 & 13.2 & 5262 & 3.32 & -2.50 & 0.18 & 0.06 \\
\hline HE $0405-4411$ & 126.1 & 11.3 & 6337 & 4.05 & -1.14 & 0.89 & 0.13 \\
\hline HE $0414-4645$ & 92.0 & 24.8 & 6197 & 4.59 & -1.02 & 0.77 & 0.06 \\
\hline HE $0440-5525$ & 87.3 & 25.2 & 6186 & 4.25 & -1.18 & 0.52 & 0.19 \\
\hline HE $0444-3536$ & 181.6 & 16.4 & 5417 & 3.96 & -1.57 & 1.16 & 0.13 \\
\hline HE $0449-1617$ & 116.7 & 15.0 & 5756 & 4.50 & -1.07 & 0.06 & 0.20 \\
\hline HE $0451-3127$ & 342.4 & 26.2 & 5373 & 3.59 & -2.97 & 1.13 & 0.13 \\
\hline HE $0500-5603$ & 156.0 & 23.6 & 4273 & 1.64 & -1.61 & -0.50 & 0.20 \\
\hline HE $0509-1611$ & 114.7 & 22.3 & 5279 & 3.80 & -1.03 & 0.36 & 0.13 \\
\hline HE $0511-3411$ & 98.9 & 34.3 & 6055 & 4.57 & -0.44 & 0.38 & 0.05 \\
\hline HE $0514-5449$ & 182.7 & 8.4 & 6414 & 4.16 & -0.86 & 0.32 & 0.20 \\
\hline HE $0518-3941$ & 58.7 & 36.4 & 7153 & 3.34 & -0.49 & 1.00 & 0.20 \\
\hline HE $0535-4842$ & 78.3 & 21.0 & 5910 & 4.43 & -0.99 & 0.48 & 0.13 \\
\hline HE $0536-5647$ & 180.3 & 22.5 & 5417 & 4.02 & -1.39 & -0.12 & 0.20 \\
\hline HE $0537-4849$ & 92.9 & 23.3 & 5938 & 4.71 & -0.30 & 0.10 & 0.20 \\
\hline HE $0901-0003$ & 30.4 & 20.0 & 5720 & 4.64 & -0.69 & 0.88 & 0.13 \\
\hline HE $0910-0126$ & 197.4 & 16.9 & 6694 & 3.89 & -1.92 & 1.03 & $\ldots$ \\
\hline HE $0912+0200$ & 83.5 & 15.2 & 5395 & 4.48 & -0.75 & -0.09 & 0.20 \\
\hline HE $0918-0156$ & 99.6 & 16.8 & 4237 & 1.61 & -1.12 & 0.18 & 0.20 \\
\hline
\end{tabular}


Tabela 4.5 (Continuação)

\begin{tabular}{|c|c|c|c|c|c|c|c|}
\hline Nome & $\mathrm{V}(\mathrm{km} / \mathrm{s})$ & $\sigma_{\mathrm{V}}(\mathrm{km} / \mathrm{s})$ & $T_{\text {eff }}(\mathrm{K})$ & $\log g(\operatorname{cgs})$ & {$[\mathrm{Fe} / \mathrm{H}]$} & {$[\mathrm{C} / \mathrm{Fe}]^{\mathrm{a}}$} & $\sigma_{[\mathrm{C} / \mathrm{Fe}]}$ \\
\hline HE $0922-0337$ & 78.3 & 62.2 & 4943 & 4.14 & -1.38 & -0.14 & 0.20 \\
\hline HE $0923-0323$ & 127.9 & 17.7 & 5905 & 4.27 & -0.48 & 0.46 & 0.27 \\
\hline HE $0928+0003$ & -133.9 & 70.5 & 4402 & 4.09 & -1.14 & -0.11 & 0.20 \\
\hline HE $0928+0059$ & 13.6 & 7.8 & 6598 & 4.39 & -0.83 & 0.59 & 0.09 \\
\hline HE $0933-0733$ & 61.7 & 16.7 & 5982 & 4.39 & -1.03 & 0.77 & 0.14 \\
\hline HE $0934-1058$ & -406.9 & 37.1 & 4702 & 3.14 & -1.77 & -0.50 & 0.25 \\
\hline HE $0948+0107$ & 514.9 & 5.2 & 5382 & 4.46 & -2.14 & 0.20 & 0.06 \\
\hline HE $0948-0234$ & 147.3 & 54.4 & 6021 & 4.55 & -0.44 & 0.38 & 0.19 \\
\hline HE 0950-0401 & 144.0 & 14.4 & 6197 & 4.46 & -1.62 & 2.01 & 0.13 \\
\hline HE $0950-1248$ & 87.6 & 18.3 & 5982 & 4.41 & -0.30 & 0.10 & 0.20 \\
\hline HE $0951+0114$ & -255.2 & 32.9 & 4882 & 4.61 & -1.32 & -0.50 & 0.20 \\
\hline HE $1001-1621$ & -10.4 & 26.2 & 5888 & 4.30 & -0.92 & 0.17 & 0.20 \\
\hline HE $1002-1405$ & 99.2 & 9.5 & 6077 & 4.50 & -0.44 & 0.38 & 0.05 \\
\hline HE $1007-1524$ & 96.5 & 18.3 & 6077 & 4.43 & -0.64 & 0.46 & 0.19 \\
\hline HE $1009-1342$ & -154.3 & 17.3 & 4242 & 4.30 & -1.72 & 0.02 & 0.20 \\
\hline HE 1009-1613 & 91.0 & 11.8 & 5883 & 4.34 & -0.67 & 0.84 & 0.15 \\
\hline HE $1009-1646$ & 21.3 & 39.6 & 5883 & 4.46 & -0.70 & 0.41 & 0.13 \\
\hline HE $1010-1445$ & 202.0 & 14.0 & 5117 & 3.43 & -0.89 & -0.03 & 0.20 \\
\hline HE $1022-0730$ & 110.3 & 11.4 & 6060 & 4.41 & -1.58 & 0.99 & 0.13 \\
\hline HE $1027-1217$ & 146.6 & 27.5 & 5720 & 2.00 & -1.49 & $\ldots$ & $\ldots$ \\
\hline HE $1028-1505$ & 65.4 & 33.9 & 4886 & 3.84 & -0.57 & 0.04 & 0.20 \\
\hline HE 1039-1019 & 117.1 & 12.4 & 5878 & 4.55 & -0.67 & 0.92 & 0.08 \\
\hline HE $1045+0226$ & 214.2 & 21.5 & 5109 & 1.90 & -3.05 & 2.30 & 0.25 \\
\hline HE $1046-1644$ & -39.5 & 25.6 & 5168 & 3.02 & -0.60 & 0.19 & 0.20 \\
\hline HE 1049-0922 & -34.7 & 30.3 & 5074 & 4.71 & -0.63 & 0.33 & 0.20 \\
\hline HE $1049-1025$ & -175.7 & 43.4 & 5634 & 4.50 & -0.78 & -0.50 & 0.20 \\
\hline HE $1104-0238$ & 166.8 & 24.0 & 4450 & 1.77 & -0.94 & -0.5 & 0.05 \\
\hline HE $1110-1625$ & 123.5 & 17.7 & 5998 & 4.46 & -0.30 & 0.11 & 0.20 \\
\hline HE $1112-0203$ & 8.8 & 41.0 & 4235 & 4.23 & -0.91 & -0.50 & 0.20 \\
\hline HE $1125-1343$ & -169.4 & 33.2 & 4752 & 4.48 & -1.02 & -0.03 & 0.20 \\
\hline HE $1129-1405$ & 189.3 & 41.7 & 5476 & 3.34 & -2.02 & 0.60 & 0.09 \\
\hline HE $1132-0915$ & 51.5 & 41.7 & 5905 & 2.00 & -1.56 & $\cdots$ & $\cdots$ \\
\hline HE $1133-0802$ & 27.5 & 13.9 & 5431 & 4.07 & -1.40 & 0.57 & 0.06 \\
\hline HE $1135-0800$ & 221.3 & 7.8 & 5225 & 3.05 & -2.28 & 0.08 & 0.03 \\
\hline HE $1137-1259$ & 138.1 & 23.5 & 5050 & 4.64 & -1.05 & 0.16 & 0.20 \\
\hline HE $1142-0637$ & 118.4 & 24.3 & 5089 & 4.14 & -1.58 & -0.04 & 0.20 \\
\hline HE $1146-1040$ & -15.0 & 27.2 & 5382 & 4.57 & -1.18 & 0.37 & 0.05 \\
\hline
\end{tabular}


Tabela 4.5 (Continuação)

\begin{tabular}{|c|c|c|c|c|c|c|c|}
\hline Nome & $\mathrm{V}(\mathrm{km} / \mathrm{s})$ & $\sigma_{\mathrm{V}}(\mathrm{km} / \mathrm{s})$ & $T_{\text {eff }}(\mathrm{K})$ & $\log g(\operatorname{cgs})$ & {$[\mathrm{Fe} / \mathrm{H}]$} & {$[\mathrm{C} / \mathrm{Fe}]^{\mathrm{a}}$} & $\sigma_{[\mathrm{C} / \mathrm{Fe}]}$ \\
\hline HE $1146-1126$ & 332.1 & 14.1 & 5062 & 2.84 & -2.26 & 0.00 & 0.20 \\
\hline HE $1147-1057$ & 113.9 & 10.6 & 5971 & 4.52 & -0.89 & 0.42 & 0.06 \\
\hline HE $1148-1020$ & 238.6 & 19.3 & 5835 & 4.39 & -1.34 & 0.15 & 0.20 \\
\hline HE $1148-1025$ & 194.6 & 28.6 & 5792 & 4.52 & -0.83 & 0.03 & 0.20 \\
\hline HE $1212-1123$ & 111.6 & 21.8 & 6503 & 4.07 & -1.35 & 0.93 & 0.06 \\
\hline HE $1217-1054$ & 60.2 & 34.9 & 5156 & 4.57 & -0.96 & -0.02 & 0.20 \\
\hline HE $1217-1633$ & 155.6 & 24.6 & 5300 & 3.27 & -1.90 & 1.03 & 0.38 \\
\hline HE $1222-1631$ & 104.6 & 13.7 & 5101 & 3.05 & -2.07 & 0.18 & 0.06 \\
\hline HE 1223-0930 & 187.0 & 14.0 & 5377 & 3.43 & -2.19 & 1.76 & 0.19 \\
\hline HE $1224-0723$ & 64.9 & 24.7 & 5803 & 4.57 & -0.67 & 0.84 & 0.15 \\
\hline HE $1224-1043$ & 303.0 & 21.9 & 6094 & 3.32 & -1.67 & -0.08 & 0.20 \\
\hline HE $1228-0750$ & 353.6 & 14.1 & 6444 & 3.68 & -1.60 & 0.40 & 0.20 \\
\hline HE $1228-1438$ & 176.1 & 19.5 & 4434 & 2.27 & -0.92 & -0.50 & 0.05 \\
\hline HE $1231-3136$ & 81.9 & 49.2 & 6279 & 3.59 & -1.51 & 0.99 & 0.06 \\
\hline HE $1255-2734$ & -21.2 & 34.6 & 5730 & 4.43 & -2.14 & 1.30 & 0.13 \\
\hline HE $1301+0014$ & 72.0 & 19.5 & 5571 & 3.61 & -2.37 & 0.44 & 0.06 \\
\hline HE $1301-1405$ & 43.0 & 7.9 & 5467 & 3.41 & -1.29 & -0.11 & 0.20 \\
\hline HE $1302-0954$ & 145.7 & 22.9 & 5417 & 4.00 & -2.30 & 0.77 & 0.13 \\
\hline HE 1311-3002 & 213.6 & 27.8 & 5043 & 2.86 & -2.39 & 0.64 & 0.09 \\
\hline HE $1320-1130$ & 220.8 & 41.9 & 6238 & 4.39 & -1.62 & 1.37 & 0.08 \\
\hline HE $1320-1641$ & 84.1 & 14.5 & 4295 & 1.73 & -1.03 & -0.28 & 0.20 \\
\hline HE $1321-1652$ & 91.1 & 41.0 & 6169 & 4.61 & -1.72 & 2.13 & 0.25 \\
\hline HE $1343+0137$ & 130.6 & 19.5 & 5808 & 3.23 & -1.73 & -0.02 & 0.20 \\
\hline HE $1408-0444$ & 142.5 & 27.9 & 6912 & 3.09 & -2.38 & 1.79 & $\cdots$ \\
\hline HE $1409-1134$ & 92.2 & 12.9 & 6117 & 4.43 & -0.37 & 0.23 & 0.20 \\
\hline HE $1410-0549$ & 103.8 & 25.9 & 6742 & 2.21 & -1.70 & $\cdots$ & $\cdots$ \\
\hline HE $1414-1644$ & 91.8 & 11.8 & 5514 & 4.23 & -2.46 & 0.70 & 0.04 \\
\hline HE $1418-1634$ & 144.3 & 39.1 & 5196 & 2.91 & -2.28 & 0.12 & 0.06 \\
\hline HE $1428-0851$ & 91.3 & 22.4 & 5241 & 1.68 & -2.52 & -0.48 & $\cdots$ \\
\hline HE $1430-1518$ & 383.0 & 26.2 & 4289 & 1.93 & -1.16 & 0.41 & 0.08 \\
\hline HE $1447-1533$ & 57.1 & 24.3 & 4234 & 2.07 & -1.05 & 0.13 & 0.20 \\
\hline HE $1448-1406$ & -173.8 & 22.7 & 6060 & 2.36 & -1.67 & 0.10 & 0.20 \\
\hline HE 1451-0659 & -22.9 & 57.5 & 4882 & 4.64 & -1.47 & -0.11 & 0.20 \\
\hline HE 1458-0923 & -343.0 & 27.3 & 5829 & 4.39 & -2.27 & 1.89 & 0.13 \\
\hline HE $1458-1022$ & -61.3 & 18.2 & 5200 & 3.09 & -2.22 & 0.47 & 0.06 \\
\hline HE $1458-1226$ & -10.1 & 30.5 & 5504 & 4.68 & -1.05 & 0.39 & 0.13 \\
\hline HE $1504-1534$ & 60.3 & 6.9 & 4246 & 1.41 & -0.73 & 0.32 & 0.06 \\
\hline
\end{tabular}


Tabela 4.5 (Continuação)

\begin{tabular}{crcccccc}
\hline \hline Nome & $\mathrm{V}(\mathrm{km} / \mathrm{s})$ & $\sigma_{\mathrm{V}}(\mathrm{km} / \mathrm{s})$ & $T_{\text {eff }}(\mathrm{K})$ & $\log g(\mathrm{cgs})$ & {$[\mathrm{Fe} / \mathrm{H}]$} & {$[\mathrm{C} / \mathrm{Fe}]^{\mathrm{a}}$} & $\sigma_{[\mathrm{C} / \mathrm{Fe}]}$ \\
HE 1505-0826 & 69.2 & 18.4 & 6730 & 4.39 & -0.49 & 0.48 & 0.20 \\
HE 1507-1055 & 174.0 & 16.0 & 4267 & 1.66 & -1.14 & 0.18 & 0.20 \\
HE 1507-1104 & 124.1 & 12.0 & 4492 & 2.91 & -0.98 & -0.01 & 0.20 \\
HE 1512+0149 & -65.3 & 41.2 & 4706 & 4.57 & -0.94 & -0.50 & 0.20 \\
HE 1516-0107 & 16.9 & 28.5 & 5720 & 3.77 & -2.01 & 0.65 & 0.03 \\
HE 1518-0541 & 32.1 & 30.1 & 5217 & 4.68 & -1.03 & 0.13 & 0.20 \\
HE 1527-0740 & 27.4 & 28.4 & 5679 & 2.00 & -1.86 & 0.26 & $\ldots$ \\
HE 1529-0838 & 38.7 & 24.6 & 5960 & 4.52 & -0.69 & 0.57 & 0.19 \\
HE 2025-5221 & 237.5 & 19.7 & 5932 & 4.57 & -2.25 & 2.00 & 0.25 \\
HE 2052-5610 & 281.7 & 35.8 & 6628 & 4.59 & -1.76 & 2.69 & 0.05 \\
HE 2112-5236 & 254.5 & 15.0 & 5304 & 3.93 & -1.79 & 0.76 & 0.19 \\
HE 2117-6018 & -205.1 & 30.6 & 5023 & 4.11 & -1.93 & -0.17 & 0.20 \\
HE 2140-4746 & 70.8 & 14.7 & 6111 & 4.36 & -1.36 & 0.49 & 0.06 \\
HE 2151-0332 & -99.6 & 21.0 & 5514 & 4.30 & -2.75 & 1.45 & 0.19 \\
HE 2201-1108 & -115.3 & 19.0 & 6533 & 4.07 & -0.95 & 0.79 & 0.19 \\
HE 2207-0912 & -67.2 & 13.7 & 5824 & 4.30 & -2.40 & 0.81 & 0.13 \\
HE 2209-1212 & 107.8 & 30.7 & 6432 & 4.43 & -0.38 & 0.26 & 0.20 \\
HE 2219-1357 & 133.0 & 14.4 & 7082 & 4.25 & -0.64 & 0.72 & 0.20 \\
HE 2231-0710 & 63.1 & 34.4 & 5704 & 2.86 & -0.61 & 0.72 & 0.29 \\
HE 2257-5710 & 41.6 & 17.2 & 5343 & 3.89 & -2.97 & 1.22 & 0.06 \\
HE 2353-5329 & 105.3 & 12.6 & 6509 & 4.57 & -1.75 & 2.35 & 0.13 \\
\hline
\end{tabular}

${ }^{a}$ Os valores de $[\mathrm{C} / \mathrm{Fe}]$ que não possuem determinação de erro são limites superiores.

A Figura 4.8 mostra parte da saída padrão do SSPP para 5 candidatas a estrelas CEMP observadas com o SOAR. Os paineis à esquerda mostram o espectro original e as estimativas de temperatura. A região das linhas de CaII, sobreposta pelos espectros sintéticos, é mostrada nos painéis centrais, juntamente com as estimativas para $\log g$. Os painéis à direita mostram os espectros com o contínuo subtraído, os espectros sintéticos sobrepostos e os valores calculados de metalicidade. Os parâmetros finais adotados são os primeiros valores mostrados em cada painel. Nota-se uma boa concordância entre os espectros reais dos objetos e suas contrapartidas sintéticas para os 5 objetos mostrados, para pelo menos um dos ajustes. Também é possível observar diferenças entre os parâmetros calculados pelos diferentes métodos, o que justifica o uso de ferramentas estatísticas para eliminar inconsistências, como mencionado acima. 

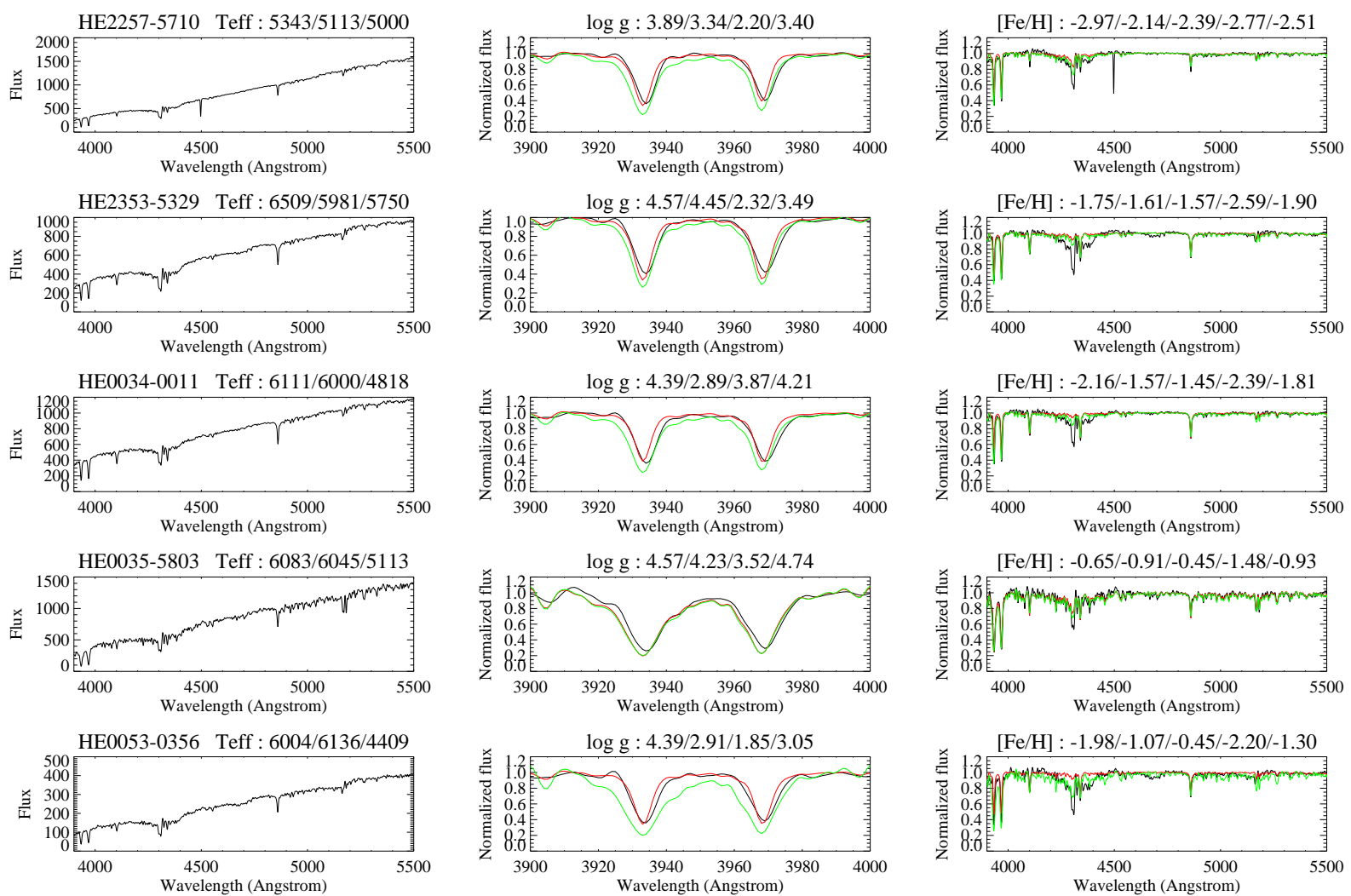

Figura 4.8: Exemplo do procedimento adotado pelo SSPP para o cálculo dos parâmetros atmosféricos para 5 das 132 candidatas a estrelas CEMP. Da esquerda para a direita são exibidos: o espectro original, a região das linha do Ca II, com os ajustes por síntese espectral e os espectros com o contínuo subtraído.

As velocidades radiais, calculadas para as estrelas-padrão observadas durante os programas mencionados acima, apresentaram erros da ordem de $50 \mathrm{~km} \mathrm{~s}^{-1}$, considerado alto para a qualidade dos dados tomados. Erros dessa magnitude provavelmente estão relacionados a falhas de correção de curvatura do espelho durante a fase de comissionamento do espectrógrafo Goodman.

Deste modo, foram utilizadas diferentes técnicas para o cálculo das velocidades radiais para os objetos observados, incluindo análise por correlação cruzada, para assegurar que erros muito elevados não eram resultado de falha no processo de determinação destes parâmetros. Pelo fato das velocidades para as estrelas de programa observadas não serem conhecidas a priori, eram esperados erros da mesma ordem daqueles das estrelas -padrão. Todavia, pelo fato das rotinas do SSPP necessitarem apenas de uma estimativa inicial da velocidade radial para realizar seus cálculos, tais erros não prejudicaram o processo de determinação dos parâmetros atmosféricos dos objetos. 

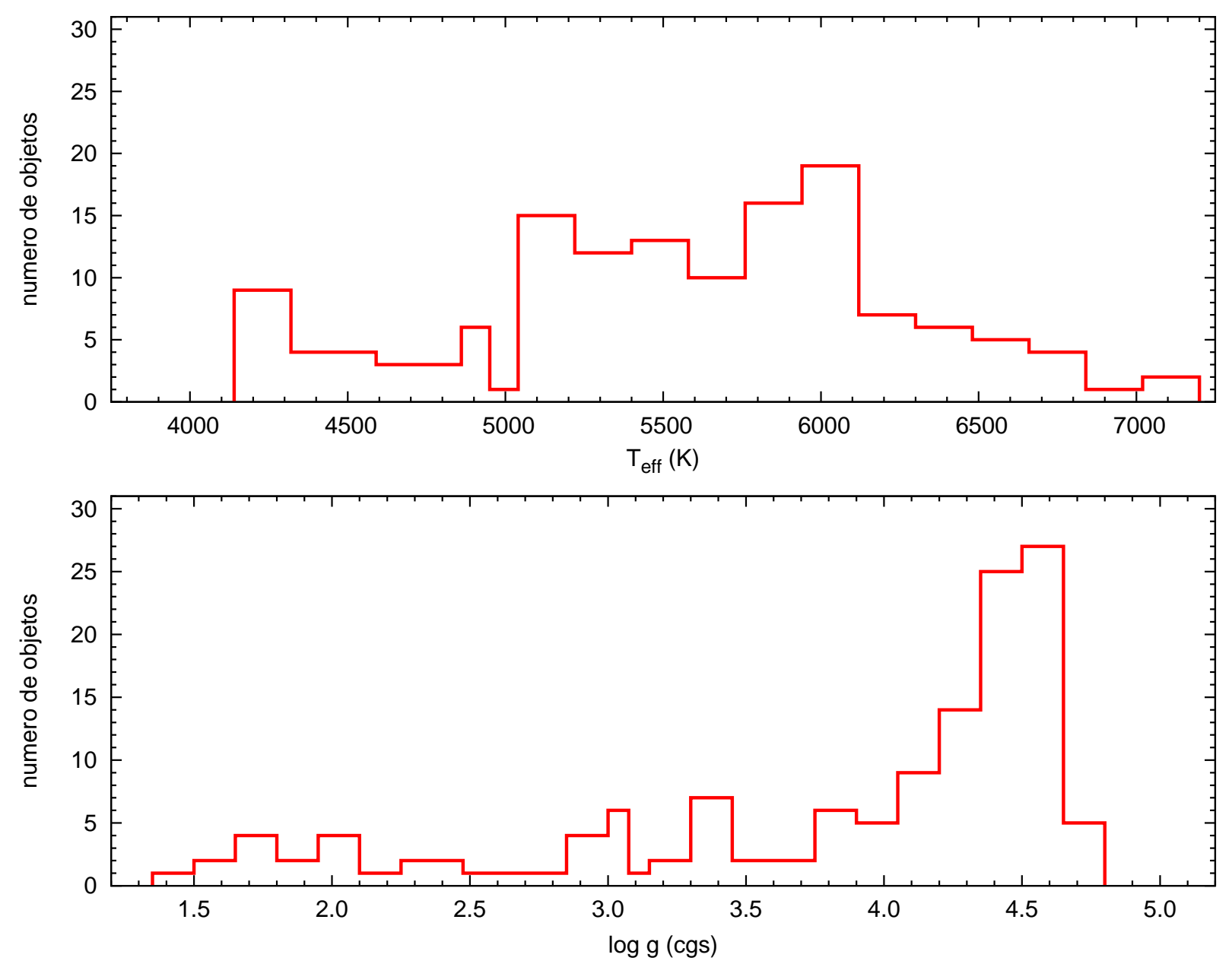

Figura 4.9: Distribuição de $T_{\text {eff }}$ e $\log g$ para as 132 candidatas observadas com o SOAR.

O comportamento das grandezas temperatura efetiva e logarítmo da gravidade superficial para as 132 estrelas da primeira subamostra é mostrado na Figura 4.9. Em relação à $T_{\text {eff }}$, nota-se que a maior parte dos objetos apresenta temperaturas maiores do que $5000 \mathrm{~K}$, com um pico na distribuição em torno de 6000 K. Este comportamento é esperado devido às características do método de seleção, dada a relação entre aumento de temperatura e intensidade da banda $\mathrm{G}$ para estrelas ricas em carbono.

Além disso, ao observar o painel inferior da Figura 4.9, cuja distribuição apresenta um máximo em $\sim 4.5$, conclui-se que a amostra é dominada por estrelas anãs. Esse viés de seleção foi introduzido pela limitação em magnitude das estrelas observadas. Dado um certo valor de magnitude, é maior a probabilidade de observar estrelas anãs (com temperaturas e luminosidades maiores) frente a estrelas gigantes e sub-gigantes. Essa tendência não configura um problema para a identificação de estrelas pobres em metais 
e CEMP proposta por este trabalho, uma vez que existem observações de estrelas anãs pobres em metais cna região $[\mathrm{Fe} / \mathrm{H}]<-3.0$ (Norris et al., 2000; Sivarani et al., 2006; Aoki et al., 2007), incluindo a estrela HE 1327-2326 ([Fe/H] $=-5.6$ - Frebel et al., 2005).

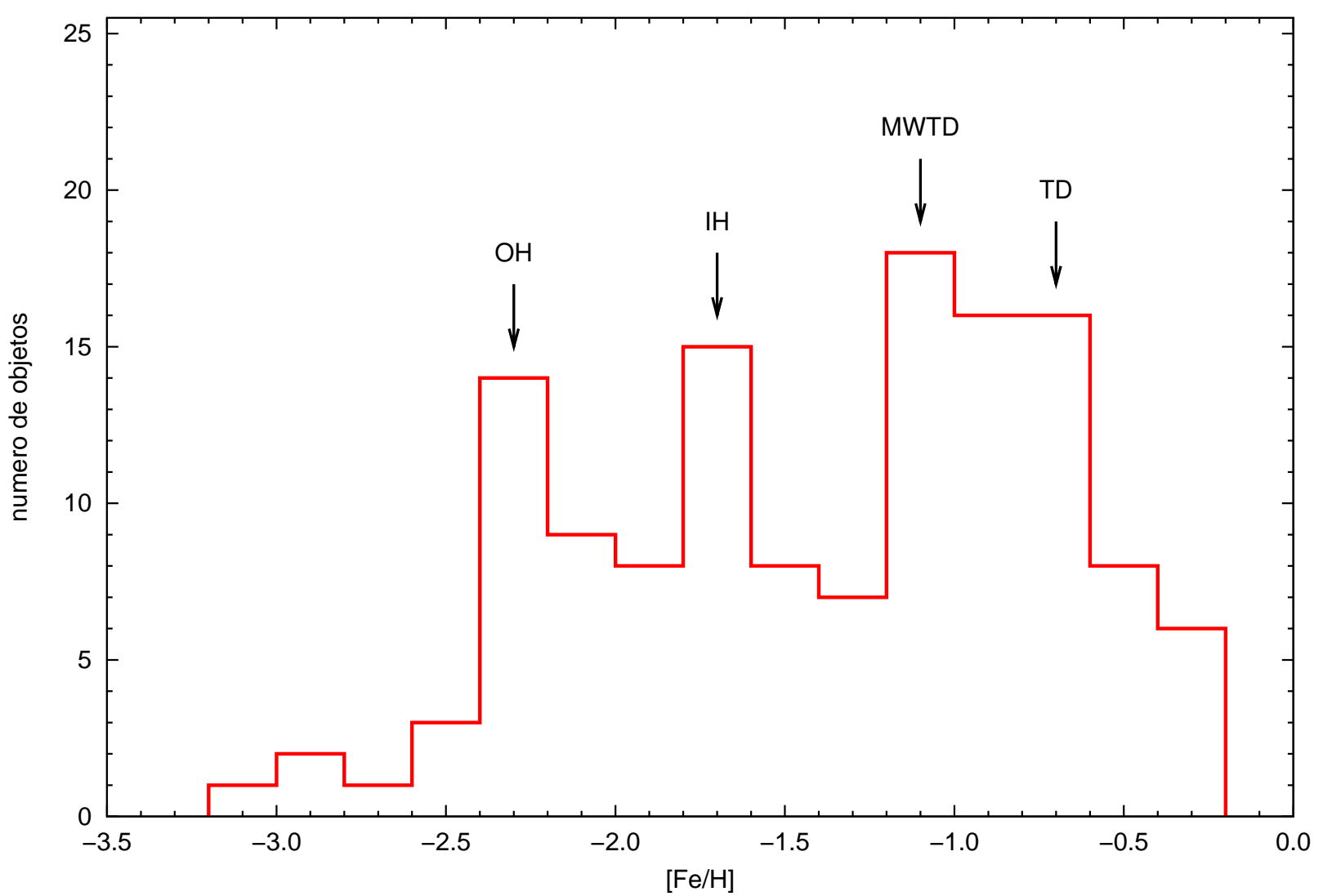

Figura 4.10: Distribuição de metalicidades para as 132 candidatas observadas com o SOAR. As setas indicam os locais dos picos em $[\mathrm{Fe} / \mathrm{H}]$ para a distribuição observada, que encontram-se próximos àqueles associados pelo trabalho de Carollo et al. (2007) às populações do halo externo $(\mathrm{OH} ;[\mathrm{Fe} / \mathrm{H}]=-2.2)$, halo interno $(\mathrm{IH} ;[\mathrm{Fe} / \mathrm{H}]=-1.6)$, disco espesso pobre em metal $(\mathrm{MWTD} ;[\mathrm{Fe} / \mathrm{H}]=-1.3)$ e disco espesso canônico $(\mathrm{TD} ;[\mathrm{Fe} / \mathrm{H}]=-0.6)$.

A Figura 4.10 mostra a distribuição de metalicidade observada para as estrelas presentes na Tabela 4.5. É interessante notar que os dois picos proeminentes a baixas metalicidades posicionam-se próximos aos picos associados, segundo Carollo et al. (2007), com as populações do halo externo $([\mathrm{Fe} / \mathrm{H}]=-2.2)$ e do halo interno $([\mathrm{Fe} / \mathrm{H}]=-1.6)$. O restante das estrelas pode estar associado às populações do disco espesso da Galáxia, tanto a porção pobre em metal quanto a parte chamada canônica (Wyse et al., 2006). 
Dessa forma, conclui-se que o processo de seleção de candidatas a estrelas CEMP obteve resultados distribuídos dentro do intervalo de metalicidade de interesse.

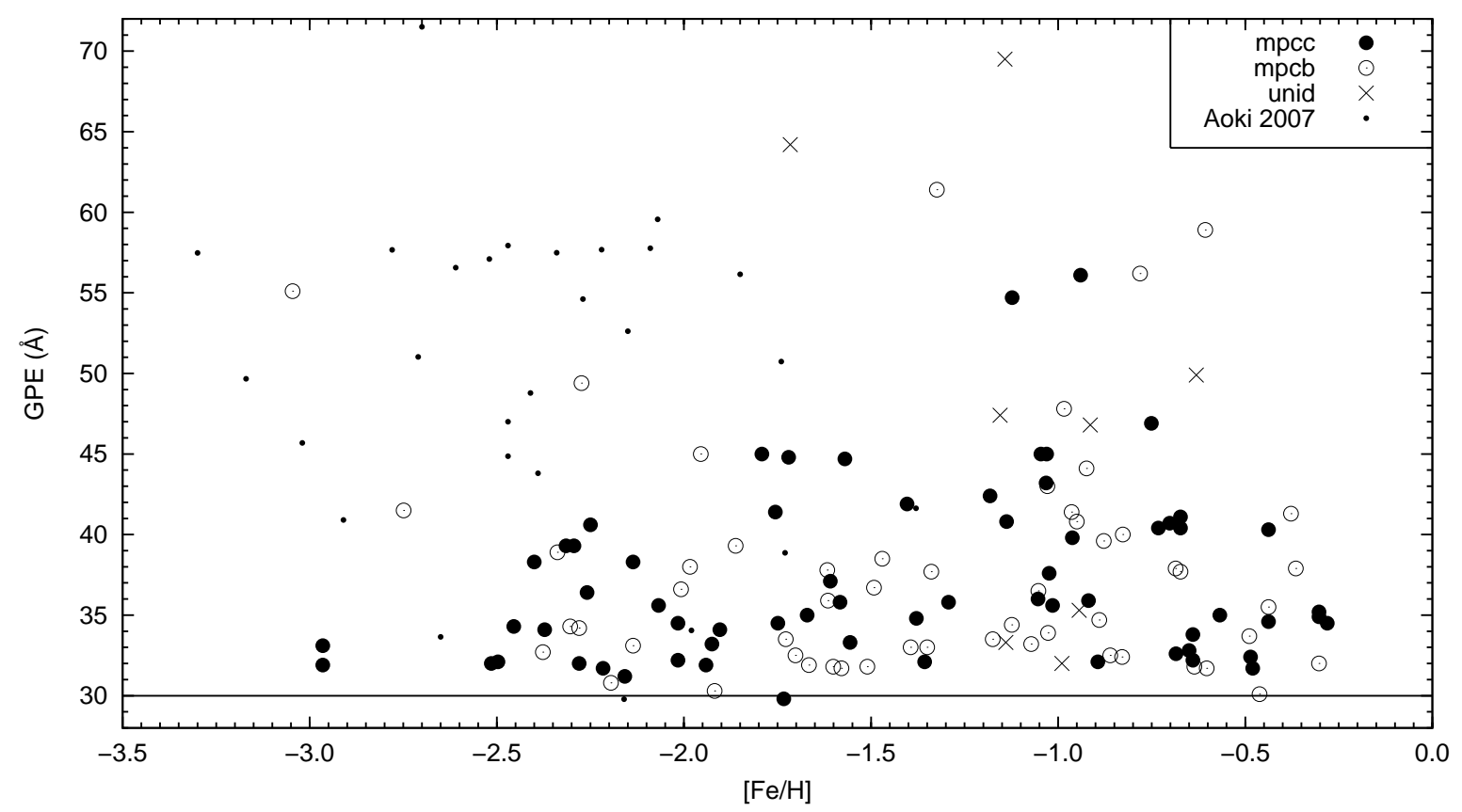

Figura 4.11: Comportamento da metalicidade em função do índice GPE para as candidatas observadas e para as estrelas CEMP de Aoki et al. (2007).

As tendências do índice GPE em função da metalicidade estimada estão apresentadas na Figura 4.11. Também é possível observar a relação entre as metalicidades obtidas em alta resolução por Aoki et al. (2007) e o índice GPE, calculado diretamente dos espectros em baixa resolução do HES. Não é possível fazer distinção entre os regimes para as estrelas mpcc e mpcb. Também, como esperado, as metalicidades maiores que -0.5 vistas na Figura 4.11 estão associadas às classes cujos objetos apresentam maiores temperaturas, e não a objetos da classe unid. De fato, um dos objetivos desta busca por estrelas CEMP é encontrar objetos que preencham a parte superior direita da Figura, que encontra-se subamostrada na faixa $[\mathrm{Fe} / \mathrm{H}]>-2.5$.

Para as estimativas das abundâncias de carbono, foram geradas (pela pesquisadora Thirupathi Sivarani) grades de espectros sintéticos na faixa de comprimentos de onda entre 3600-4600 A. Os parâmetros estelares desta grade cobrem os seguintes intervalos: 3500 a $9500 \mathrm{~K}$ para $T_{\text {eff }} ; 0.0$ a 5.0 para $\log g$ e; -2.5 a 0.0 para $[\mathrm{Fe} / \mathrm{H}]$. As abundâncias em carbono (na forma $[\mathrm{C} / \mathrm{H}]$ ) encontram-se na faixa $[\mathrm{Fe} / \mathrm{H}]-0.5 \leq[\mathrm{C} / \mathrm{H}] \leq+0.5$, para um 
dado valor de metalicidade. Para gerar tais espectros sintéticos, foi utilizada a versão mais atual do código de síntese espectral turbospectrum (Alvarez e Plez, 1998), juntamente com os modelos de atmosferas NEWODF de Kurucz (Castelli e Kurucz, 2003). A lista de linhas é a mesma utilizada em Sivarani et al. (2006).
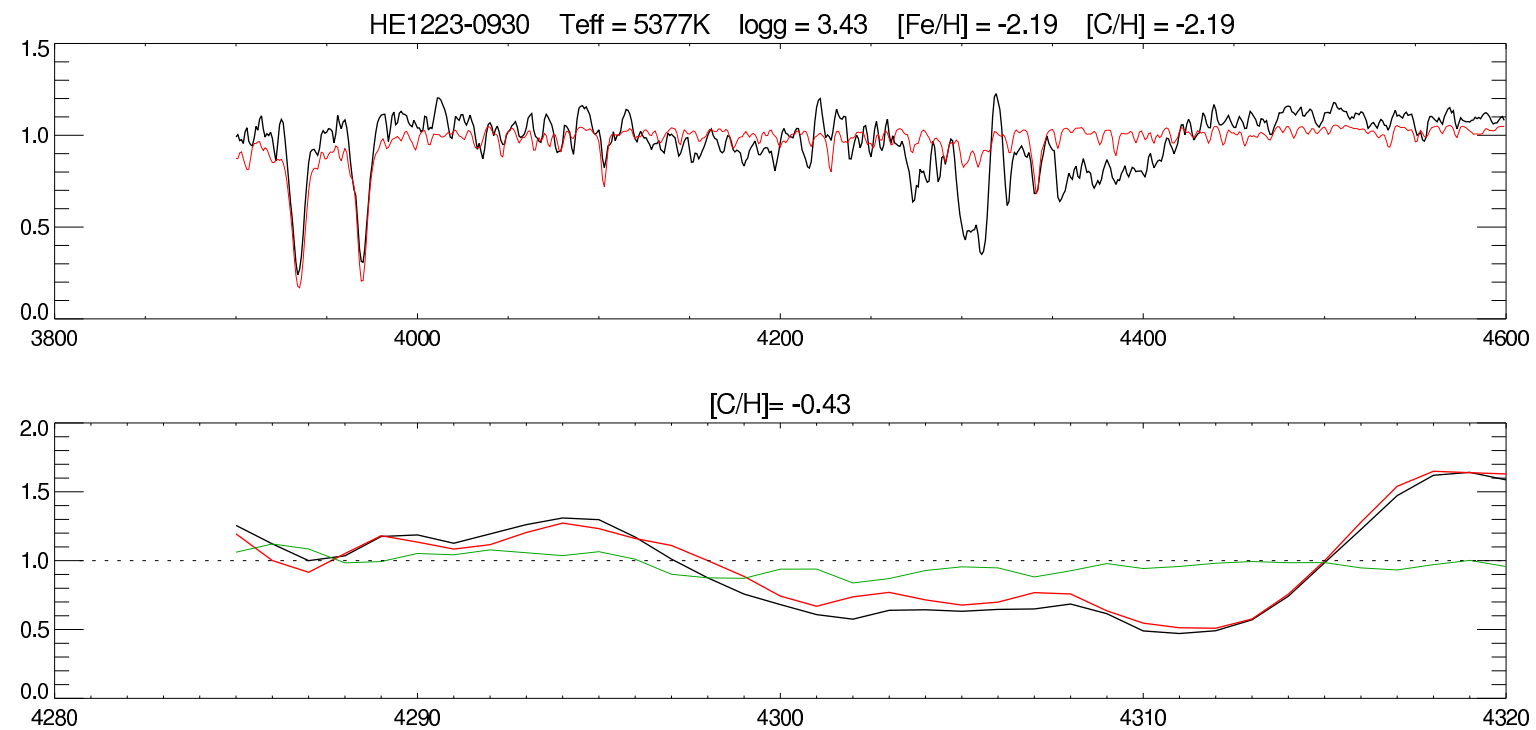

HE1223-0930 Teff $=5377 \mathrm{~K} \quad \operatorname{logg}=3.43 \quad[\mathrm{Fe} / \mathrm{H}]=-2.19 \quad[\mathrm{C} / \mathrm{H}]=-0.43$

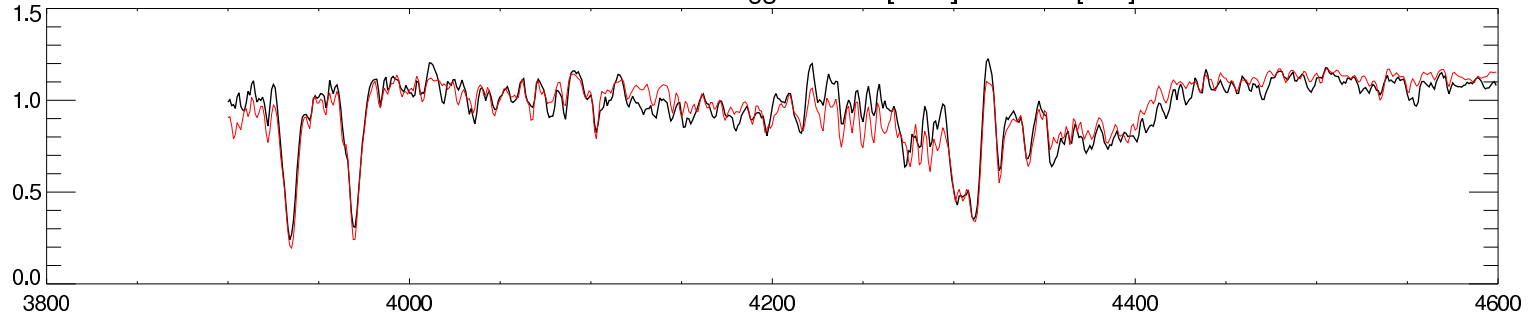

Figura 4.12: Determinação da abundância de carbono para uma das estrelas da subamostra. O painel superior mostra parte do espectro original (em preto) sobreposto por um espectro sintético (em vermelho) com os parâmetros atmosféricos listados e $[\mathrm{C} / \mathrm{Fe}]=0.0$. O painel central mostra a região ao redor da banda G, com uma linha vermelha mostrando o melhor ajuste. A linha verde representa a divisão entre o espectro original e o espectro sintético, que deve apresentar valores próximos de 1.0 para um ajuste considerado satisfatório. O painel inferior mostra o resultado do melhor ajuste com o valor listado de $[\mathrm{C} / \mathrm{H}]$.

A estimativa da abundância de carbono foi obtida através da minimização de $\chi^{2}$ entre o espectro observado e o sintético, na região de comprimento de onda entre 4285-4320 ̊. O valor inicial de entrada para $[\mathrm{C} / \mathrm{H}]$ é o mesmo de $[\mathrm{Fe} / \mathrm{H}]$ fornecido pelo SSPP, ou seja, uma razão solar para $[\mathrm{C} / \mathrm{Fe}]$. Um exemplo de ajuste na região da banda $\mathrm{G}$ do $\mathrm{CH}$, utilizada para estimar o valor de $[\mathrm{C} / \mathrm{Fe}]$, é mostrado na Figura 4.12. Somente a abundância de carbono é variada; todos os demais parâmetros atmosféricos são mantidos constantes. 
Para automatizar a minimização de $\chi^{2}$, foi utilizada a rotina AMOEBA (down-hill Simplex) do IDL (Landsman, 1989). Na maioria dos casos, o procedimento convergiu para um ajuste adequado, ou seja, o $\chi^{2}$ dos resíduos era mais de $1 \sigma$ distante da estimativa inicial; os erros típicos associados a estas medidas é da ordem de $\delta_{[\mathrm{C} / \mathrm{Fe}]}=0.1$ dex. Em alguns casos, embora a rotina tenha convergido, o nível de melhora ficou aquém do $1 \sigma$. Nestas situações, os erros designados foram de 0.2 dex. Os valores estimados para [C/Fe], bem como seus erros associados, estão listados na Tabela 4.5.

Outro teste realizado, com o intuito de diferenciar valores reais de $[\mathrm{C} / \mathrm{Fe}]$ de limites superiores, foi impor que o valor integrado em uma região de $20 \AA$ em torno da banda $G$ (entre $4295 \AA$ e $4315 \AA$ ) fosse de, no mínimo, $1.5 \AA$. Este valor foi estabelecido pela comparação entre espectros sintéticos com ruído artificial inserido e espectros com diferentes valores para $[\mathrm{C} / \mathrm{H}]$. Os valores que não preencheram o requisito acima foram considerados limites superiores, e foram listados na Tabela 4.5 como determinações sem erro associado.

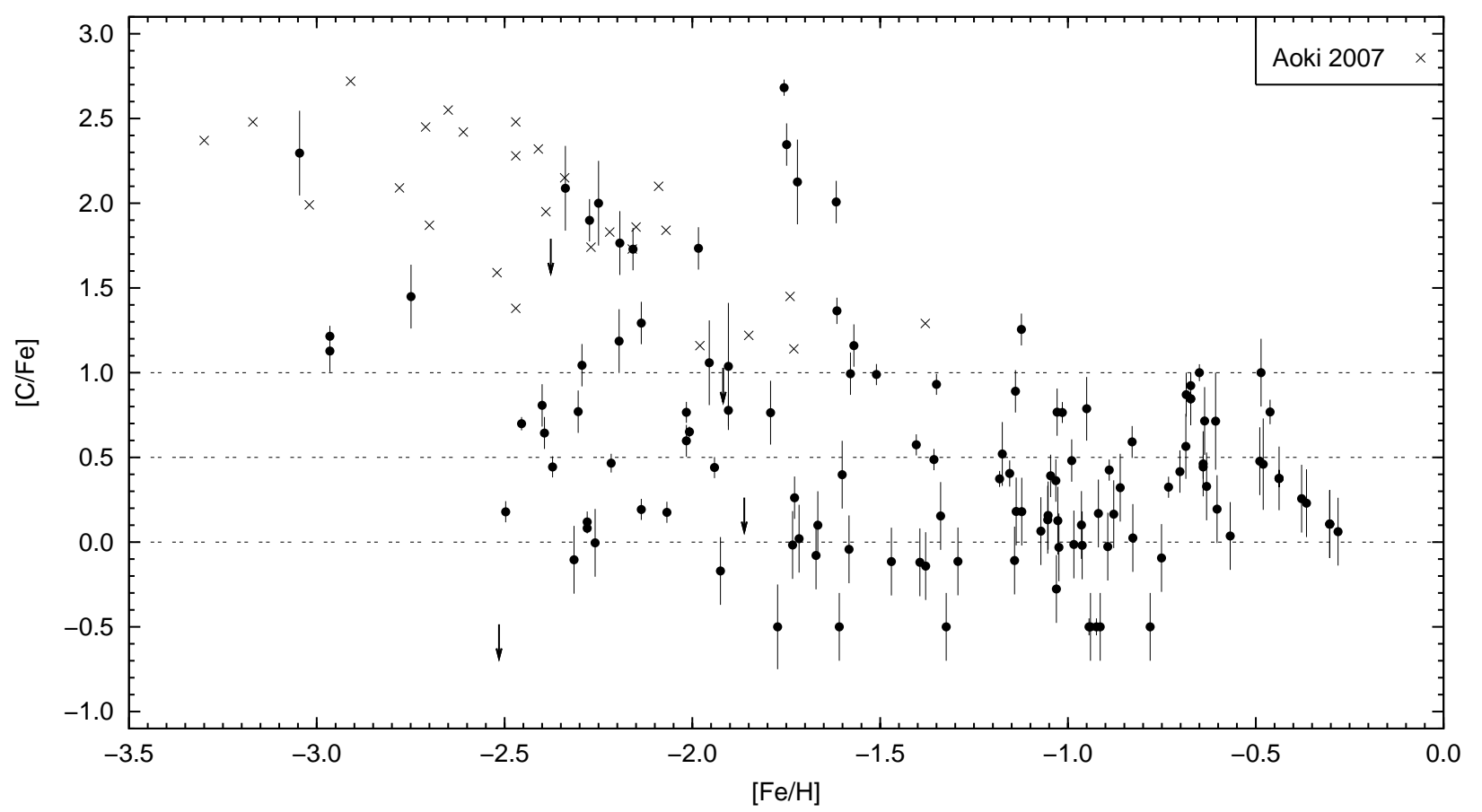

Figura 4.13: Comportamento da metalicidade com a abundância de carbono $[\mathrm{C} / \mathrm{Fe}]$ para as candidatas observadas e para as estrelas presentes em Aoki et al. (2007). As flechas representam os limites superiores. As linhas pontilhadas mostram valores constantes de $[\mathrm{C} / \mathrm{Fe}](0.0,+0.5 \mathrm{e}+1.0)$.

O comportamento das abundâncias de carbono calculadas pelo procedimento exposto acima, em relação aos valores de metalicidade determinados pelo SSPP, é mostrado na 
Figura 4.13. Também são exibidos os pares $[\mathrm{C} / \mathrm{Fe}]$ vs. $[\mathrm{Fe} / \mathrm{H}]$ para as estrelas CEMP de Aoki et al. (2007). Nota-se, como já explorado por outros estudos (Rossi et al., 2005; Lucatello et al., 2006), uma clara tendência para as abundâncias de carbono, que são maiores para metalicidades menores, e exibem um espalhamento crescente para $[\mathrm{Fe} / \mathrm{H}]<-2.0$. Esta tendência é claramente compartilhada pelos dados em alta resolução presentes na Figura 4.13. Também é interessante notar alguns objetos com metalicidades intermediárias $(-2.0 \leq[\mathrm{Fe} / \mathrm{H}] \leq-1.5)$ que apresentam $[\mathrm{C} / \mathrm{Fe}]>+1.5$. Caso a seleção feita levasse em conta somente a intensidade da linha K do Ca II (semelhante à busca feita por Christlieb et al., 2008), estes objetos peculiares não teriam sido observados.

Ao utilizar o novo método de seleção de estrelas CEMP proposto por este trabalho, sabendo que o mesmo possui um viés intrínseco na direção de estrelas ricas em carbono, a fração de estrelas CEMP encontradas (considerando as barras de erro) é de $\sim 25 \%$. Ao considerar somente as estrelas muito pobres em metais $([\mathrm{Fe} / \mathrm{H}]<-2.0)$, esta fração aumenta para 43\%. Para as cinco candidatas observadas que apresentam metalicidades menores que $[\mathrm{Fe} / \mathrm{H}]=-2.5$, o método atinge $80 \%$ de eficácia. Também é importante notar que a maioria das estrelas pobres em metais observadas com $[\mathrm{Fe} / \mathrm{H}]<-1.0(51 \%)$, apresentam consideráveis enriquecimentos em carbono $([\mathrm{C} / \mathrm{Fe}]>+0.5)$. Além disso, ao retirar o viés em metalicidade introduzido pela seleção com base na linha K do Ca II, o método proposto colaborou para o aumento da estatística de estrelas pobres em metais com $[\mathrm{Fe} / \mathrm{H}]>-2.0$.

\subsection{Estimativas para Abundâncias de Ba e Sr}

Em adição aos parâmetros atmosféricos e às abundâncias de carbono, também é possível estimar, com alto grau de confiança, as abundâncias dos elementos Sr e Ba. Como visto no Capítulo 1, estes dois elementos são formados predominantemente pelo processo-s (Arlandini et al., 1999) e representam também o primeiro ( $\mathrm{Sr}$ ) e segundo (Ba) picos deste processo. Dessa forma é possível, além de identificar estrelas CEMP, classificar as estrelas observadas quanto ao grau de enriquecimento destes elementos.

O trabalho de Cruz et al. (2009) utiliza dois métodos de calibração para estimar as abundâncias de bário e estrôncio a partir dos índices de linha em espectros em média resolução: regressões polinomiais e redes neurais artificiais (ANN - Artificial Neural Networks). Ambos os métodos utilizam como parâmetros de entrada as abundâncias disponíveis em 
alta resolução ([Ba/Fe] ou [Sr/Fe]), o índice KP de Beers et al. (1999), os índices definidos pelos autores $(\mathrm{Ba}$ ou $\mathrm{Sr})$ e o índice de cor $(\mathrm{J}-\mathrm{K})_{0}$. Os valores das abundâncias para as estrelas observadas com o SOAR foram calculadas utilizando o método ANN (cedidas por Monique Cruz). As abundâncias não foram calculadas para objetos cujos índices de Ba e Sr não se encontravam dentro do intervalo de calibração utilizado por Cruz et al. (2009). No total foram obtidas abundâncias de Ba para 107 objetos e de Sr para 103 objetos.

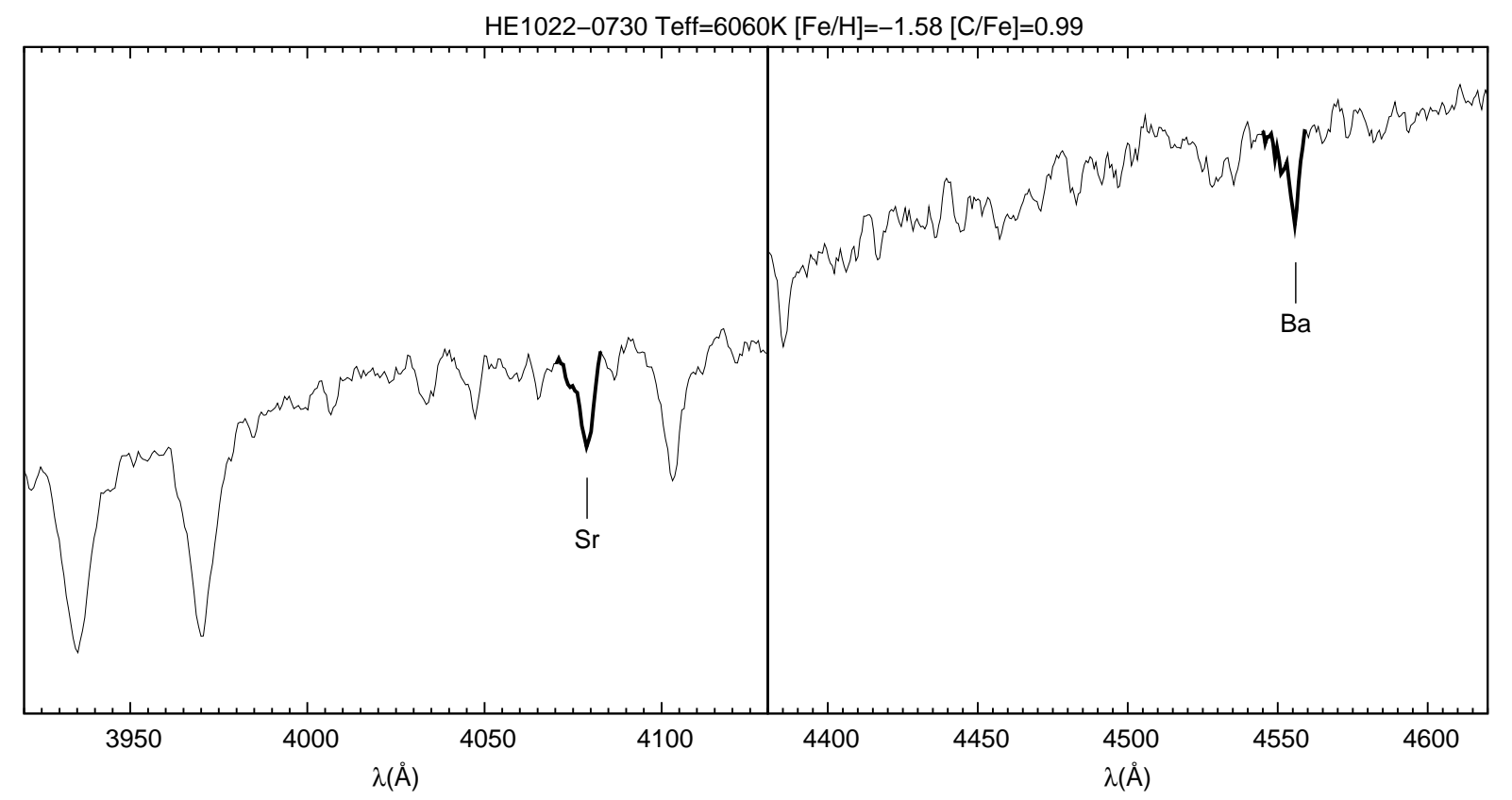

Figura 4.14: Exemplo de identificação das linhas de $\operatorname{Sr}(4077 \AA)$ e Ba $(4554 \AA)$.

A Figura 4.14 mostra, para uma das candidatas a estrela CEMP, a localização das linhas de $\mathrm{Ba}$ e Sr utilizadas para encontrar as abundâncias. Percebe-se que essas linhas (quando presentes) são facilmente identificadas em espectros em média resolução, tornando possível a obtenção das abundâncias pelos métodos supracitados. Porém, deve-se ter cautela quanto à determinação dos índices de $\mathrm{Ba}$ e $\mathrm{Sr}$, pois estes utilizam interpolação linear entre as bandas laterais para estimar o contínuo. Como visto na Seção 2.1, a presença de bandas de carbono intensas pode rebaixar o nível do contínuo e prejudicar sua determinação por interpolação linear. Dessa forma, a utilização do método ANN torna-se mais confiável em comparação com as regressões polinomiais, uma vez que são atribuídos pesos menores para os possíveis desvios gerados no cálculo dos índices.

O comportamento das abundâncias de $\mathrm{Ba}$ e $\mathrm{Sr}$ em função da metalicidade para os 


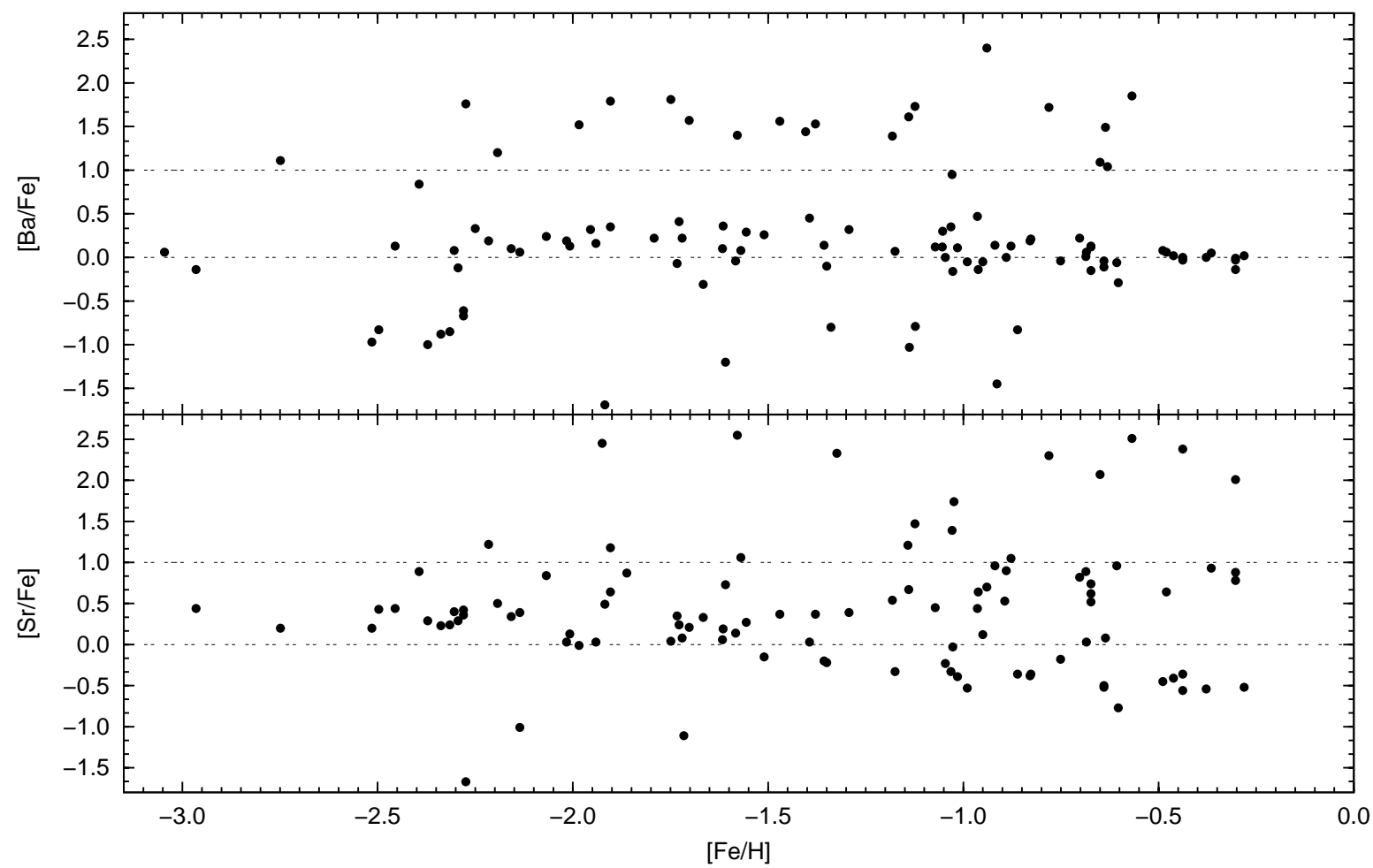

Figura 4.15: Comportamento das abundâncias estimadas dos elementos Ba e Sr em função da metalicidade. As linhas pontilhadas mostram valores constantes das abundâncias $(0.0 \mathrm{e}+1.0)$.

objetos onde foi possível aplicar o ANN está exibido na Figura 4.15. Não é possível notar nehuma tendência de aumento ou diminuição nos valores das abundâncias com a variação da metalicidade, que pode ser resultado de processos de enriquecimento homogêneo para o intervalo de $[\mathrm{Fe} / \mathrm{H}]$ mostrado. Porém, existe uma diminuição da frequência de estrelas ricas em elementos formados pelo processo-s com a diminuição da metalicidade. Essa tendência pode estar relacionada às escalas de tempo associadas com o processo-s, pois as frações ligadas ao processo-s só começam a dominar as abundâncias de Ba e Sr para valores de metalicidade $[\mathrm{Fe} / \mathrm{H}] \gtrsim-2.6$ (Johnson e Bolte, 2002; Simmerer et al., 2004).

Para identificar com maior facilidade os objetos das diferentes subclasses de estrelas CEMP presentes na Tabela 1.2, foi feita a distribuição das abundâncias de bário em função da abundância de carbono, mostrada na Figura 4.16. Além disso, é mostrada uma divisão em $[\mathrm{Fe} / \mathrm{H}]$ para os objetos, onde os pontos maiores representam menores metalicidades. Nota-se, em geral, uma correlação crescente entre as abundâncias de carbono e bário, o que corrobora com as hipóteses de enriquecimento em elementos formados por processo-s em sistemas binários, formados a partir da fonte de nêutrons ${ }^{13} \mathrm{C}$ em estrelas de baixa massa 


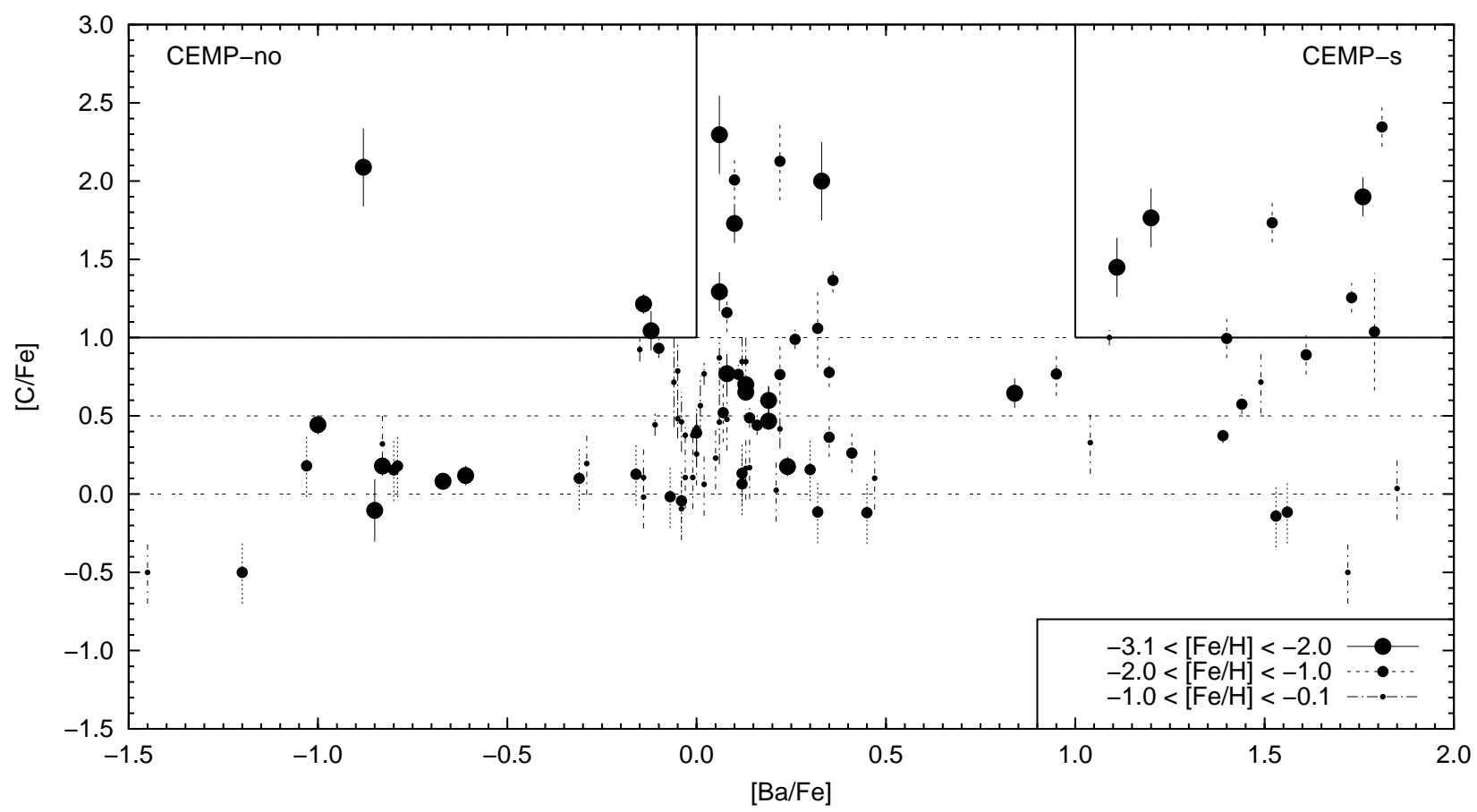

Figura 4.16: Distribuição das abundâncias de carbono em relação ao bário. O tamanho dos pontos indica a escala de metalicidade. As áreas delimitadas representam as definições das classes de estrelas CEMP presentes na Tabela 1.2. As linhas pontilhadas mostram valores constantes de $[\mathrm{C} / \mathrm{Fe}](0.0,+0.5$ e +1.0$)$.

quando no AGB (Masseron et al., 2010).

Outrossim, é possível identificar alguns objetos cujas abundâncias condizem com a classificação CEMP-no (Ito et al., 2009; Behara et al., 2010) que, juntamente com as estrelas CEMP-s, apresentam metalicidades menores que -2.0. As estrelas CEMP-no são de particular importância, pois acredita-se que os processos de enriquecimento em carbono destes objetos provavelmente não estão associados a estrelas no AGB. Dessa forma, este trabalho também contribui para o aumento da estatística para diferentes tipos de estrelas CEMP, que podem ser alvos de estudos futuros em alta resolução, com o intuito de determinar seus padrões de abundâncias além de suas possíveis origens.

\subsection{Discussão}

Neste Capítulo foi mostrado o desenvolvimento de um novo método para a busca de estrelas CEMP, com o auxílio de um novo índice de linha (GPE - ver Seção 2.2) para a banda G do CH em 4304 Å. Este índice possui a vantagem de coletar mais informação acerca 
da abundância de carbono na estrela, uma vez que sua largura leva em conta as "asas" da banda molecular, que pode incluir informação advinda de outras moléculas de carbono próximas, quando presentes no espectro. Ademais, o índice GPE, por utilizar um contínuo ajustado ao espectro como referência nos cálculos, não sofre influências significativas (como os índices anteriormente definidos em, por exemplo, Beers et al., 1999) de outras bandas moleculares de carbono.

Com o intuito de testar o método proposto, foi obtida uma subamostra de estrelas do HES, cujos índices foram comparados com aqueles calculados para os espectros em baixa resolução de estrelas CEMP (confirmadas por estudos em alta resolução, como Aoki et al., 2007). A partir da subamostra de 669 candidatas inéditas, foram feitas observações em média resolução para 132 objetos com o espectrógrafo Goodman no telescópio SOAR. A nova técnica de seleção alcançou uma taxa de $43 \%$ na identificação de estrelas CEMP para $[\mathrm{Fe} / \mathrm{H}]<-2.0$; além disso, quatro das cinco candidatas com $[\mathrm{Fe} / \mathrm{H}]<-2.5$ exibem altos enriquecimentos em carbono $([\mathrm{C} / \mathrm{Fe}]>+1.0)$. Deve-se levar em conta que as frações apresentadas não são simplesmente frações de estrelas CEMP em função da metalicidade, mas sim uma medida da relação entre os resultados obtidos (em uma amostra com viés para altas abundâncias em carbono) e os objetivos pretendidos nesta nova proposta de identificação de estrelas com enriquecimento em carbono.

No passado, estrelas CEMP foram selecionadas de duas formas distintas: (1) como candidatas a estrelas pobres em metais do survey HK ou HES, baseado na intensidade da linha K do Ca II, que depois seriam reconhecidas como CEMP por espectroscopia em média resolução ou (2) selecionadas como estrelas ricas em carbono com base na soma de índices de linha de carbono molecular presente nos espectros (Christlieb et al., 2001). Convém salientar que ambas as técnicas possuem limitações. A técnica descrita em (1) perde estrelas CEMP com temperaturas mais elevadas e metalicidades $[\mathrm{Fe} / \mathrm{H}]>-2.5$ e, devido ao intervalo de cor utilizado na seleção, deixa de levar em conta estrelas CEMP com cor estimada $B-V>0.9$ (ver Figura 4.6), pois a presença de linhas intensas de carbono desloca os objetos para fora da janela de seleção. A técnica (2) claramente obtém sucesso em identificar estrelas ricas em carbono frias, uma vez que seleciona objetos através da intensidade total dos índices moleculares de $\mathrm{C}_{2}$ e $\mathrm{CN}$ no espectro em baixa resolução. Mesmo estrelas que apresentem a banda $\mathrm{G}$ do $\mathrm{CH}$ intensa (ou seja, estrelas ricas em 
carbono) geralmente não preenchem os requisitos necessários para esta seleção, caso sejam quentes o suficiente para não exibir as bandas moleculares de carbono.

Tabela 4.6 - Critérios de seleção para estrelas ricas em carbono (Christlieb et al., 2001).

\begin{tabular}{cc|cc}
\hline \hline Índice de linha & Intervalo $(\AA)$ & Índice de linha & Intervalo $(\AA)$ \\
\hline $\mathrm{C}_{2}(\lambda$ 4737) & {$[15,114]$} & $\mathrm{CN}(\lambda$ 3883) & {$[13,55]$} \\
$\mathrm{C}_{2}(\lambda$ 5165) & {$[10,91]$} & $\mathrm{CN}(\lambda 4216)$ & {$[2,56]$} \\
\hline
\end{tabular}

A Tabela 4.6 mostra os intervalos utilizados por Christlieb et al. (2001) para localizar estrelas ricas em carbono. Estas estrelas, segundo os critérios do trabalho mencionado acima, deveriam apresentar valores de índices dentro dos intervalos propostos para ambos os índices de $\mathrm{C}_{2}$ e/ou de CN. Os limites superiores apresentados na tabela foram estabelecidos para evitar contaminação da amostra por possíveis erros nas placas fotográficas ou sobreposições de espectros, que poderiam gerar altos valores para a quantidade integrada.
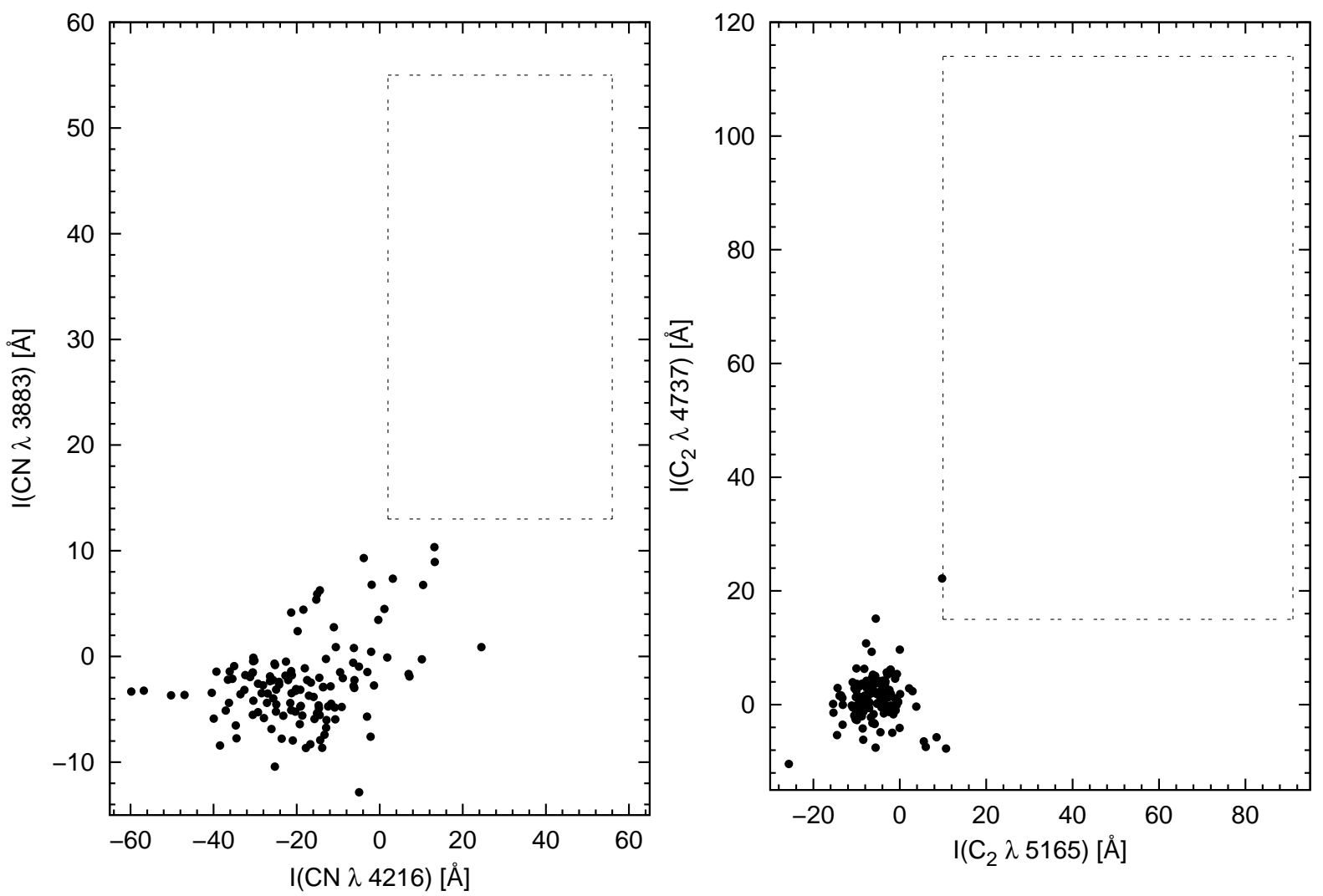

Figura 4.17: Critério de seleção para estrelas ricas em carbono no plano dos índices $\mathrm{C}_{2}$ e CN. As linhas tracejadas delimitam a área de ocorrência das estrelas ricas em carbono segundo Christlieb et al. (2001). 
A Figura 4.17 mostra a distribuição dos índices de $\mathrm{C}_{2}$ e $\mathrm{CN}$ (disponíveis na base de dados do HES) para as estrelas observadas com o SOAR. As áreas delimitadas pelas linhas tracejadas representam os critérios apresentados na Tabela 4.6. Como pode ser visto em ambos os painéis, nenhuma das 132 candidatas a estrelas CEMP apresentadas satisfaz tais critérios, e mesmo assim possuem consideráveis enriquecimentos em carbono. Esse fato confirma as hipóteses apresentada de que muitas estrelas pobres em metais e ricas em carbono foram negligenciadas em buscas anteriores, e que de fato as novas definições de índices de linha são úteis para identificação de tais objetos.

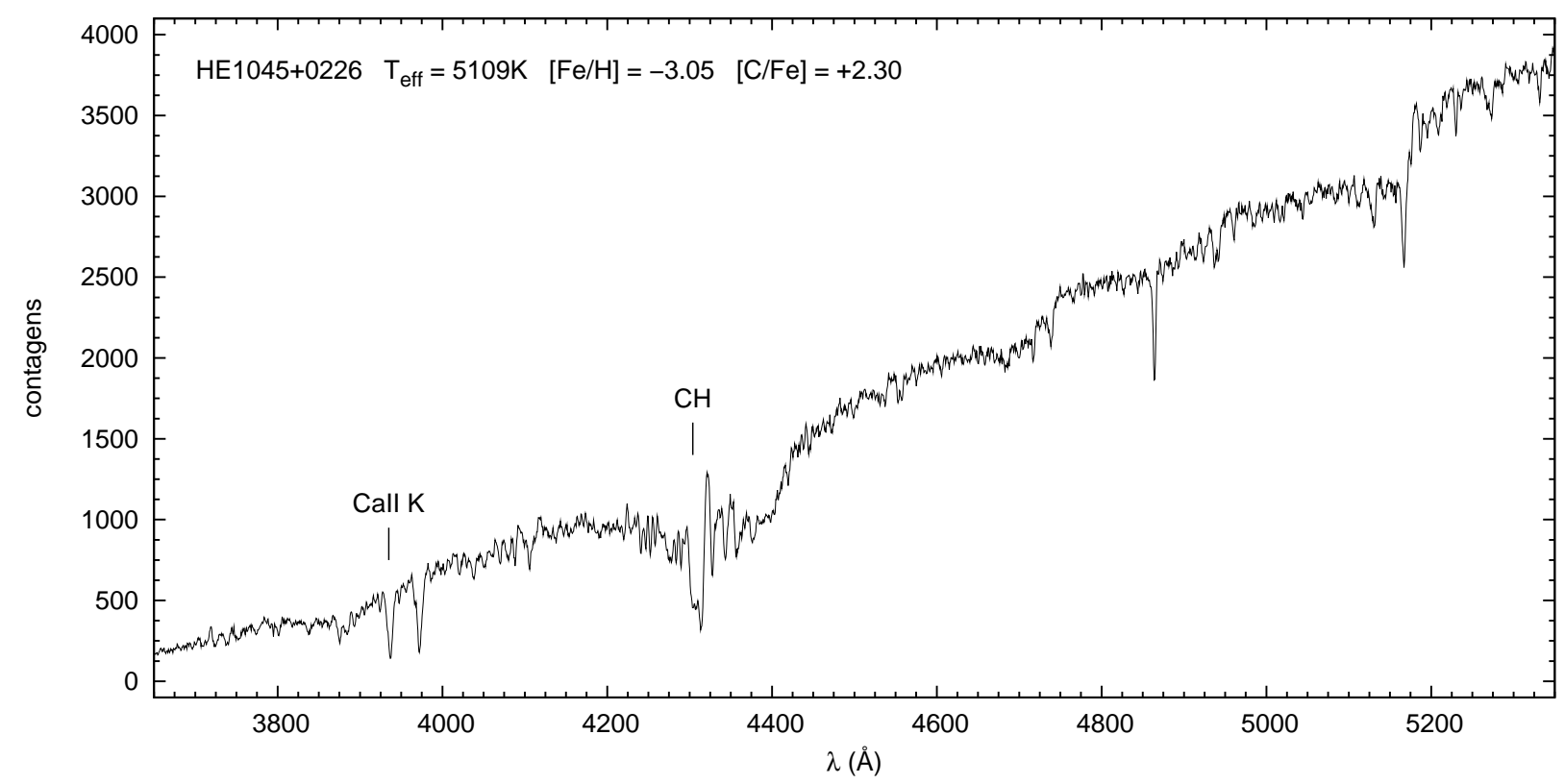

Figura 4.18: Estrela EMP HE 1045+0226 observada neste trabalho. Em destaque estão a linha K do Ca II e a banda $\mathrm{G}$ do $\mathrm{CH}$.

Dentro da amostra observada com o SOAR, foi encontrada uma estrela extremamente pobre em metais $([\mathrm{Fe} / \mathrm{H}]<-3.0$ - EMP - Beers e Christlieb, 2005) com uma quantidade de carbono quase 200 vezes maior que o equivalente para o Sol $([\mathrm{C} / \mathrm{Fe}]=+2.30)$. O espectro da estrela HE 1045+0226 encontra-se na Figura 4.18 (e também no Apêndice A). Este é um exemplo claro do sucesso da busca por estrelas CEMP proposta neste trabalho: mesmo com $T_{\text {eff }}=5109 \mathrm{~K}$ (o que a desqualificaria no critério de Christlieb et al., 2001) e linhas H e K do CaII proeminentes (KPHES=7.4 - também podendo ser descartada pelo método de Christlieb et al., 2008), esta estrela satisfaz o critério de seleção para o índice GPE (valor calculado de $53.6 \AA$ ), o que permitiu sua observação em média resolução e posterior 
confirmação de seu status de estrela EMP. Além disso, dada sua abundância estimada de bário ([Ba/Fe] $\approx 0.06)$, este objeto está muito próximo da definição de estrelas CEMP-no, portanto seu estudo em alta resolução pode ser muito útil para pesquisas nessa área.

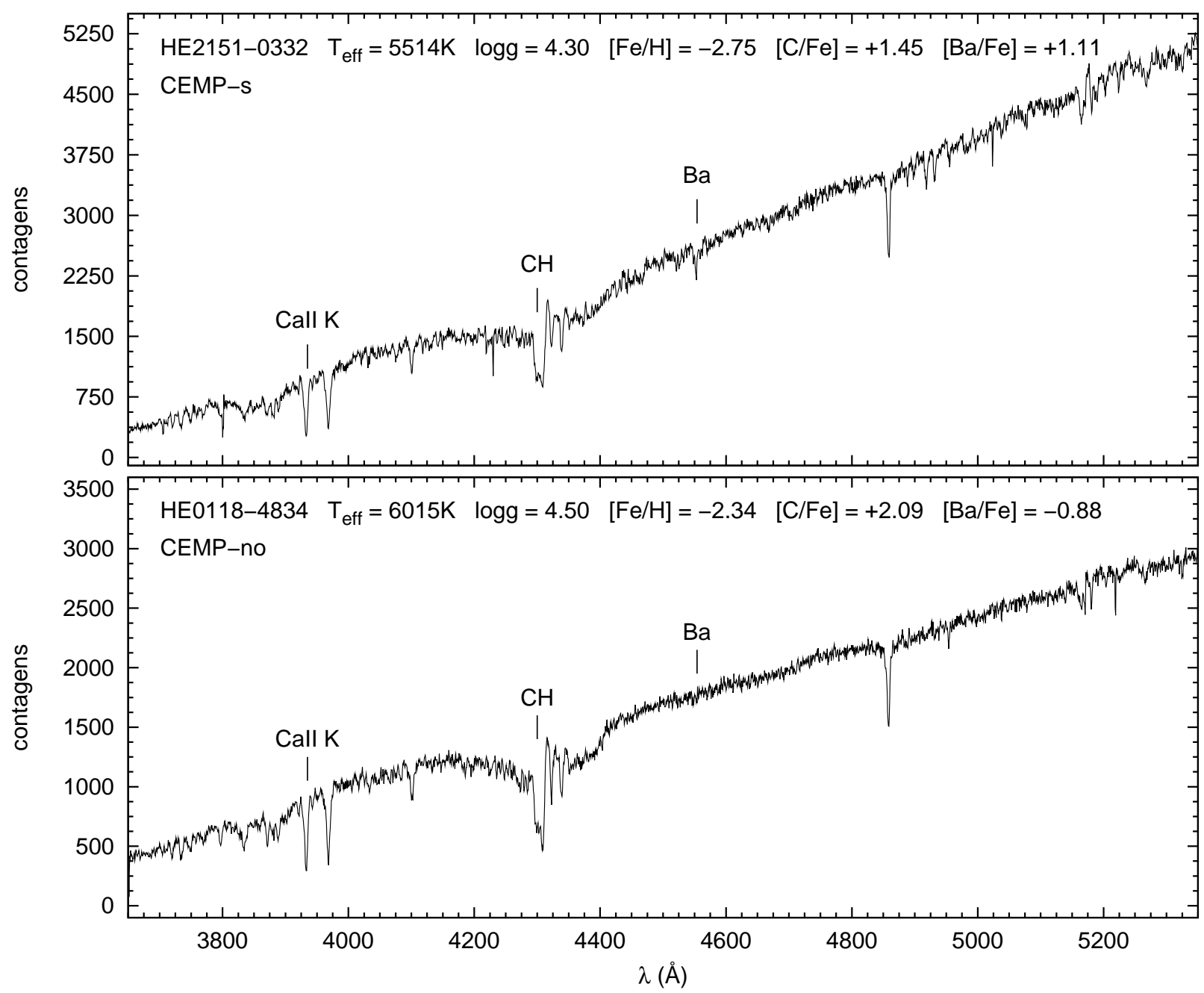

Figura 4.19: Estrelas CEMP inéditas na literatura observadas com o SOAR.

Outro aspecto importante do método de busca por estrelas CEMP exibido neste trabalho reside no fato de que são amostradas, além de estrelas em um grande intervalo de metalicidade, diversos tipo de estrelas CEMP, identificadas a partir de estimativas de abundâncias de elementos formados por processo-s. Essa distinção é fundamental para entender com maior clareza a verdadeira natureza destes objetos (Behara et al., 2010; Goswami e Aoki, 2010). A espectroscopia em média revelou objetos ainda inéditos na literatura, tais como as estrelas HE 2151-0332 e HE 0118-4834, cujos espectros estão exibidos na Figura 4.19. Ambas as estrelas são anãs muito pobres em metais, com considerável so- 
breabundância em carbono. Porém, nota-se que a diferença entre suas abundâncias do elemento Ba difere em quase duas ordens de grandeza, ou seja, é certo que a origem da sobreabundância em carbono dessas duas estrelas é distinta (Ryan et al., 2005). Porém, essa afirmação só pode ser confirmada com estudos em alta resolução, necessários para obter abundâncias de um maior número de elementos e entender a evolução de tais objetos.

Os demais objetos presentes na lista de 669 candidatas a estrelas CEMP inéditas gerada pelo novo critério de seleção, serão oportunamente colocados à disposição pública para futuras observações, com o intuito de enriquecer ainda mais a literatura referente a estrelas pobres em metais enriquecidas em carbono. Além disso, como visto na Seção 4.3, é possível também estimar as abundâncias de elementos como o Ba e o Sr para tais objetos, o que pode ser decisivo na escolha de alvos para estudos em alta resolução que, além de colocá-las em suas verdadeiras subclasses (de acordo com a Tabela 1.2), podem também, através de um estudo detalhado de abundâncias elementais (por exemplo, Sneden et al., 2003; Frebel et al., 2007; Norris et al., 2007), explorar os sítios astrofísicos associados à produção de carbono (Roederer et al., 2008; Masseron et al., 2010). 
Capítulo 5

\section{Segunda Subamostra}

Devido aos bons resultados encontrados com as observações espectroscópicas de followup no telescópio SOAR para as candidatas a estrelas CEMP apresentadas no Capítulo 4, uma segunda subamostra foi extraída da base de dados do HES (Placco et al., 2010b, em preparação). Uma das funções dessa nova subamostra é não apenas testar novamente o índice GPE, mas também utilizar o índice EGP (Seção 2.3) como parâmetro auxiliar na seleção de objetos. A principal diferença entre esta segunda subamostra e os dados apresentados do Capítulo 4 é a inclusão das chamadas "fontes brilhantes" (bright sources) do HES na seleção, o que aumenta a faixa de temperatura da amostra e pode enriquecer o número de candidatas com $[\mathrm{Fe} / \mathrm{H}]>-2.0$. A principal característica que distingue a classe das fontes brilhantes da classe das estrelas é o fato de que as fontes brilhantes encontramse próximas (ou até mesmo além) do limite de saturação das placas fotográficas do HES. Além disso, os métodos de extração dos espectros são distintos para essas duas classes de objetos.

A análise desta nova subamostra presta-se também como uma forma distinta de testar a eficiência dos novos índices. Para tanto, foi adotada uma direção contrária àquela utilizada no Capítulo 4 na seleção das candidatas: na primeira subamostra a base de dados foi restringida por motivos observacionais e as candidatas foram escolhidas a partir da restrição em GPE. A segunda subamostra foi extraída sem qualquer informação sobre os índices de linha, e as seleções no plano (índice de cor) vs. (índice de linha) foram feitas antes das restrições em GPE e EGP. Desta forma, é possível inserir os índices posteriormente e observar se seu comportamento está dentro do esperado. 


\subsection{Restrições à Base de Dados}

Dadas as diferenças intrínsecas entre as duas classes de objetos mencionadas, foi necessário aplicar um conjunto de restrições distinto para cada uma delas. Dentro da base de dados do HES, a classificação stars possui um total de 3537737 objetos, e para a classificação bright esse total é de 584707. Os demais objetos do HES estão classificados como fontes extensas e não são utilizados neste trabalho. Os procedimentos adotados (semelhantes aos descritos no Capítulo 4) para a seleção das candidatas são explicados a seguir.

\subsubsection{Estrelas - Source type: STARS}

Para essa parte da subamostra existem pequenas diferenças nos critérios aplicados. Além dos flags de detecção do 2MASS e das magnitudes J e K, foi feita uma seleção utilizando o índice de cor $(\mathrm{B}-\mathrm{V})$, com o objetivo de diminuir o número de objetos para a inspeção visual. As restrições aplicadas foram as seguintes:

- objtype $=$ stars $($ remove fontes extensas e brilhantes);

- isin2MASS = 1 (flag do 2MASS. Fonte do HES encontrada/não encontrada);

- JmagOK = 1 (magnitude na banda J medida);

- KmagOK = 1 (magnitude na banda K medida);

- $0.20 \leq(\mathrm{J}-\mathrm{K})_{0} \leq 0.75$

- $0.30 \leq(\mathrm{B}-\mathrm{V}) \leq 1.00$.

Nota-se que o intervalo de $(\mathrm{J}-\mathrm{K})_{0}$ é menor do que aquele utilizado para os objetos da primeira subamostra. Ao inspecionar a Figura 4.5, conclui-se que essa diminuição evita a contaminação da amostra por estrelas das classes $h b a b$, habs e unid ${ }^{1}$. Já a restrição em $(\mathrm{B}-\mathrm{V})$ é útil para limitar a amostra em número e ainda assim incluir possíveis candidatas que eventualmente não tenham determinação de magnitudes nas bandas J e K. Para os objetos que satisfizeram as restrições mostradas acima, foram calculadas duas quantidades, $\mathrm{KP}_{\mathrm{JK}}$ e $\mathrm{KP}_{\mathrm{BV}}$, relacionadas às Equações 5.1 e 5.2. Estes ajustes polinomiais correspondem

\footnotetext{
${ }^{1}$ Ver definições na Tabela 4.2 .
} 
a valores constantes de metalicidade $([\mathrm{Fe} / \mathrm{H}]=-2.0$, ver Christlieb et al., 2008, e Seção 4.1.3 desta tese para mais detalhes), e são obtidos por meio das expressões abaixo:

$$
\begin{array}{r}
\mathrm{KP}_{\mathrm{JK}}([\mathrm{Fe} / \mathrm{H}]=-2.0)=-2.37+14.75 \cdot(\mathrm{J}-\mathrm{K})_{0}+40.39 \cdot(\mathrm{J}-\mathrm{K})_{0}^{2} \\
-90.64 \cdot(\mathrm{J}-\mathrm{K})_{0}^{3}+51.52 \cdot(\mathrm{J}-\mathrm{K})_{0}^{4},
\end{array}
$$

e

$$
\begin{array}{r}
\mathrm{KP}_{\mathrm{BV}}([\mathrm{Fe} / \mathrm{H}]=-2.0)=18.24-155.03 \cdot(\mathrm{B}-\mathrm{V})+504.44 \cdot(\mathrm{B}-\mathrm{V})^{2} \\
-683.79 \cdot(\mathrm{B}-\mathrm{V})^{3}+421.71 \cdot(\mathrm{B}-\mathrm{V})^{4}-97.22 \cdot(\mathrm{B}-\mathrm{V})^{5}
\end{array}
$$

Em seguida, é aplicado mais um conjunto de restrições, que leva em conta, além dos valores calculados pelas equações acima, a razão sinal/ruído dos espectros e o limite de detecção da linha K do Ca II. São elas:

- KPHES > msigKP (valores de KPHES maiores do que o limite mínimo de detecção da linha K do Ca II na resolução dos espectros do HES);

- no overlap flag = 1 (sem sobreposições de espectros);

- $\mathrm{SN}_{\mathrm{CaHK}}>5$ (seleciona espectros com razão sinal/ruído maior do que 5);

- $\operatorname{KPHES}<\mathrm{KP}_{\mathrm{JK}}([\mathrm{Fe} / \mathrm{H}]=-2.0)$ ou KPHES $<\mathrm{KP}_{\mathrm{BV}}([\mathrm{Fe} / \mathrm{H}]=-2.0)$.

Os objetos selecionados devem preencher ambas as restrições nos índices de cor e pelo menos uma das restrições feitas pelas funções de metalicidade constante (semelhante à primeira subamostra). Este procedimento selecionou 62311 objetos.

\subsubsection{Fontes brilhantes - Source type: BRIGHT}

O primeiro conjunto de restrições para as fontes brilhantes é semelhante ao das estrelas, a menos da seleção pelo índice de cor $(B-V)$. São elas:

- objtype $=$ bright (remove fontes extensas);

- $\operatorname{isin} 2 \mathrm{MASS}=1$ (flag do 2MASS. Fonte do HES encontrada/não encontrada); 
- JmagOK = 1 (magnitude na banda J medida);

- $\mathrm{KmagOK}=1$ (magnitude na banda K medida);

- $0.20 \leq(\mathrm{J}-\mathrm{K})_{0} \leq 0.75$.

A exclusão da seleção em $(B-V)$ foi necessária pelo fato de que os espectros desses objetos, por serem brilhantes, estão mais sujeitos à saturação nas placas fotográficas do HES, o que prejudica fortemente as determinações das magnitudes B e V. Além disso, como as fontes brilhantes perfazem um número mais de seis vezes menor do que o de estrelas, não é necessário introduzir filtros para diminuir o total de objetos. Porém, para garantir que a amostra contenha o maior número possível de candidatas a estrelas pobres em metais, novamente foi feita a seleção em $(\mathrm{J}-\mathrm{K})_{0}$, a partir da equação 5.1. Assim, foram aplicadas as restrições:

- $\operatorname{KPHES}<\operatorname{KP}([\mathrm{Fe} / \mathrm{H}]=-2.0)$;

- KPHES > msigKP (valores de KPHES maiores do que o limite mínimo de detecção da linha na resolução dos espectros do HES);

- no overlap flag = 1 (sem sobreposições de espectros);

- $\mathrm{SN}_{\mathrm{CaHK}}>5$ (seleciona espectros com razão sinal/ruído maior do que 5).

Dessa forma, foram selecionadas 18532 fontes brilhantes.

\subsubsection{Comportamento dos Índices de Linha}

A série de restrições aplicadas acima forneceu uma subamostra contendo 80843 objetos. Assim, foi possível extrair da base de dados do HES os valores para os índices GPE e EGP, com o intuito de filtrar a amostra para proceder com a inspeção visual. Para a segunda subamostra foram utilizados os dois índices, diferentemente da primeira subamostra, que utilizou apenas o índice GPE. A utilização do segundo índice na seleção é útil para remover, por exemplo, objetos que tenham seu contínuo superestimado devido a uma superposição de espectros. Porém, para inserir esse filtro, é necessário que os índices estejam na mesma escala para todos os objetos, o que não ocorre no caso das fontes brilhantes, pois seus 
espectros estão sujeitos à saturação. Esse efeito pode ocorrer devido à superexposição das placas fotográficas do HES, uma vez que uma mesma placa pode conter tanto objetos brilhantes quanto estrelas mais fracas.

Dessa forma, para as fontes brilhantes, uma vez que uma dada região do espectro tenha atingido o nível de saturação, esta não receberá mais nenhuma contribuição vinda do objeto. No entanto, a região da banda G (e outras regiões em absorção) continua recebendo fótons, o que diminui o contraste entre o contínuo e banda, e consequentemente diminui o valor dos índices de linha. Esse efeito pode ser claramente visto na Figura 5.1, que mostra uma fonte brilhante saturada no painel superior, em comparação com uma fonte não saturada no painel inferior.

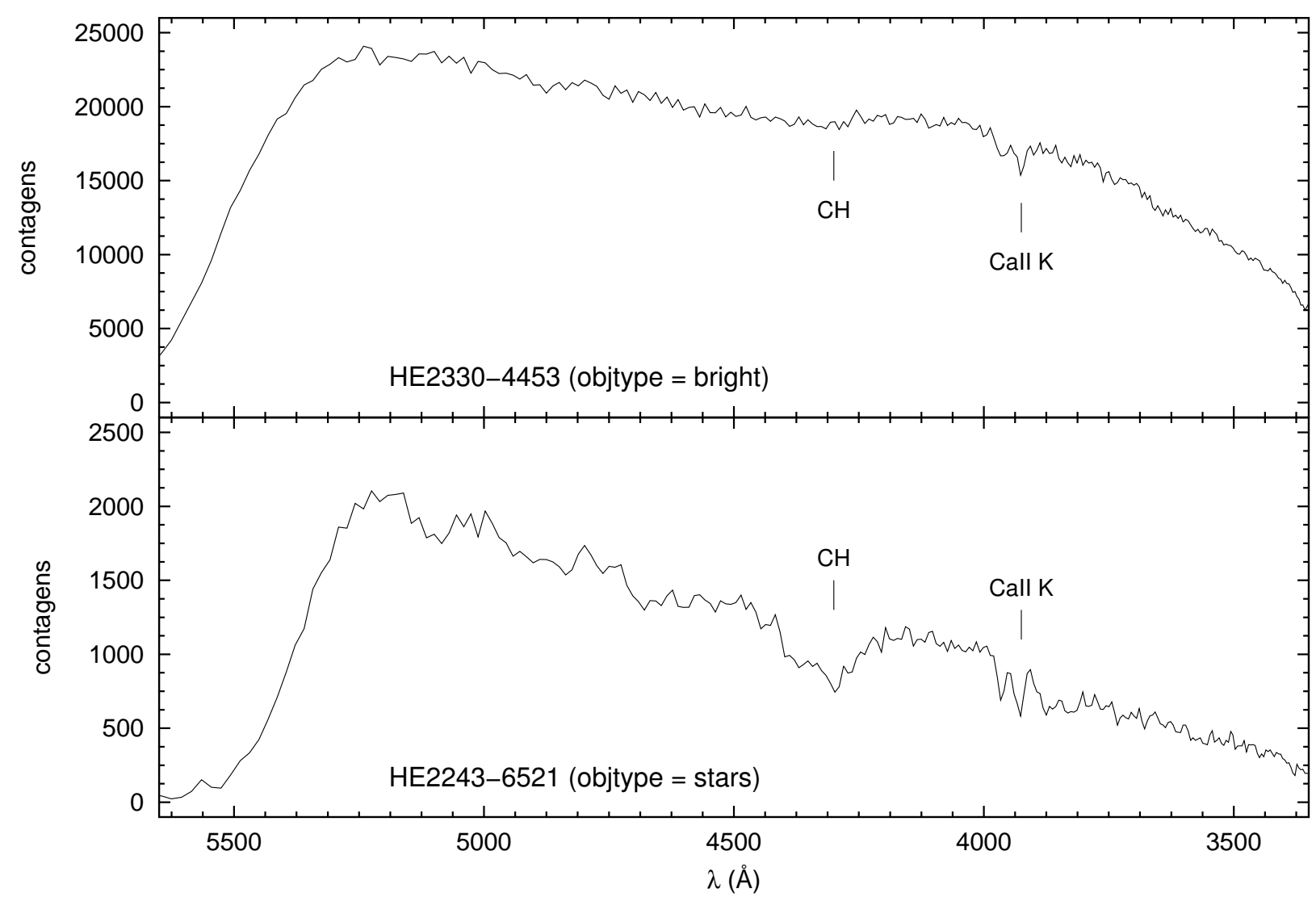

Figura 5.1: Painel superior: exemplo de fonte brilhante saturada. Painel inferior: exemplo de espectro não saturado. Note a diferença na ordem de grandeza no eixo $y$, que representa as contagens.

Nota-se que o espectro saturado possui o nível do contínuo mais plano e com linhas em absorção menos intensas. Além disso, o número máximo de contagens do objeto não saturado é mais de uma ordem de grandeza menor que o valor correspondente da fonte 
saturada. Sendo assim, espera-se que esse efeito prejudique a identificação das estrelas CEMP a partir dos índices GPE e EGP. É possível que alguns objetos próximos ao nível de saturação não possuam, de fato, uma banda G pronunciada (estrelas sem enriquecimento em carbono), mas nesse caso é mais correto aplicar uma correção em GPE e EGP para incluir objetos com valores menores de índices (e excluí-los posteriormente caso necessário) do que eliminá-los antes na inspeção visual.
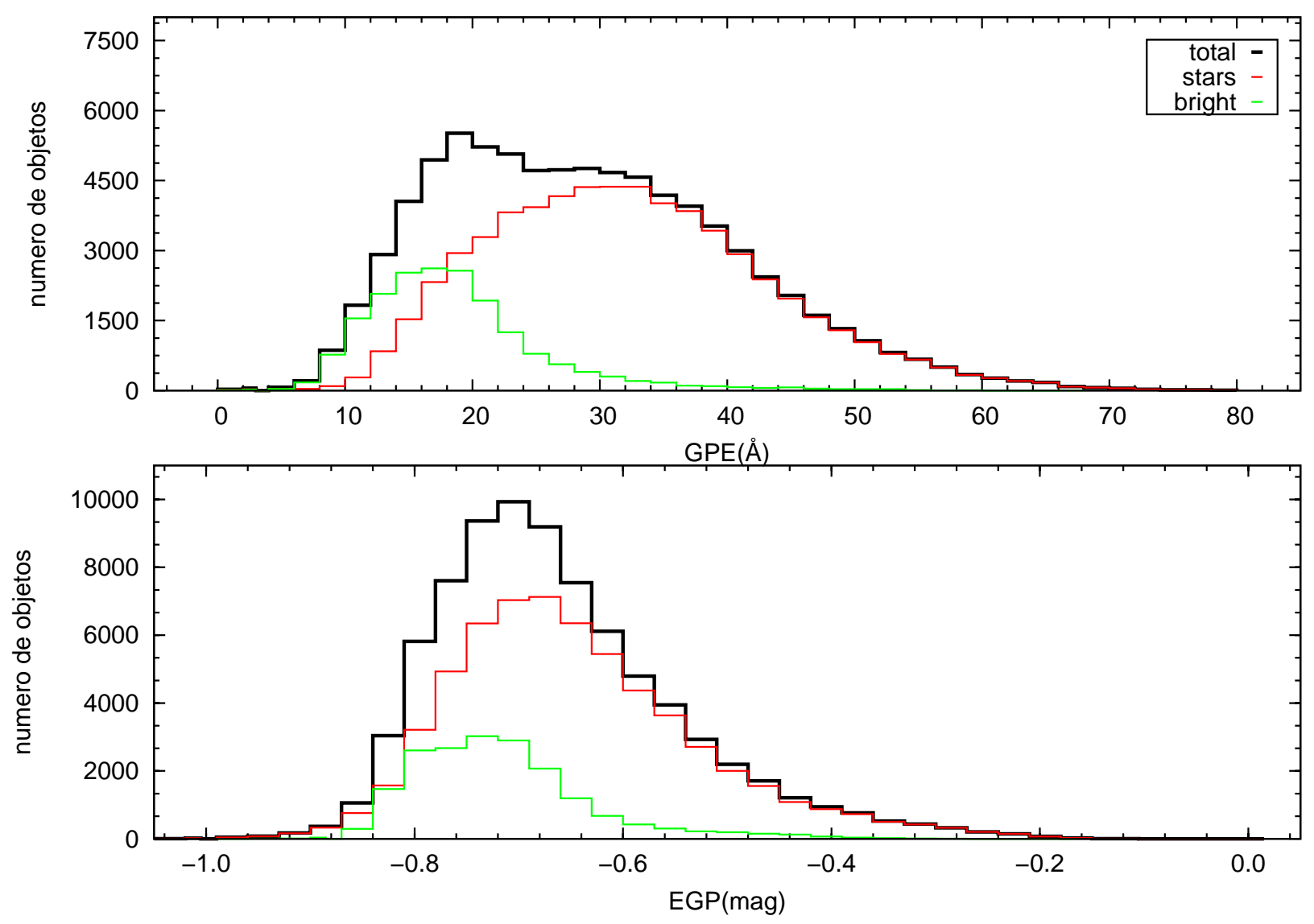

Figura 5.2: Distribuição dos índices de linha GPE e EGP para os objetos da segunda subamostra, divididos por tipo de fonte. A escala do eixo $y$ é dada em frequência relativa, para facilitar a visualização.

A Figura 5.2 mostra as distribuições dos índices de linha, separadas por tipo de fonte, e a distribuição total dos objetos da segunda subamostra. É possível notar o efeito da saturação das fontes brilhantes nos valores dos índices de linha, principalmente para a distribuição em GPE. Assim, antes de proceder com a inspeção visual, foi necessário desenvolver um método para corrigir os índices de linha das fontes brilhantes, com o intuito de adicionar a informação perdida devido à saturação. 


\subsection{Correções de Saturação para Fontes Brilhantes}

Para compensar o efeito da saturação nos espectros das fontes brilhantes, foi feito um procedimento de correção estatística, que não levou em conta apenas efeitos de saturação individuais, mas sim tendências para grupos específicos de objetos. Essa correção foi feita a partir dos valores da variável spcmag do HES, que é uma medida interna de magnitude do survey, baseada na densidade fotográfica integrada na banda $\mathrm{B}_{\mathrm{J}}$ (medida nas placas do DSS - também chamada BHES). O valor limite de $\mathrm{B}_{\mathrm{J}}$ para o qual a saturação ocorre varia entre as placas fotográficas do HES, portanto não pode ser utilizado como um parâmetro uniforme para as correções dos índices das fontes brilhantes. No entanto, a quantidade spcmag é um bom indicador global do nível de saturação, ou seja, deve ser válido para todas as placas.

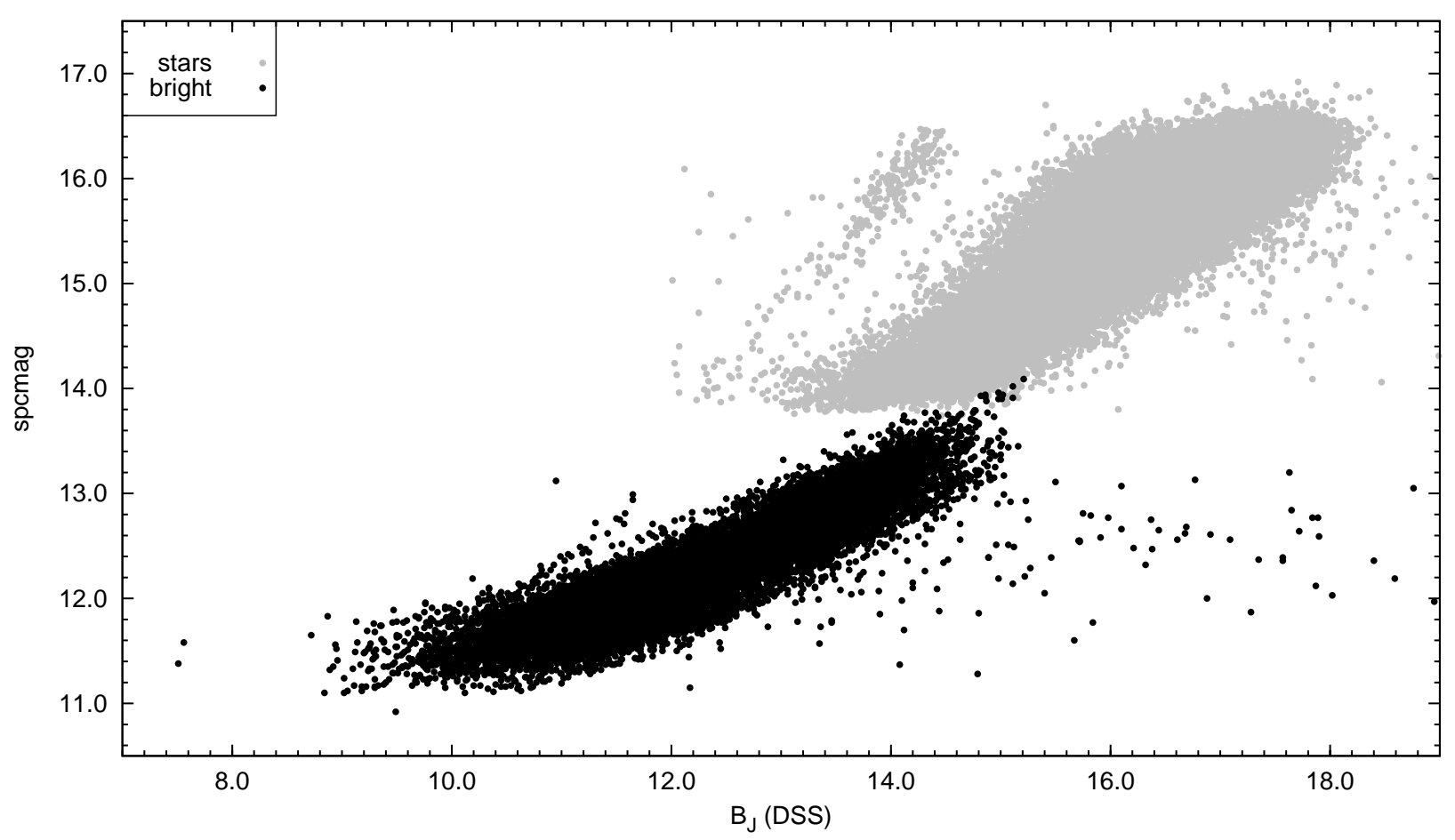

Figura 5.3: Comportamento da magnitude B em função da magnitude interna spcmag.

O comportamento da magnitude interna spcmag em função da magnitude $\mathrm{B}_{\mathrm{J}}$, para as fontes saturadas e não saturadas, é exibido na Figura 5.3. Nota-se que, de fato, os dois tipos de fonte não compartilham o mesmo intervalo das grandezas apresentadas, o que também caracteriza as diferenças intrínsecas entre eles. Assim, é feita a hipótese de que, 
para um dado intervalo de spcmag, as fontes brilhantes apresentarão o mesmo nível de saturação nos índices de linha. Dessa forma, para corrigir tal efeito, deve-se comparar a distribuição dos índices em cada intervalo com a distribuição para as fontes não saturadas.

A amostra contendo as fontes brilhantes (com 18532 objetos) foi dividida em nove partes segundo os valores de spcmag. As distribuições normalizadas para cada parte foram comparadas com a distribuição normalizada das fontes não saturadas (contendo todos os 62311 objetos classificados como stars). As Figuras 5.4 e 5.5 mostram, respectivamente, as distribuições para os índices GPE e EGP. Os histogramas em preto representam a distribuição das fontes não saturadas. Os histogramas em verde representam a distribuição dos índices para cada uma das nove divisões, cujo número de objetos, intervalo e valor médio de spcmag são mostrados em cada painel. Os histogramas em vermelho mostram as distribuições corrigidas, determinadas segundo o critério explicado a seguir.

Para uma dada distribuição, $\mathrm{GPE}_{\mathrm{I}}, \mathrm{EGP}_{\mathrm{I}}, \mathrm{GPE}_{\mathrm{F}}$ e $\mathrm{EGP}_{\mathrm{F}}$ são, respectivamente, os valores máximos das distribuições saturadas (I) e não saturadas (F) dos índices GPE e EGP. Assim, as correções de saturação para cada divisão em spcmag são quantificadas pelo deslocamento horizontal de cada distribuição, de forma que os valores máximos das distribuições coincidam. Porém, foi feito um teste para garantir que estes deslocamentos ( $\Delta$ GPE e $\Delta$ EGP nas Figuras 5.4 e 5.5) são aqueles que melhor representam as correções. Definiu-se então uma "medida de equivalência" $q$ para cada um dos índices de linha:

$$
q_{\mathrm{GPE}}=\sum\left(f_{\mathrm{GPE}_{\mathrm{e}}}-f_{\mathrm{GPE}_{\mathrm{o}}}\right)^{2} \text { e } q_{\mathrm{EGP}}=\sum\left(f_{\mathrm{EGP}_{\mathrm{e}}}-f_{\mathrm{EGP}_{\mathrm{o}}}\right)^{2}
$$

onde $f_{\mathrm{GPE}_{\mathrm{e}}}$ e $f_{\mathrm{GPE}_{\mathrm{o}}}$ são, respectivamente, os valores de frequência esperada (relacionada às fontes não saturadas - histogramas em preto) e de frequência observada (para o conjunto de fontes saturadas - histogramas em verde) para um dado valor de GPE. Assim, os valores de $q$ representam a soma dos quadrados das diferenças entre dois histogramas. A seguir, calcula-se este parâmetro para uma série de valores de deslocamento, dentro do intervalo $\left[\mathrm{GPE}_{\mathrm{I}}, \mathrm{GPE}_{\mathrm{F}}\right]$. O tamanho dos passos utilizados é dado pela resolução dos histogramas (2.0 ̊ para GPE e 0.030 mag para EGP). O valor final de $\triangle$ GPE é aquele associado ao menor valor de $q_{\mathrm{GPE}}$. $\mathrm{O}$ mesmo procedimento se aplica para as correções do índice EGP. Como resultado, os deslocamentos associados aos valores mínimos de $q$, coincidiram com os valores esperados para todas as distribuições exceto aquelas onde spcmag >12.75 mag. 


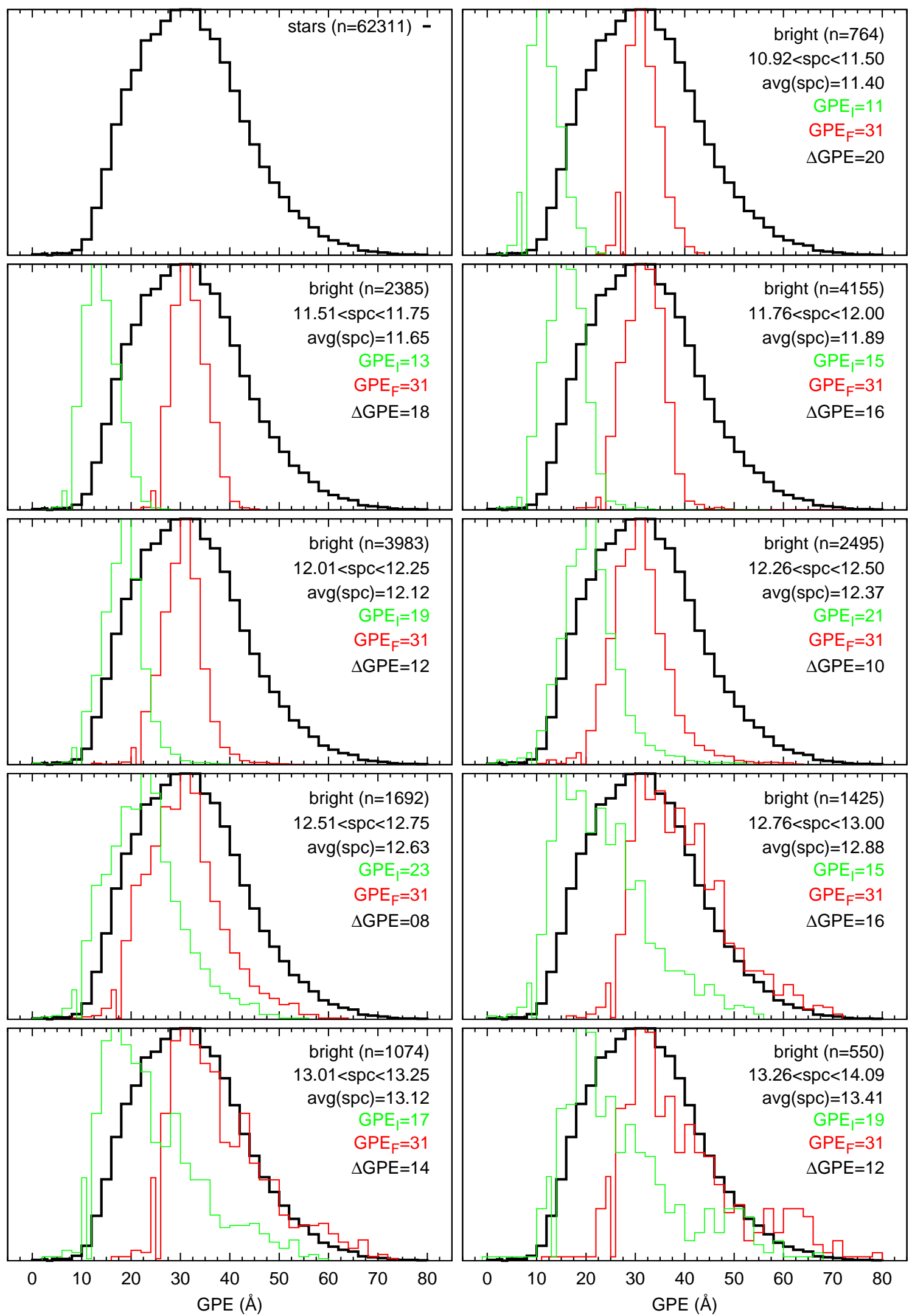

Figura 5.4: Histogramas normalizados para correção do índice GPE, divididos em intervalos de spcmag. 


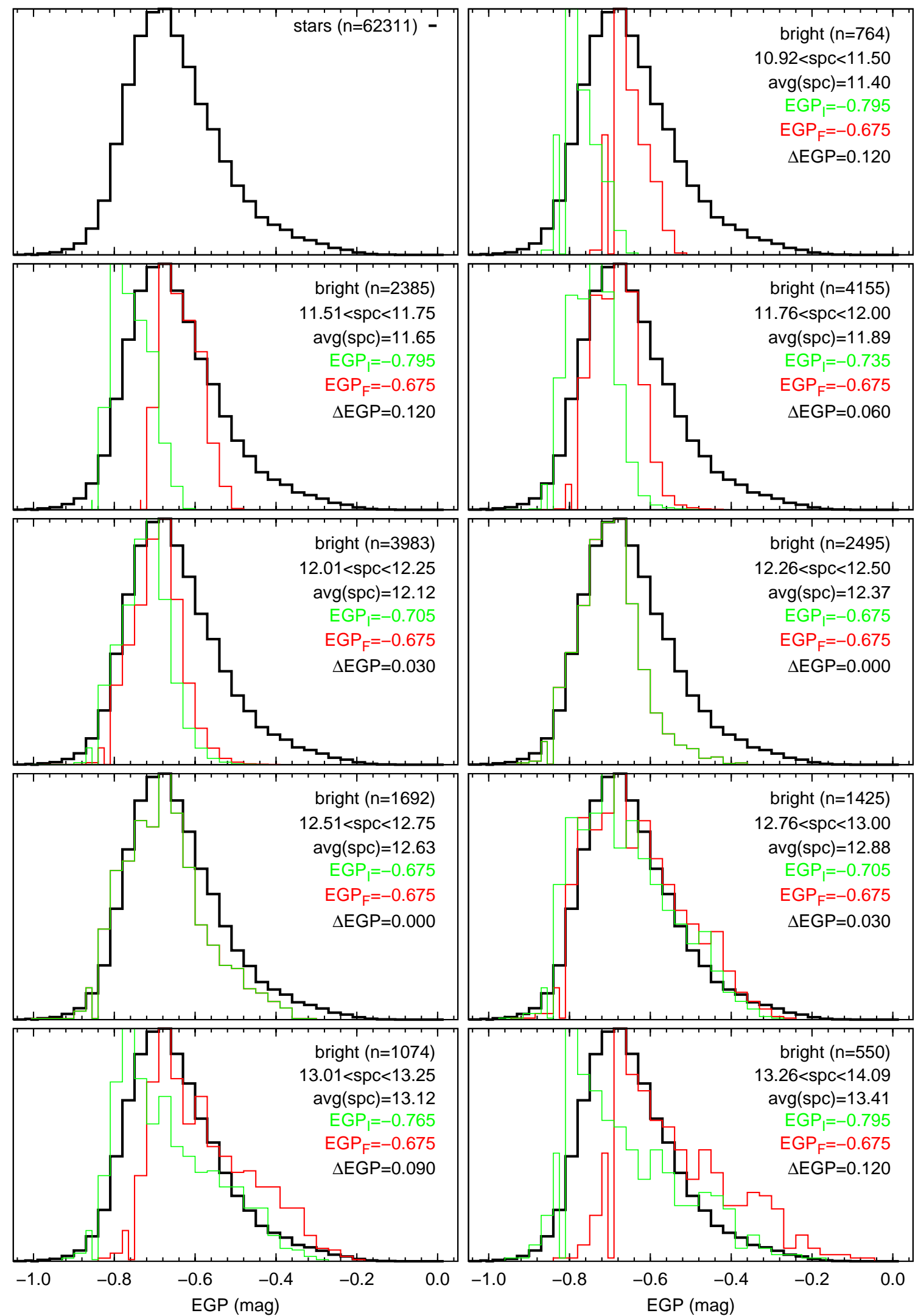

Figura 5.5: Histogramas normalizados para correção do índice EGP, divididos em intervalos de spcmag. 
É interessante notar que os deslocamentos das distribuições para o índice EGP são proporcionalmente menores do que os valores para GPE, sendo que para o intervalo $12.26<\operatorname{spcmag}(\mathrm{mag})<12.75$ não existe deslocamento em EGP. Além disso, os valores dos deslocamentos tendem a diminuir com o aumento de spcmag até $\sim 12.75$ mag. A partir deste ponto os valores voltam a aumentar. Ao analisar os histogramas das Figuras 5.4 e 5.5, pode-se concluir que esse aumento (para spcmag > $12.75 \mathrm{mag}$ ) atribui-se principalmente à forma das distribuições que, por conterem objetos mais fracos, apresentam valores mais dispersos para os índices de linha. Com efeito, foi feita a opção de não levar em conta os deslocamentos calculados para as três últimas distribuições mostradas nas Figuras 5.4 e 5.5. Para estas (paineis 7, 8 e 9 das figuras) foram utilizados os valores calculados de $\Delta$ GPE e $\Delta$ EGP para a distribuição imediatamente anterior a elas (painel 6 das figuras). A Tabela 5.1 sumariza os resultados encontrados:

Tabela 5.1 - Parâmetros adotados para as correções de saturação.

\begin{tabular}{c|c|ccc|ccc|ccc}
\hline \multicolumn{3}{c}{ spcmag(mag) } & \multicolumn{3}{c}{ GPE $(\AA)$} & \multicolumn{3}{c}{ EGP $(\mathrm{mag})$} \\
\hline$\#$ & $n$ & mínimo & máximo & médio & GPE $_{\mathrm{I}}$ & $\mathrm{GPE}_{\mathrm{F}}$ & $\Delta \mathrm{GPE}$ & $\mathrm{EGP}_{\mathrm{I}}$ & $\mathrm{EGP}_{\mathrm{F}}$ & $\Delta \mathrm{EGP}$ \\
\hline 1 & 764 & 10.92 & 11.50 & 11.40 & 11 & 31 & 20 & -0.795 & -0.675 & 0.12 \\
2 & 2385 & 11.51 & 11.75 & 11.65 & 13 & 31 & 18 & -0.795 & -0.675 & 0.12 \\
3 & 4155 & 11.76 & 12.00 & 11.89 & 15 & 31 & 16 & -0.735 & -0.675 & 0.06 \\
4 & 3983 & 12.01 & 12.25 & 12.12 & 19 & 31 & 12 & -0.705 & -0.675 & 0.03 \\
5 & 2495 & 12.26 & 12.50 & 12.37 & 21 & 31 & 10 & -0.675 & -0.675 & 0.00 \\
6 & 1692 & 12.51 & 12.75 & 12.63 & 23 & 31 & 8 & -0.675 & -0.675 & 0.00 \\
7 & 1425 & 12.76 & 13.00 & 12.88 & 15 & 31 & $8^{\mathrm{a}}$ & -0.705 & -0.675 & $0.00^{\mathrm{a}}$ \\
8 & 1074 & 13.01 & 13.25 & 13.12 & 17 & 31 & $8^{\mathrm{a}}$ & -0.765 & -0.675 & $0.00^{\mathrm{a}}$ \\
9 & 550 & 13.26 & 14.09 & 13.41 & 19 & 31 & $8^{\mathrm{a}}$ & -0.795 & -0.675 & $0.00^{\mathrm{a}}$ \\
\hline
\end{tabular}

${ }^{\text {a }}$ Valores adotados a partir dos critérios explicados no texto.

Uma vez encontrados os deslocamentos necessários para corrigir os índices de linha em cada intervalo de spcmag, procedeu-se com a determinação das funções de correção para GPE e EGP. Para tanto, foram feitos ajustes polinomiais para os pares de dados $[\operatorname{avg}(\mathrm{spc}), \Delta \mathrm{GPE}] \mathrm{e}[\operatorname{avg}(\mathrm{spc}), \Delta \mathrm{EGP}]$, como pode ser visto na Figura 5.6. 


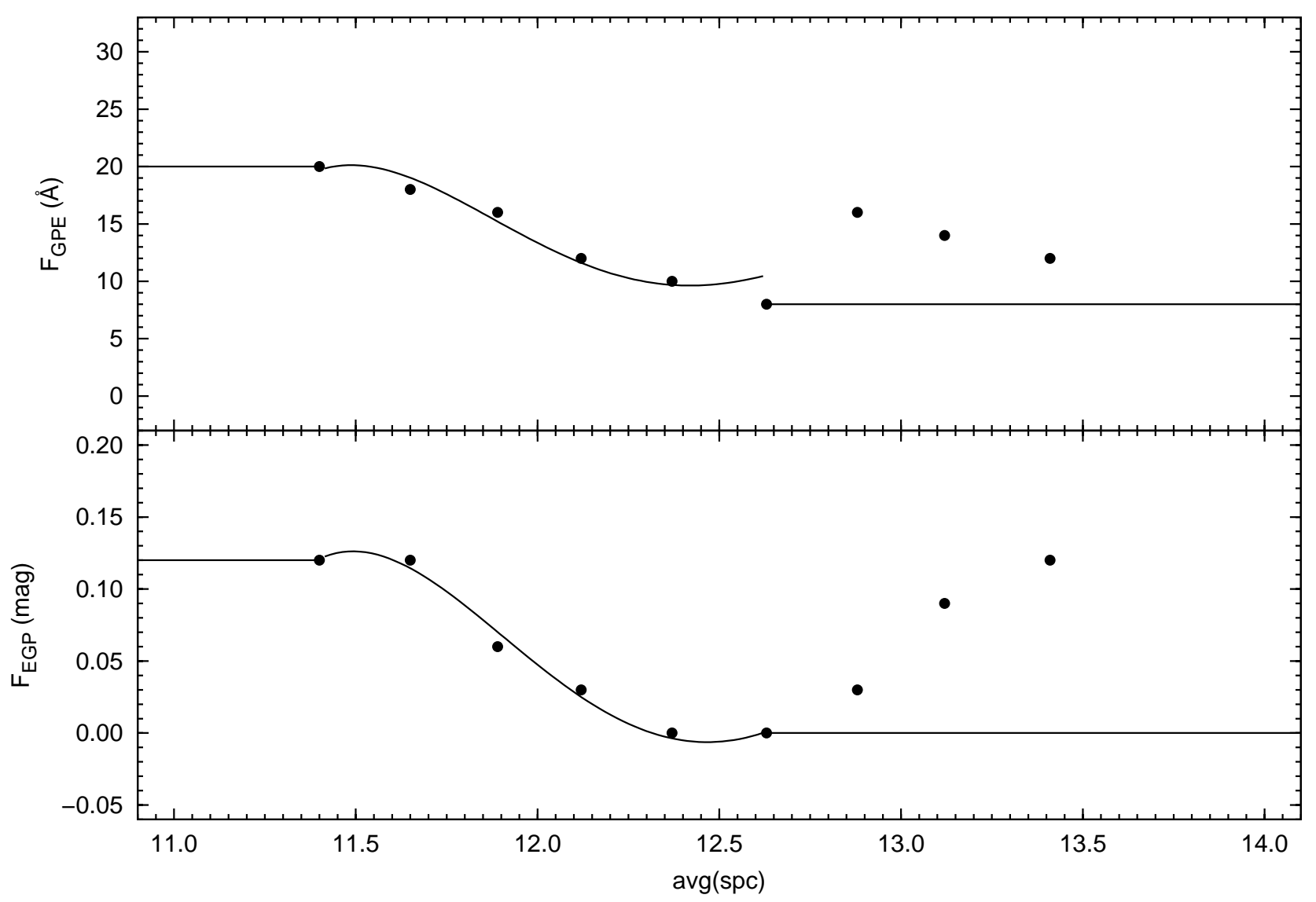

Figura 5.6: Ajustes polinomiais para as correções de saturação dos índices de linha.

Foram feitas algumas tentativas de ajustar os dados disponíveis com polinômios desde grau 1 até 5 , sendo que os erros associados aos parâmetros mostraram-se menores para o ajuste de grau 4. No entanto, mesmo estes ajustes não se mostraram satisfatórios para os intervalos spcmag $<11.40$, onde as funções ajustadas decrescem rapidamente, e spcmag $>12.63$, que mostra um aumento inesperado nos valores dos deslocamentos. Assim, as correções aplicadas aos objetos com spcmag < 11.40 são aquelas associadas aos menores valores de $\operatorname{avg}(\mathrm{spc}): 20 \AA$ para GPE e $0.12 \mathrm{mag}$ para EGP. Para os objetos que apresentam spcmag > 12.63, utiliza-se 8̊ para GPE e para EGP não são feitas correções (ver discussão acima e Tabela 5.1). A equação resultante do ajuste para o índice GPE é dada por:

$$
\begin{aligned}
\mathrm{F}_{\mathrm{GPE}}=-371276+ & 120767 \cdot[\operatorname{avg}(\mathrm{spc})]-14707.10 \cdot[\operatorname{avg}(\mathrm{spc})]^{2} \\
+ & 794.77 \cdot[\operatorname{avg}(\mathrm{spc})]^{3}-16.08 \cdot[\operatorname{avg}(\mathrm{spc})]^{4},
\end{aligned}
$$

onde $[\operatorname{avg}(\mathrm{spc})]$ são os valores médios de cada distribuição corrigida, que são substituídos 
pelos valores de spcmag para os calculos dos valores finais dos índices. Então, os critérios de correção de saturação do índice GPE para as fontes brilhantes são:

$$
\Delta \mathrm{GPE}(\AA)=\left\{\begin{array}{rrr}
20, & \text { spcmag } & <11.40 \\
\mathrm{~F}_{\mathrm{GPE}}(\text { spcmag }), & 11.40 \leq \text { spcmag } & \leq 12.63 \\
8, & \text { spcmag } & >12.63
\end{array}\right.
$$

Da mesma forma, para o índice EGP tem-se:

$$
\begin{array}{r}
\mathrm{F}_{\mathrm{EGP}}=-3527.32+1139.05 \cdot[\operatorname{avg}(\mathrm{spc})]-137.65 \cdot[\operatorname{avg}(\mathrm{spc})]^{2} \\
+7.38 \cdot[\operatorname{avg}(\mathrm{spc})]^{3}-0.15 \cdot[\operatorname{avg}(\mathrm{spc})]^{4},
\end{array}
$$

sendo os critérios finais para a correção de saturação:

$$
\Delta \mathrm{EGP}(\mathrm{mag})=\left\{\begin{aligned}
0.12, & \text { spcmag } & <11.40 \\
\mathrm{~F}_{\mathrm{EGP}}(\text { spcmag }), & 11.40 \leq \text { spcmag } & \leq 12.63 \\
0, & \text { spcmag } & >12.63
\end{aligned}\right.
$$

Uma vez aplicados os conjuntos de correções de saturação mostrados acima para as fontes brilhantes, foi possível refazer a distribuição dos índices de linha para os 80843 objetos da segunda subamostra, cujos resultados estão exibidos na Figura 5.7. Além disso, os conjuntos de critérios de correção dos índices GPE e EGP determinados nesta seção foram inseridos na base de dados do HES, com o objetivo de incluir as fontes brilhantes em futuras seleções e buscas por estrelas CEMP.

Ao inspecionar a Figura 5.7, nota-se claramente o deslocamento da distribuição das fontes brilhantes em relação àquela mostrada na Figura 5.2. Além desse deslocamento, é possível perceber que as distribuições corrigidas ocupam um intervalo menor dos índices de linha, devido ao fato das correções serem quantificadas a partir dos valores de spcmag. Dessa forma, torna-se possível aplicar um mesmo conjunto de restrições para os índices de linha tanto para as fontes não saturadas quanto para as fontes brilhantes. 

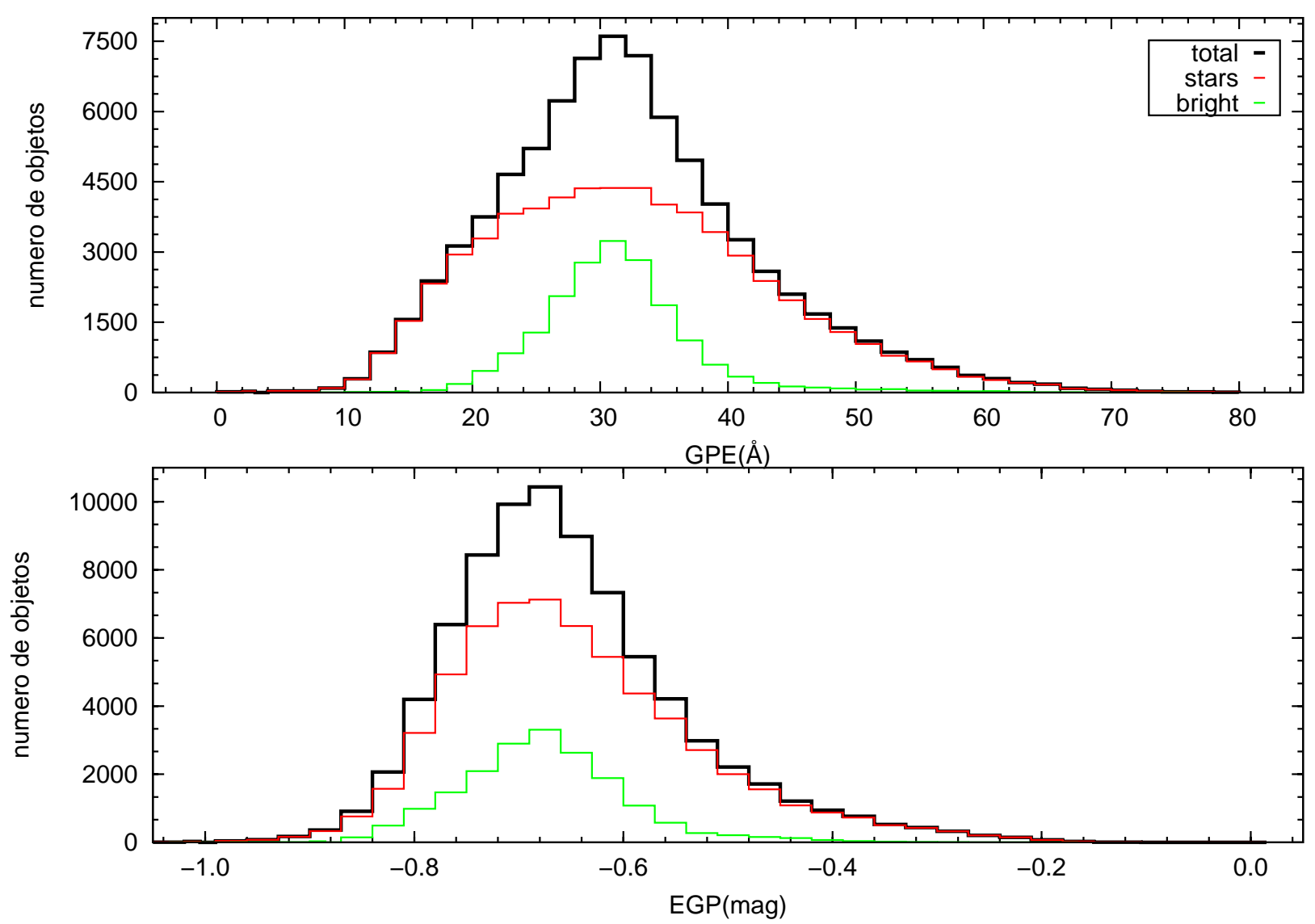

Figura 5.7: Distribuição dos índices de linha corrigidos da segunda subamostra.

\subsection{Critério de seleção baseado nos índices GPE e EGP}

Uma vez que os índices de linha encontram-se em uma escala comum para os dois tipos de fonte presentes na segunda subamostra, torna-se possível aplicar apenas um conjunto de restrições para selecionar candidatas a estrelas CEMP. A vantagem de se trabalhar com os dois índices na mesma região do espectro reside no fato de que eventuais erros, por exemplo, no cálculo do contínuo, não afetarão os dois valores, pois os índices GPE e EGP foram calculados de formas distintas. Este procedimento é semelhante àquele adotado por Christlieb et al. (2001), que utilizaram um conjunto de índices para localizar as estrelas ricas em carbono (ver Tabela 4.6 desta tese). Também, pelo fato dos índices serem diretamente proporcionais (como visto no Capítulo 2 desta tese), desvios consideráveis dessa relação podem ser interpretados como erros e podem ser separados mais facilmente do restante da amostra. Assim, obtem-se um maior grau de confiança na seleção de objetos, o que diminui o tempo da inspeção visual. 
A Figura 5.8 mostra a distribuição de GPE em função do índice de cor $(\mathrm{J}-\mathrm{K})_{0}$ para os 80843 objetos da segunda subamostra e também para as contrapartidas em baixa resolução dos espectros das estrelas presentes no estudo de Aoki et al. (2007). De forma distinta daquela mostrada na Seção 4.1.1, onde foram selecionados apenas objetos com GPE > $30 \AA$, a Figura 5.8 exibe restrições tanto em GPE quanto em EGP $(31 \AA$ e -0.675 , respectivamente). Estes limites são os valores mais frequentes das distribuições dos índices, como mostrado nas Figuras 5.4 e 5.5.

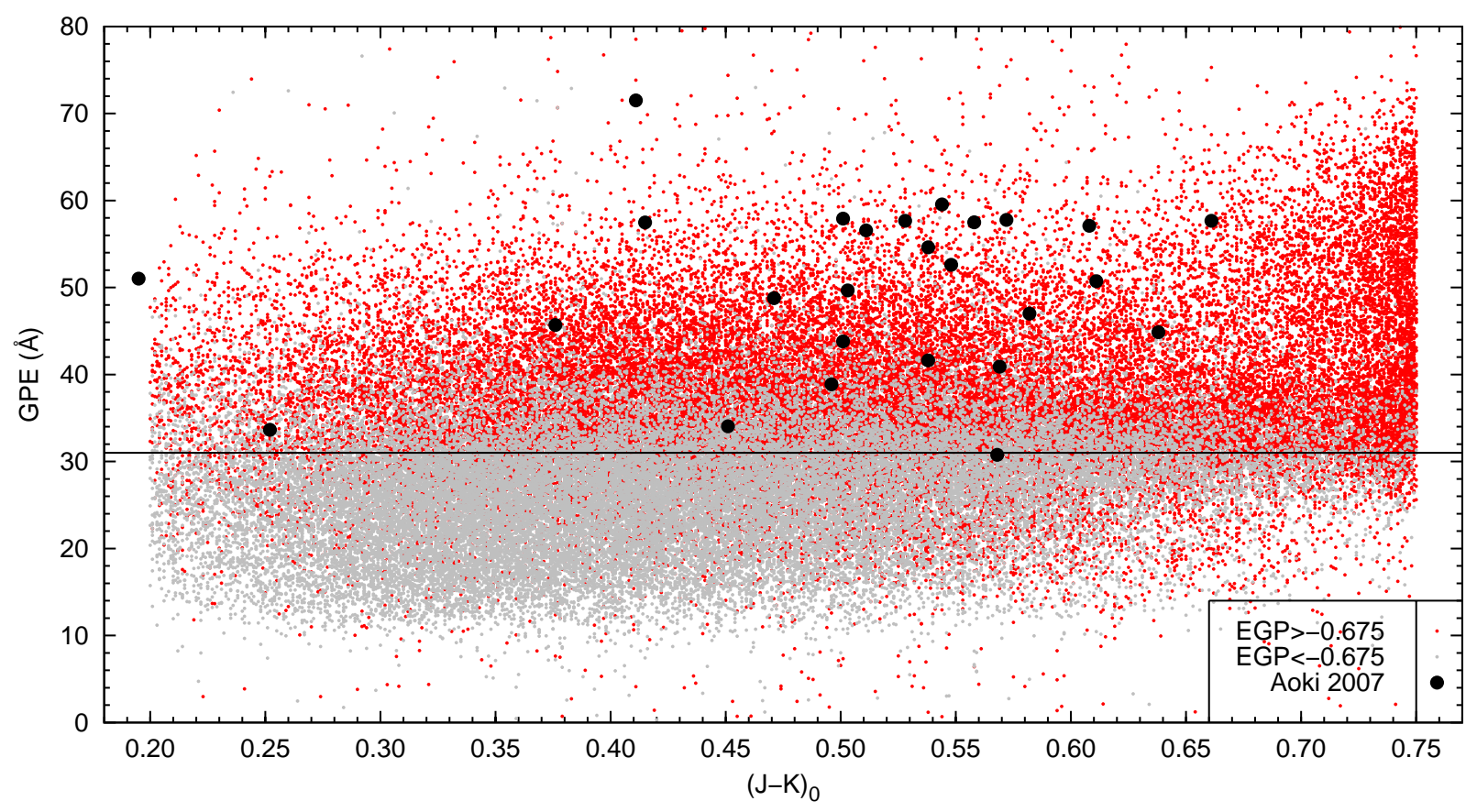

Figura 5.8: Comportamento do índice GPE em função de $(\mathrm{J}-\mathrm{K})_{0}$ para os dados da segunda subamostra, separados em dois intervalos de EGP. Os círculos pretos mostram os dados de Aoki et al. (2007).

No total, a segunda subamostra contém 41454 objetos com GPE > 31 A e 42823 objetos com EGP > -0.675, sendo que 31889 satisfazem ambas as condições. É interessante notar que na primeira subamostra uma fração de 7\% foi selecionada após a restrição em GPE. Já para a segunda subamostra, essa fração é de $\sim 51 \%$, o que confirma a eficiência das restrições aplicadas à base de dados do HES (Seção 5.1) e das correções de saturação dos índices de linha (Seção 5.2). Dessa forma, pode-se restringir ainda mais a subamostra, com o intuito de selecionar uma fração maior de estrelas CEMP. É possível notar um acúmulo de objetos com $(\mathrm{J}-\mathrm{K})_{0}>0.7$ na Figura 5.8, que foram pré-selecionados devido 
ao método menos restritivo de seleção no plano $\mathrm{KP}$ vs. $(\mathrm{J}-\mathrm{K})_{0}$, que utiliza uma função constante de $[\mathrm{Fe} / \mathrm{H}]=-2.0$. Os trabalhos de Christlieb et al. (2008) e Schörck et al. (2009) utilizam como restrição uma função constante de $[\mathrm{Fe} / \mathrm{H}]=-2.5$, que seleciona com sucesso estrelas com metalicidades menores. Visto que um dos objetivos deste trabalho é obter dados de estrelas em um grande intervalo de metalicidade, restringir a amostra em metalicidade não é ideal. Dessa forma, optou-se por impor $(\mathrm{J}-\mathrm{K})_{0}<0.7$, que também pode ser justificado pelo fato de que, para estrelas mais frias, a precisão das determinações de metalicidade a partir de espectros com resolução moderada são limitadas tanto pela falta de estrelas de calibração quanto pela baixa intensidade da linha $\mathrm{H} \delta$, utilizada como indicador de temperatura (Schörck et al., 2009).

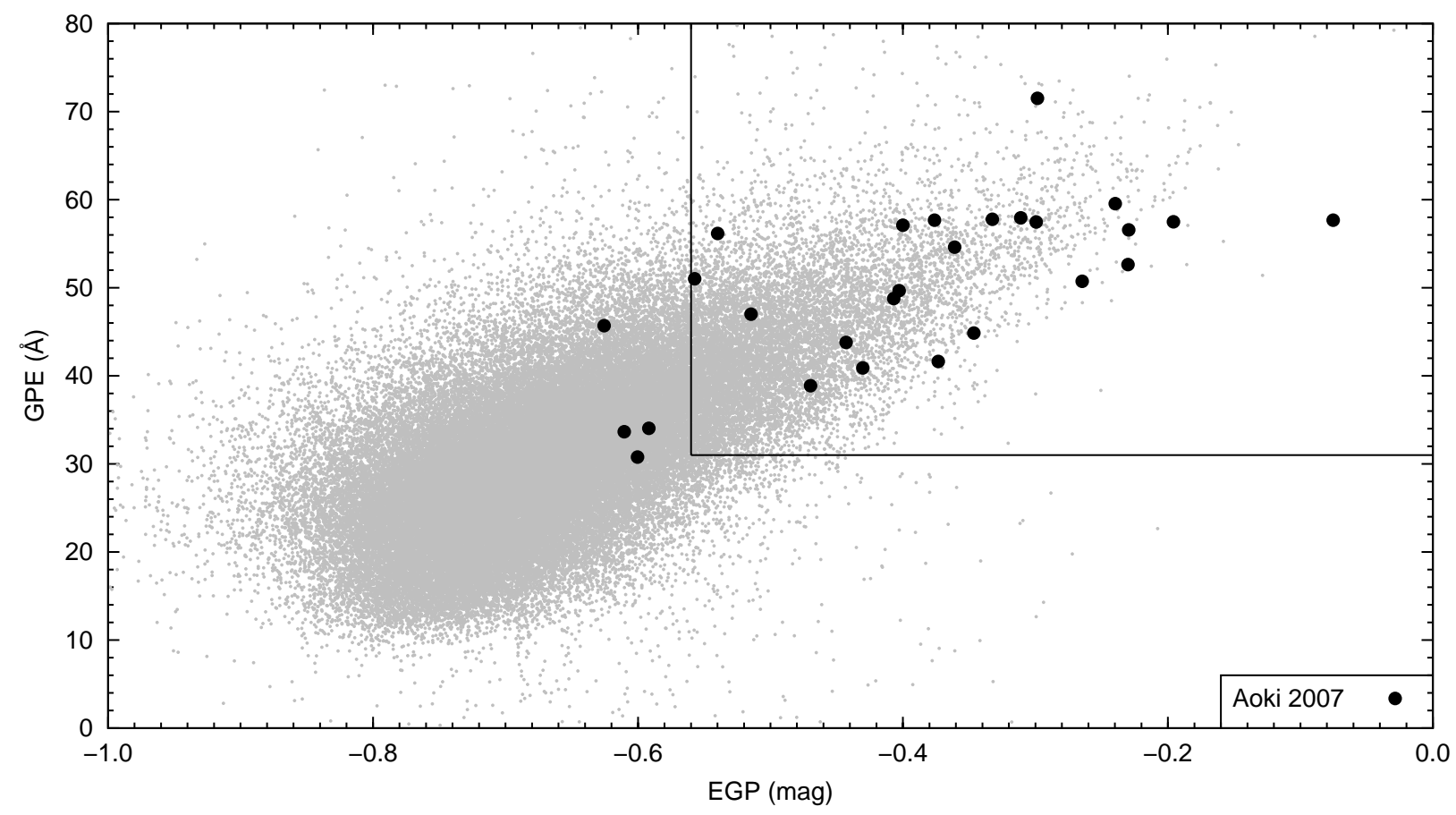

Figura 5.9: Distribuição dos índices de linha GPE e EGP para os dados da segunda subamostra. As linhas pretas mostram os limites definidos para a inspeção visual das candidatas a estrelas CEMP. Os círculos pretos mostram os dados de Aoki et al. (2007).

O comportamento dos índices GPE e EGP para os objetos da segunda subamostra com $(\mathrm{J}-\mathrm{K})_{0}<0.7$ é exibido na Figura 5.9, juntamente aos dados referentes às estrelas do trabalho de Aoki et al. (2007). As duas linhas cheias mostram as restrições impostas aos índices. No caso do EGP, 4 estrelas do trabalho de Aoki et al. (2007) foram excluídas dos critérios de seleção. De forma análoga àquela adotada no Capítulo 4 desta tese, os 
valores adotados são um compromisso entre o número de objetos que seriam sujeitos à inspeção visual e a possível fração de candidatas a estrelas CEMP encontradas. Visto que dos 27083 objetos da segunda amostra com GPE > 31 A, EGP > -0.675 e $(\mathrm{J}-\mathrm{K})_{0}>0.7$, 16767 encontram-se entre $-0.675<$ EGP $<-0.560$, foi feita a opção de não selecionar este último intervalo de EGP.

Pelo exposto acima, as restrições finais aplicadas aos índices de linha corrigidos e ao índice de cor $(\mathrm{J}-\mathrm{K})_{0}$ dos objetos da segunda subamostra foram: (i) GPE > $31 \AA$; (ii) EGP $>-0.56$ mag e; (iii) $(\mathrm{J}-\mathrm{K})_{0}<0.7$ mag. Este conjunto de restrições selecionou 10314 objetos, que foram sujeitos à inspeção visual, como mostrado na próxima seção.

\subsection{Inspeção Visual}

A inspeção visual, dos objetos selecionados da segunda subamostra segundo as restrições apresentadas, procedeu seguindo a mesma metodologia daquela apresentada na Seção 4.1.2. Mesmo com a inclusão das fontes brilhantes, os objetos foram classificados a partir das mesmas prescrições descritas na Tabela 4.2. De modo semelhante à primeira subamostra, a distribuição das classes atribuídas via inspeção visual da segunda subamostra foi dominada por objetos com a linha K do Ca II intensa ( $m p c c$ ). Esse fato pode ser justificado pela distribuição cumulativa de metalicidade (ver, por exemplo, Beers e Christlieb, 2005) que, para uma dada amostra de estrelas de campo do halo da Galáxia, mostra um aumento na fração relativa de estrelas com o aumento da metalicidade. No entanto, dados os conjuntos distintos de restrições adotados (incluindo a utilização do índice EGP), esperava-se que a distribuição dos objetos entre as demais classes apresentadas fosse direfente. A Tabela 5.2 exibe a distribuição dos 10314 espectros inspecionados:

Tabela 5.2 - Distribuição das candidatas selecionadas via inspeção visual.

\begin{tabular}{cc|cc|cc}
\hline \hline Classe & $\mathrm{n}^{\mathrm{o}}$ de objetos & Classe & $\mathrm{n}^{\mathrm{o}}$ de objetos & Classe & $\mathrm{n}^{\mathrm{o}}$ de objetos \\
\hline mpca & 55 & fhlc & 317 & nois & 2320 \\
mpcb & 452 & unid & 224 & ovl & 1038 \\
mpcc & 5184 & hbab & 0 & art & 721 \\
& & habs & 3 & & \\
\hline
\end{tabular}


Nota-se um elevado número de objetos com baixa razão sinal/ruído. Isto ocorre pelo fato de não ter sido feita nenhuma restrição nos valores de magnitude dos objetos, com o objetivo de selecionar estrelas mais distantes e/ou menos luminosas, e aumentar a probabilidade de amostrar, por exemplo, o halo externo da Galáxia. Ademais, as classes mpca, mpcb e fhlc obtiveram um número satisfatório de candidatas, proporcionalmente maior do que aquele determinado para a primeira subamostra (ver Tabela 4.3), o que significa que as frações de estrelas com $[\mathrm{Fe} / \mathrm{H}]<-2.0$ deve aumentar em relação à inspeção anterior.

Outra observação importante é a de que foram encontrados apenas três objetos com linhas intensas de hidrogênio na amostra, pertencentes à classe habs. Isso se deve, em parte, à restrição $(\mathrm{J}-\mathrm{K})_{0}>0.2$, mas principalmente devido à combinação dos índices de linha GPE e EGP, já que os valores de EGP para esses objetos tendem a ser menores do que aqueles para objetos mais frios, pois estes últimos apresentam um contraste maior entre a banda da linha e o fluxo integrado na região do vermelho.

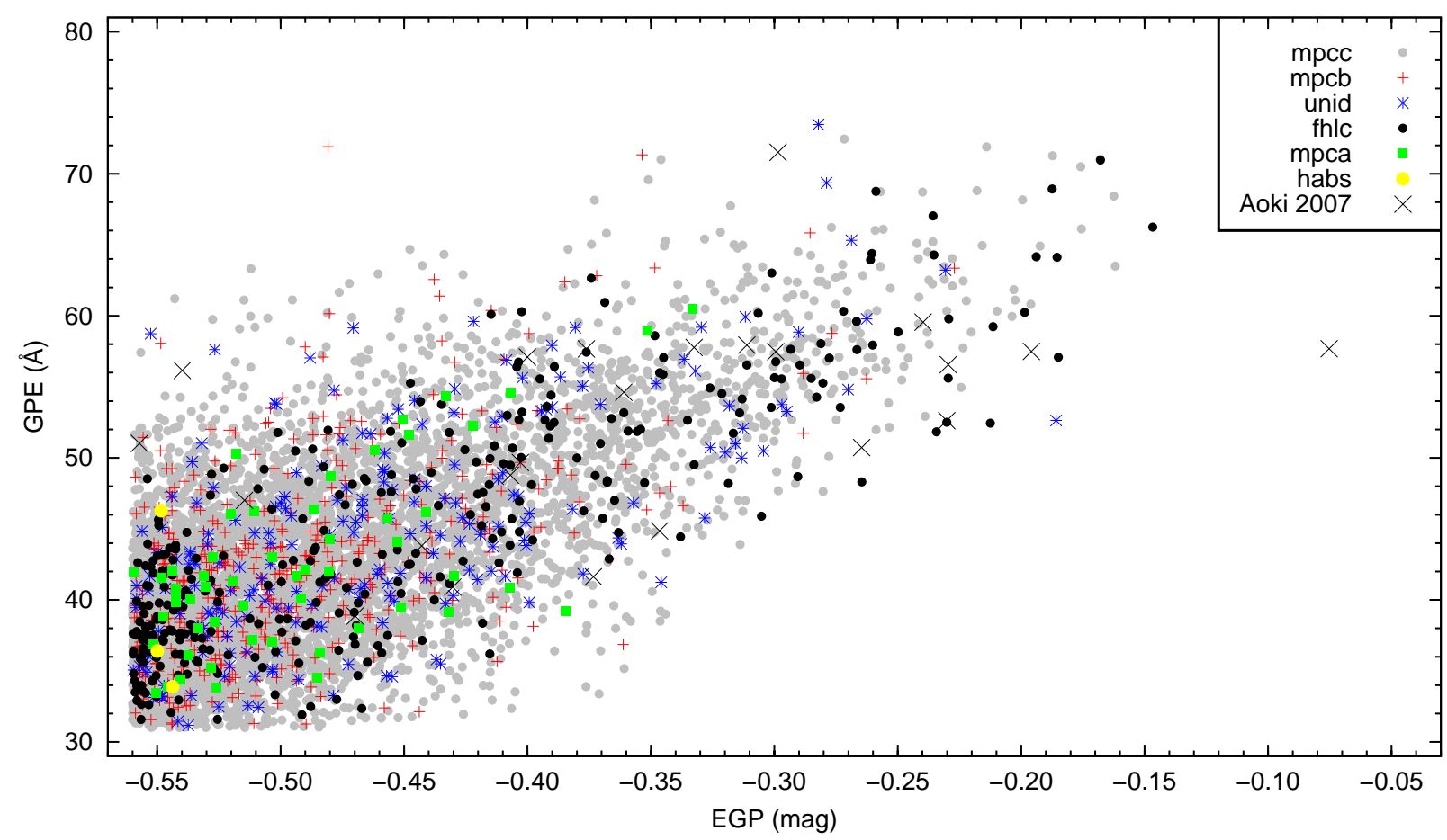

Figura 5.10: Comportamento dos índices de linha para os objetos inspecionados da segunda subamostra, divididos de acordo com as classes da Tabela 4.3.

A Figura 5.10 mostra a distribuição dos índices de linha para as estrelas inspecionadas, excluindo as classes nois, ovl e art. As demais classes apresentam-se distribuídas homo- 
geneamente na região preenchida pelos objetos, com exceção das estrelas de classe mpca e $m p c b$, que se concentram em uma região com menores valores dos índices. Os três objetos da classe habs encontram-se próximos aos limites inferiores dos índices de linha. Em adição, ao comparar a Figura 5.10 com a região delimitada da Figura 5.9, percebe-se que existe uma tendência clara entre os índices, e que objetos distantes dessa tendência (por exemplo, com valores de GPE $<40 \AA$ e EGP $>0.3 \mathrm{mag}$ ) possuem espectros associados às classes excluídas da figura, que contêm valores espúrios para os índices.

As estrelas com a linha K do Ca II intensa ( $m p c c$ ) encontram-se distribuídas por quase todo o plano delimitado pelos índices de linha. Assim, conclui-se que estas apresentarão uma variedade de valores de $[\mathrm{C} / \mathrm{Fe}]$. Nesse mesmo contexto, elas também encontrar-se-ão em um amplo intervalo de metalicidades, uma vez que até mesmo estrelas gigantes frias com $[\mathrm{Fe} / \mathrm{H}] \sim-2.0$ apresentam linhas de cálcio intensas (Schörck et al., 2009).

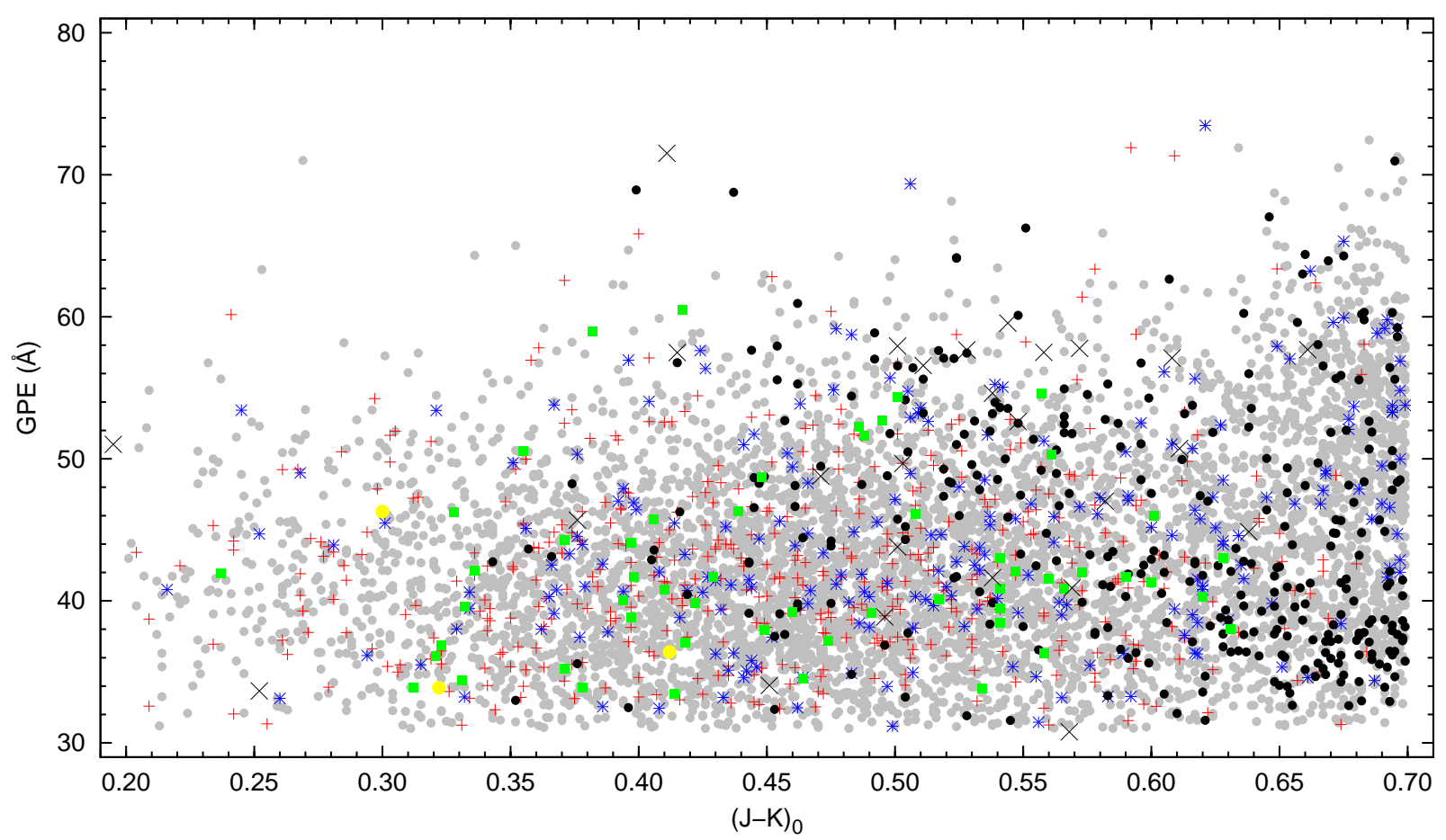

Figura 5.11: Comportamento do índice GPE em função da cor $(\mathrm{J}-\mathrm{K})_{0}$. Os símbolos utilizados são os mesmos exibidos na Figura 5.10.

O comportamento do índice de cor $(\mathrm{J}-\mathrm{K})_{0}$ em função de GPE é exibido na Figura 5.11. Nota-se um acúmulo dos objetos com linhas moleculares de carbono intensas (fhlc) com o aumento de $(\mathrm{J}-\mathrm{K})_{0}$. Essa é uma consequência direta da relação entre a temperatura 
dos objetos e a presença de bandas moleculares no espectro. Além disso, a fração de estrelas com temperaturas mais elevadas (habs e $h b a b)$, na região $(\mathrm{J}-\mathrm{K})_{0} \lesssim 0.3$, diminui em relação àquela apresentada na primeira subamostra (ver Figura 4.5). Assim, conclui-se que a combinação de GPE e EGP é eficiente tanto em filtrar contaminações na amostra quanto em selecionar candidatas a estrelas CEMP.

Por fim, foi feita uma busca na literatura por objetos da segunda subamostra que já tenham sido identificados por outros estudos. Dentre as 6235 estrelas pertencentes às classes exibidas nas Figuras 5.10 e 5.11, 5454 não constam em nenhum estudo até o momento. Estes objetos, juntamente com as 669 candidatas encontradas com a metodologia apresentada no Capítulo 4, são listados no Apêndice C desta tese, com valores de GPE e classificação atribuída via inspeção visual.

\subsection{Discussão}

Neste capítulo foi apresentado um método de busca por estrelas CEMP baseado na combinação dos índices de linha GPE e EGP, desenvolvidos neste trabalho (ver Seções 2.2 e 2.3, respectivamente). De forma alternativa àquela apresentada no Capítulo 4, as seleções nos planos índice de cor vs. KP foram feitas antes da imposição de restrições nos índices da banda $\mathrm{G}$, resultando em um número maior de candidatas a estrelas pobres em metais na subamostra.

A inclusão de fontes brilhantes na segunda subamostra de dados do HES, sujeitas à saturação, resultou no desenvolvimento de uma metodologia de correção dos índices de linha, baseada em características fotométricas das placas fotográficas do survey. Após aplicar as correções à base de dados, o comportamento dos índices de linha foi comparado com os valores de índice para as contrapartidas em baixa resolução das estrelas CEMP de Aoki et al. (2007), com o intuito de localizar a região de maior concentração de estrelas ricas em carbono no plano GPE vs. EGP. Estabelecido um compromisso entre as restrições para os índices de linha e o número de candidatas para inspeção visual, foram selecionados 10314 objetos que apresentam GPE $>30 \AA$, EGP $>-0.56$ mag e $(\mathrm{J}-\mathrm{K})_{0}<0.7$ mag.

As correções de saturação, aliadas às restrições impostas para os índices de linha, dobraram o número de fontes brilhantes presentes na inspeção visual. Além disso, este método alternativo selecionou uma fração maior de estrelas com bandas moleculares intensas de 
carbono $(f h l c)$, ou seja, a utilização conjunta dos índices engloba o método de seleção proposto por Christlieb et al. (2001), além de selecionar também as estrelas ricas em carbono mais quentes. Finalmente, a combinação de GPE e EGP excluiu com sucesso objetos com linhas intensas de hidrogênio, que foram selecionados como contaminação na primeira subamostra. A Tabela 5.3 apresenta as frações efetivas das duas subamostras, onde foram excluídas as classes nois, ovl e art.

Tabela 5.3 - Comparação dos resultados das inspeções visuais.

\begin{tabular}{c|cc|cc}
\hline \hline & \multicolumn{2}{|c|}{ primeira subamostra } & \multicolumn{2}{c}{ segunda subamostra } \\
\hline Classe & $n$ & fração & $n$ & fração \\
\hline mpca & 4 & $0.07 \%$ & 55 & $0.88 \%$ \\
mpcb & 293 & $5.32 \%$ & 452 & $7.25 \%$ \\
mpcc & 4711 & $85.58 \%$ & 5184 & $83.14 \%$ \\
fhlc & 31 & $0.56 \%$ & 317 & $5.08 \%$ \\
unid & 155 & $2.81 \%$ & 224 & $3.60 \%$ \\
hbab & 235 & $4.28 \%$ & 0 & $0.00 \%$ \\
habs & 76 & $1.38 \%$ & 3 & $0.05 \%$ \\
\hline Total & 5505 & $100 \%$ & 6235 & $100 \%$ \\
\hline
\end{tabular}

Alguns pontos importantes podem ser levantados acerca das frações exibidas na Tabela 5.3: (i) as amostras "limpas" possuem um número próximo de candidatas, porém a segunda subamostra não possui restrições em magnitude, o que ajuda a diminuir o viés para estrelas mais brilhantes e/ou mais próximas; (ii) as frações associadas à classe mpcc para as duas subamostras são muito próximas, o que sugere que as estrelas dessa classe estão igualmente distribuídas no espaço de parâmetros associado às inspeções visuais; (iii) as frações para as classes mpca e fhlc cresceram uma ordem de grandeza para a segunda subamostra, e formam um subconjunto com grande probabilidade de ocorrência de estrelas $\operatorname{EMP}([\mathrm{Fe} / \mathrm{H}]<-3.0)$ ricas em carbono; (iv) os objetos com linhas intensas de hidrogênio (classes habs e hbab), que foram considerados como contaminação da primeira subamostra, foram (com exceção de três objetos) removidos da segunda subamostra pelo método de seleção baseado na combinação dos índices de linha e pela restrição imposta em $(\mathrm{J}-\mathrm{K})_{0} ;(\mathrm{v})$ as classes $m p c b$ e unid não tiveram mudanças consideráveis em suas frações. 
A Figura 5.12 mostra seis objetos selecionados pela inspeção visual da segunda subamostra, pertencentes às classes $m p c a, m p c c$ e fhlc. Estes são exemplos claros de alguns dos alvos principais de estudo deste trabalho. Os painéis superiores mostram dois exemplos de estrelas com bandas moleculares de carbono, que são naturalmente selecionadas pois também apresentam uma banda $\mathrm{G}$ intensa. Os painéis centrais mostram duas candidatas a estrelas EMP, em que a linha K do Ca II é extremamente fraca, o que sugere um valor de metalicidade abaixo de -3.0. Em contrapartida, os painéis inferiores mostram duas estrelas com linhas de Ca intensas, sendo que HE 2152-4307 apresenta um forte enriquecimento em carbono (GPE $=55.39 \AA)$.
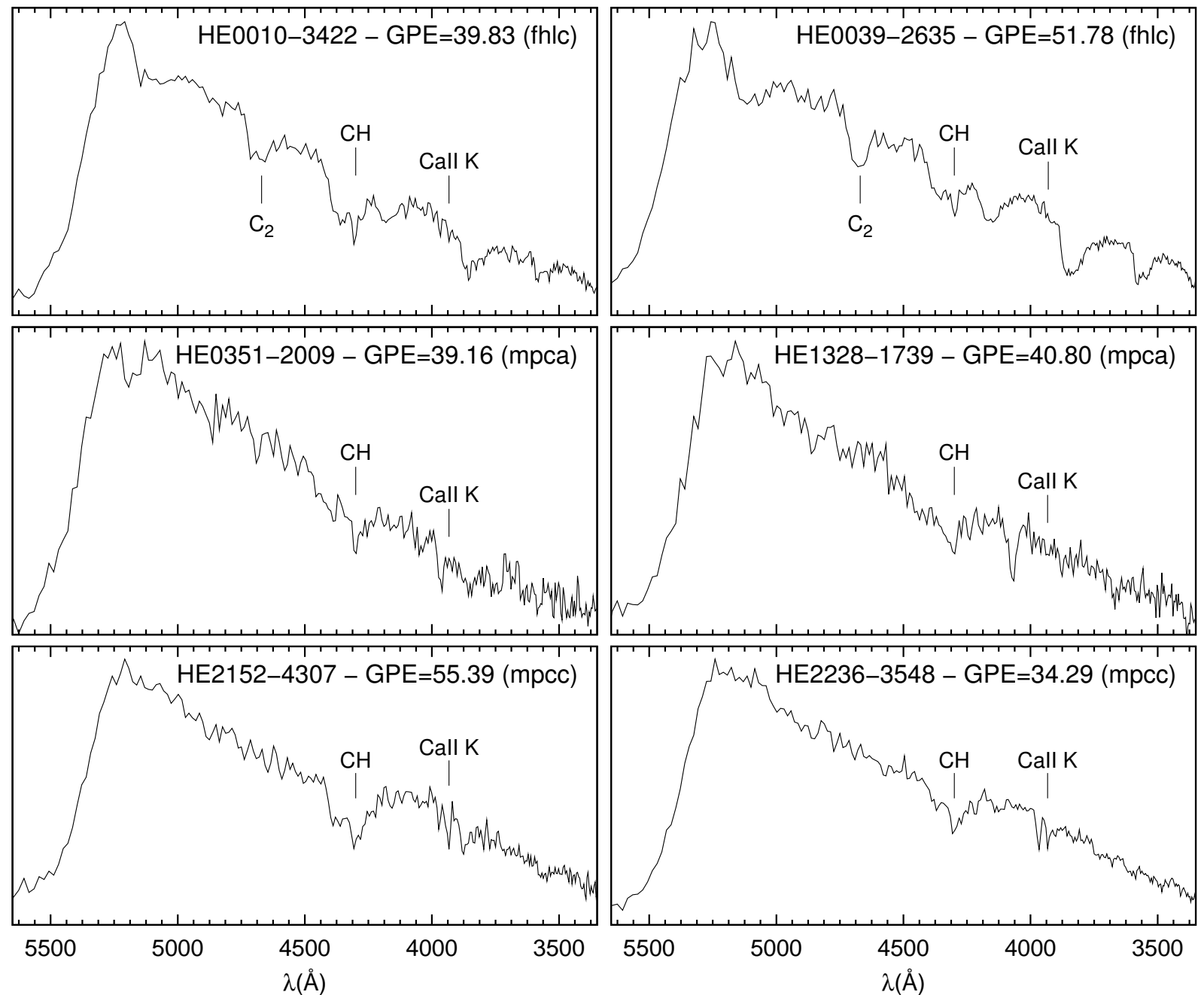

Figura 5.12: Candidatas selecionadas por inspeção visual da segunda subamostra do HES. Os painéis superiores mostram estrelas com bandas moleculares de carbono intensas (fhlc). Nos painéis centrais e inferiores estão exibidas, respectivamente, estrelas com a linha K do Ca II fraca ( $m p c a)$ e intensa (mpcc). Também estão identificadas as principais linhas características de cada espectro. 
O fato de serem selecionados objetos com intensidades da banda $\mathrm{G}$ e da linha $\mathrm{K}$ do Ca II tão distintas reitera uma das conclusões apresentadas no Capítulo 4 (e confirmada por observações em média resolução - Placco et al., 2010a), de que a busca por estrelas pobres em metais baseada na abundância em carbono é bem sucedida em amostrar um grande intervalo de metalicidades, e pode ajudar a desvendar os principais motivos do comportamento das abundâncias de carbono em função da quantidade de metais (Pols et al., 2009; Masseron et al., 2010).

Deste modo, o método de seleção a partir da combinação dos índices GPE e EGP obtém resultados satisfatórios no que se refere à busca por estrelas CEMP, e mostra-se capaz de eliminar contaminações na amostra. A lista com 5454 candidatas a estrelas CEMP inéditas HES (Placco et al., 2010b, - em preparação) enriquece a literatura nessa área e fornece subsídios para continuar a busca pelas estrelas mais pobres em metais da Galáxia (Christlieb et al., 2008; Li et al., 2010).

Vale lembrar que um passo essencial nos estudos de estrelas CEMP é a espectroscopia em alta resolução, que fornece abundâncias químicas para vários elementos químicos, inclusive aqueles formados por processos de captura de nêutrons. Nesse ínterim, a pré-seleção de candidatas interessantes para estudos desse tipo tem um papel fundamental no direcionamento de projetos observacionais, e colabora com a otimização do tempo dispendido na escolha de alvos. 
Capítulo 6

\section{Conclusões}

De uma maneira concisa, é possível sumarizar os principais resultados encontrados nesta tese, e também apresentar perspectivas para pesquisas futuras, baseadas nas contribuições deixadas por este trabalho.

\subsection{Principais Resultados}

- Busca por estrelas CEMP: Este trabalho demonstrou, através das novas definições de índices de linha para a banda G e da análise das duas subamostras extraídas da parte estelar do Hamburg/ESO Survey, que é possível buscar estrelas pobres em metais a partir da hipótese de que uma grande fração destas será rica em carbono. Além disso, os novos métodos de busca propostos, exibidos nas Seções 4.1.1 e 5.3, tornaram possível incluir nas buscas as estrelas ricas em carbono que possuem temperaturas mais elevadas e por isso não satisfazem os critérios propostos pelo trabalho de Christlieb et al. (2001). Como resultado, foram selecionados objetos em uma grande faixa de abundância de carbono e metalicidade.

- Novos índices de linha para a banda G do CH: Foram introduzidos dois novos índices de linha, GPE e EGP, para a região da banda G, em 4304Å. Estes índices superam as falhas dos índices definidos anteriormente na literatura para a mesma região do espectro (Seção 2.1). Além disso, pelo fato do índice GPE (Seção 2.2) utilizar um contínuo "verdadeiro" ao invés da interpolação linear de bandas laterais, e do índice EGP (Seção 2.3) utilizar uma razão de fluxos que não depende do contínuo, estes podem ser utilizados em conjunto (como visto no Capítulo 5 desta 
tese) para evitar contaminações na amostra (provenientes, por exemplo, de estrelas com linhas intensas da série de Balmer do hidrogênio), diminuir o número de objetos para inspeção visual e direcionar melhor esforços observacionais para buscar por estrelas CEMP em média resolução.

- Introdução de novo parâmetro para a base de dados do HES: Os novos índices de linha GPE e EGP definidos nesta tese foram calculados para toda a parte estelar do HES, com mais de 4.4 milhões de espectros disponíveis em baixa resolução (Seção 3.2.2). Ademais, foram calculadas correções de saturação dos índices de linha para todas as fontes brilhantes (ver Seção 5.2) e, em seguida, estes parâmetros foram inseridos na base de dados do HES. Desta forma, os índices também podem ser utilizados como critério de seleção para buscas por estrelas pobres em metais enriquecidas em carbono realizadas no futuro.

- Novas estrelas pobres em metais adicionadas à literatura: O estudo piloto (Capítulo 4 desta tese e Placco et al., 2010a) baseado na nova metodologia para buscar estrelas pobres em metais com enriquecimento em carbono gerou uma lista de 669 estrelas inéditas na literatura. Destas, 132 foram observadas com o telescópio SOAR e tiveram seus espectros em média resolução obtidos com o espectrógrafo Goodman. A análise feita posteriormente, utilizando ferramentas como o SSPP para o cálculo dos parâmetros atmosféricos e síntese espectral para a determinação das abundâncias de carbono, mostrou que 5 estrelas possuem $[\mathrm{Fe} / \mathrm{H}]<-2.5,25$ possuem $-2.5 \leq[\mathrm{Fe} / \mathrm{H}] \leq-2.0,28$ possuem $-2.0<[\mathrm{Fe} / \mathrm{H}] \leq-1.5,28$ possuem $-1.5<[\mathrm{Fe} / \mathrm{H}] \leq-1.0$ e 46 estrelas apresentam metalicidades $[\mathrm{Fe} / \mathrm{H}]>-1.0 . \mathrm{A}$ distribuição de metalicidade destes objetos (Figura 4.10) reproduz satisfatoriamente os resultados encontrados na literatura (Carollo et al., 2007) para as diversas componentes estruturais da Galáxia. Em relação às abundâncias de carbono, metade das estrelas com $[\mathrm{Fe} / \mathrm{H}]<-1.0$ apresentam $[\mathrm{C} / \mathrm{Fe}]>+0.5$. Além disso, a fração encontrada de estrelas CEMP com $[\mathrm{Fe} / \mathrm{H}]<-2.0$ é de $43 \%$ e quatro das cinco candidatas com $[\mathrm{Fe} / \mathrm{H}]<-2.5$ exibem $[\mathrm{C} / \mathrm{Fe}]>+1.0$. Também foram identificadas, a partir de estimativas das abundâncias dos elementos bário e estrôncio, 9 estrelas que satisfazem a classificação de CEMP-s e 4 estrelas ricas em carbono que não apresen- 
tam enriquecimento em elementos formados pelo processo-s, chamadas de CEMP-no. Nesse ínterim, foram confirmadas as tendências crescentes entre as abundâncias de bário e estrôncio e a abundância de carbono, que corroboram com as hipóteses de enriquecimento por transferência de matéria em sistemas binários (ver, por exemplo, Lucatello et al., 2006) para as estrelas CEMP-s.

- Lista com candidatas a estrelas CEMP inéditas: A análise da segunda subamostra extraída do HES (Capítulo 5 desta tese e Placco et al., 2010b, - em preparação) gerou, após inspeção visual de 10314 espectros em baixa resolução, uma lista de 5454 candidatas a estrelas pobres em metais e ricas em carbono ainda não catalogadas, que inclui fontes brilhantes, cujos índices GPE e EGP foram corrigidos dos efeitos de saturação utilizando um método baseado em características fotométricas das placas fotográficas do survey. Além disso, ficou demonstrada a eficácia do uso de dois índices em conjunto para restringir o número de objetos sujeitos à inspeção visual e para diminuir a contaminação da amostra por estrelas com linhas intensas de hidrogênio. O uso do índice EGP mostrou-se muito útil para filtrar valores altos de GPE associados a erros nas placas fotográficas além de baixa razão sinal/ruído, pois o EGP não utiliza o cálculo do contínuo. As diferenças nas definições dos índices foram de vital importância para o sucesso das buscas por candidatas a estrelas CEMP, pois restringem ainda mais a região de ocorrência desses objetos no plano GPE vs. EGP. As frações para as classes mpca e fhlc, a primeira associada a estrelas EMP e a segunda relacionada com bandas moleculares intensas de carbono, cresceram uma ordem de grandeza em relação à primeira subamostra. O subconjunto formado por estes objetos será alvo de estudos dedicados em média/alta resolução, pois a probabilidade de encontrar estrelas com $[\mathrm{Fe} / \mathrm{H}]<-3.0$ ricas em carbono é elevada. A lista completa de objetos inéditos identificados pelos métodos propostos nos Capítulos 4 e 5 deste trabalho, com 6123 candidatas a estrelas CEMP, é exibida no Apêndice C. Este material tornar-se-á público, com o intuito de colaborar com o direcionamento de projetos observacionais dedicados a buscas por estrelas CEMP.

- Pistas sobre a origem do carbono: Dado o grande intervalo de valores encontrados, tanto para as grandezas calculadas nos espectros em baixa resolução (GPE e 
EGP) quanto para aquelas calculadas em espectros em média resolução (parâmetros atmosféricos, $[\mathrm{C} / \mathrm{Fe}]$ e estimativas de $[\mathrm{Ba} / \mathrm{Fe}]$ e $[\mathrm{Sr} / \mathrm{Fe}])$, conclui-se que este espalhamento reflete não só um problema de amostragem (cujas listas de candidatas geradas por este trabalho pretendem auxiliar a resolver) mas também uma visão clara de quão intrincada é a estrutura e a evolução das diferentes populações estelares dentro da Via Láctea. As relações encontradas entre as abundâncias de bário, carbono e a metalicidade (ver Figura 4.16) sugerem que as estrelas CEMP-s, associadas à transferência de massa em sistemas binários, podem ocorrer até em metalicidades tão altas quanto -1.0, sugerindo que o padrão de abundância desses objetos é dominado pela influência da companheira já extinta. Para restringir a faixa de massas e parâmetros cinemáticos desses sistemas binários, é necessário obter espectros em alta resolução, além de realizar monitoramento de velocidade radial (Aoki et al., 2008). Como foi mostrado na Figura 4.19, as estimativas de abundâncias de bário para estrelas com $[\mathrm{Fe} / \mathrm{H}] \sim-2.5$ podem variar em até duas ordens de grandeza, ou seja, estrelas com parâmetros atmosféricos muito semelhantes e formadas a partir de uma nuvem com mesma metalicidade podem apresentar evoluções e padrões de abundâncias completamente distintos. Este é o caso da estrela CEMP-no HE 0118-4834 ([Fe/H] $=-2.34$, $[\mathrm{C} / \mathrm{Fe}]=+2.09$ e $[\mathrm{Ba} / \mathrm{Fe}]=-0.88)$. As abundâncias apresentadas por este objeto excluem a possibilidade de formação em um sistema binário, e sugerem fortemente uma fonte alternativa de enriquecimento em carbono (Beers e Christlieb, 2005). Dessa forma, é necessário um estudo mais detalhado desta estrela, para que possam ser determinadas, por exemplo, abundâncias de nitrogênio (para comparação com os modelos de Meynet et al., 2006) e chumbo, que pode explicar a baixa abundância de bário nas estrelas CEMP mesmo em sistemas binários (Cohen et al., 2006). Esse fato mostra todas as possibilidades abertas com a descoberta de novas estrelas CEMP. Até mesmo o conhecimento considerado bem estabelecido em relação às origens do carbono nas estrelas CEMP está sujeito a mudanças. Alguns estudos (por exemplo Masseron et al., 2010) argumentam que, para as estrelas CEMP-no, o enriquecimento em carbono diminui para metalicidades $[\mathrm{Fe} / \mathrm{H}]<-3.2$, fato que não é previsto por nenhum modelo de síntese em estrela AGB até o momento. 


\subsection{Perspectivas}

- Observações em média/alta resolução: Uma vez que os métodos de busca por estrelas CEMP propostos por este trabalho foram testados e obtiveram resultados satisfatórios (Placco et al., 2010a), será possível fazer novos pedidos de tempo em telescópios de médio e grande porte, tais como SOAR e Gemini, com o objetivo de aumentar a lista de candidatas a estrelas CEMP observadas e contribuir para uma melhor estatística para o cálculo das frações destas estrelas em função da metalicidade (Pols et al., 2009). Além disso, pedidos individuais para espectroscopia em alta resolução de algumas das candidatas mais interessantes identificadas por este trabalho também serão feitos.

- Projeto Observacional no Gemini: Foram observadas 49 estrelas candidatas a estrelas CEMP adicionais da lista gerada por este trabalho (Capítulo 4) com o telescópio Gemini Sul, em um programa associado a condições climáticas adversas (Bad Weather Proposal). Mesmo sob estas condições, os espectros em média resolução observados possuem razão sinal ruído suficiente para aplicar os métodos descritos na Seção 4.2 desta tese. Os espectros dessas estrelas estão em processo de análise e os resultados serão publicados em breve. A execução deste projeto em tais condições abre um precedente importante para um futuro survey dedicado à observação de estrelas CEMP no halo da Galáxia.

- Abundâncias de elementos formados por captura de nêutrons: Os espectros em média resolução permitem os cálculos das abundâncias para alguns elementos formados por captura de nêutrons, tais como bário e estrôncio (ver Seção 4.3 desta tese). Além disso, uma vez confirmada a quais subclasses pertencem as estrelas CEMP (segundo a Tabela 1.2), é possível fazer observações em alta resolução para determinar padrões de abundâncias tanto de elementos formados pelo processo-s quanto pelo processo-r (Barklem et al., 2005; Jonsell et al., 2006).

- Análise cinemática: As estrelas observadas em média resolução poderão ter seus parâmetros cinemáticos (posições e velocidades espaciais) calculados, com o intuito de obter distribuições espaciais e funções de distribuição de metalicidade para os componentes estruturais da Galáxia (ver Figura 4.10 e Carollo et al., 2007). Em 
adição, as abundâncias de carbono determinadas na Seção 4.2.2 desta tese poderão ser utilizadas também para identificar as diferentes populações estelares presentes na Via Láctea (Carollo et al., 2010).

Como pôde ser verificado ao longo deste projeto, e sumarizado nestas conclusões, este trabalho aprimorou os métodos de busca por estrelas pobres em metais enriquecidas em carbono a partir de espectros em baixa resolução, contribuiu com uma lista de 6123 novas candidatas a estrelas CEMP e apresentou resultados de espectroscopia em média resolução para 132 estrelas inéditas na literatura. Estas contribuições, juntamente com os esforços teóricos e observacionais em curso na área de estrelas pobres em metais, possuem um papel importante na busca por descrições cada vez mais completas das origens das populações estelares e da estrutura da Galáxia. 


\section{Referências Bibliográficas}

Abazajian K. N., Adelman-McCarthy J. K., Agüeros M. A., Allam S. S., Allende Prieto C., An D., Anderson K. S. J., Anderson S. F., Annis J., Bahcall N. A. e. a., The Seventh Data Release of the Sloan Digital Sky Survey, ApJS, 2009, vol. 182, p. 543

Allen D. M., Barbuy B., Analysis of 26 barium stars. II. Contributions of s-, r-, and p-processes in the production of heavy elements, A\&A, 2006, vol. 454, p. 917

Allende Prieto C., Sivarani T., Beers T. C., Lee Y. S., Koesterke L., Shetrone M., Sneden C., Lambert D. L., Wilhelm R., Rockosi C. M., Lai D. K., Yanny B., Ivans I. I., Johnson J. A., Aoki W., Bailer-Jones C. A. L., Re Fiorentin P., The SEGUE Stellar Parameter Pipeline. III. Comparison with High-Resolution Spectroscopy of SDSS/SEGUE Field Stars, AJ, 2008, vol. 136, p. 2070

Alvarez R., Plez B., Near-infrared narrow-band photometry of M-giant and Mira stars: models meet observations, A\&A, 1998, vol. 330, p. 1109

Aoki W., Barklem P. S., Beers T. C., Christlieb N., Inoue S., García Pérez A. E., Norris J. E., Carollo D., Lithium Abundances of Extremely Metal-Poor Turnoff Stars, ApJ, 2009, vol. 698, p. 1803

Aoki W., Beers T. C., Christlieb N., Norris J. E., Ryan S. G., Tsangarides S., Carbonenhanced Metal-poor Stars. I. Chemical Compositions of 26 Stars, ApJ, 2007, vol. 655, p. 492 
Aoki W., Beers T. C., Sivarani T., Marsteller B., Lee Y. S., Honda S., Norris J. E., Ryan S. G., Carollo D., Carbon-Enhanced Metal-Poor Stars. III. Main-Sequence Turnoff Stars from the SDSS SEGUE Sample, ApJ, 2008, vol. 678, p. 1351

Aoki W., Frebel A., Christlieb N., Norris J. E., Beers T. C., Minezaki T., Barklem P. S., Honda S., Takada-Hidai M., Asplund M., Ryan S. G., Tsangarides S., Eriksson K., Steinhauer A., Deliyannis C. P., Nomoto K., Fujimoto M. Y., Ando H., HE 1327-2326, an Unevolved Star with $[\mathrm{Fe} / \mathrm{H}]<-5.0$. I. A Comprehensive Abundance Analysis, ApJ, 2006, vol. 639, p. 897

Aoki W., Norris J. E., Ryan S. G., Beers T. C., Ando H., Detection of Lead in the Carbonrich, Very Metal-poor Star LP 625-44: A Strong Constraint on S-Process Nucleosynthesis at Low Metallicity, ApJ, 2000, vol. 536, p. L97

Aoki W., Norris J. E., Ryan S. G., Beers T. C., Ando H., The Chemical Composition of Carbon-rich, Very Metal Poor Stars: A New Class of Mildly Carbon Rich Objects without Excess of Neutron-Capture Elements, ApJ, 2002, vol. 567, p. 1166

Arlandini C., Käppeler F., Wisshak K., Gallino R., Lugaro M., Busso M., Straniero O., Neutron Capture in Low-Mass Asymptotic Giant Branch Stars: Cross Sections and Abundance Signatures, ApJ, 1999, vol. 525, p. 886

Asplund M., Lambert D. L., Nissen P. E., Primas F., Smith V. V., Lithium Isotopic Abundances in Metal-poor Halo Stars, ApJ, 2006, vol. 644, p. 229

Ballero S. K., Matteucci F., Chiappini C., The effects of Population III stars and variable IMF on the chemical evolution of the Galaxy, New Astronomy, 2006, vol. 11, p. 306

Barbuy B., Cayrel R., Spite M., Beers T. C., Spite F., Nordstroem B., Nissen P. E., Analysis of two CH/CN-strong very metal-poor stars., A\&A, 1997, vol. 317, p. L63

Barklem P. S., Christlieb N., Beers T. C., Hill V., Bessell M. S., Holmberg J., Marsteller B., Rossi S., Zickgraf F.-J., Reimers D., The Hamburg/ESO R-process enhanced star survey (HERES). II. Spectroscopic analysis of the survey sample, A\&A, 2005, vol. 439, p. 129 
Beers T. C., The Chemo-Dynamical History of the Milky Way as Revealed by SDSS/SEGUE, ArXiv e-prints, 2009

Beers T. C., Christlieb N., The Discovery and Analysis of Very Metal-Poor Stars in the Galaxy, ARA\&A, 2005, vol. 43, p. 531

Beers T. C., Preston G. W., Shectman S. A., A search for stars of very low metal abundance. I, AJ, 1985, vol. 90, p. 2089

Beers T. C., Preston G. W., Shectman S. A., A search for stars of very low metal abundance. II, AJ, 1992, vol. 103, p. 1987

Beers T. C., Rossi S., Norris J. E., Ryan S. G., Shefler T., Estimation of Stellar Metal Abundance. II. A Recalibration of the Ca II K Technique, and the Autocorrelation Function Method, AJ, 1999, vol. 117, p. 981

Behara N. T., Bonifacio P., Ludwig H., Sbordone L., González Hernández J. I., Caffau E., Three carbon-enhanced metal-poor dwarf stars from the SDSS. Chemical abundances from $\mathrm{CO}^{5}$ BOLD 3D hydrodynamical model atmospheres, A\&A, 2010, vol. 513, p. A72+

Bessell M. S., Christlieb N., Gustafsson B., On the Oxygen Abundance of HE 0107-5240, ApJ, 2004, vol. 612, p. L61

Bonifacio P., Spite M., Cayrel R., Hill V., Spite F., François P., Plez B., Ludwig H., Caffau E., Molaro P., Depagne E., Andersen J., Barbuy B., Beers T. C., Nordström B., Primas F., First stars XII. Abundances in extremely metal-poor turnoff stars, and comparison with the giants, A\&A, 2009, vol. 501, p. 519

Bromm V., Larson R. B., The First Stars, ARA\&A, 2004, vol. 42, p. 79

Burbidge E. M., Burbidge G. R., Fowler W. A., Hoyle F., Synthesis of the Elements in Stars, Reviews of Modern Physics, 1957, vol. 29, p. 547

Campbell S. W., Lattanzio J. C., Evolution and nucleosynthesis of extremely metal-poor and metal-free low- and intermediate-mass stars. I. Stellar yield tables and the CEMPs, A\&A, 2008, vol. 490, p. 769 
Cardiel N., Gorgas J., Cenarro J., Gonzalez J. J., Reliable random error estimation in the measurement of line-strength indices, A\&AS, 1998, vol. 127, p. 597

Carney B. W., Latham D. W., The kinematics of halo red giants, AJ, 1986, vol. 92, p. 60

Carollo D., Beers T. C., Chiba M., Norris J. E., Freeman K. C., Lee Y. S., Ivezić Ž., Rockosi C. M., Yanny B., Structure and Kinematics of the Stellar Halos and Thick Disks of the Milky Way Based on Calibration Stars from Sloan Digital Sky Survey DR7, ApJ, 2010, vol. 712 , p. 692

Carollo D., Beers T. C., Lee Y. S., Chiba M., Norris J. E., Wilhelm R., Sivarani T., Marsteller B., Munn J. A., Bailer-Jones C. A. L., Fiorentin P. R., York D. G., Two stellar components in the halo of the Milky Way, Nature, 2007, vol. 450, p. 1020

Castelli F., Kurucz R. L., New Grids of ATLAS9 Model Atmospheres. In Modelling of Stellar Atmospheres, vol. 210 of IAU Symposium, 2003, p. 20P

Chamberlain J. W., Aller L. H., The Atmospheres of A-Type Subdwarfs and 95 Leonis., ApJ, 1951, vol. 114, p. 52

Chiappini C., Matteucci F., Gratton R., The Chemical Evolution of the Galaxy: The Two-Infall Model, ApJ, 1997, vol. 477, p. 765

Christlieb N., Finding the Most Metal-poor Stars of the Galactic Halo with the Hamburg/ESO Objective-prism Survey (With 6 Figures). In Reviews in Modern Astronomy , vol. 16 of Reviews in Modern Astronomy, 2003, p. 191

Christlieb N., Beers T. C., Barklem P. S., Bessell M., Hill V., Holmberg J., Korn A. J., Marsteller B., Mashonkina L., Qian Y.-Z., Rossi S., Wasserburg G. J., Zickgraf F.-J., Kratz K.-L., Nordström B., Pfeiffer B., Rhee J., Ryan S. G., The Hamburg/ESO Rprocess Enhanced Star survey (HERES). I. Project description, and discovery of two stars with strong enhancements of neutron-capture elements, A\&A, 2004, vol. 428, p. 1027

Christlieb N., Bessell M. S., Beers T. C., Gustafsson B., Korn A., Barklem P. S., Karlsson T., Mizuno-Wiedner M., Rossi S., A stellar relic from the early Milky Way, Nature, 2002, vol. 419, p. 904 
Christlieb N., Green P. J., Wisotzki L., Reimers D., The stellar content of the Hamburg/ESO survey II. A large, homogeneously-selected sample of high latitude carbon stars, A\&A, 2001, vol. 375, p. 366

Christlieb N., Schörck T., Frebel A., Beers T. C., Wisotzki L., Reimers D., The stellar content of the Hamburg/ESO survey. IV. Selection of candidate metal-poor stars, A\&A, 2008, vol. 484 , p. 721

Christlieb N., Wisotzki L., Reimers D., Homeier D., Koester D., Heber U., The stellar content of the Hamburg/ESO survey I. Automated selection of DA white dwarfs, A\&A, 2001, vol. 366, p. 898

Cohen J. G., McWilliam A., Shectman S., Thompson I., Christlieb N., Melendez J., Ramirez S., Swensson A., Zickgraf F., Carbon Stars in the Hamburg/ESO Survey: Abundances, AJ, 2006, vol. 132, p. 137

Cohen J. G., Shectman S., Thompson I., McWilliam A., Christlieb N., Melendez J., Zickgraf F., Ramírez S., Swenson A., The Frequency of Carbon Stars among Extremely Metal-poor Stars, ApJ, 2005, vol. 633, p. L109

Cowan J. J., Sneden C., Lawler J. E., den Hartog E. A., Collier J., Abundance Signatures in Halo Stars: Clues to Nucleosynthesis in the First Stars. In First Stars III , vol. 990 of American Institute of Physics Conference Series, 2008, p. 148

Cruz M. A., Rossi S., Beers T. C., Searching for s-Process-Enhanced Metal-Poor Stars, Publications of the Astronomical Society of Australia, 2009, vol. 26, p. 335

Dahn C. C., Liebert J., Kron R. G., Spinrad H., Hintzen P. M., G77-61 - A dwarf carbon star, ApJ, 1977, vol. 216, p. 757

Dearborn D. S. P., Liebert J., Aaronson M., Dahn C. C., Harrington R., Mould J., Greenstein J. L., On the nature of the dwarf carbon star G77-61, ApJ, 1986, vol. 300, p. 314

Depagne E., Hill V., Spite M., Spite F., Plez B., Beers T. C., Barbuy B., Cayrel R., Andersen J., Bonifacio P., François P., Nordström B., Primas F., First Stars. II. Ele- 
mental abundances in the extremely metal-poor star CS 22949-037. A diagnostic of early massive supernovae, A\&A, 2002, vol. 390, p. 187

Downes R. A., Margon B., Anderson S. F., Harris H. C., Knapp G. R., Schroeder J., Schneider D. P., York D. G., Pier J. R., Brinkmann J., Faint High-Latitude Carbon Stars Discovered by the Sloan Digital Sky Survey: An Initial Catalog, AJ, 2004, vol. 127, p. 2838

Du C.-h., Zhou X., Ma J., Shi J.-r., Chen A. B.-C., Jiang Z.-j., Chen J.-s., The Metallicity Distribution of F/G Dwarfs Derived from BATC Survey Data, AJ, 2004, vol. 128, p. 2265

Dunkley J., Komatsu E., Nolta M. R., Spergel D. N., Larson D., Hinshaw G., Page L., Bennett C. L., Gold B., Jarosik N., Weiland J. L., Halpern M., Hill R. S., Kogut A., Limon M., Meyer S. S., Tucker G. S., Wollack E., Wright E. L., Five-Year Wilkinson Microwave Anisotropy Probe Observations: Likelihoods and Parameters from the WMAP Data, ApJS, 2009, vol. 180, p. 306

Frebel A., Aoki W., Christlieb N., Ando H., Asplund M., Barklem P. S., Beers T. C., Eriksson K., Fechner C., Fujimoto M. Y., Honda S., Kajino T., Minezaki T., Nomoto K., Norris J. E., Ryan S. G., Nucleosynthetic signatures of the first stars, Nature, 2005, vol. 434 , p. 871

Frebel A., Christlieb N., Norris J. E., Beers T. C., Bessell M. S., Rhee J., Fechner C., Marsteller B., Rossi S., Thom C., Wisotzki L., Reimers D., Bright Metal-poor Stars from the Hamburg/ESO Survey. I. Selection and Follow-up Observations from 329 Fields, ApJ, 2006, vol. 652, p. 1585

Frebel A., Norris J. E., Aoki W., Honda S., Bessell M. S., Takada-Hidai M., Beers T. C., Christlieb N., Chemical Abundance Analysis of the Extremely Metal-poor Star HE 1300+0157, ApJ, 2007, vol. 658, p. 534

Fulbright J. P., Wyse R. F. G., Grebel E. K., RAVE collaboration Very Metal-poor Stars And The Rave Survey. In Bulletin of the American Astronomical Society, vol. 41 of Bulletin of the American Astronomical Society, 2010, p. 479 
García Pérez A. E., Aoki W., Inoue S., Ryan S. G., Suzuki T. K., Chiba M., ${ }^{6}$ Li/7 Li estimates for metal-poor stars, A\&A, 2009, vol. 504, p. 213

Girard T. M., Dinescu D. I., van Altena W. F., Platais I., Monet D. G., López C. E., The Southern Proper Motion Program. III. A Near-Complete Catalog to V=17.5, AJ, 2004, vol. 127 , p. 3060

Goswami A., Aoki W., HD209621: abundances of neutron-capture elements, MNRAS, 2010, vol. 404, p. 253

Goswami A., Aoki W., Beers T. C., Christlieb N., Norris J. E., Ryan S. G., Tsangarides S., A high-resolution spectral analysis of three carbon-enhanced metal-poor stars, MNRAS, 2006, vol. 372 , p. 343

Green P. J., Faint High-Latitude Carbon Stars, PASP, 1992, vol. 104, p. 977

Grevesse N., Sauval A. J., Standard Solar Composition, Space Science Reviews, 1998, vol. 85 , p. 161

Hambly N. C., Davenhall A. C., Irwin M. J., MacGillivray H. T., The SuperCOSMOS Sky Survey - III. Astrometry, MNRAS, 2001, vol. 326, p. 1315

Hanson R. B., Klemola A. R., Jones B. F., Monet D. G., Lick Northern Proper Motion Program. III. Lick NPM2 Catalog, AJ, 2004, vol. 128, p. 1430

Herwig F., Evolution and Yields of Extremely Metal-poor Intermediate-Mass Stars, ApJS, 2004, vol. 155 , p. 651

Herwig F., Evolution of Asymptotic Giant Branch Stars, ARA\&A, 2005, vol. 43, p. 435

Hill V., Barbuy B., Spite M., Spite F., Cayrel R., Plez B., Beers T. C., Nordström B., Nissen P. E., Heavy-element abundances in the $\mathrm{CH} / \mathrm{CN}$-strong very metal-poor stars CS 22948-27 and CS 29497-34, A\&A, 2000, vol. 353, p. 557

Ito H., Aoki W., Honda S., Beers T. C., BD+44²493: A Ninth Magnitude Messenger from the Early Universe; Carbon Enhanced and Beryllium Poor, ApJ, 2009, vol. 698, p. L37 
Ivezić Ž., Lupton R. H., Schlegel D., Boroski B., Adelman-McCarthy J., Yanny B., Kent S., Stoughton C., Finkbeiner D., Padmanabhan N., SDSS data management and photometric quality assessment, Astronomische Nachrichten, 2004, vol. 325, p. 583

Johnson J. A., Bolte M., Abundances in the Very Metal Poor s-Process-rich Star CS 22183-015, ApJ, 2002, vol. 579, p. L87

Jonsell K., Barklem P. S., Gustafsson B., Christlieb N., Hill V., Beers T. C., Holmberg J., The Hamburg/ESO R-process enhanced star survey (HERES). III. HE 0338-3945 and the formation of the $\mathrm{r}+\mathrm{s}$ stars, A\&A, 2006, vol. 451, p. 651

Kappeler F., Beer H., Wisshak K., s-process nucleosynthesis-nuclear physics and the classical model, Reports on Progress in Physics, 1989, vol. 52, p. 945

Karlsson T., Primordial Stellar Feedback and the Origin of Hyper-Metal-poor Stars, ApJ, 2006, vol. 641, p. L41

Knapp G. R., Tremonti C. A., Rockosi C. M., Schlegel D. J., Yanny B., Beers T. C., Allende Prieto C., Wilhelm R., Lupton R. H., Gunn J. E., Niederste-Ostholt M., Schneider D. P., Covey K., Seth A., Ivezić Ž., SDSS J103913.70+533029.7: A Super Star Cluster in the Outskirts of a Galaxy Merger, AJ, 2006, vol. 131, p. 859

Landsman W. B., The IDL Astronomy User's Library. In Bulletin of the American Astronomical Society, vol. 21 of Bulletin of the American Astronomical Society, 1989, p. 784

Lau H. H. B., Stancliffe R. J., Tout C. A., The evolution of low-metallicity asymptotic giant branch stars and the formation of carbon-enhanced metal-poor stars, MNRAS, 2009, vol. 396, p. 1046

Lee Y. S., Beers T. C., Sivarani T., Allende Prieto C., Koesterke L., Wilhelm R., Re Fiorentin P., Bailer-Jones C. A. L., Norris J. E., Rockosi C. M., Yanny B., Newberg H. J., Covey K. R., Zhang H.-T., Luo A.-L., The Segue Stellar Parameter Pipeline. I. Description and Comparison of Individual Methods, AJ, 2008, vol. 136, p. 2022

Li H. N., Christlieb N., Schörck T., Norris J. E., Bessell M. S., Yong D., Beers T. C., Lee Y. S., Frebel A., Zhao G., The stellar content of the Hamburg/ESO survey VI. 
The metallicity distribution of main-sequence turnoff stars in the Galactic halo, ArXiv e-prints, 2010

Lucatello S., Beers T. C., Christlieb N., Barklem P. S., Rossi S., Marsteller B., Sivarani T., Lee Y. S., The Frequency of Carbon-enhanced Metal-poor Stars in the Galaxy from the HERES Sample, ApJ, 2006, vol. 652, p. L37

Lucatello S., Gratton R., Cohen J. G., Beers T. C., Christlieb N., Carretta E., Ramírez S., Stellar Archaeology: A Keck Pilot Program on Extremely Metal-Poor Stars From the Hamburg/ESO Survey. III. The Lead (Pb) Star HE 0024-2523, AJ, 2003, vol. 125, p. 875

Luck R. E., Bond H. E., Subgiant CH stars. II - Chemical compositions and the evolutionary connection with barium stars, ApJS, 1991, vol. 77, p. 515

Margon B., Anderson S. F., Harris H. C., Strauss M. A., Knapp G. R., Fan X., Schneider D. P., Vanden Berk D. E., Schlegel D. J., Deutsch E. W., Ivezić Ž., Hall P. B., Williams B. F., Davidsen A. F., Faint High-Latitude Carbon Stars Discovered by the Sloan Digital Sky Survey: Methods and Initial Results, AJ, 2002, vol. 124, p. 1651

Marsteller B. E., The frequency of carbon-enhanced metal-poor stars and the origin of carbon in the universe, Michigan State University, 2007, Tese de Doutorado

Masseron T., Johnson J. A., Plez B., van Eck S., Primas F., Goriely S., Jorissen A., A holistic approach to carbon-enhanced metal-poor stars, A\&A, 2010, vol. 509, p. A93+

Masseron T., van Eck S., Famaey B., Goriely S., Plez B., Siess L., Beers T. C., Primas F., Jorissen A., CS 30322-023: an ultra metal-poor TP-AGB star?, A\&A, 2006, vol. 455, p. 1059

Meléndez J., Ramírez I., Casagrande L., Asplund M., Gustafsson B., Yong D., Do Nascimento J. D., Castro M., Bazot M., The solar, exoplanet and cosmological lithium problems, Ap\&SS, 2009, pp 221-+

Meynet G., Ekström S., Maeder A., The early star generations: the dominant effect of rotation on the CNO yields, A\&A, 2006, vol. 447, p. 623 
Miller G. E., Scalo J. M., The initial mass function and stellar birthrate in the solar neighborhood, ApJS, 1979, vol. 41, p. 513

Miralda-Escudé J., The Dark Age of the Universe, Science, 2003, vol. 300, p. 1904

Morrison H. L., Norris J., Mateo M., Harding P., Olszewski E. W., Shectman S. A., DohmPalmer R. C., Helmi A., Freeman K. C., Mapping the Galactic Halo. VI. Spectroscopic Measures of Luminosity and Metallicity, AJ, 2003, vol. 125, p. 2502

Munn J. A., Monet D. G., Levine S. E., Canzian B., Pier J. R., Harris H. C., Lupton R. H., Ivezić Ž., Hindsley R. B., Hennessy G. S., Schneider D. P., Brinkmann J., An Improved Proper-Motion Catalog Combining USNO-B and the Sloan Digital Sky Survey, AJ, 2004, vol. 127 , p. 3034

Nomoto K., Tominaga N., Umeda H., Kobayashi C., Maeda K., Nucleosynthesis yields of core-collapse supernovae and hypernovae, and galactic chemical evolution, Nuclear Physics A, 2006, vol. 777, p. 424

Norris J. E., Beers T. C., Ryan S. G., Extremely Metal-poor Stars. VII. The Most Metalpoor Dwarf, CS 22876-032, ApJ, 2000, vol. 540, p. 456

Norris J. E., Christlieb N., Korn A. J., Eriksson K., Bessell M. S., Beers T. C., Wisotzki L., Reimers D., HE 0557-4840: Ultra-Metal-Poor and Carbon-Rich, ApJ, 2007, vol. 670, p. 774

Norris J. E., Ryan S. G., Beers T. C., Extremely Metal-poor Stars. IV. The Carbon-rich Objects, ApJ, 1997, vol. 488, p. 350

Norris J. E., Ryan S. G., Beers T. C., Aoki W., Ando H., Extremely Metal-poor Stars. IX. CS 22949-037 and the Role of Hypernovae, ApJ, 2002, vol. 569, p. L107

Piau L., Beers T. C., Balsara D. S., Sivarani T., Truran J. W., Ferguson J. W., From First Stars to the Spite Plateau: A Possible Reconciliation of Halo Stars Observations with Predictions from Big Bang Nucleosynthesis, ApJ, 2006, vol. 653, p. 300

Placco V. M., Padrões de Abundâncias entre Estrelas Muito Pobres em Metais no Halo da Galáxia, Universidade de São Paulo, 2007, Dissertação de Mestrado 
Placco V. M., Christlieb N., Rossi S., Beers T. C., A Search for Additional Metal-Poor Candidates from HES using Carbon Abundance Estimates, em preparação, 2010

Placco V. M., Kennedy C. R., Rossi S., Beers T. C., Lee Y. S., Christlieb N., Sivarani T., Reimers D., Wisotzki L., A Search for Unrecognized Carbon-Enhanced Metal-Poor Stars in the Galaxy, AJ, 2010, vol. 139, p. 1051

Plez B., Cohen J. G., Analysis of the carbon-rich very metal-poor dwarf G77-61, A\&A, 2005, vol. 434, p. 1117

Pols O. R., Izzard R. G., Glebbeek E., Stancliffe R. J., The Puzzling Frequencies of CEMP and NEMP Stars, Publications of the Astronomical Society of Australia, 2009, vol. 26, p. 327

Qian Y., Nuclear physics and astrophysics of the r-process, Nuclear Physics A, 2005, vol. 752 , p. 550

Qian Y., Wasserburg G. J., Stellar Sources for Heavy r-Process Nuclei, ApJ, 2003, vol. 588, p. 1099

Raue M., Kneiske T., Mazin D., First stars and the extragalactic background light: how recent $\gamma$-ray observations constrain the early universe, A\&A, 2009, vol. 498, p. 25

Reimers D., A wide-angle objective prism survey for bright quasars., The Messenger, 1990, vol. 60 , p. 13

Reimers D., Wisotzki L., The Hamburg/ESO Survey., The Messenger, 1997, vol. 88, p. 14

Roederer I. U., Frebel A., Shetrone M. D., Allende Prieto C., Rhee J., Gallino R., Bisterzo S., Sneden C., Beers T. C., Cowan J. J., The Hobby-Eberly Telescope Chemical Abundances of Stars in the Halo (CASH) Project. I. The Lithium-, s-, and r-enhanced Metal-poor Giant HKII 17435-00532, ApJ, 2008, vol. 679, p. 1549

Roederer I. U., Kratz K., Frebel A., Christlieb N., Pfeiffer B., Cowan J. J., Sneden C., The End of Nucleosynthesis: Production of Lead and Thorium in the Early Galaxy, ApJ, 2009, vol. 698, p. 1963 
Röser S., An updated GSC as the astrometric reference for minor planet observations. In Dynamics, Ephemerides, and Astrometry of the Solar System , vol. 172 of IAU Symposium, 1996, p. 481

Rossi S., Beers T. C., Sneden C., Carbon Abundances for Metal-Poor Stars Based on Medium-Resolution Spectra. In The Third Stromlo Symposium: The Galactic Halo , vol. 165 of Astronomical Society of the Pacific Conference Series, 1999, p. 264

Rossi S., Beers T. C., Sneden C., Sevastyanenko T., Rhee J., Marsteller B., Estimation of Carbon Abundances in Metal-Poor Stars. I. Application to the Strong G-Band Stars of Beers, Preston, and Shectman, AJ, 2005, vol. 130, p. 2804

Ryan S. G., Observations of r- and s-process elements in population II stars, Nuclear Physics A, 2003, vol. 718, p. 317

Ryan S. G., Aoki W., Norris J. E., Beers T. C., The Origins of Two Classes of Carbonenhanced, Metal-poor Stars, ApJ, 2005, vol. 635, p. 349

Salpeter E. E., The Luminosity Function and Stellar Evolution., ApJ, 1955, vol. 121, p. 161

Salvadori S., Schneider R., Ferrara A., Cosmic stellar relics in the Galactic halo, MNRAS, 2007, vol. 381, p. 647

Scalo J., The IMF Revisited: A Case for Variations. In The Stellar Initial Mass Function (38th Herstmonceux Conference), vol. 142 of Astronomical Society of the Pacific Conference Series, 1998, p. 201

Schlegel D. J., Finkbeiner D. P., Davis M., Maps of Dust Infrared Emission for Use in Estimation of Reddening and Cosmic Microwave Background Radiation Foregrounds, ApJ, 1998, vol. 500, p. 525

Schörck T., Christlieb N., Cohen J. G., Beers T. C., Shectman S., Thompson I., McWilliam A., Bessell M. S., Norris J. E., Meléndez J., The stellar content of the Hamburg/ESO survey. V. The metallicity distribution function of the Galactic halo, A\&A, 2009, vol. 507, p. 817 
Schuler S. C., Margheim S. J., Sivarani T., Asplund M., Smith V. V., Cunha K., Beers T. C., Carbon Abundances of Three Carbon-Enhanced Metal-Poor Stars from HighResolution Gemini-S/bHROS Spectra of the $\lambda 8727$ [C I] Line, AJ, 2008, vol. 136, p. 2244

Shigeyama T., Tsujimoto T., Yoshii Y., Excavation of the First Stars, ApJ, 2003, vol. 586, p. L57

Simmerer J., Sneden C., Cowan J. J., Collier J., Woolf V. M., Lawler J. E., The Rise of the s-Process in the Galaxy, ApJ, 2004, vol. 617, p. 1091

Sivarani T., Beers T. C., Bonifacio P., Molaro P., Cayrel R., Herwig F., Spite M., Spite F., Plez B., Andersen J., Barbuy B., Depagne E., Hill V., François P., Nordström B., Primas F., First stars X. The nature of three unevolved carbon-enhanced metal-poor stars, A\&A, 2006, vol. 459, p. 125

Skrutskie M. F., Cutri R. M., Stiening R., Weinberg M. D., Schneider S., Carpenter J. M., Beichman C., Capps R., Chester T., Elias J. e. a., The Two Micron All Sky Survey (2MASS), AJ, 2006, vol. 131, p. 1163

Smith G. H., Norris J., Subtle differences in the CN and CH bands of two M55 red giants, PASP, 1983, vol. 95, p. 635

Sneden C., Cowan J. J., Lawler J. E., Ivans I. I., Burles S., Beers T. C., Primas F., Hill V., Truran J. W., Fuller G. M., Pfeiffer B., Kratz K.-L., The Extremely Metal-poor, Neutron Capture-rich Star CS 22892-052: A Comprehensive Abundance Analysis, ApJ, 2003, vol. 591, p. 936

Sneden C., McWilliam A., Preston G. W., Cowan J. J., Burris D. L., Armosky B. J., The Ultra-Metal-poor, Neutron-Capture-rich Giant Star CS 22892-052, ApJ, 1996, vol. 467, p. 819

Spite M., Spite F., Li isotopes in metal-poor halo dwarfs, a more and more complicated story, ArXiv e-prints, 2010

Stancliffe R. J., Glebbeek E., Thermohaline mixing and gravitational settling in carbonenhanced metal-poor stars, MNRAS, 2008, vol. 389, p. 1828 
Suda T., Katsuta Y., Yamada S., Suwa T., Ishizuka C., Komiya Y., Sorai K., Aikawa M., Fujimoto M. Y., Stellar Abundances for the Galactic Archeology (SAGA) Database Compilation of the Characteristics of Known Extremely Metal-Poor Stars, PASJ, 2008, vol. 60 , p. 1159

Tody D., The IRAF Data Reduction and Analysis System. In Society of Photo-Optical Instrumentation Engineers (SPIE) Conference Series, vol. 627 of Presented at the Society of Photo-Optical Instrumentation Engineers (SPIE) Conference, 1986, p. 733

Tumlinson J., Chemical Evolution in Hierarchical Models of Cosmic Structure. I. Constraints on the Early Stellar Initial Mass Function, ApJ, 2006, vol. 641, p. 1

Tumlinson J., Carbon-enhanced Hyper-Metal-poor Stars and the Stellar IMF at Low Metallicity, ApJ, 2007, vol. 665, p. 1361

Wanajo S., Ishimaru Y., r-process calculations and Galactic chemical evolution, Nuclear Physics A, 2006, vol. 777, p. 676

Wisotzki L., Christlieb N., Bade N., Beckmann V., Köhler T., Vanelle C., Reimers D., The Hamburg/ESO survey for bright QSOs. III. A large flux-limited sample of QSOs, A\&A, 2000, vol. 358, p. 77

Wyse R. F. G., Gilmore G., Norris J. E., Wilkinson M. I., Kleyna J. T., Koch A., Evans N. W., Grebel E. K., Further Evidence of a Merger Origin for the Thick Disk: Galactic Stars along Lines of Sight to Dwarf Spheroidal Galaxies, ApJ, 2006, vol. 639, p. L13

Yanny B., Rockosi C., Newberg H. J., Knapp G. R., Adelman-McCarthy J. K., Alcorn B., Allam S., Allende Prieto C., An D., Anderson K. S. J., Anderson S., Bailer-Jones C. A. L. e. a., SEGUE: A Spectroscopic Survey of 240,000 Stars with g = 14-20, AJ, 2009, vol. 137, p. 4377

York D. G., Adelman J., Anderson Jr. J. E., Anderson S. F., Annis J., Bahcall N. A., Bakken J. A., Barkhouser R., Bastian S., Berman E., Boroski W. N., Bracker S., Briegel C. e. a., The Sloan Digital Sky Survey: Technical Summary, AJ, 2000, vol. 120, p. 1579 
Zacharias N., Urban S. E., Zacharias M. I., Wycoff G. L., Hall D. M., Monet D. G., Rafferty T. J., The Second US Naval Observatory CCD Astrograph Catalog (UCAC2), AJ, 2004, vol. 127 , p. 3043

Zwitter T., Siebert A., Munari U., Freeman K. C., Siviero A., Watson F. G., Fulbright J. P., Wyse R. F. G., Campbell R., Seabroke G. M., Williams M. e. a., The Radial Velocity Experiment (rave): Second Data Release, AJ, 2008, vol. 136, p. 421 
Apêndice 

Apêndice A

\section{Estrelas Observadas com o SOAR}

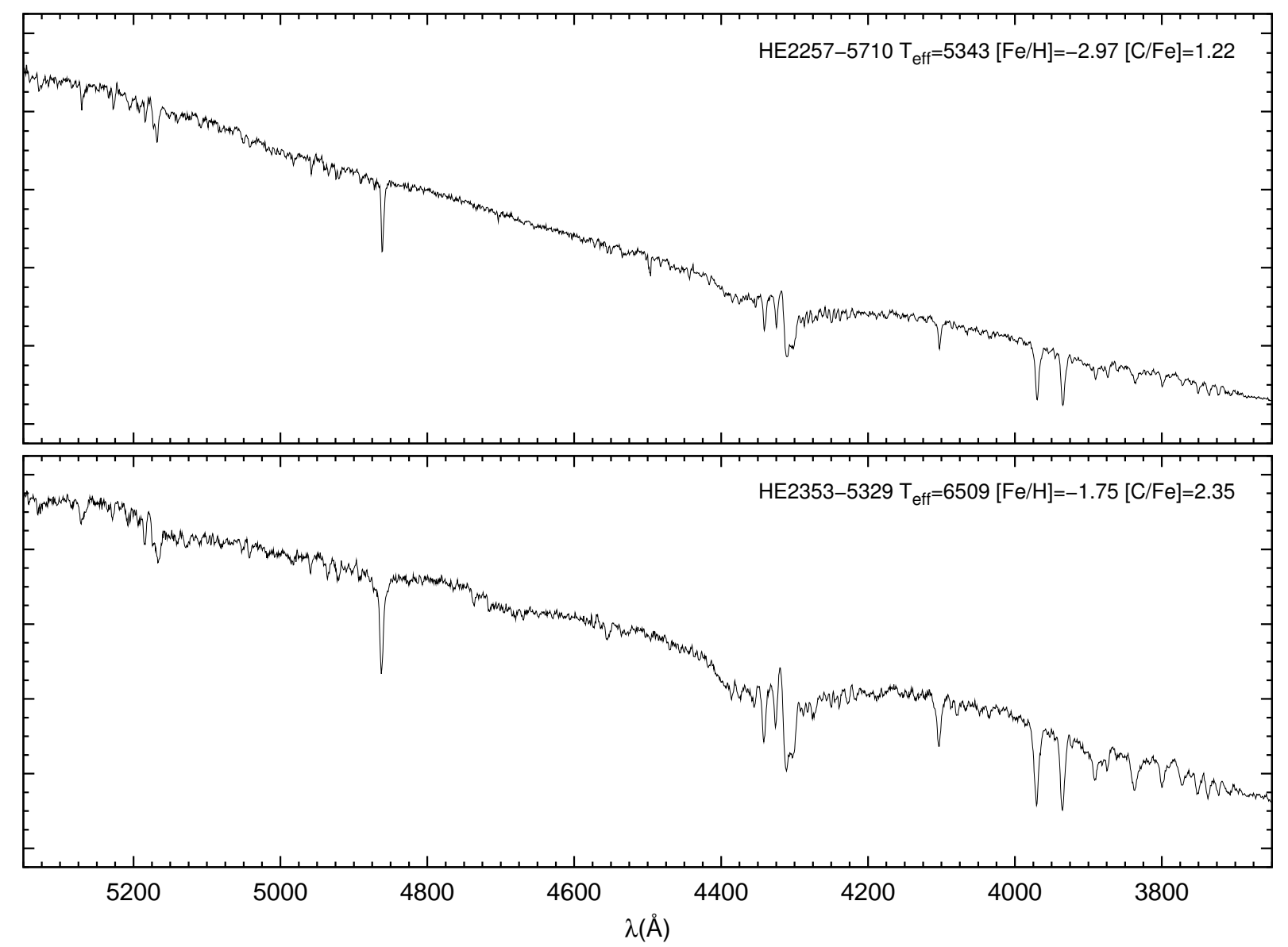

Figura A.1: Espectros das estrelas observadas com o SOAR (1). 


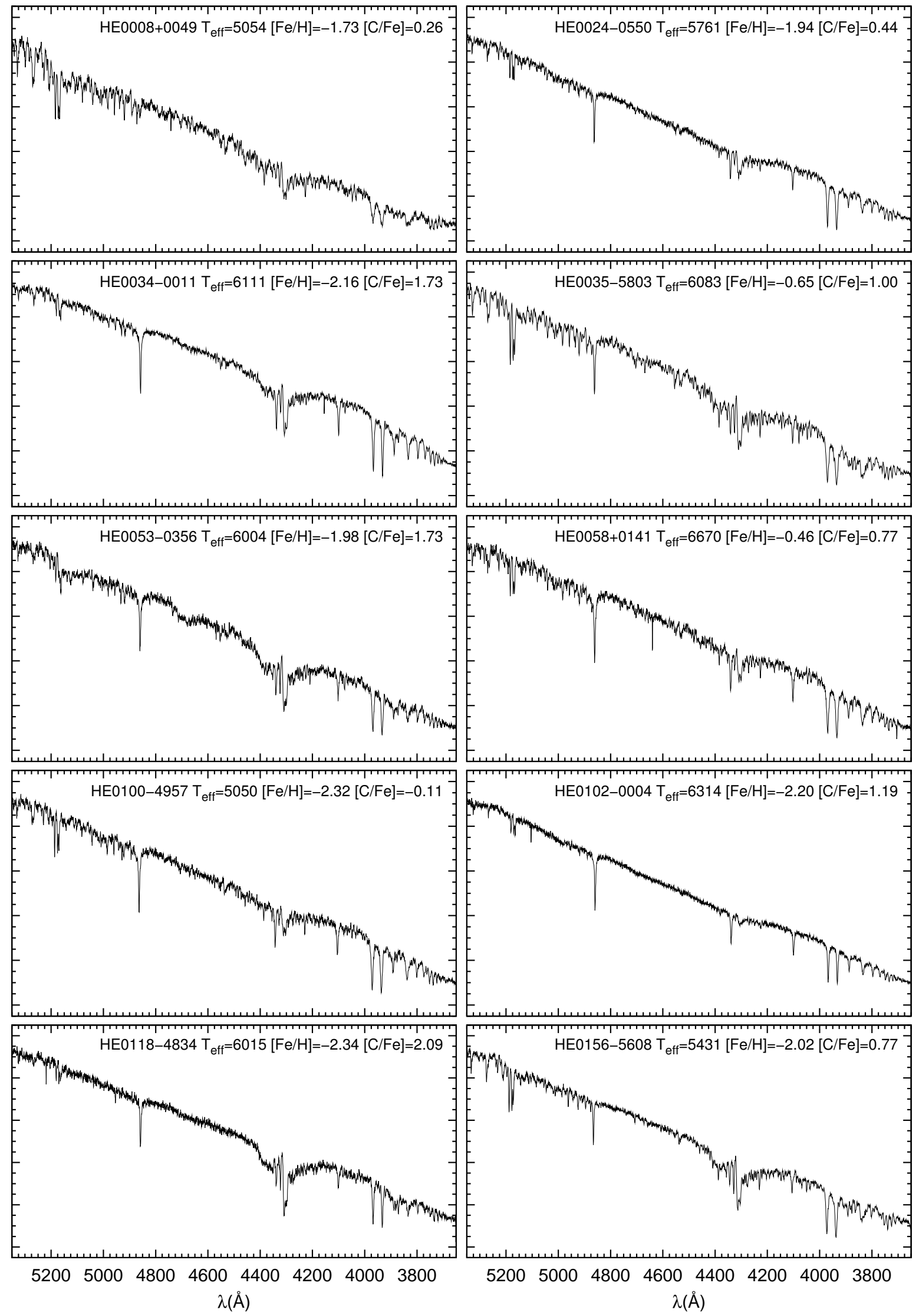

Figura A.2: Espectros das estrelas observadas com o SOAR (2). 

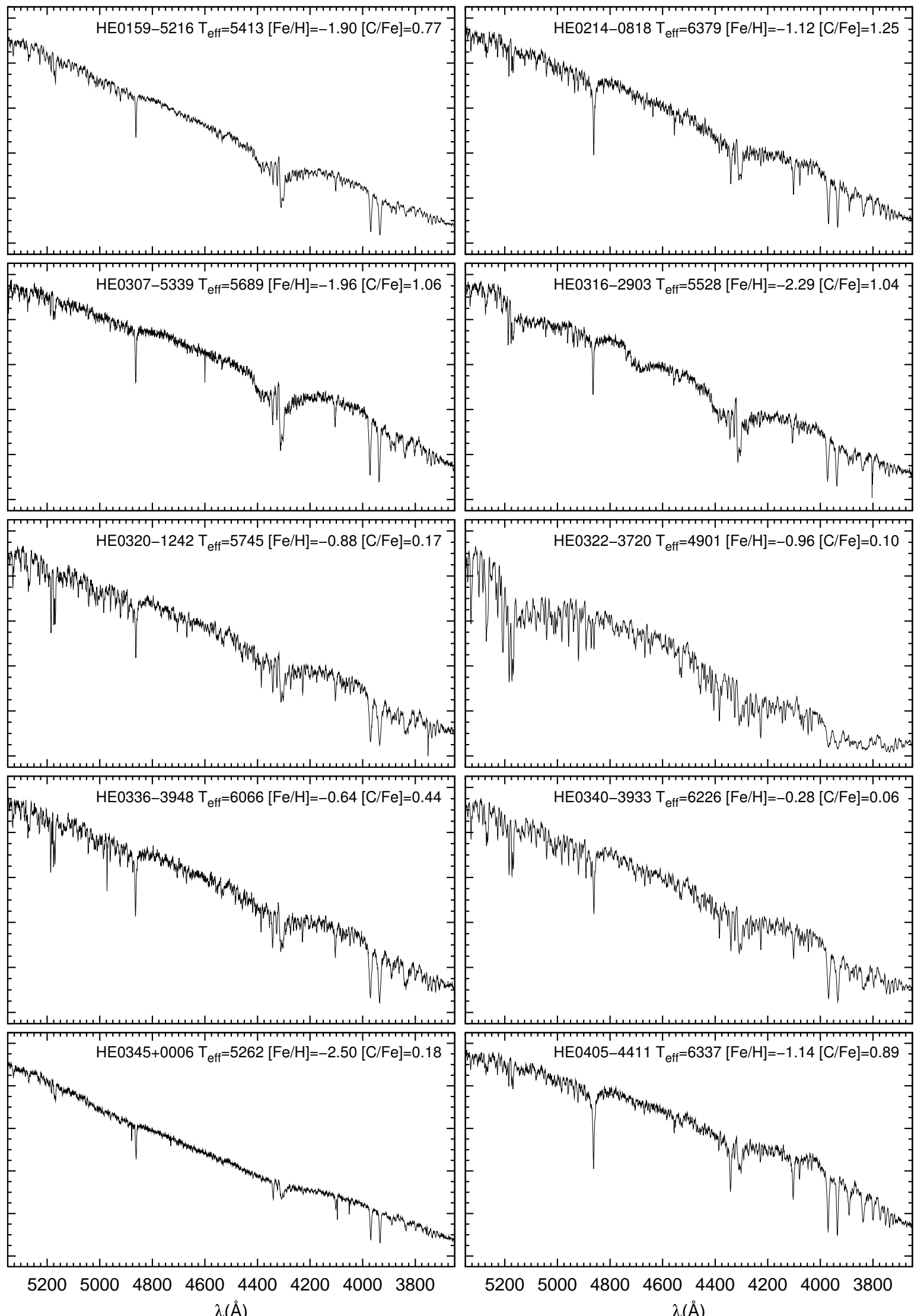

$\lambda(\AA)$

$\lambda(\AA)$

Figura A.3: Espectros das estrelas observadas com o SOAR (3). 

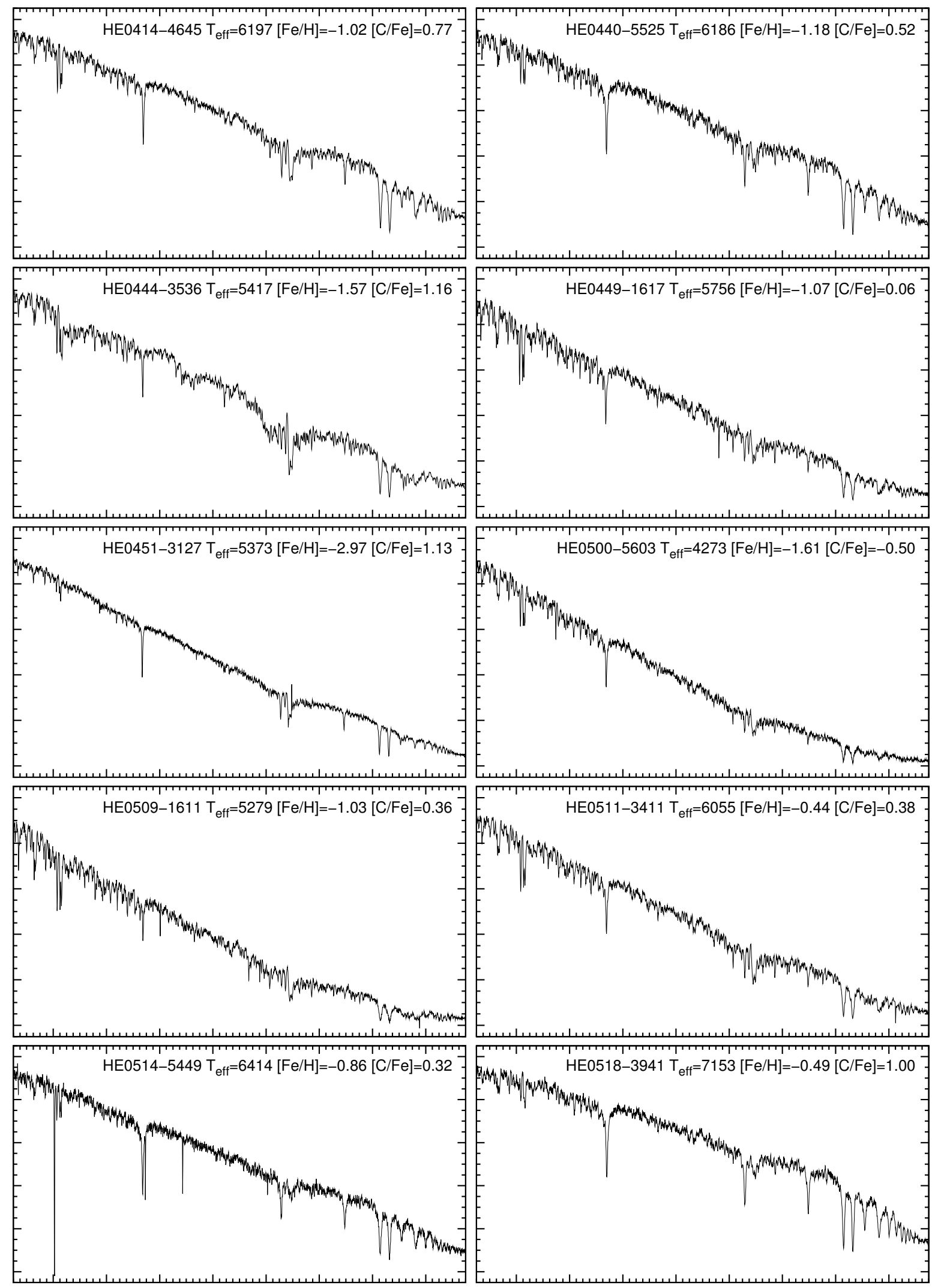

$\begin{array}{llllllll}5200 & 5000 & 4800 & 4600 & 4400 & 4200 & 4000 \quad 3800\end{array}$ $\lambda(\AA)$

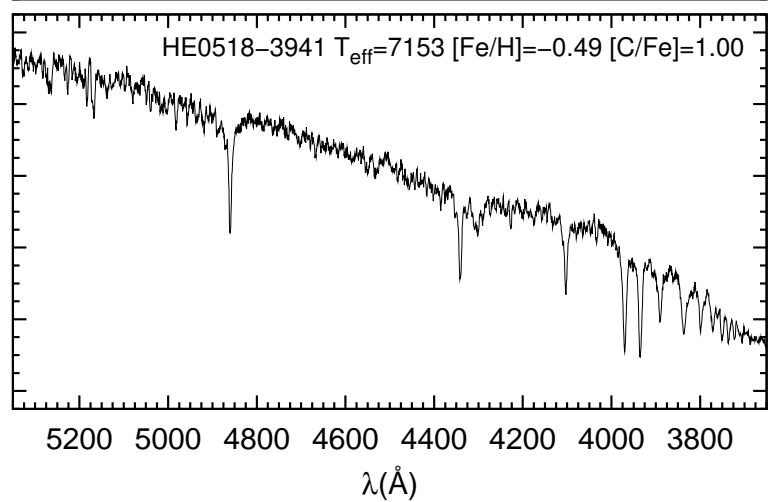

Figura A.4: Espectros das estrelas observadas com o SOAR (4). 

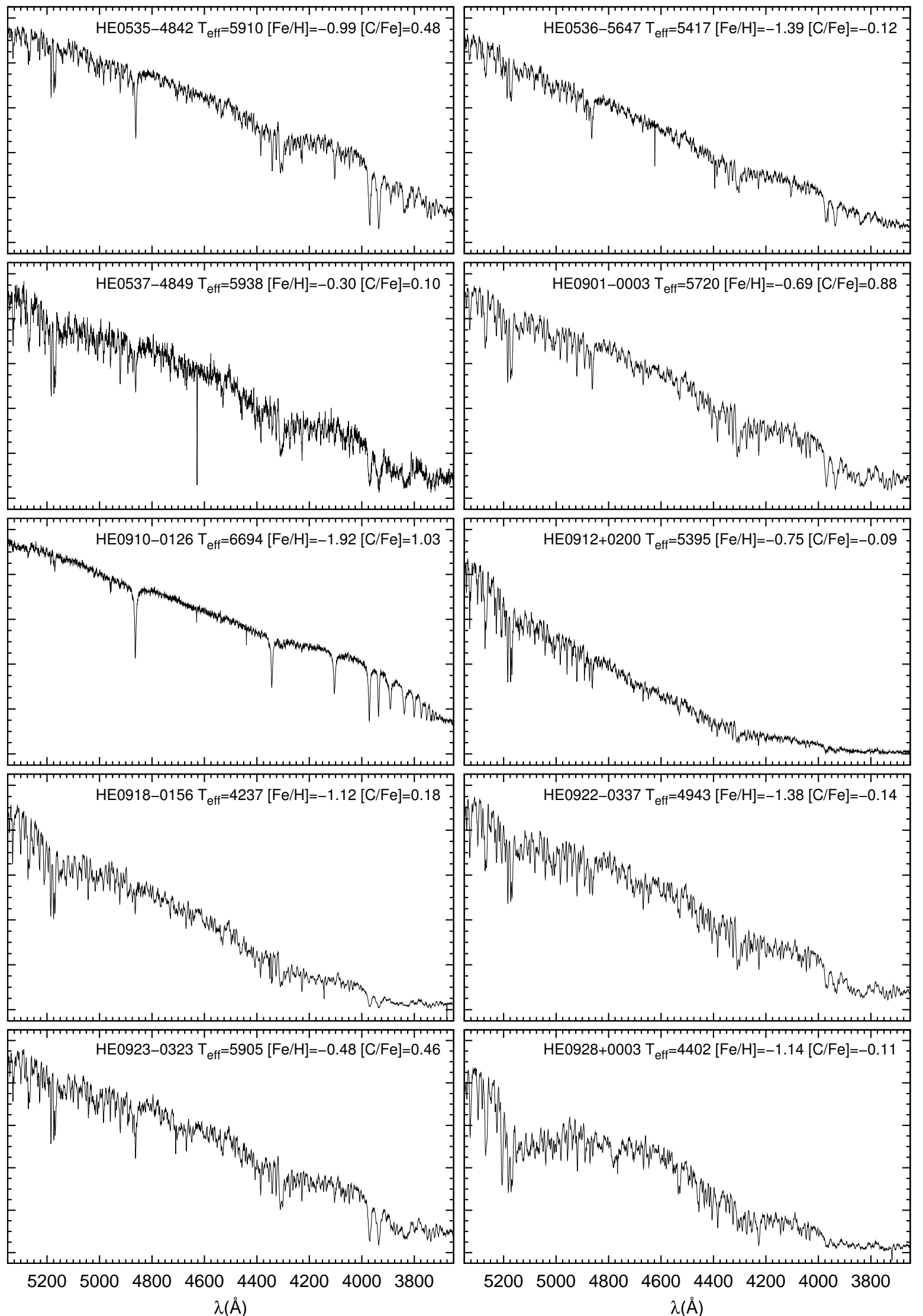

$\lambda(\AA ̊)$

$\lambda(\AA)$

Figura A.5: Espectros das estrelas observadas com o SOAR (5). 

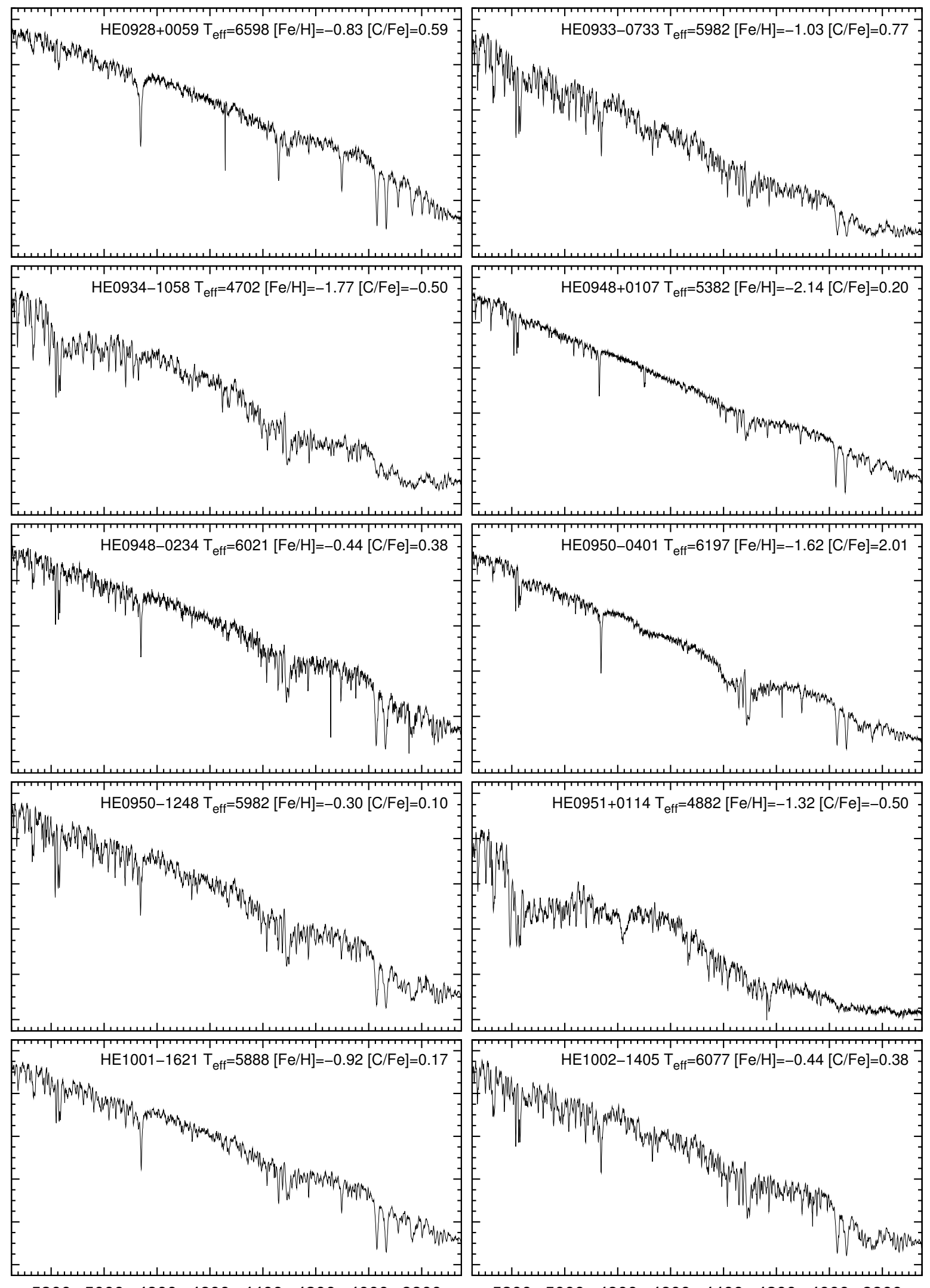

$\begin{array}{llllllll}5200 & 5000 & 4800 & 4600 & 4400 & 4200 & 4000 & 3800\end{array}$ $\lambda(\AA)$ $\mathrm{HE} 1002-1405 \mathrm{~T}_{\text {eff }}=6077[\mathrm{Fe} / \mathrm{H}]=-0.44[\mathrm{C} / \mathrm{Fe}]=0.38$

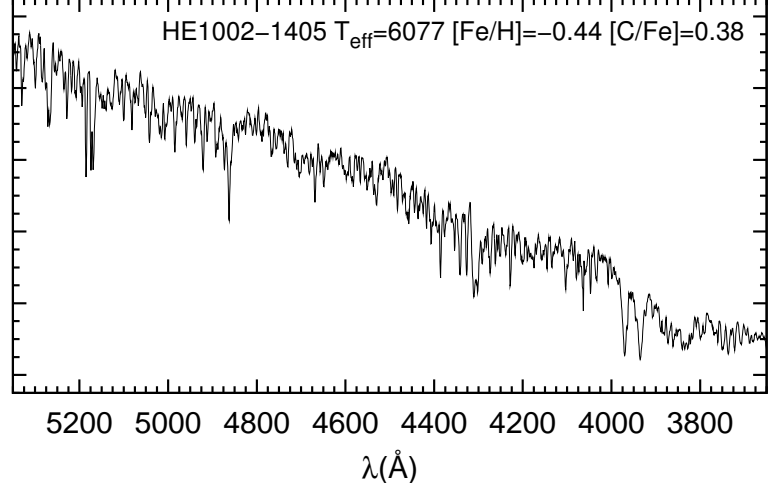

Figura A.6: Espectros das estrelas observadas com o SOAR (6). 

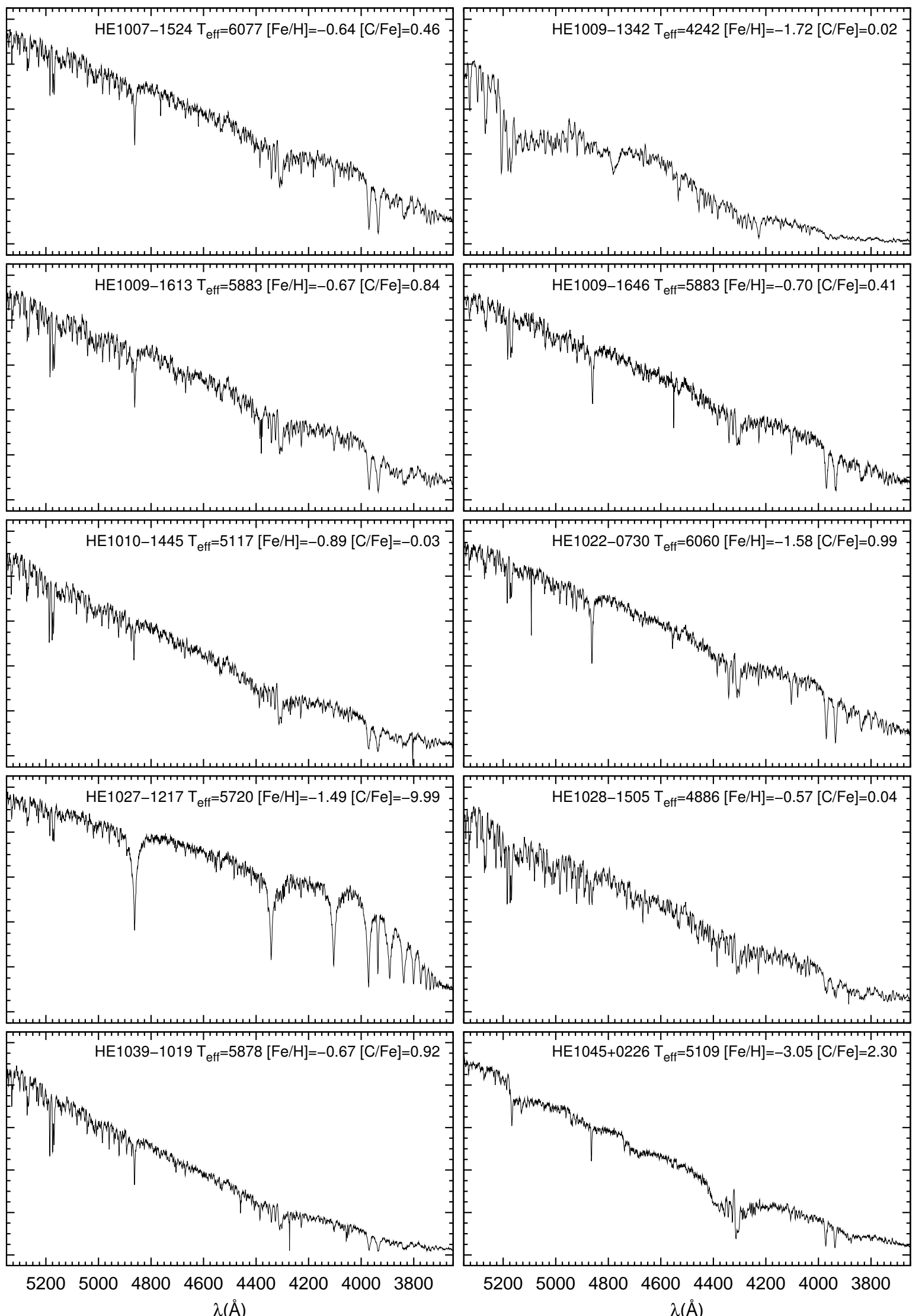

$\lambda(\AA)$

$\lambda(\AA)$

Figura A.7: Espectros das estrelas observadas com o SOAR (7). 

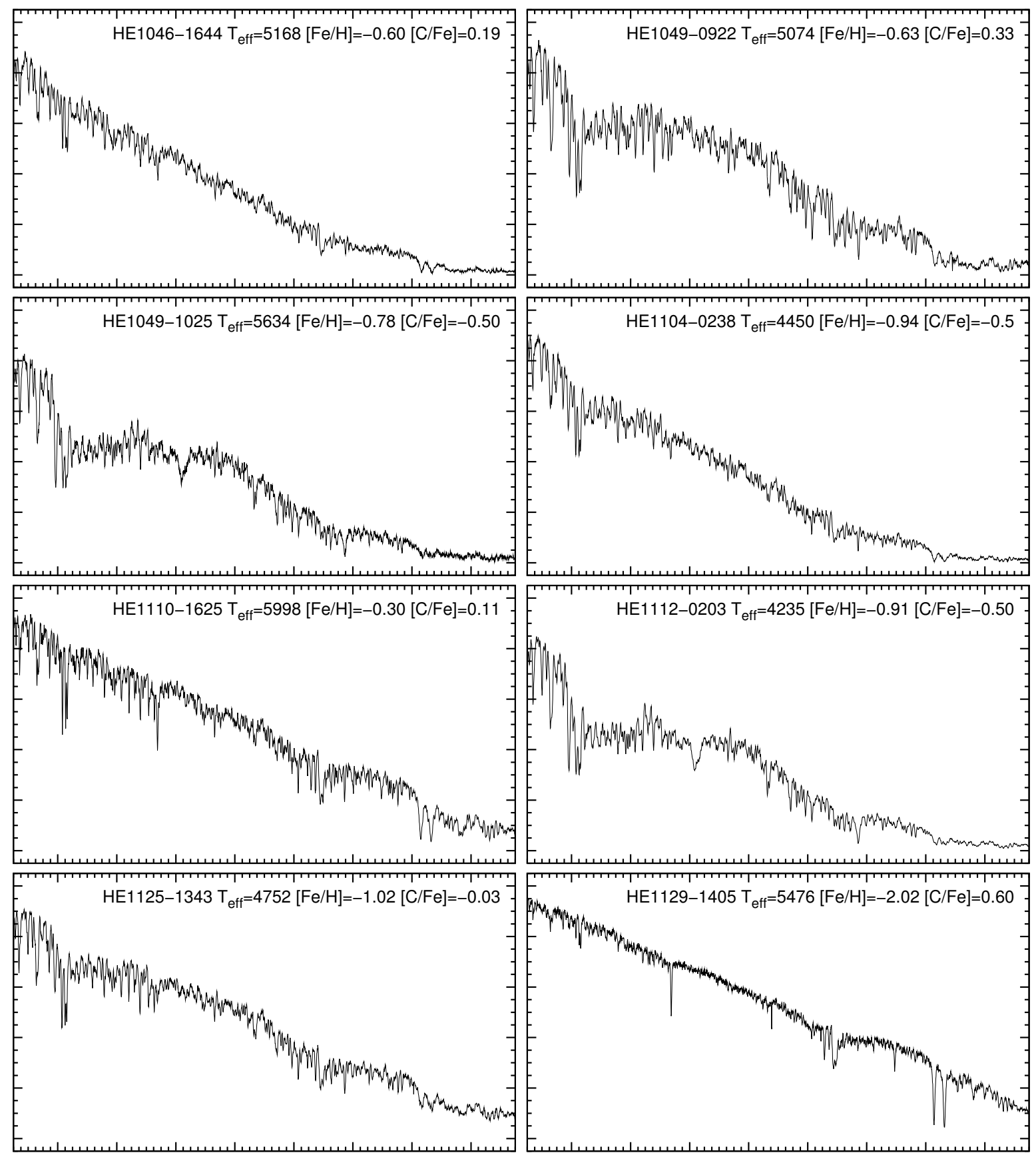

19 HE1132-0915 $\left.\mathrm{T}_{\text {eff }}=5905[\mathrm{Fe} / \mathrm{H}]=-1.56[\mathrm{C} / \mathrm{Fe}]=-9.99\right]$

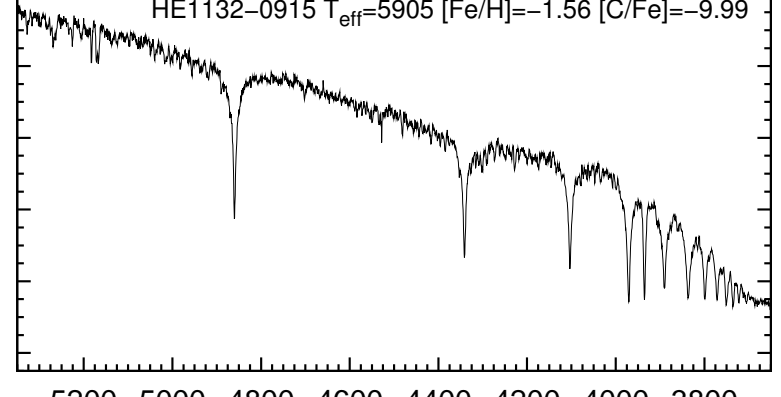

$\begin{array}{llllllll}5200 & 5000 & 4800 & 4600 & 4400 & 4200 & 4000 & 3800\end{array}$ $\lambda(\AA)$

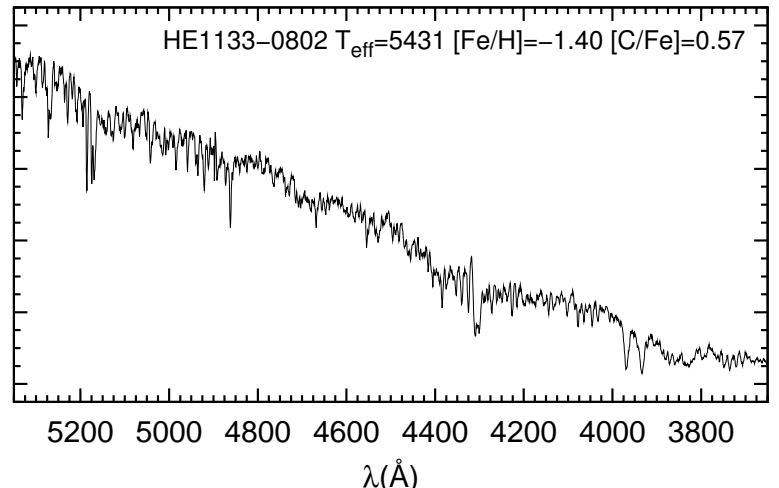

Figura A.8: Espectros das estrelas observadas com o SOAR (8). 

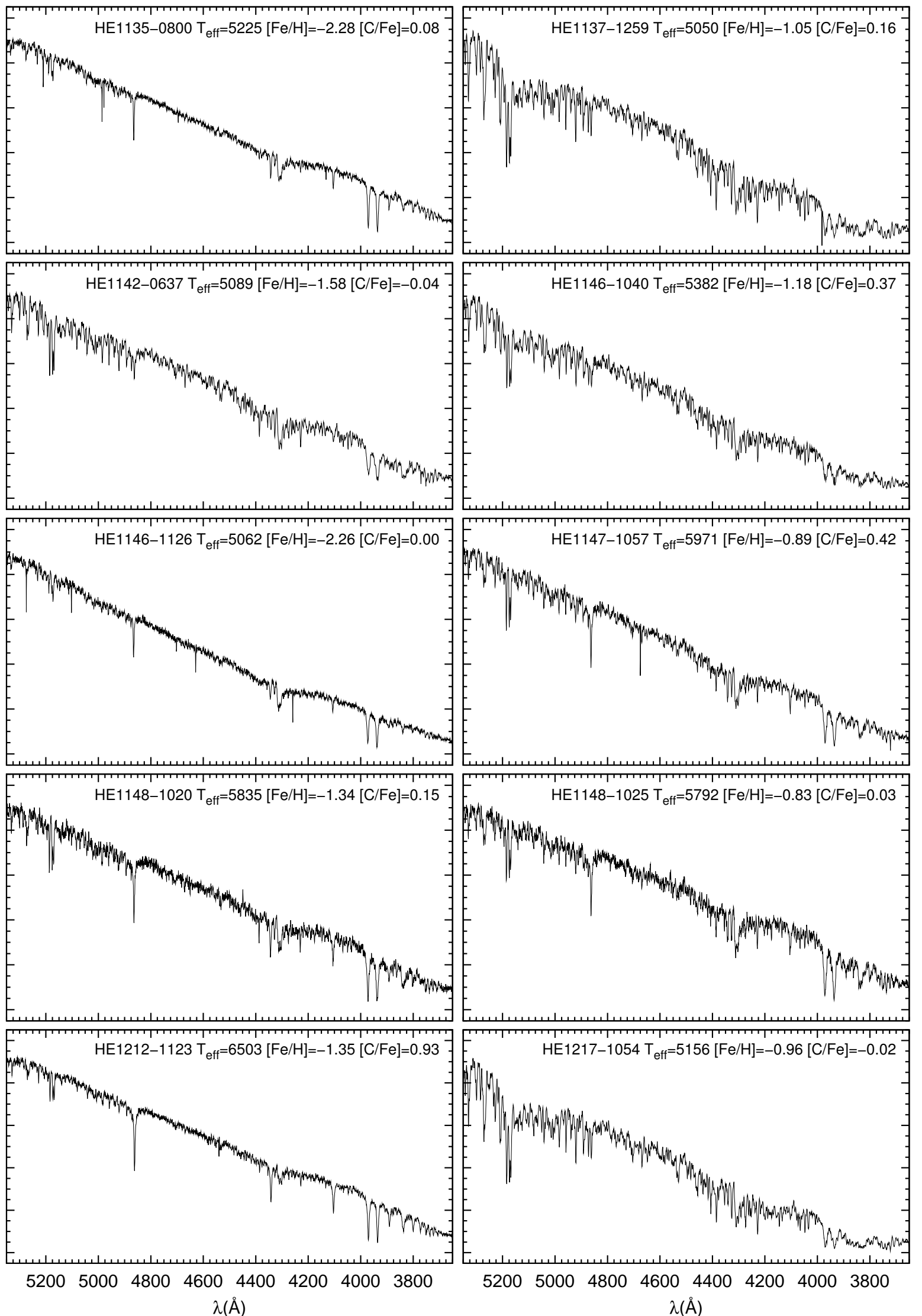

$\lambda(\AA ̊)$

$\lambda(\AA)$

Figura A.9: Espectros das estrelas observadas com o SOAR (9). 


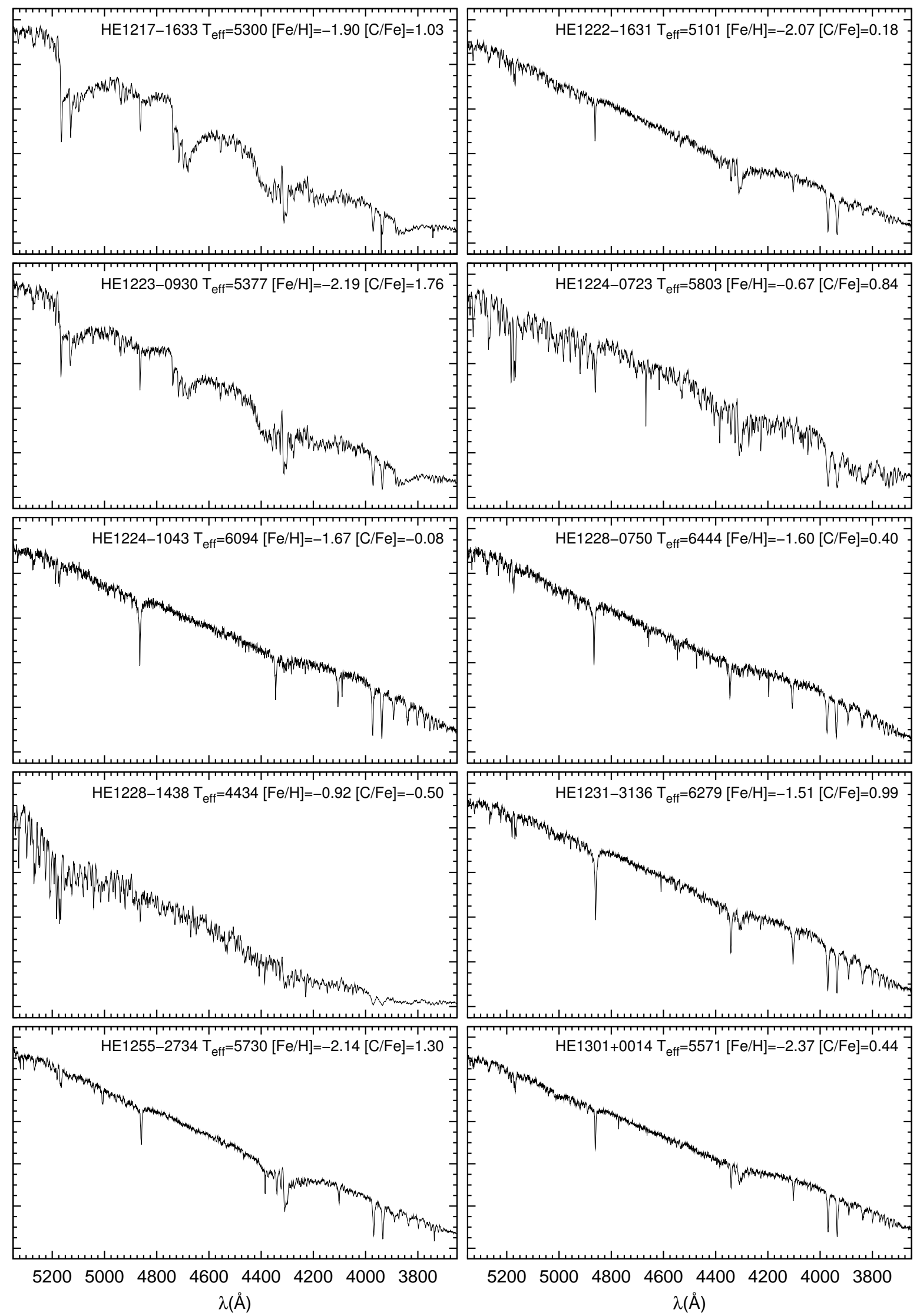

Figura A.10: Espectros das estrelas observadas com o SOAR (10). 

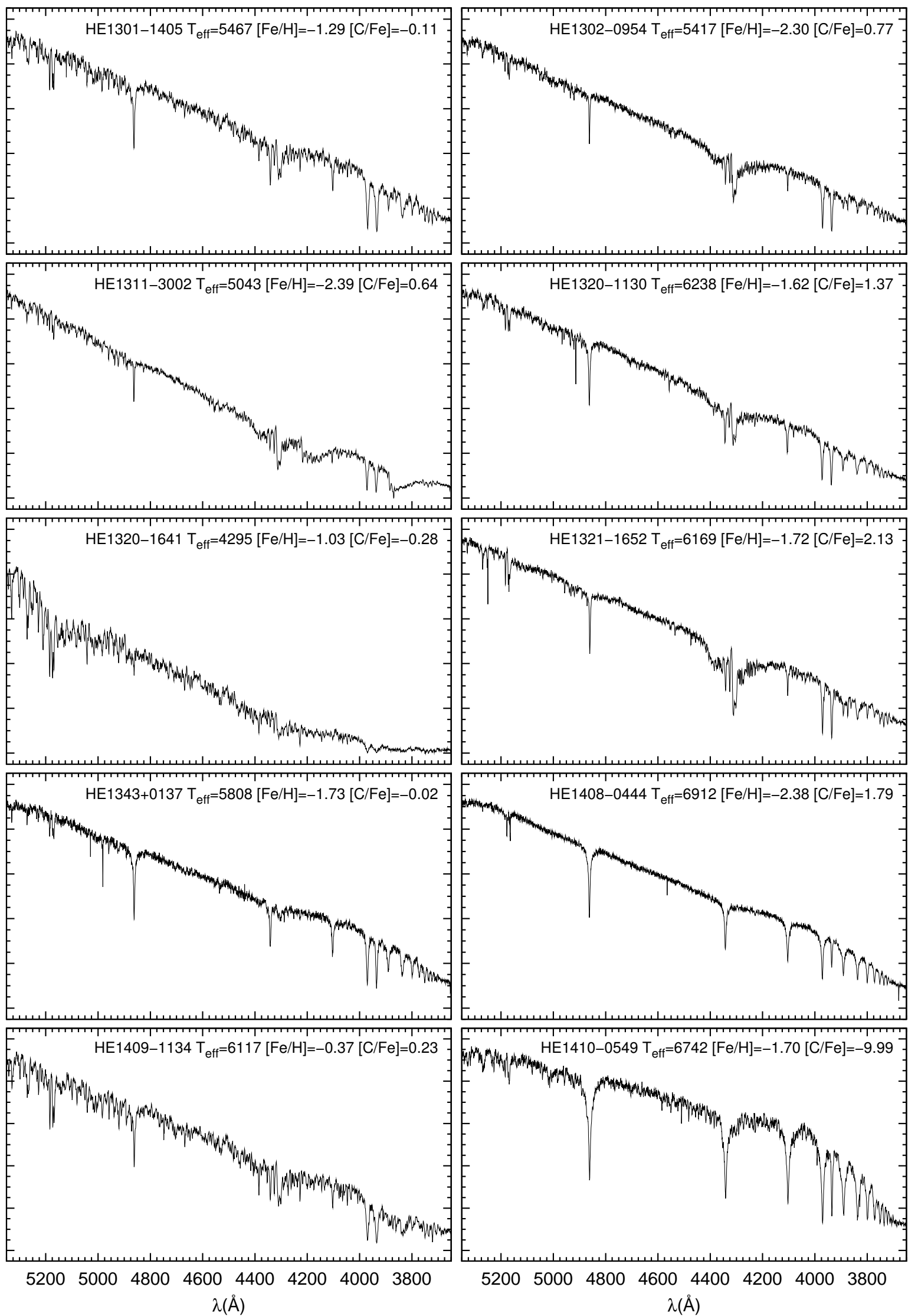

Figura A.11: Espectros das estrelas observadas com o SOAR (11). 

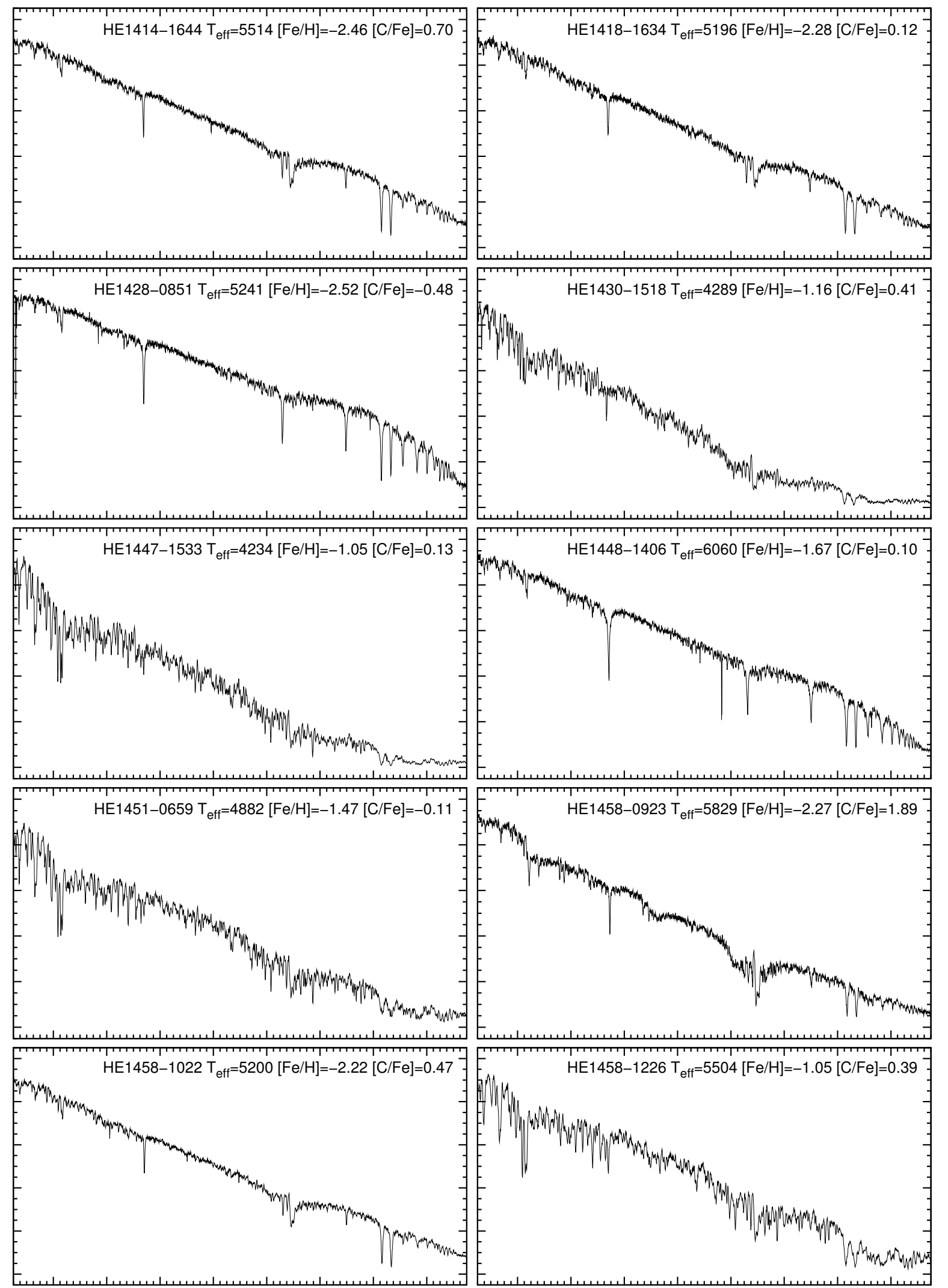

52005000480046004400420040003800 $\lambda(\AA)$
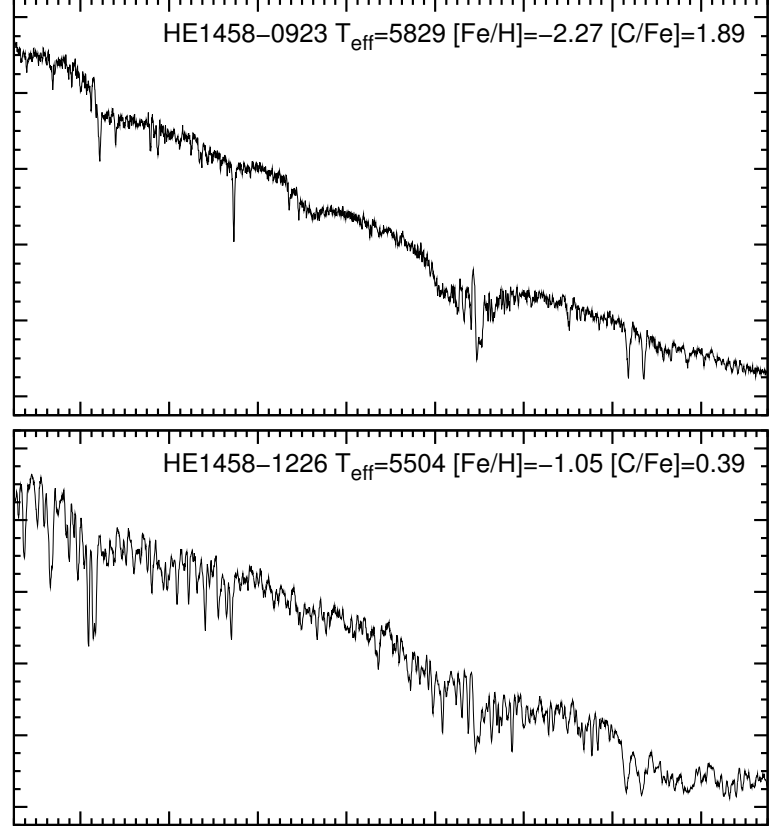

52005000480046004400420040003800

$\lambda(\AA)$

Figura A.12: Espectros das estrelas observadas com o SOAR (12). 

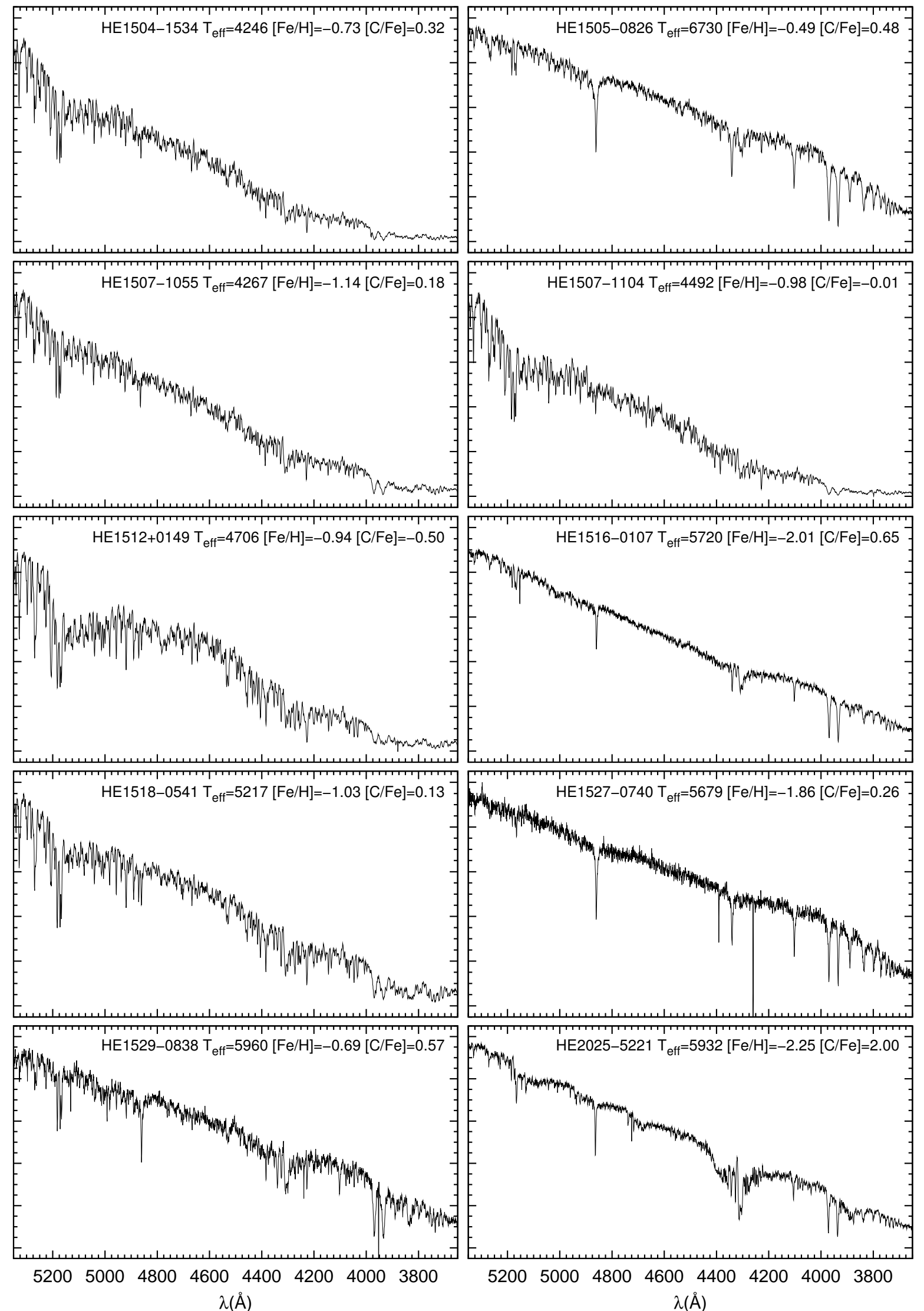

Figura A.13: Espectros das estrelas observadas com o SOAR (13). 


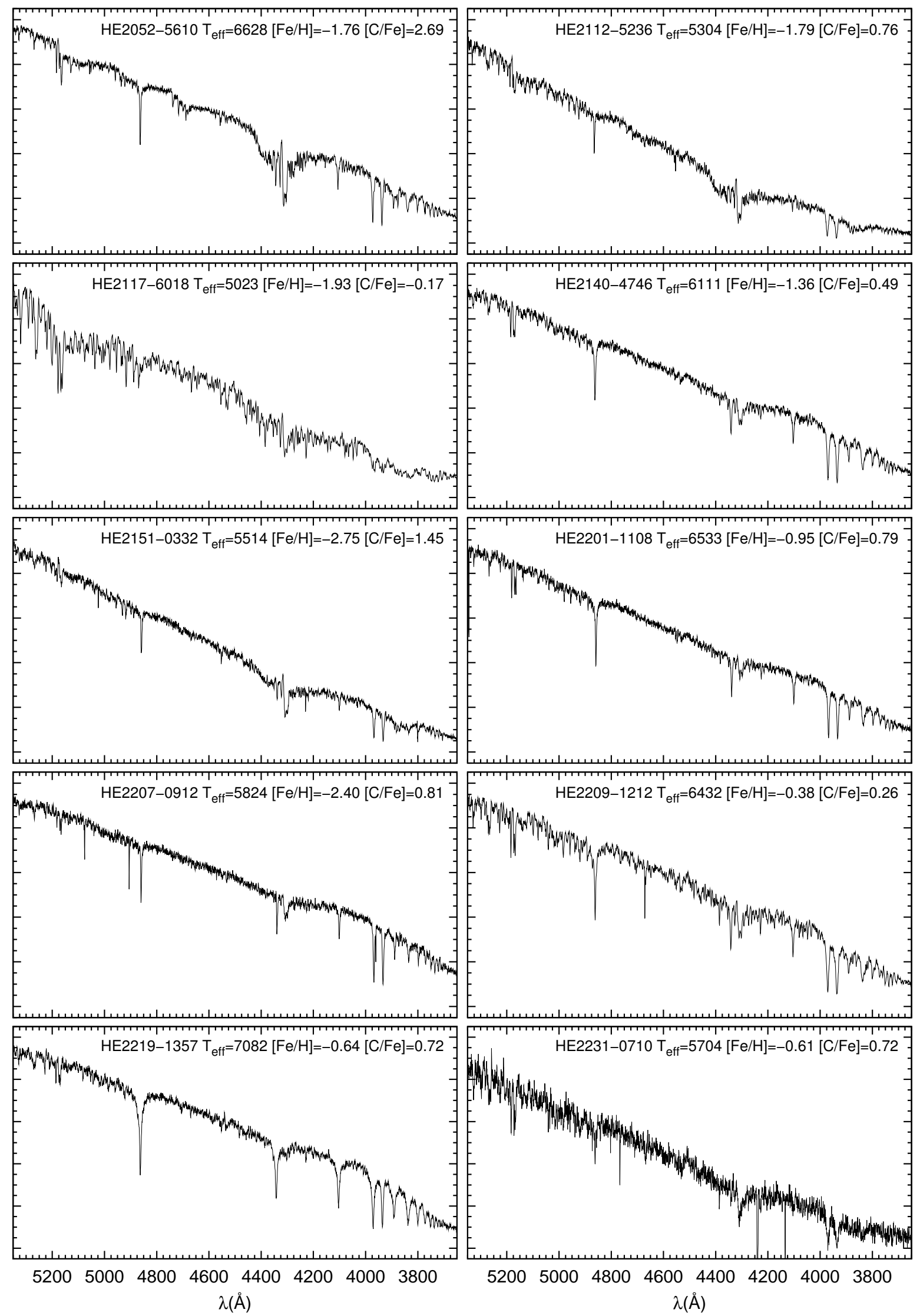

Figura A.14: Espectros das estrelas observadas com o SOAR (14). 
Apêndice B

Código Fonte para Cálculo dos Índices de Linha

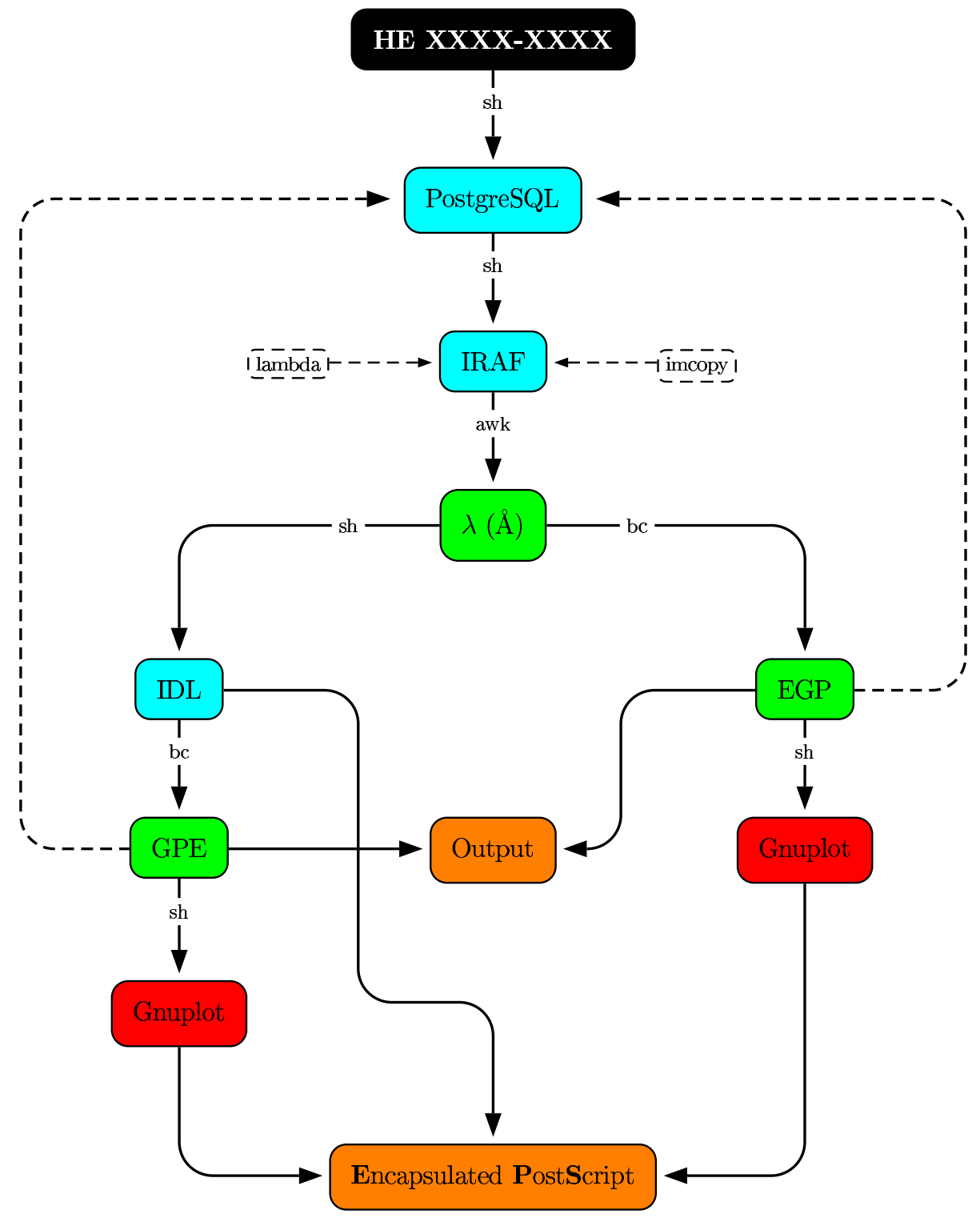

Figura B.1: Fluxograma de cálculo dos índices GPE e EGP 


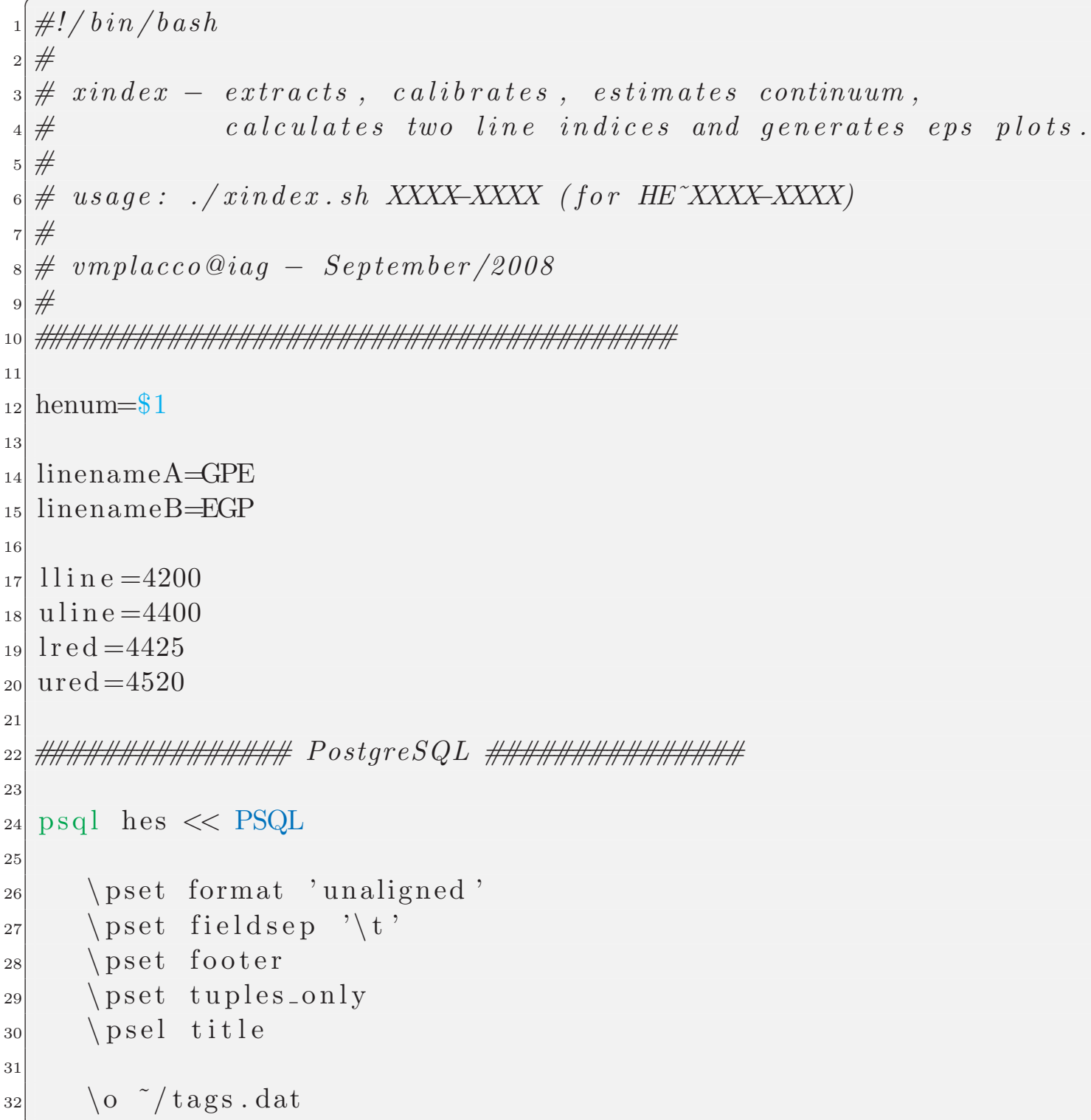




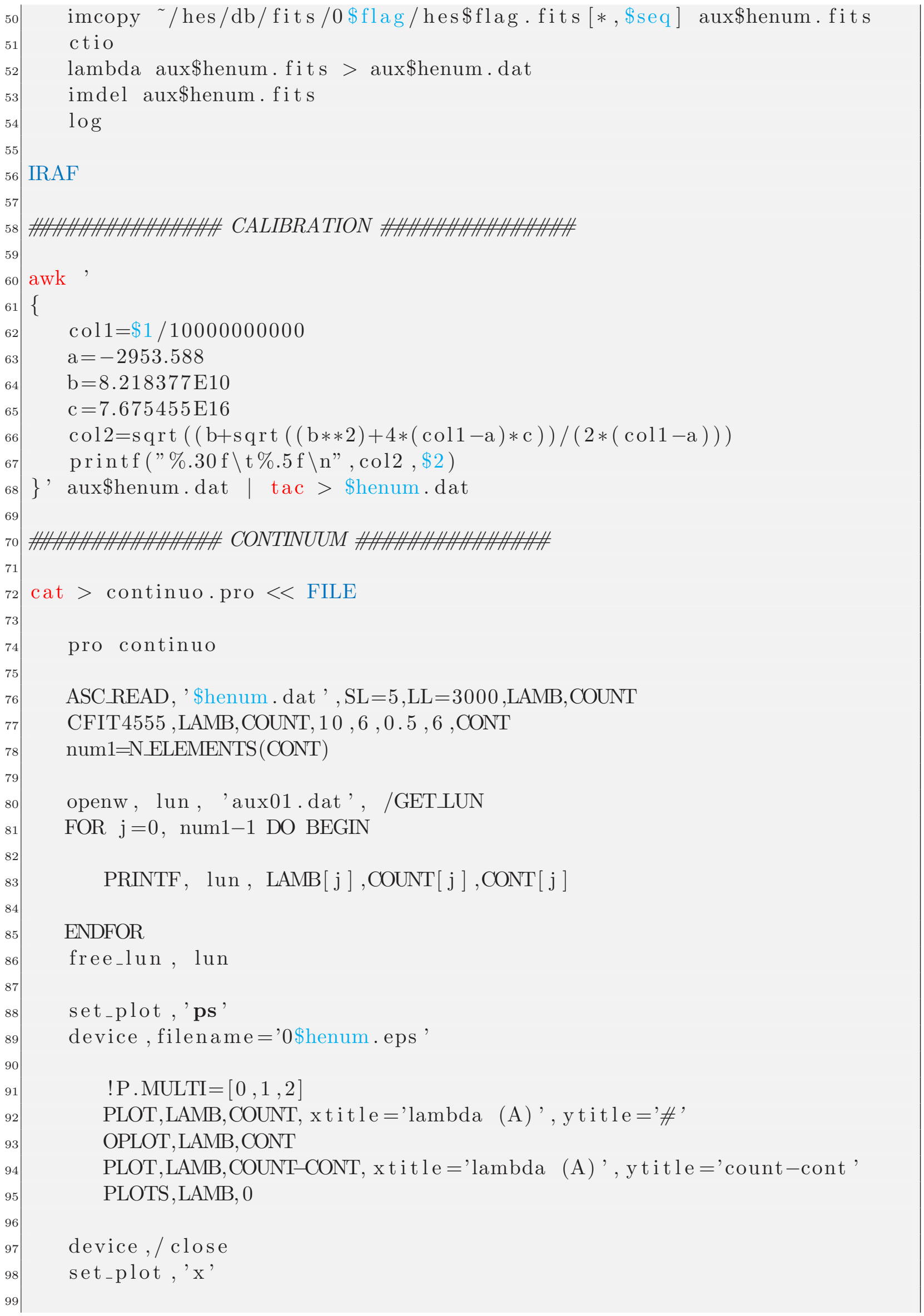




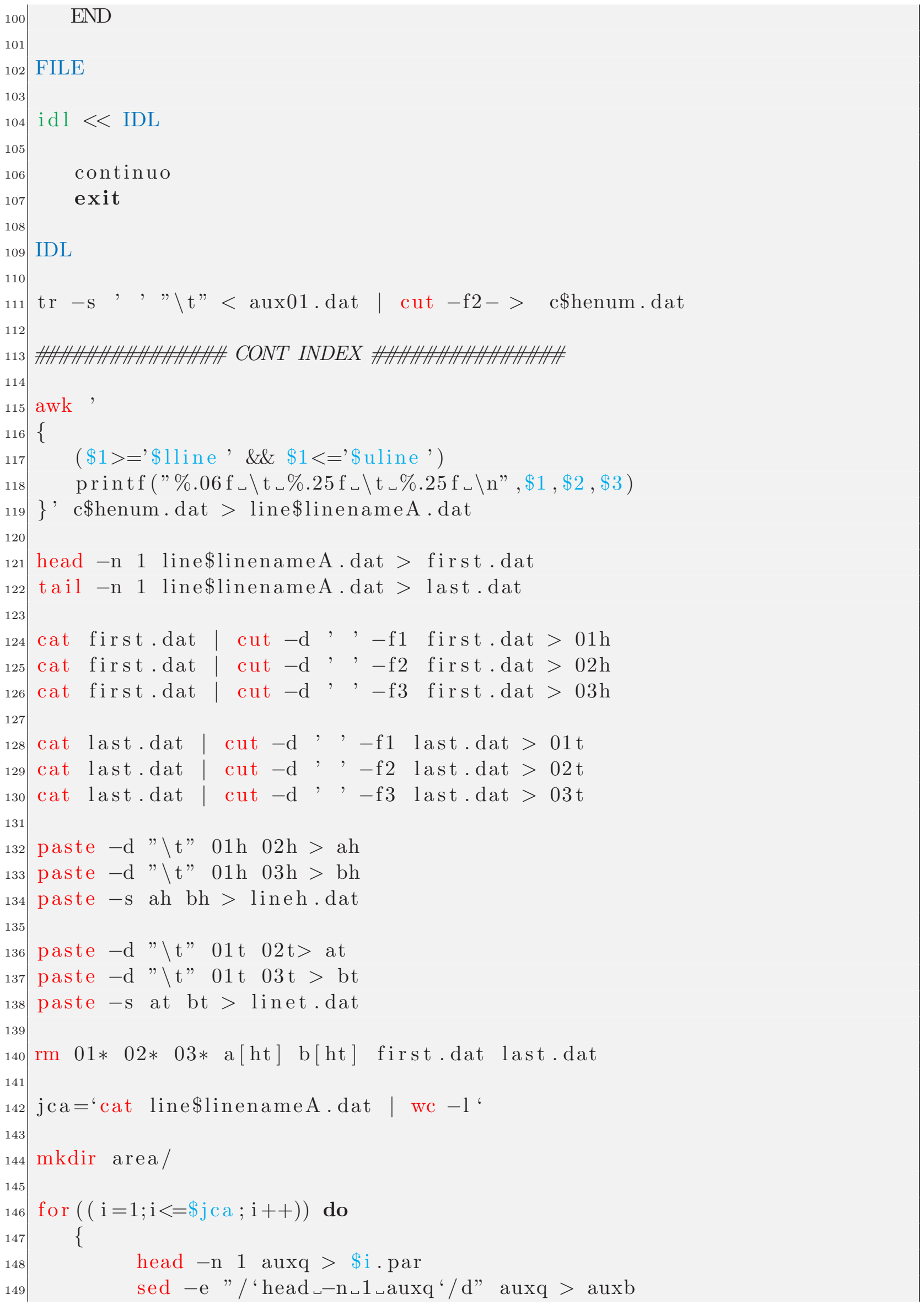




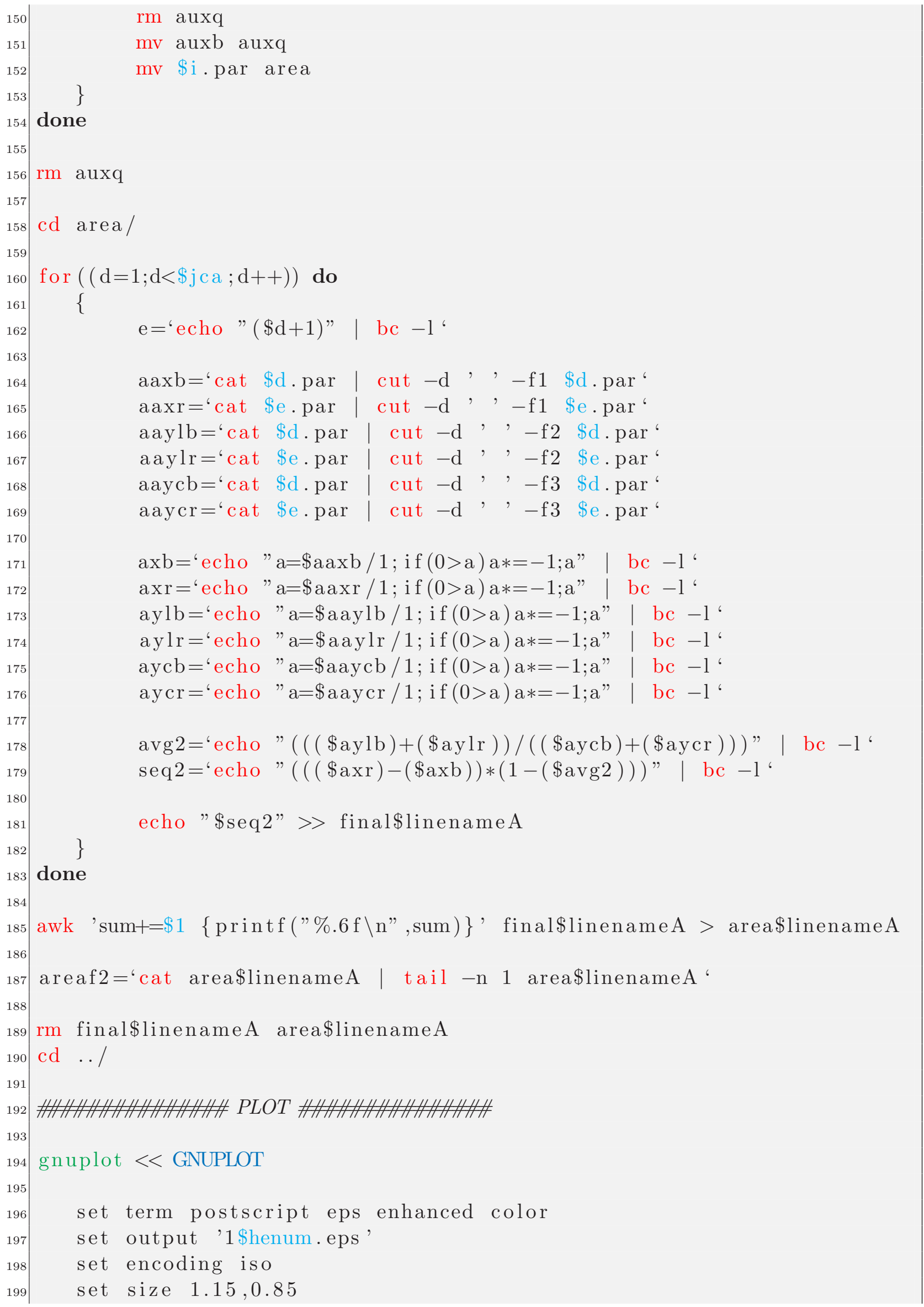




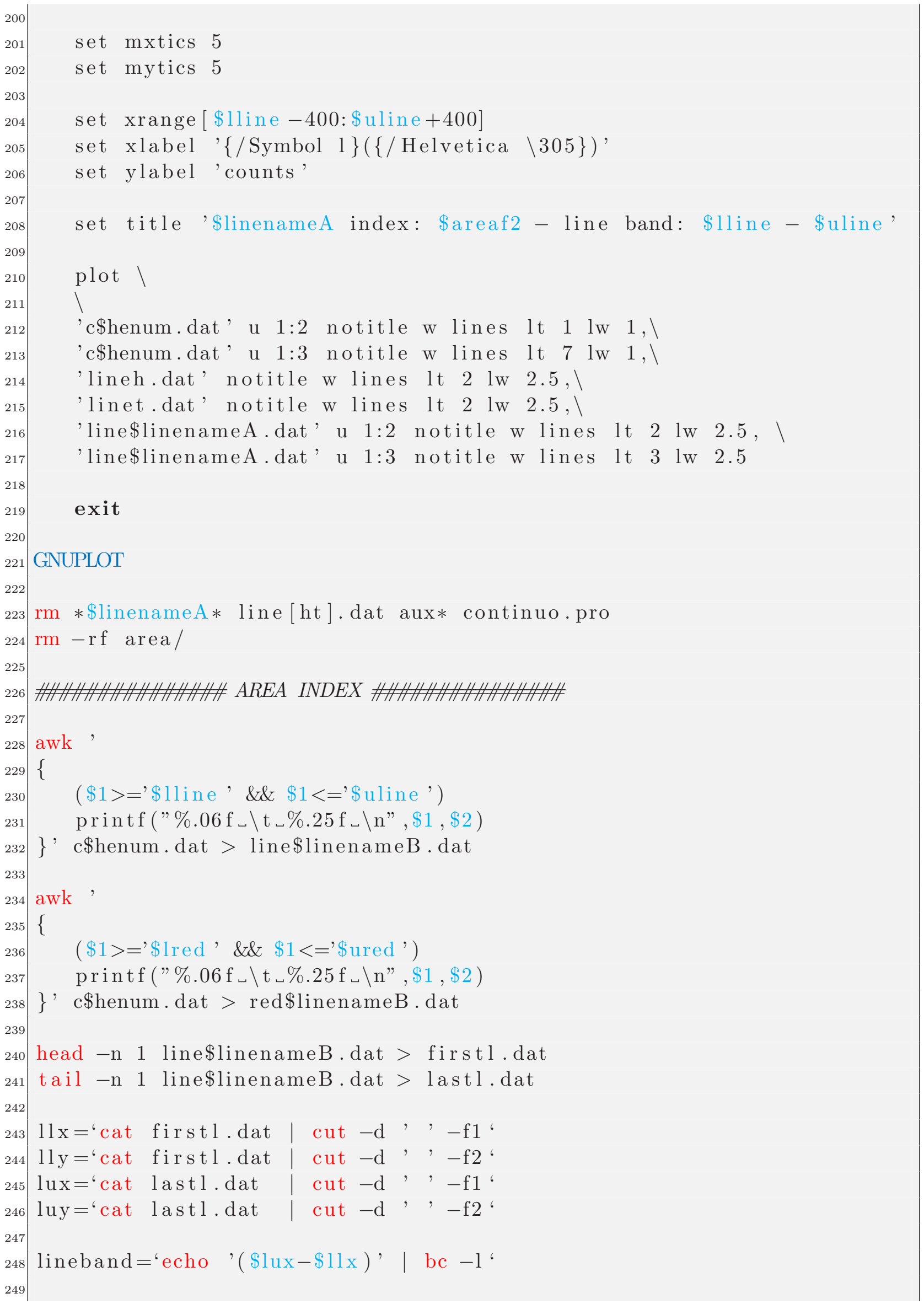




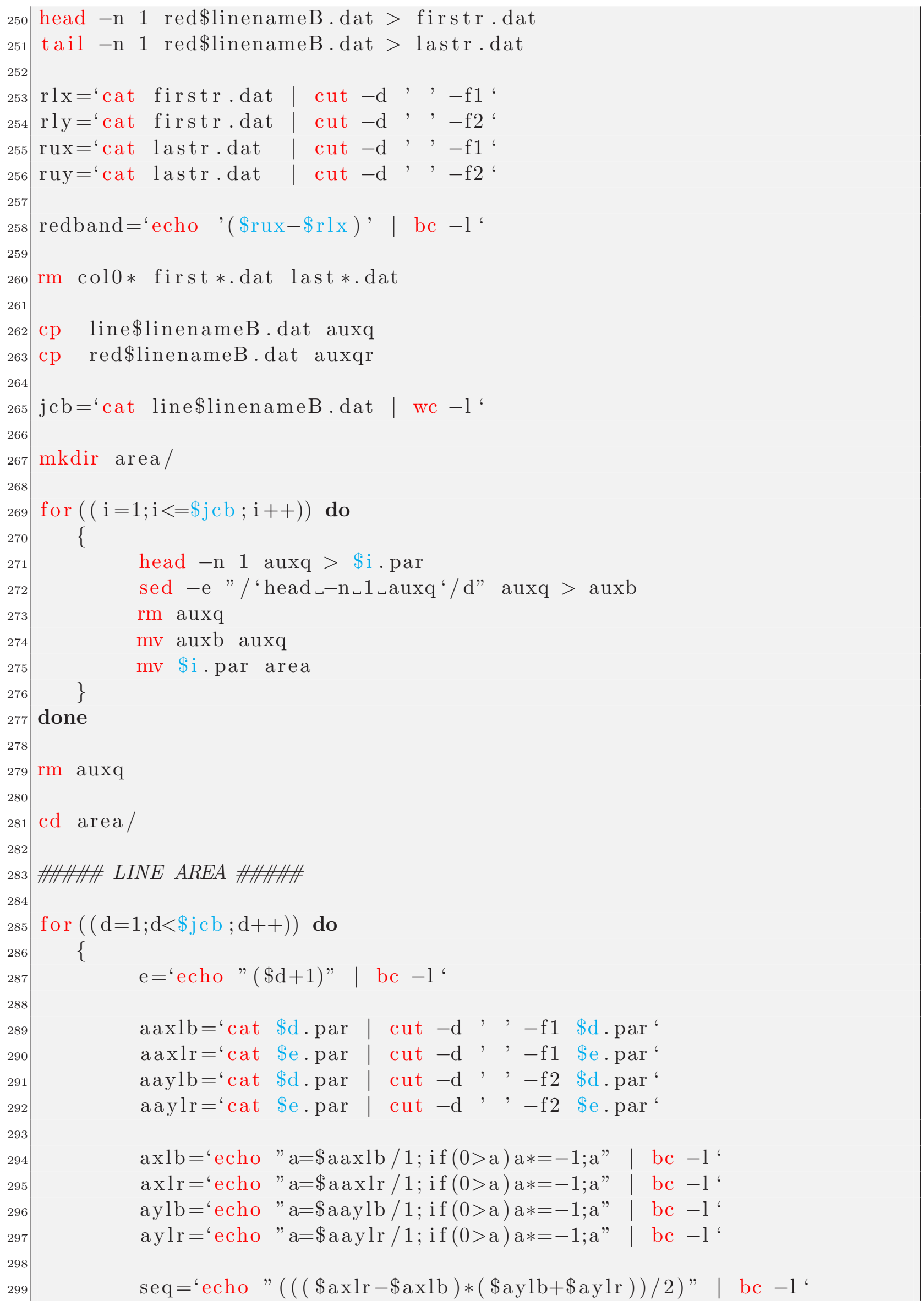




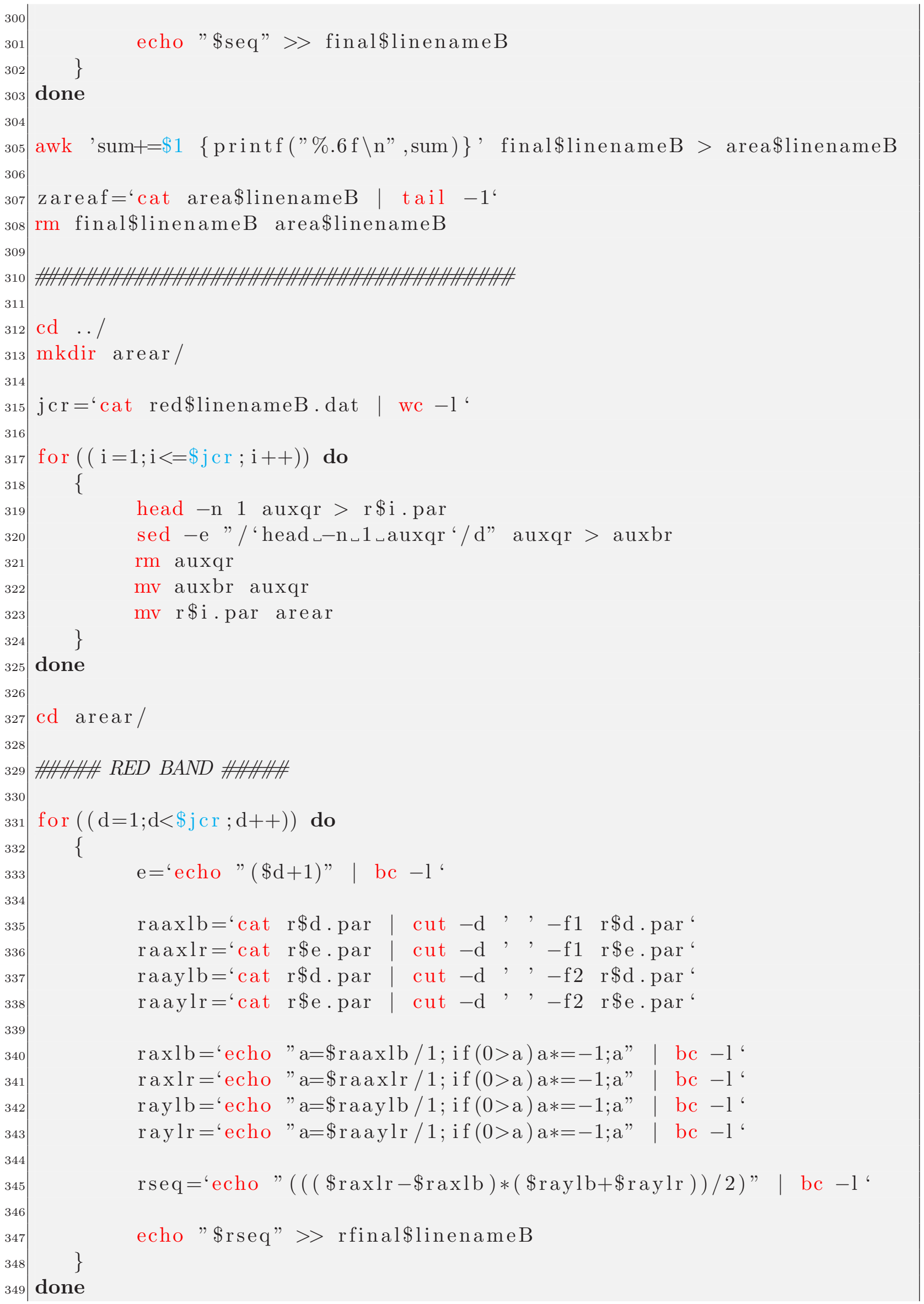




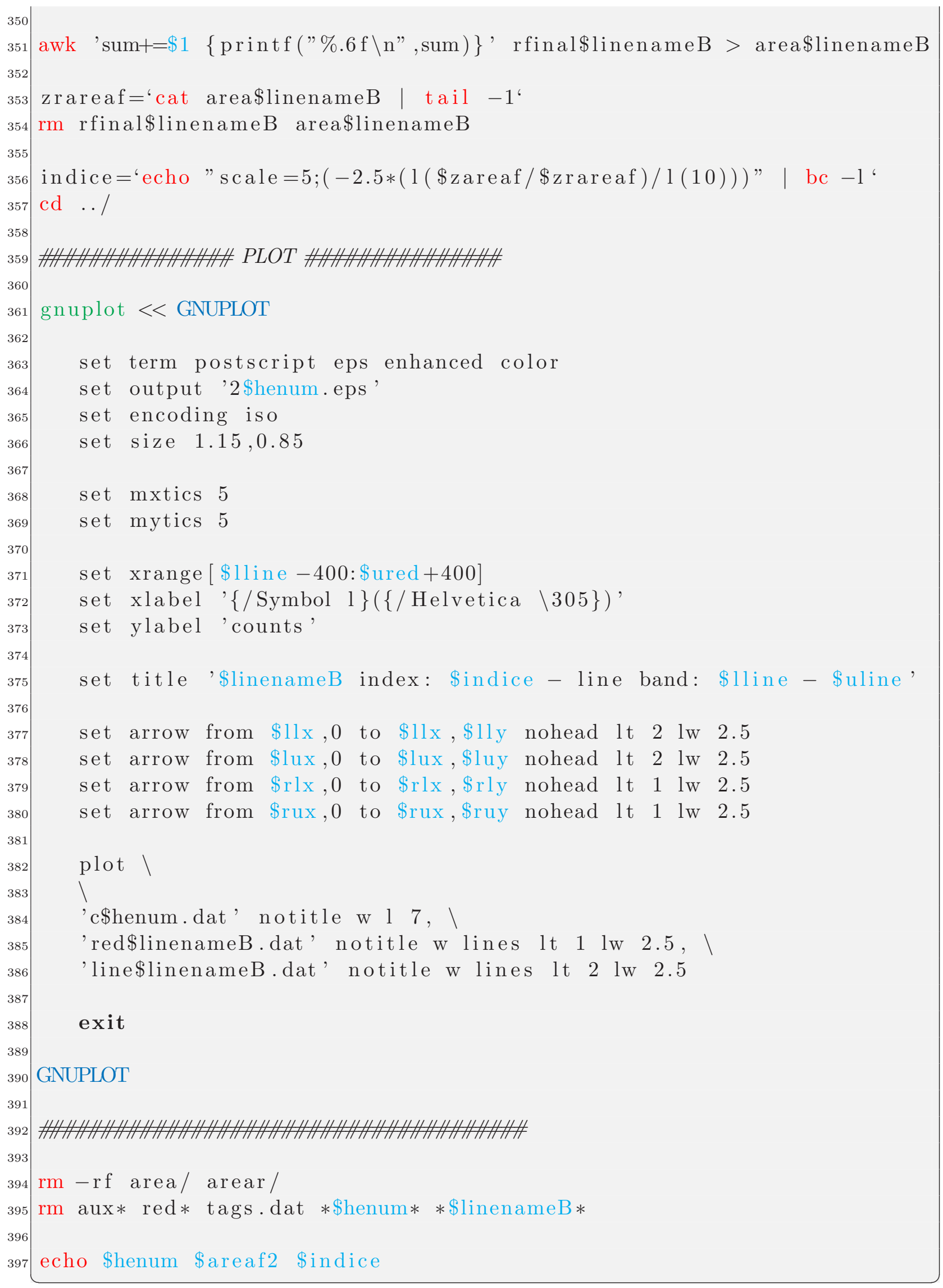


Apêndice C

Objetos Inéditos Classificados por Inspeção Visual 
Tabela C.1 - Objetos inéditos selecionados neste trabalho. O índice GPE é dado em Å.

\begin{tabular}{|c|c|c|c|c|c|c|c|c|c|c|c|c|c|}
\hline & $\mathrm{PE}$ & & & & & & $\mathrm{PE}$ & & tome & $\mathrm{PE}$ & & Tome & GPE \\
\hline 008 & & & 412 & & & 5211 & & & $19-2$ & & & $2217-$ & \\
\hline & & & & & & & & & & & & & \\
\hline E0000-0451 & 54.5 & mpcc & E0251-1645 & 57.5 & mpcc & E0537-4849 & & & E1320-1641 & & & IE $2217-2106$ & 55.9 \\
\hline & & & & & & & & & & & & & \\
\hline & & & & & & & & & & & & & 41.2 \\
\hline HE0000-2132 & 7.2 & & & 43.8 & & & 50.2 & & & 43.0 & & & \\
\hline & & & & & & & & & & & & & \\
\hline HE0000-3029 & 9.7 & & E0252-0626 & 51.7 & & E0538-5010 & 56.7 & & HE1321-1652 & & & HE2217-3439 & \\
\hline [E0000-3710 & 54.9 & & & 37.8 & & & & & & & & & 41.2 \\
\hline $20000-3909$ & & & E0252-4145 & 37.8 & & $0540-3733$ & & & $1-2003$ & 38.7 & & 532 & 41.5 \\
\hline & 8.7 & mpcb & & 36.7 & & & & & & & & & 51.2 \\
\hline [E0000-4424 & 44.9 & & & 50.4 & & $0540-4108$ & & & E1321-3133 & 31.6 & & & 51.7 \\
\hline & 5.4 & & & 49.0 & & & 56.3 & & & 57.8 & & & 52.7 \\
\hline & 2.3 & & & & & & & & & & & & \\
\hline & & & & 50.4 & & & 53.6 & & & & & & \\
\hline & & & & & & & & & & & & & 52.4 \\
\hline $1+0211$ & & & & & & & & & & & & & \\
\hline & & & & & & & & & & & & & \\
\hline $01-4354$ & & & $54-5828$ & & & 2. 4 & & & & & & & \\
\hline & 0.1 & & & & & & & & & & & & \\
\hline $02-1933$ & & & 46 & & & & & & & & & & 43.6 \\
\hline & & & & & & & & & & & & & \\
\hline & & & & & & & & & & & & & \\
\hline & & & & & & & & & & & & & \\
\hline & & & & & & & & & & & & & \\
\hline & & & & & & & & & & & & & \\
\hline & 0.5 & & & & & & & & & & & & \\
\hline-1602 & & & & & & & & & & & & & \\
\hline & & & & & & & & & & & & & \\
\hline & & & & & & & & & & & & & \\
\hline & & & & & & & & & & & & & \\
\hline & & & & & & & & & & & & & \\
\hline & & & & & & & & & & & & & 42.1 \\
\hline & & & & & & & & & & & & & 14.3 \\
\hline & 5.0 & & & & & & & & & & & & \\
\hline & & & & & & & & & & & & & 38.3 \\
\hline & & & & & & & & & & & & & \\
\hline & & & & & & & & & & & & & \\
\hline & & & & & & & & & & 34 & & & 36.4 \\
\hline $4-2715$ & & & & & & & & & & & & & \\
\hline & & & & & & & & & & & & & \\
\hline & & & & & & & & & & & & & \\
\hline & & & & & & & & & & & & & \\
\hline & & & & & & & & & & & & & 9 \\
\hline-5806 & & & & & & & & & & & & & .5 \\
\hline & & & & & & & & & & & & & 57 \\
\hline & & & & & & & & & & & & & \\
\hline & & & & & & & & & & & & & .2 \\
\hline & & & & & & & & & & & & & \\
\hline-3051 & & & & & & & & & & & & & 41.2 \\
\hline & & & & & & & & & & & & & 41.1 \\
\hline-4546 & & & -0958 & & & & & & & & & & 57.2 \\
\hline-6512 & & & & & & & & & & 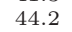 & & & 40.7 \\
\hline-0644 & & & 150 & & & 7 & & & & & & & 44.2 \\
\hline-2305 & & & & & & & & & & & & & 49.9 \\
\hline & & & & & & & & & & & & & \\
\hline & & & & & & & & & & & & & 51.4 \\
\hline & & & & & & & & & & & & & \\
\hline & & & & & & & & & & & & & 47.3 \\
\hline & & & & & & & & & & & & & \\
\hline & & & & & & & & & & & & & 457 \\
\hline & & & & & & & & & & & & & \\
\hline & & & & & & & & & & & & & 50.4 \\
\hline+0049 & 2.7 & & & & & & 42 & & & & & & 49.5 \\
\hline & & & & & & & & & & & & & \\
\hline & & & & & & & & & & & & & 49.3 \\
\hline & & & & & & & & & & & & & \\
\hline & & & & & & & & & & & & & \\
\hline & & & & & & & & & & & & & \\
\hline & & & & & & & & & & & & & 567 \\
\hline & & & & & & & & & & & & & \\
\hline & & & & & & & & & & & & & \\
\hline-59 & & & $\mathrm{H}$ & & & & & & 14 & & & & 44.5 \\
\hline & & & & & & & & & & & & & \\
\hline $\mathrm{H}$ & & & -4446 & & & 10 & & & 53 & & & 03 & 44.1 \\
\hline & & & & & & & & & & & & & \\
\hline $\mathrm{H}$ & & & 45 & & & 4 & & & 2 & & & 47 & 33.7 \\
\hline & & & & & & & & & & 46.7 & & & \\
\hline & & & & & & & & & & & & & 44.2 \\
\hline & & & & & & & & & & & & & 35.4 \\
\hline & & & & & & & & & & & & & \\
\hline & & & & 39 & & & 45 & & & 30.5 & & & 43.6 \\
\hline & & & & & & & & & & & & & 42.1 \\
\hline HE0010-0134 & 46.3 & mpcc & HE0304-1156 & 57.1 & $\mathrm{mpcc}$ & HE0854+0 & 55.3 & fhlc & HE1338-2938 & 40.1 & mpcc & HE $2222-5801$ & 43.5 \\
\hline
\end{tabular}


Tabela C.1 (Continuação)

\begin{tabular}{|c|c|c|c|c|c|c|c|c|c|c|c|c|c|}
\hline Nome & $\mathrm{PE}$ & lasse & Nome & $\mathrm{PE}$ & Classe & Nome & $\mathrm{PE}$ & Classe & Nome & $\mathrm{PE}$ & Classe & Nome & GPE \\
\hline HE0010-0747 & 37.1 & mpcc & IE0304-3234 & 50.0 & mpcc & HE0856+0222 & 36.2 & mpcc & HE1339-0018 & 35.7 & $\mathrm{mpcc}$ & ה2 & \\
\hline & & & & 48.7 & & & 35.1 & & HE $1339-0057$ & & & & \\
\hline & 9.3 & & & 35.9 & & & 0.1 & & & & & & \\
\hline HE0010-1745 & 6.9 & & E0304-4526 & 40.5 & & [E0900-0136 & 40.4 & & E1339-0101 & & & & \\
\hline HE0010-1928 & 3.4 & & & 34.4 & & & 32.1 & & & & & & \\
\hline HE0010-3035 & 5.4 & & E0305-0600 & 53.4 & & E0903+0009 & & & E1339-0517 & & & IE $2223-2512$ & \\
\hline & 1.9 & & & 61.5 & & & 39.4 & & & & & & \\
\hline & 4.2 & & E0305-3727 & 44.1 & & HE0904+0018 & 43.0 & & HE1339-2844 & & & $\mathrm{HE} 2223-2700$ & \\
\hline & 5.5 & & & 36.6 & & & 45.9 & & & & & & \\
\hline HE0011-2028 & 3.5 & & & & & & & & & & & & 36.3 \\
\hline HE0011- 2340 & 3.4 & & & 39.5 & & & 0.7 & & & & & & \\
\hline & 4.6 & & & & & & & & & & & & \\
\hline E0011-4158 & 3.1 & & & 52.3 & & & 35.7 & & & & & & \\
\hline & 4 & & & & & & & & & & & & \\
\hline HE0012+0015 & 5.5 & & $206 \quad 26$ & 52.8 & & & 41.7 & & & & & & \\
\hline & 40.8 & & & 43.6 & & & 42.5 & & & 61.1 & & & \\
\hline & 53.6 & & & 36.3 & & & 44.9 & & & & & & \\
\hline & 42.3 & & & 54.8 & & & 45.0 & & & & & & \\
\hline & 3.8 & & & 49.1 & & & 47.6 & & & & & & \\
\hline & 8.0 & & & 45.8 & & & 48.9 & & & & & & \\
\hline & 2.0 & & & 36.0 & & & & & & & & & \\
\hline & 6.5 & & & 44.7 & & & & & & & & & \\
\hline & 4.5 & & & & & & & & & & & & \\
\hline & 3.3 & & & 40.0 & & & & & & & & & \\
\hline & 41.2 & & & & & & & & & & & & \\
\hline $13-1629$ & 1.1 & & & 51.9 & & & 55. & & & & & & \\
\hline & 1.5 & & & 35.9 & & & & & & & & & \\
\hline $3-1828$ & 7.0 & & & 38.4 & & & 35. & & & & & & \\
\hline & 7.6 & & & 46.6 & & & & & & & & & \\
\hline & 5.9 & & & & & & & & & & & & \\
\hline & 4.8 & & & 33. & & & & & & & & & \\
\hline & 0.0 & & & 34. & & & & & & & & & \\
\hline & 6.1 & & & 51.6 & & & & & & & & & \\
\hline $13-6413$ & 2.4 & & & 39.7 & & & & & & & & & \\
\hline & 2.3 & & & 40.8 & & & & & & & & & \\
\hline & 71 & & & & & & & & & & & & \\
\hline & 1.2 & & & 9.5 & & & & & & & & & \\
\hline & 4 & & & & & & & & & & & & \\
\hline & 1.0 & & & 60.4 & & & & & & & & & \\
\hline & 5.7 & & & 9. & & & & & & & & & \\
\hline & 9.5 & & & 44.6 & & & 5 & & & & & & \\
\hline & 1.1 & & & 31. & & & & & & & & & \\
\hline & 9.1 & & & 372 & & & & & & & & & \\
\hline & 6.2 & & & 10. & & & 43 & & & & & & \\
\hline & & & & 23 & & & & & & & & & \\
\hline-2740 & 4.0 & & & . & & & & & & & & & \\
\hline & 2.6 & & & 37.5 & & & & & & & & & \\
\hline & 5.3 & & & & & & & & & & & & \\
\hline & 3 & & & & & & & & & & & & .7 \\
\hline $5-4141$ & 0.0 & & & 30 & & & & & & & & & \\
\hline & 9.2 & & & & & & & & & & & & \\
\hline & 0.9 & & & 41. & & & & & & & & & \\
\hline & 4.1 & & & & & & & & & & & & \\
\hline & 4.6 & & & & & & & & & & & & \\
\hline & 3.6 & & & & & & & & & & & & \\
\hline & 4.1 & & & & & & & & & & & & \\
\hline & 1.8 & & & & & & & & & 71 & & & 49. \\
\hline-4915 & 4.0 & & & & & & & & & & & & 9.2 \\
\hline-5040 & 1.2 & & & & & & & & & & & & \\
\hline-5207 & 7.0 & & & & & & & & & & & & \\
\hline & & & & & & & & & & & & & \\
\hline & 0.4 & & & & & & & & & & & & 5 \\
\hline & & & & & & & & & & & & & \\
\hline & 3 & & & & & & & & & & & & \\
\hline & 9.0 & & & & & & & & & & & & \\
\hline & 3 & & & & & & & & & & & & 39 \\
\hline & 1.1 & & & 40 & & & & & & & & & \\
\hline & & & & & & & & & & & & & \\
\hline & 4.4 & & & & & & & & & & & & 41.5 \\
\hline & & & & & & & & & & & & & \\
\hline $7-6128$ & 3.9 & & & 31. & & & 59 & & & 30.7 & & & 48.9 \\
\hline & & & & & & & & & & & & & \\
\hline & & & & & & & & & & & & & 56.1 \\
\hline & & & & & & & & & & & & & \\
\hline & & & & & & & & & & & & & \\
\hline & 4 & & & & & & & & & & & & \\
\hline & & & & & & & & & & & & & \\
\hline & 4.2 & & & & & & 33 & & & & & & \\
\hline & & & & & & & & & & & & & \\
\hline $019-0801$ & 37.3 & & $0314-5422$ & 40.9 & & 1 & 44.8 & & 52 & 33.5 & & 17 & 30.4 \\
\hline & 53.1 & & & 39.2 & & & 44. & & & & & & \\
\hline & 44.6 & & & 50.1 & & & 42. & & & 31 & & 36 & 69.0 \\
\hline & 34.9 & & & & & & & & & & & & \\
\hline HE0019-5703 & 37.9 & mpcb & HE0315 - 2531 & 37.7 & & HE0940-0925 & 48.2 & & HE $1353-3131$ & 31.7 & mpcc & HE2230-0351 & 41.8 \\
\hline
\end{tabular}


Tabela C.1 (Continuação)

\begin{tabular}{|c|c|c|c|c|c|c|c|c|c|c|c|c|c|}
\hline Nome & $\mathrm{PE}$ & Classe & Nome & $\mathrm{APE}$ & lasse & Nome & GPE & Classe & Nome & GPE & Classe & Nome & GPE \\
\hline HE0020-1316 & 39.4 & mpcc & HE0315-5028 & 51.2 & 1рсc & (109-1040 & 54.2 & прсс & HE $1354+0022$ & 40.8 & $\operatorname{mncc}$ & $2230-03$ & 42.9 \\
\hline & & & HE0316-1509 & 44.6 & & IE0940-1418 & & & HE $1354-0841$ & 38.7 & & & 43.9 \\
\hline E0020-2549 & 3.9 & & & & & & & & & 37.4 & & & 84.0 \\
\hline E0020-3435 & & & E0316-2135 & 46.3 & & E0942-0208 & 36.2 & & E1354-2427 & 42.9 & & IE2230-0635 & 36.5 \\
\hline E0020-3813 & 0.2 & & & 35.9 & & & & & & 34.8 & & & 66.3 \\
\hline E0020-6033 & & & E0316-2903 & & & E0942-1448 & & & HE1354-2817 & 33.9 & & HE2230-0706 & \\
\hline $0020-6125$ & 4.9 & & & 37.8 & & & & & & & & & \\
\hline E0020-6153 & 39.8 & & E0316-4534 & & & E0943-0734 & & & HE $1355-0740$ & 36.9 & & HE $2230-3429$ & 33.7 \\
\hline & 52.1 & & & 36.3 & ipcc & & 43.7 & & & 45.7 & & & 34.4 \\
\hline HE0021-0545 & & & E0316-4836 & & & & & & & & & & 40.0 \\
\hline HE0021-1627 & & & & & & & & & & & & & \\
\hline & & & & & & & & & & & & & \\
\hline-2239 & & & $\mathrm{E} 0316-6212$ & 72.8 & & & & & & & & & \\
\hline & & & & & & & & & & & & & \\
\hline $0021-3703$ & & & $\mathrm{E} 0317-2317$ & & & & & & & 49.8 & & & \\
\hline & 40.2 & $\mathrm{mpcc}$ & & 34.3 & & & & & & 34.0 & & & 37.7 \\
\hline $1-5142$ & 52.7 & & & 48.7 & & & 53.2 & & & 54.3 & & & 68.9 \\
\hline & 40.1 & & & 45.7 & & & & & & & & & \\
\hline-6420 & 40.0 & & & 40.8 & & & & & & 37.4 & & & 86.9 \\
\hline & 512 & & & & & & & & & & & & \\
\hline & 42.0 & & & & & & & & & & & & 38.5 \\
\hline 2541 & & & & & & & & & & & & & \\
\hline & & & & & & & & & & & & & \\
\hline & & & & & & & & & & & & & \\
\hline & & & & & & & & & & & & & \\
\hline $22-3152$ & 3.6 & & & & & & & & & 44 & & & \\
\hline & 0.0 & & & & & & & & & & & & \\
\hline & 1.1 & & & & & & & & & & & & \\
\hline & & & & & & & & & & & & & \\
\hline & & & & & & & & & & & & & \\
\hline & & & & & & & & & & 54 & & & \\
\hline & & & & & & & & & & & & & \\
\hline & 5 & & & & & & & & & 51 & & & \\
\hline-1733 & 5 & & & & & & & & & & & & \\
\hline-2445 & 1.1 & & & & & & & & & & & & \\
\hline & & & & & & & & & & & & & \\
\hline $3-3009$ & & & & & & & & & & & & & \\
\hline & & & & & & & & & & & & & \\
\hline & & & & & & & & & & & & & \\
\hline & & & & & & & & & & 3 & & & \\
\hline & & & & & & & & & & & & & \\
\hline & 2.0 & & & & & & & & & 41 & & & \\
\hline & & & & & & & & & & & & & \\
\hline & & & & & & & & & & 35 & & & .5 \\
\hline & & & & & & & & & & & & & \\
\hline-5959 & & & & & & & & & & 4 & & & .6 \\
\hline & & & & & & & & & & & & & 3 \\
\hline & & & & & & & & & & & & & \\
\hline & & & & & & & & & & 3 & & & 3 \\
\hline & & & & & & & & & & & & & \\
\hline & & & & & & & & & & 41 & & & .9 \\
\hline 2354 & & & & & & & & & & & & & \\
\hline & & & & & & & & & & & & & 9 \\
\hline & & & & & & & & & & & & & \\
\hline & & & & & & & & & & & & & \\
\hline & & & & & & & & & & & & & \\
\hline & & & & & & & & & & 40 & & & 53.3 \\
\hline-3751 & & & & & & & & & & 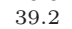 & & & 62.5 \\
\hline-5043 & & & & & & & & & & & & & \\
\hline-6703 & & & & & & & & & & & & & 41.0 \\
\hline & & & & & & & & & & & & & \\
\hline & & & & & & & & & & & & & 49.0 \\
\hline & & & & & & & & & & & & & \\
\hline & & & & & & & & & & & & & 13.7 \\
\hline & & & & & & & & & & & & & \\
\hline 9 & & & & & & & & & & 6 & & & 65.6 \\
\hline & & & & & & & & & & & & & \\
\hline & & & & & & & & & & & & & \\
\hline & & & & & & & & & & & & & 47.5 \\
\hline & & & & & & & & & & & & & \\
\hline-2103 & 1.4 & & & & & & & & & 33 & & 24 & 76.8 \\
\hline & & & & & & & & & & & & & \\
\hline & & & & & & & & & & & & & \\
\hline & & & & & & & & & & & & & \\
\hline & & & & & & & & & & & & & 65.4 \\
\hline & & & & & & & & & & & & & \\
\hline & & & & & & & & & & & & & \\
\hline & & & & & & & & & & & & & \\
\hline & & & & & & & & & & & & & \\
\hline-322 & & & E0327-3958 & 49 & & 32 & & & 24 & 45.9 & & $2233-0620$ & 66.4 \\
\hline & & & & & & & & & & 56. & & & \\
\hline & & & $7-4923$ & & & & & & & & & $\$ 49$ & 62 \\
\hline & & & & & & & & & & & & & \\
\hline HE $0028-2303$ & 51.3 & & HE $0328+0144$ & 41.5 & & HE $1004-0350$ & 49.8 & mpcc & HE $1413-1333$ & 43.0 & mpcc & HE2233-2401 & 56.0 \\
\hline
\end{tabular}


Tabela C.1 (Continuação)

\begin{tabular}{|c|c|c|c|c|c|c|c|c|c|c|c|c|c|}
\hline Nome & GPE & lasse & Nome & $\mathrm{PE}$ & Classe & Nome & $\mathrm{PE}$ & Classe & Nome & GPE & Classe & Nome & GPE \\
\hline HE0028-4026 & 38.3 & mpcc & IE0328-1204 & 48.1 & fhlc & HE1005+0010 & 35.2 & 1рсc & HE1413-1958 & 37.8 & $\mathrm{mpcc}$ & HE2233-3305 & 39.1 \\
\hline HE0028-5427 & 0.4 & & & 45.4 & & & 34.7 & & HE $1413-2014$ & & & & \\
\hline HE0028-6138 & 0.5 & & & 2.4 & & & & & & & & & \\
\hline HE0029-0006 & 7.4 & & E0328-5106 & 4.2 & & E1006-0146 & 43.4 & & E1414-0522 & & & & \\
\hline & 7.0 & & & 51.5 & & & & & & & & & \\
\hline HE0029-2030 & 1.4 & & E0328-5138 & & & E1006-1832 & 42.3 & & E1415-0029 & & & HE $2233-7408$ & \\
\hline & 4.2 & & & 48.2 & & & 41.0 & & & & & & \\
\hline HE0029-3904 & 6.2 & & E0329-1429 & & & HE $1007-1006$ & 57.1 & & F1 $1415-1$ & & & HE2234-0218 & \\
\hline & 2.9 & & & 30.4 & & & 32.3 & & & & & & \\
\hline HE0029-4821 & 38.6 & & & & & & & & & & & & \\
\hline $29-5337$ & 7.5 & & & 1.7 & & & & & & 53.0 & & & \\
\hline & 3.4 & & & & & & & & & & & & \\
\hline $0-3213$ & 8.4 & & & 352 & & & 33.7 & & & & & & \\
\hline & & & & & & & & & & & & & \\
\hline $30-3513$ & 8.5 & & & 42.1 & & & & & & & & & \\
\hline & 42.8 & & & & & & & & & & & & \\
\hline & 36.2 & & & & & & & & & & & & \\
\hline & 0.5 & & & & & & & & & & & & \\
\hline-0707 & 3.9 & & & 1.1 & & & & & & & & & \\
\hline & 1.1 & & & & & & & & & & & & \\
\hline & 7.4 & & & & & & & & & & & & \\
\hline & 7.1 & & & & & & & & & & & & \\
\hline & 7.1 & & & & & & & & & & & & \\
\hline & 1.9 & & & & & & & & & & & & \\
\hline & & & & & & & & & & & & & \\
\hline $2-3545$ & 0.2 & & & & & & & & & & & & \\
\hline-4445 & 35.3 & & & 9 & & & & & & & & & \\
\hline-4604 & 52.8 & & & & & & & & & & & & \\
\hline & 47.1 & & & & & & & & & & & & \\
\hline & 43.2 & & & & & & & & & & & & \\
\hline & 1.1 & & & & & & & & & & & & \\
\hline & 1.3 & & & & & & & & & & & & \\
\hline & 3.5 & & & & & & & & & & & & \\
\hline $3-5414$ & 51.3 & & & 4 & & & & & & & & & \\
\hline $3-5431$ & 9.3 & & & & & & & & & & & & \\
\hline-5431 & 28 & & & & & & & & & & & & \\
\hline & 1.0 & & & & & & & & & & & & \\
\hline & & & & & & & & & & & & & \\
\hline & 3.9 & & & & & & & & & & & & \\
\hline & 6.3 & & & & & & & & & & & & \\
\hline & 8.1 & & & & & & & & & & & & \\
\hline & 5.1 & & & & & & & & & & & & \\
\hline & 4.3 & & & & & & & & & & & & \\
\hline & 8.8 & & & & & & & & & & & & \\
\hline & 14 & & & & & & & & & & & & \\
\hline-3741 & 6.1 & & & & & & & & & & & & \\
\hline & 8.6 & & & & & & & & & & & & .4 \\
\hline & 4.5 & & & & & & & & & & & & \\
\hline & 9.5 & & & & & & & & & & & & .3 \\
\hline & 1.3 & & & & & & & & & & & & \\
\hline & 4.5 & & & & & & & & & & & & 44.3 \\
\hline & 4.8 & & & & & & & & & & & & \\
\hline & 1.5 & & & & & & & & & & & & \\
\hline & & & & & & & & & & & & & \\
\hline & 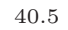 & & & & & & & & & & & & \\
\hline & & & & & & & & & & & & & \\
\hline & 6. & & & & & & & & & & & & \\
\hline & 4.1 & & & & & & & & & & & & 5 \\
\hline-2154 & 4 & & & & & & & & & & & & \\
\hline-2321 & 9.5 & & & & & & & & & & & & \\
\hline & 37 & & & & & & & & & & & & \\
\hline & 4.9 & & & & & & & & & & & & 5.9 \\
\hline & & & & & & & & & & & & & \\
\hline & & & & & & & & & & & & & \\
\hline & 6. & & & & & & & & & & & & \\
\hline & 7 & & & & & & & & & & & & 52. \\
\hline & 4. & & & & & & & & & & & & \\
\hline & & & & & & & & & & & & & \\
\hline & 8.7 & & & & & & & & & & & & 76.1 \\
\hline & & & & & & & & & & & & & \\
\hline-0001 & 5.0 & & & & & & & & & & & & 75.4 \\
\hline & & & & & & & & & & & & & \\
\hline & & & & & & & & & & & & & \\
\hline & & & & & & & & & & & & & \\
\hline & & & & & & & & & & & & & \\
\hline & & & & & & & & & & & & & \\
\hline & & & & & & & & & & & & & \\
\hline & & & & 40 & & & & & & & & & \\
\hline & & & & & & & & & & & & & \\
\hline $0-2206$ & 44.8 & & 2 & 59.9 & & & 50 & & 28 & 39.6 & & IE $2236-61$ & 51.6 \\
\hline & 35.3 & & & 44. & & & & & & & & & \\
\hline-2709 & 55.4 & & & 42. & & & 41. & & & 54 & & 34 & 32.4 \\
\hline & & & & & & & & & & & & & \\
\hline HE0040-3928 & 57.8 & & HE $0339-4527$ & 57.7 & & HE1026-0337 & 40.0 & mpcc & HE $1439-2012$ & 63.0 & fhlc & HE2237-0315 & 62.1 \\
\hline
\end{tabular}


Tabela C.1 (Continuação)

\begin{tabular}{|c|c|c|c|c|c|c|c|c|c|c|c|c|c|}
\hline Nome & $\mathrm{PE}$ & Classe & Nome & $\mathrm{APE}$ & lasse & Nome & GPE & Classe & Nome & GPE & Classe & Nome & GPE \\
\hline HE0040-4725 & 51.0 & mpcc & HE0340-0804 & 56.4 & mpcc & $1026-0$ & 59.5 & mpcc & $1440-021$ & 60.5 & ynid & 2237 & 49.4 \\
\hline HE0041-0749 & & & HE0340-0829 & & & IE1026-0632 & & & HE $1440-0556$ & 49.3 & & & 57.5 \\
\hline E0041-0933 & 4.5 & & & 56.6 & & & & & & & & & 53.9 \\
\hline E0041-1301 & & & E0340-1928 & 33.0 & & E1026-0944 & & & E1440-1441 & 49.4 & & IE $2237-0501$ & 63.1 \\
\hline E0041-1459 & 3.2 & & & 35.8 & & & 40.2 & & & & & & 60.0 \\
\hline E0041-1546 & & & E0340-3420 & & & E1027-1217 & & & HE1440-1937 & 34.5 & & HE2237-0517 & \\
\hline E0041-2230 & 8.6 & & & 33.0 & & & & & & & & & \\
\hline E0041-3010 & 7.8 & & E0340-3952 & & & E1028-0433 & & & HE $1441-1010$ & 45.2 & & & \\
\hline & 3.8 & & & 42.3 & & & 32.9 & & & 42.2 & & & \\
\hline HE0041-3139 & 6.5 & & E0340-6139 & & & & & & $\mathrm{HE} 1442+0012$ & & & & 30.2 \\
\hline HE0041-3245 & 3.5 & & $50.340-01$ & 47.2 & & & & & 756 & & & & \\
\hline & & & & & & & & & & & & & \\
\hline $00042-0421$ & 49.5 & & & 47.9 & & & 37.5 & & & & & & \\
\hline & & & & 37.3 & & & & & & & & & \\
\hline $0042-2049$ & & & E0341-2414 & 35.7 & & 1020 & & & & & & & \\
\hline & 36.9 & npcc & & 40.6 & & & & & & & & & \\
\hline & 43.0 & & -3009 & 45.8 & & & 53.7 & & & 44.9 & & & \\
\hline & 33.2 & & & 42.6 & & & & & & & & & \\
\hline $2-3828$ & 55.6 & & & 42.4 & & & & & & 37.9 & & & 32.9 \\
\hline $2-4414$ & $=39.8$ & & & & & & & & & & & & \\
\hline & & & & & & & & & & & & & \\
\hline & & & & & & & & & & & & & \\
\hline & & & & & & & & & & & & & \\
\hline & & & & & & & & & & & & & \\
\hline & & & & & & & & & & & & & \\
\hline $43-3617$ & 0.3 & & & & & & & & & 3 & & & \\
\hline & & & & & & & & & & & & & \\
\hline & 5.7 & & & & & & & & & & & & \\
\hline & & & & & & & & & & & & & \\
\hline & & & & & & & & & & & & & \\
\hline & & & & & & & & & & & & & \\
\hline & & & & & & & & & & & & & \\
\hline & & & & & & & & & & 39.0 & & & \\
\hline & & & & & & & & & & & & & \\
\hline $14-3547$ & & & & & & & & & & & & & \\
\hline & & & & & & & & & & & & & \\
\hline $44-5151$ & & & & & & & & & & & & & \\
\hline & & & & & & & & & & & & & \\
\hline & & & & & & & & & & & & & \\
\hline & & & & & & & & & & 5 & & & \\
\hline & & & & & & & & & & & & & \\
\hline & 2.5 & & & & & & & & & & & & \\
\hline 1730 & & & & & & & & & & & & & \\
\hline & the & & & & & & & & & 46 & & & 72 \\
\hline & & & & & & & & & & & & & \\
\hline-3658 & & & & & & & & & & 8 & & & 42.5 \\
\hline & & & & & & & & & & & & & .1 \\
\hline-4630 & & & & & & & & & & & & & \\
\hline & & & & & & & & & & & & & \\
\hline 4712 & & & & & & & & & & & & & \\
\hline & & & & & & & & & & & & & 4.6 \\
\hline 5646 & & & & & & & & & & & & & \\
\hline & & & & & & & & & & & & & 36 \\
\hline & & & & & & & & & & & & & \\
\hline & & & & & & & & & & & & & \\
\hline & & & & & & & & & & & & & \\
\hline 5624 & & & & & & & & & & & & & 46.8 \\
\hline-6142 & 7.2 & & & & & & & & & 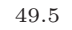 & & & .3 \\
\hline 0108 & & & & & & & & & & & & & \\
\hline & & & & & & & & & & & & & 40.8 \\
\hline & & & & & & & & & & & & & \\
\hline & & & & & & & & & & & & & 9 \\
\hline & & & & & & & & & & & & & \\
\hline & & & & & & & & & & & & & 0.6 \\
\hline & & & & & & & & & & & & & \\
\hline 5824 & & & & & & & & & & 46 & & & 549 \\
\hline & & & & & & & & & & & & & \\
\hline & & & & & & & & & & & & & \\
\hline & & & & & & & & & & 6.1 & & & 55.9 \\
\hline & & & & & & & & & & & & & \\
\hline-0157 & & & & & & & & & 22 & 0.2 & & 31 & 80.7 \\
\hline & & & & & & & & & & & & & \\
\hline & & & & & & & & & & & & & 2.3 \\
\hline & & & & & & & & & & & & & \\
\hline & & & & & & & & & & & & & 0 \\
\hline & & & & & & & & & & & & & 58.4 \\
\hline & & & & & & & & & & & & & \\
\hline & & & & & & & & & & & & & 64.2 \\
\hline & & & & & & & & & & & & & \\
\hline $51-2530$ & 44.4 & & 14 & & & & & & 14 & 39.1 & & 359 & 31.3 \\
\hline & & & & & & & & & & 36. & & & 91.3 \\
\hline $\mathrm{H}$ & & & & & & & & & & & & [E2240-0414 & 52.4 \\
\hline & & & & & & & & & & & & & \\
\hline HE0052-2 & 33.7 & & HE $0348-3504$ & 44.6 & & HE $1042-1351$ & 44.4 & nid & HE $1502-1025$ & 43.9 & npcb & HE $2240-0423$ & 48.3 \\
\hline
\end{tabular}


Tabela C.1 (Continuação)

\begin{tabular}{|c|c|c|c|c|c|c|c|c|c|c|c|c|c|}
\hline Nome & $\mathrm{PE}$ & lasse & Nome & GPE & Classe & Nome & $\mathrm{PE}$ & Classe & Nome & $\mathrm{PE}$ & Classe & Nome & GPE \\
\hline HE0052-2259 & 36.2 & mpcc & IE $0348-3651$ & 39.6 & mpcc & HE $1042-1447$ & 32.4 & pec & 1502 & 41.5 & apcb & $2240-04$ & \\
\hline & & & & 35.1 & & & 393 & & HE $1503+0239$ & & & & \\
\hline HE0052-2901 & 0.6 & & & 30.2 & & & & & & & & & \\
\hline HE $0052-3620$ & 2.3 & & E0348-4917 & 32.5 & & [E1043-0109 & 5.0 & & E1503-0659 & 38.7 & & & \\
\hline HE0052-3901 & 5.1 & & & 47.0 & & & 51.4 & & & & & & \\
\hline & 2.6 & & E0349-2701 & 31.5 & & HE $1043-0942$ & 48.3 & & E1503-1550 & & & IE $2240-0450$ & \\
\hline & 5.0 & & & 46.0 & & & 64.9 & & & & & & \\
\hline & 35.6 & & & 40.4 & & HE $1043-1516$ & 53.2 & & E1504-0111 & & & & \\
\hline & 36.5 & mpcb & & 43.3 & & & 63.6 & mpcc & & & & & \\
\hline HE0053-0805 & 0.2 & & & & & & & & & & & & \\
\hline HE0053-2548 & 9.2 & & & 46.9 & & & 7.4 & & 36 & & & & \\
\hline & 2.4 & & & & & & & & & & & & \\
\hline E0053-3510 & 4.6 & & & 47.3 & & & 44.1 & & & & & & \\
\hline & 0.7 & & & & & & & & & & & & \\
\hline HE0053-3850 & 2.3 & & $50-5$ & 41.4 & & HE $1045+02$ & 53.0 & & & & & & \\
\hline & 52.6 & & & 47.3 & & & 53.9 & & & & & & \\
\hline $0053-6240$ & 4.5 & & & 41.8 & & & 40.8 & & & & & & \\
\hline & 33.7 & & & 40.9 & & & & & & & & & \\
\hline & 7.6 & & & 33.6 & & & 45.4 & & & & & & 69.2 \\
\hline & 9.2 & & & 43.3 & & & 38.4 & & & & & & \\
\hline & 3.4 & & & & & & & & & & & & \\
\hline & 4.4 & & & 35 & & & & & & & & & \\
\hline & 2.5 & & & & & & & & & & & & \\
\hline $5-1438$ & 1.7 & & & 49 & & & & & & & & & \\
\hline & 7.7 & & & & & & & & & & & & \\
\hline $55-2111$ & 40.4 & & & 35. & & & 41. & & & & & & \\
\hline & 42.1 & & & 42. & & & & & & & & & \\
\hline-2716 & 35.8 & & & 58.6 & & & 35.0 & & & & & & \\
\hline & 5.5 & & & 56. & & & & & & & & & \\
\hline & 1.4 & & & & & & & & & & & & \\
\hline & 8.0 & & & & & & & & & & & & \\
\hline & 7.8 & & & & & & & & & & & & \\
\hline & 4.9 & & & 38.1 & & & 45. & & & 32 & & & \\
\hline $56-1458$ & 3.2 & & & 42.4 & & & & & & & & & \\
\hline & 2.3 & & & & & & & & & & & & \\
\hline & 4 & & & & & & & & & & & & \\
\hline & 5.0 & & & 40. & & & 3 & & & & & & \\
\hline & 5 & & & & & & & & & & & & \\
\hline & 4.3 & & & 53 & & & 40 & & & & & & \\
\hline & 1.9 & & & & & & & & & & & & \\
\hline & 8.6 & & & 52 & & & 44 & & & & & & \\
\hline & 6.9 & & & 36. & & & $48-2-1$ & & & & & & \\
\hline & 4.3 & & & 41 & & & 54 & & & & & & \\
\hline & 8.6 & & & 37. & & & 45. & & & & & & \\
\hline & 37 & & & & & & & & & & & & \\
\hline $7-3650$ & 5.9 & & & & & & & & & & & & \\
\hline & 2.3 & & & & & & & & & & & & \\
\hline & 2.0 & & & & & & & & & & & & \\
\hline & 41.8 & & & 42. & & & & & & & & & 4 \\
\hline $7-6445$ & 5.6 & & & & & & & & & & & & \\
\hline & 0.8 & & & & & & & & & & & & .0 \\
\hline & 5.7 & & & 55 & & & & & & & & & \\
\hline & 9.4 & & & & & & & & & & & & \\
\hline & 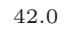 & & & & & & & & & & & & \\
\hline & 5.2 & & & & & & & & & & & & \\
\hline & 2.6 & & & & & & & & & & & & \\
\hline & 1.6 & & & & & & & & & 42 & & & 37. \\
\hline & 4.5 & & & & & & & & & & & & 40.4 \\
\hline $9-0447$ & 27 & & & & & & & & & & & & \\
\hline-0824 & 6.7 & & & & & & & & & & & & \\
\hline & 8.2 & & & & & & & & & & & & \\
\hline & 2.2 & & & & & & & & & & & & 1 \\
\hline & & & & & & & & & & & & & \\
\hline & 3 & & & & & & & & & & & & 4 \\
\hline & 4.8 & & & & & & & & & & & & \\
\hline & s & & & & & & & & & 34 & & & 56 \\
\hline & 2. & & & & & & & & & & & & \\
\hline & 3 & & & & & & & & & & & & \\
\hline-4957 & 7.8 & & & & & & & & & & & & 59.0 \\
\hline & & & & & & & & & & & & & \\
\hline $0-5950$ & 5.1 & & & & & & & & & 57. & & & 87.0 \\
\hline & & & & & & & & & & & & & \\
\hline & & & & & & & & & & & & & \\
\hline & & & & & & & & & & & & & \\
\hline & & & & & & & & & & & & & \\
\hline & 5. & & & & & & & & & & & & \\
\hline & & & & & & & & & & & & & \\
\hline & 3.5 & & & & & & & & & & & & \\
\hline & & & & & & & & & & & & & \\
\hline $0102-0247$ & 35.2 & & $0359-2100$ & 36.8 & & HE1058-07 & 40.0 & & 54 & 56.4 & & $3-0650$ & 48.4 \\
\hline & 41.4 & & & 31.9 & & & & & & & & & \\
\hline-2553 & 34.5 & & & & & & 33. & & & 41. & & 19 & 52.4 \\
\hline & 42.9 & & & & & & & & & & & & \\
\hline HE $0102-3417$ & 55.4 & & HE0 $400-0116$ & 52.8 & & HE $1059+0135$ & 34.8 & & HE2003-6029 & 45.3 & mpcc & HE2243-4119 & 43.6 \\
\hline
\end{tabular}


Tabela C.1 (Continuação)

\begin{tabular}{|c|c|c|c|c|c|c|c|c|c|c|c|c|c|}
\hline Nome & $\mathrm{PE}$ & asse & Nome & $\mathrm{PE}$ & lasse & Nome & GPE & Classe & Nome & GPE & Classe & Nome & GPE \\
\hline HE0102-3936 & 46.8 & unid & E0400-1228 & 40.5 & fhlc & E1059-0033 & 42.8 & mpcc & $20005-584$ & 38.4 & $\mathrm{mpcc}$ & $2243-41$ & 33.9 \\
\hline HE0102-4121 & & & & 46.7 & & & & & & 35.5 & & & \\
\hline E0102-4515 & 5.3 & & & 63.5 & & & 46.4 & & & 41.5 & & & 40.2 \\
\hline E0103-0352 & 57.7 & & E0400-2441 & 39.7 & & E1059-0806 & 40.2 & & IE2007-5556 & 45.0 & & & 35.2 \\
\hline E0103-0923 & 9.5 & & & 43.2 & & & 42.1 & & & 68.4 & & & 32.7 \\
\hline E0103-2229 & & & $\mathrm{E} 0400-3006$ & 35.3 & & E1059-1408 & 39.2 & & HE $2008-5853$ & 39.5 & & $\mathrm{IE} 2243-6314$ & \\
\hline & & & & 37.5 & & & 43.9 & & & 52.6 & & & \\
\hline [E0103-2329 & 5.8 & & E0400-4643 & 42.9 & & E1059-1808 & & & HE $2009-5530$ & 55.2 & & & 45.2 \\
\hline & 1.6 & & & 44.6 & & & 58.1 & & & 39.4 & & & \\
\hline HE0103-4234 & & & E0401-0825 & & & E1059-2559 & & & & & & & \\
\hline HE0104-0022 & & & & 36.4 & & & 9.4 & & 708 & 7.1 & & & \\
\hline & & & & & & & & & & & & & \\
\hline $04-1820$ & & & & 39.7 & & & 43.2 & & & 39.7 & & & \\
\hline & & & & & & & & & & & & & \\
\hline $04-4003$ & 7.9 & & -2449 & 35.8 & & & 36.1 & & F & & & & \\
\hline & 9.2 & & & 50.1 & & & 58.6 & & & 52.5 & & & 72.6 \\
\hline & 3.4 & & & 34.6 & & & 36.6 & & & 37.4 & & & 40.7 \\
\hline & 2.8 & & & 33.0 & & & 37.4 & & & 45.8 & & & \\
\hline $1-4446$ & 9.2 & & & 37.7 & & & 34.0 & & & 35.7 & & & $\$ 8.3$ \\
\hline & & & & 37.1 & & & 49.0 & & & 50.4 & & & \\
\hline & & & & & & & & & & & & & \\
\hline & 3 & & & 40.6 & & & 43.3 & & & & & & \\
\hline & & & & & & & & & & & & & 36.9 \\
\hline & & fhlc & & 42.7 & & & 56.8 & & & & & & \\
\hline & & & & & & & & & & & & & \\
\hline $5-4717$ & 5.1 & & & 45.7 & & & 53. & & & 0 & & & 53.1 \\
\hline & 44.4 & & & 50.5 & & & 54. & & & & & & \\
\hline $6-0244$ & 3.7 & & & 43.9 & & & 44. & & & & & & \\
\hline & & & & 38.1 & & & 62 . & & & & & & \\
\hline & 3 & & & & & & & & & & & & \\
\hline & 5 & & & 42. & & & 65 & & & & & & \\
\hline & 4 & & & & & & & & & & & & \\
\hline & 1.1 & & & 42.0 & & & 47.0 & & & 47.1 & & & \\
\hline $6-3519$ & 2.0 & & & & & & & & & & & & \\
\hline & .6 & & & & & & 40. & & & 6 & & & \\
\hline & & & & & & & & & & & & & \\
\hline & 3 & & & & & & & & & 47. & & & \\
\hline & & & & & & & & & & & & & \\
\hline & & & & & & & & & & & & & \\
\hline & & & & & & & 35. & & & . & & & .7 \\
\hline & & & & & & & & & & & & & \\
\hline & 2.3 & & & 31. & & & 32 & & & & & & 47 \\
\hline & & & & 45.9 & & & & & & & & & \\
\hline & & & & 50.5 & & & 36. & & & 47. & & & .9 \\
\hline & & & & & & & & & & & & & \\
\hline 0541 & 7 & & & & & & 3 & & & 7.3 & & & .4 \\
\hline & & & & 40. & & & & & & . & & & .6 \\
\hline & & & & & & & & & & & & & \\
\hline & & & & & & & & & & & & & .3 \\
\hline-3436 & & & & & & & & & & & & & \\
\hline & 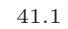 & & & 47. & & & 47. & & & & & & .3 \\
\hline & & & & & & & & & & & & & \\
\hline & & & & & & & & & & & & & 38 \\
\hline & & & & & & & & & & & & & \\
\hline & & & & & & & & & & & & & 47 \\
\hline & & & & & & & & & & & & & \\
\hline & & & & & & & 5 & & & 57 & & & 48.6 \\
\hline & & & & & & & 3 & & & 3.2 & & & 36.9 \\
\hline & & & & & & & & & & & & & \\
\hline & & & & & & & 42 & & & & & & 43.2 \\
\hline & & & & & & & & & & & & & \\
\hline & & & & & & & & & & & & & \\
\hline & & & & & & & & & & & & & \\
\hline & & & & & & & & & & & & & 442 \\
\hline & & & & & & & & & & & & & \\
\hline & & & & & & & & & & 40 & & & 59.6 \\
\hline & & & & & & & & & & & & & \\
\hline & & & & & & & & & & & & & \\
\hline-1854 & 3 & & & & & & & & & 42 & & & \\
\hline & & & & & & & & & & & & & \\
\hline $1-3002$ & 4 & & & & & & & & & 4.8 & & & 42.4 \\
\hline & & & & & & & & & & & & & \\
\hline & & & & & & & & & & & & & 43.7 \\
\hline & & & & & & & & & & & & & \\
\hline & & & & & & & & & & & & & 44. \\
\hline & & & & & & & & & & & & & 67 \\
\hline & & & & & & & & & & & & & \\
\hline & & & & & & & & & & 44 & & & 68.0 \\
\hline & & & & & & & & & & & & & 63.6 \\
\hline 6 & & & 4 & 70 & & & 36. & & 8 & 50.6 & & -0342 & 67 \\
\hline & & & & 34.8 & & & 37. & & & 34. & & & 103.2 \\
\hline & 43. & & & 37.9 & & & & & & & & & 31.6 \\
\hline & 41.3 & & & & & & & & & & & & \\
\hline HE0114+0205 & 47.1 & mpcb & HE0408 - 5639 & 36.1 & mpcc & HE $1112-3154$ & 46.7 & mpcc & HE $2053-4822$ & 40.9 & mpcc & HE $2247-0555$ & 65.2 \\
\hline
\end{tabular}


Tabela C.1 (Continuação)

\begin{tabular}{|c|c|c|c|c|c|c|c|c|c|c|c|c|c|}
\hline Nome & $\mathrm{PE}$ & lasse & Nome & GPE & Classe & Nome & $\mathrm{PE}$ & Classe & Nome & GPE & Classe & Nome & GPE \\
\hline HE0114-1657 & 43.5 & mpcc & [E0409-0153 & 30.7 & mpcb & HE1113-0010 & 53.8 & pec & IE $2053-5154$ & 43.7 & apcc & 2247 & \\
\hline & & & & 46.9 & & HE $1113-0404$ & 372 & & & & & & \\
\hline & 2.5 & & & 42.1 & & & & & & & & & \\
\hline HE0114-2323 & 9.0 & & E0409-1834 & 37.0 & & [E1113-1224 & 46 & & E2054-5000 & & & IE $2247-3359$ & \\
\hline & 3.9 & & & 39.7 & & & & & & & & & \\
\hline HE0114-6514 & 5.5 & & E0409-2458 & 36.9 & & HE $1113-2022$ & & & E2054-5322 & & & IE $2247-5151$ & \\
\hline & 5.1 & & & 51.1 & & & & & & & & & \\
\hline & 54.7 & & E0409-2933 & 36.1 & & HE $1113-2431$ & & & HE $2055-5326$ & & & IE $2248-0245$ & \\
\hline & 44.7 & & & 30.5 & & & 45.4 & & & & & & \\
\hline HE0115-3207 & 4.6 & & & & & HE $1113-3136$ & & & HE $2055-5454$ & & & $\mathrm{HE} 2248-0312$ & 45.8 \\
\hline HE0115-4116 & 7.6 & & & 4 & & - & 35.4 & & HE2056-5043 & & & & \\
\hline & 44.0 & & & & & & & & & & & & \\
\hline $115-4432$ & 35.9 & & & 34.0 & & & 33.1 & & & & & & \\
\hline & 9.5 & & & & & & & & & & & & \\
\hline HE0115-5720 & 0.1 & & 10 (1) & 32.1 & & F $1115-1$ & 53.4 & & & & & & \\
\hline & 50.8 & & & 42.5 & & & 36.7 & & & & & & \\
\hline & 3.8 & & & 35.4 & & & 50.0 & & & & & & \\
\hline & 42.6 & & & 42.5 & & & & & & & & & \\
\hline & 47.6 & & & 40.6 & & & 45.4 & & & & & & 100.7 \\
\hline & 45.7 & & & 47.3 & & & 39.7 & & & & & & \\
\hline & 6.1 & & & 3 & & & & & & & & & \\
\hline & 4.3 & & & 40.3 & & & & & & & & & \\
\hline & 6.2 & & & & & & & & & & & & \\
\hline & 7.2 & & & 43. & & & & & & & & & \\
\hline & 0.9 & & & & & & & & & & & & \\
\hline $17-3751$ & 1.0 & & & 55.7 & & & 42 & & & & & & \\
\hline & 5.6 & & & & & & & & & & & & \\
\hline-3130 & 1.0 & & & 34.6 & & & & & & & & & \\
\hline & 9.5 & & & 56.3 & & & & & & & & & \\
\hline & 1.8 & & & 47. & & & & & & & & & \\
\hline & 7.8 & & & 40. & & & & & & & & & \\
\hline & 5.5 & & & 3 & & & & & & & & & \\
\hline & 7.4 & & & 39.6 & & & & & & & & & \\
\hline & 6.8 & & & 46.2 & & & & & & & & & \\
\hline & 2.7 & & & 52.8 & & & & & & & & & \\
\hline & 4 & & & & & & & & & & & & \\
\hline $8-5419$ & 4.5 & & & 48. & & & & & & & & & \\
\hline & 7.1 & & & & & & & & & & & & \\
\hline $8-6041$ & 7.2 & & & 4. & & & & & & & & & \\
\hline & 1.7 & & & 37. & & & & & & & & & \\
\hline & 5.9 & & & 33. & & & & & & & & & \\
\hline & 9.1 & & & 36. & & & & & & & & & \\
\hline & 0.4 & & & 392 & & & & & & & & & \\
\hline & 3.1 & & & 16. & & & 42 & & & & & & \\
\hline & 2.0 & & & & & & & & & & & & \\
\hline & 9.9 & & & 0. & & & & & & & & & \\
\hline & 8.1 & & & 47.8 & & & & & & & & & \\
\hline-5200 & 6.6 & & & & & & & & & & & & \\
\hline & 47.2 & & & & & & & & & & & & \\
\hline & 9.8 & & & 70 & & & & & & & & & \\
\hline & 3.4 & & & 52. & & & & & & & & & \\
\hline & 8.3 & & & 77 & & & & & & & & & \\
\hline & 0.1 & & & & & & & & & & & & \\
\hline & 1.6 & & & & & & & & & & & & \\
\hline & 0.3 & & & & & & & & & & & & \\
\hline & $9.8 \mathrm{r}=\mathrm{s}$ & & & & & & & & & & & & \\
\hline & 4.9 & & & & & & 3 & & & & & & \\
\hline-4045 & 3.9 & & & 40 & & & & & & & & & 3 \\
\hline-4240 & 85 & & & & & & & & & & & & \\
\hline $1-4243$ & 1.1 & & & & & & & & & & & & \\
\hline $1-4839$ & 1.8 & & & & & & & & & & & & \\
\hline & 5.2 & & & & & & & & & & & & \\
\hline & 3.2 & & & & & & & & & & & & \\
\hline & 3 & & & & & & & & & & & & \\
\hline & 0.7 & & & & & & & & & & & & \\
\hline & 5 & & & & & & & & & 42 & & & 50. \\
\hline & 5.9 & & & & & & & & & & & & \\
\hline & 4 & & & & & & & & & & & & \\
\hline-4511 & 6.9 & & & & & & & & & & & & 37.0 \\
\hline & & & & & & & & & & & & & \\
\hline-5017 & 4.4 & & & 43. & & & & & & & & & 34.4 \\
\hline & & & & & & & & & & & & & \\
\hline & & & & & & & & & & & & & \\
\hline & 2.3 & & & & & & & & & & & & \\
\hline & 41 & & & & & & & & & & & & \\
\hline & 5. & & & & & & & & & & & & \\
\hline & & & & & & & & & & & & & \\
\hline & 1.2 & & & & & & & & & & & & \\
\hline & & & & & & & & & & & & & \\
\hline $123-3747$ & 44.9 & & & 47.8 & & HE $1129-1006$ & & & & 39.6 & & 57 & 50.2 \\
\hline & 37.6 & & & 35.5 & & & & & & & & & \\
\hline $3-4445$ & 48.9 & & & & & & 43 & & & & & $252-4$ & 42.2 \\
\hline & 59.2 & & & & & & & & & & & & \\
\hline HE0124-0004 & 46.6 & & HE $0421-2826$ & 31.2 & арсс & HE $1129-2450$ & 42.8 & mpcc & HE $2117-6000$ & 37.5 & mpcc & HE $2252-6740$ & 54.6 \\
\hline
\end{tabular}


Tabela C.1 (Continuação)

\begin{tabular}{|c|c|c|c|c|c|c|c|c|c|c|c|c|c|}
\hline Nome & $\mathrm{PE}$ & Classe & Nome & $\mathrm{APE}$ & lasse & Nome & GPE & Classe & Nome & GPE & Classe & Nome & GPE \\
\hline HE0124-2546 & 45.9 & $\mathrm{mpcc}$ & HE0421-2828 & 44.5 & mpcc & E1129-2809 & 43.4 & mpcc & $217-601$ & 31.7 & (DCc & 52 & 32.5 \\
\hline HE0124-3727 & & & HE0421-3043 & & & E1129-2850 & & & HE $2117-6018$ & 31.7 & & & \\
\hline E0124-3751 & 5.8 & & & 37.6 & & & & & IE $2118-3134$ & 52.1 & & & 36.3 \\
\hline E0124-4531 & 6.9 & & E0421-3423 & 33.2 & & E1130-0139 & & & IE $2118-4835$ & 40.8 & & IE $2253-1055$ & \\
\hline [E0124-4634 & 3.0 & & & 49.4 & & & & & & 36.7 & & & 33.5 \\
\hline [E0124-6703 & & & E0421-4811 & & & E1130-1257 & & & $\mathrm{HE} 2118-5654$ & 41.0 & & HE2253-5111 & \\
\hline E0125-0317 & 3.3 & & & 33.6 & & & & & & 42.0 & & & \\
\hline & 39.9 & & E0421-5717 & 47.1 & & E1130-1515 & & & HE $2118-5821$ & & & HE $2253-7714$ & 57.2 \\
\hline & 41.7 & & & 34.6 & mpcc & & 41.9 & & & 32.2 & & & 53.4 \\
\hline E0125-2015 & & & E0422-2050 & & & & & & & & & & 33.4 \\
\hline $25-2300$ & & & 22 & 47.8 & & 219 & & & & 46.0 & & 741 & 40.1 \\
\hline & & & & & & & & & & & & & \\
\hline $26-2147$ & & & 49 & & & & & & & & & & \\
\hline & & & & & & & & & & & & & \\
\hline $26-4518$ & 4 & & -5426 & & & & & & 1 & & & & \\
\hline & 32.9 & & & 44.0 & & & & & & & & & 39.3 \\
\hline-4704 & 40.5 & & & & & & & & & & & & 51.2 \\
\hline & 44.8 & unid & & 43.3 & & & & & & & & & \\
\hline-3323 & 43.1 & & & 50.5 & & & & & & & & & 39.0 \\
\hline & 454 & & & & & & & & & 52.2 & & & \\
\hline & 51.3 & & & & & & & & & & & & 39.5 \\
\hline & & & & & & & & & & & & & \\
\hline & & & & & & & & & & & & & 47.5 \\
\hline $7-4319$ & & & & & & & & & & & & & \\
\hline & & & & & & & & & & & & & \\
\hline $7-4433$ & & & & & & & & & & & & & \\
\hline & & & & 36 & & & & & & & & & \\
\hline-2246 & 6.7 & & & 42 & & & & & & & & & \\
\hline & & & & & & & & & & & & & \\
\hline & & & & & & & & & & & & & \\
\hline & & & & & & & & & & & & & \\
\hline & & & & & & & & & & & & & \\
\hline & 5 & & & & & & & & & 52. & & & \\
\hline+0052 & 1.8 & & & & & & & & & & & & \\
\hline $9-1610$ & & & & & & & & & & & & & \\
\hline & & & & & & & & & & & & & \\
\hline $9-2215$ & & & & & & & & & & & & & \\
\hline & & & & & & & & & & & & & \\
\hline & & & & & & & & & & & & & \\
\hline & & & & & & & & & & & & & \\
\hline & & & & & & & & & & & & & \\
\hline & 5.4 & & & & & & & & & & & & \\
\hline & & & & & & & & & & & & & \\
\hline & & & & & & & & & & 50 & & & 1 \\
\hline & & & & & & & & & & & & & \\
\hline & & & & & & & & & & & & & 47.4 \\
\hline & & & & & & & & & & & & & \\
\hline & & & & & & & & & & & & & \\
\hline & & & & & & & & & & & & & 8 \\
\hline & & & & & & & & & & & & & \\
\hline & & & & & & & & & & & & & 51.6 \\
\hline & & & & & & & & & & & & & \\
\hline & & & & & & & & & & & & & 43 \\
\hline & & & & & & & & & & & & & \\
\hline & & & & & & & & & & & & & \\
\hline & & & & & & & & & & & & & \\
\hline & & & & & & & & & & 5 & & & 498 \\
\hline & & & & & & & & & & . & & & .0 \\
\hline-2455 & & & & & & & & & & & & & \\
\hline-2742 & & & 8 & & & & & & & 3 & & 33 & .6 \\
\hline-2742 & & & & & & & & & & & & & \\
\hline & & & & & & & & & & & & & \\
\hline & & & & & & & & & & & & & \\
\hline & & & & & & & & & & & & & 48.1 \\
\hline & & & & & & & & & & & & & \\
\hline 5055 & & & & & & & & & & 3 & & & 324 \\
\hline & & & & & & & & & & & & & \\
\hline & & & & & & & & & & & & & \\
\hline & & & & & & & & & & & & & 37.3 \\
\hline & & & & & & & & & & & & & \\
\hline-474 & & & & & & & & & & 43.6 & & 24 & 43.5 \\
\hline & & & & & & & & & & & & & \\
\hline & & & & & & & & & & & & & \\
\hline & & & & & & & & & & & & & \\
\hline & & & & & & & & & & & & & \\
\hline & & & & & & & & & & & & & \\
\hline & & & & & & & & & & & & & \\
\hline & & & & & & & & & & & & & \\
\hline & & & & & & & & & & & & & \\
\hline $\mathrm{H}$ & & & 5 & & & & & & 53 & 40.2 & & 30 & 41.4 \\
\hline & & & & & & & & & & 16 & & & \\
\hline $\mathrm{H}$ & & & & & & & & & & & & 50 & 35 \\
\hline & & & & & & & & & & & & & \\
\hline HE0135-0103 & 38.6 & mpcc & HE0431-2732 & 42.0 & mpcc & HE $1142-0317$ & 43.8 & mpcc & HE $2132-0214$ & 39.9 & mpcc & HE $2304+0127$ & 47.3 \\
\hline
\end{tabular}


Tabela C.1 (Continuação)

\begin{tabular}{|c|c|c|c|c|c|c|c|c|c|c|c|c|c|}
\hline Nome & $\mathrm{PE}$ & lasse & Nome & $\mathrm{PE}$ & Classe & Nome & $\mathrm{PE}$ & Classe & Nome & $\mathrm{PE}$ & Classe & Nome & GPE \\
\hline HE0135-1735 & 39.0 & mpcc & IE0431-4106 & 35.2 & mpcc & HE1142-0637 & 34.3 & pcc & HE2132-0628 & 38.4 & apcc & $\mathrm{HE} 2304+0217$ & 43.2 \\
\hline & & & & 45.5 & & HE $1142-1058$ & 45.8 & & & & & & \\
\hline & 5.6 & & & 38.7 & & & & & & & & & \\
\hline HE0135-3253 & 3.5 & & $\mathrm{E} 0432+0127$ & 38.1 & & [E1142-1546 & 55.0 & & E2132-3549 & & & IE2304-1254 & \\
\hline & 6.1 & & & 35.1 & & & & & & & & & \\
\hline HE0135-5958 & 4.1 & & E0432-5455 & 39.3 & & HE $1142-2313$ & 33.2 & & E2132-4741 & & & IE2304-5012 & \\
\hline & 9.9 & & & 37.1 & & & 46.3 & & & & & & \\
\hline & 55.0 & & E0433-0559 & 44.8 & & HE $1142-2453$ & 42.2 & & IE $2132-6214$ & & & & \\
\hline & 44.5 & & & 38.8 & & & 48.5 & & & & & & \\
\hline HE0136-3310 & 5.8 & & & 43.2 & & HE1143-0458 & & & HE $2133-1850$ & & & & \\
\hline HE $0137+0013$ & 8.5 & & & 50.5 & mpcb & -0832 & 46.4 & & & & & & \\
\hline & 18 & & & & & & & & & & & & \\
\hline $37-0220$ & 8.8 & & & 43.5 & & & 48.0 & & & & & & \\
\hline & 34.0 & & & & & & & & & & & & \\
\hline $37-2540$ & 52.1 & & & 50.3 & & 56 & 72.4 & & & & & & \\
\hline & 37.7 & & & 65.0 & & & & & & & & & \\
\hline & 8.7 & & & 48.3 & & & 55.0 & & & & & & \\
\hline & 8.4 & & & 39.1 & & & & & & & & & \\
\hline & 8.5 & & & 44.1 & & & 62.4 & & & & & & \\
\hline & 9.7 & & & 48,5 & & & & & & & & & \\
\hline & 6.8 & & & & & & & & & & & & \\
\hline & 4.7 & & & 32.6 & & & & & & & & & \\
\hline & 5.2 & & & & & & & & & & & & \\
\hline $8-4442$ & 4.8 & & & 15.8 & & & & & & & & & \\
\hline & 9.9 & & & 4 & & & & & & & & & \\
\hline $3-4557$ & 1.7 & & & 53.5 & & & 37 & & & & & & \\
\hline & 49.9 & & & 2.0 & & & & & & & & & \\
\hline & 61.7 & & & 59.2 & & & 44 & & & & & & \\
\hline & 7.0 & & & 44.7 & & & & & & & & & \\
\hline & 4.0 & & & & & & & & & & & & \\
\hline & 3.3 & & & 32. & & & & & & & & & \\
\hline & 8.7 & & & & & & & & & & & & \\
\hline & 3.9 & & & 35.9 & & & 37. & & & 39 & & & \\
\hline & 5.4 & & & 5 & & & & & & & & & \\
\hline & 6.0 & & & 1.2 & & & & & & & & & \\
\hline & 5 & & & & & & & & & & & & \\
\hline & 1.8 & & & 8. & & & & & & & & & \\
\hline & 51.5 & & & & & & & & & & & & \\
\hline & 41.5 & & & 9. & & & & & & & & & \\
\hline & 0.5 & & & 9. & & & & & & & & & \\
\hline & 6.3 & & & 4.1 .45 & & & & & & & & & \\
\hline & 8.7 & & & 50. & & & & & & & & & \\
\hline & 9.9 & & & 54.3 & & & & & & & & & \\
\hline & 0.3 & & & 41.4 & & & 40 & & & & & & \\
\hline & 5.2 & & & & & & & & & & & & \\
\hline-0332 & 7.1 & & & 3 & & & & & & & & & \\
\hline & 6.5 & & & & & & & & & & & & \\
\hline & 0.2 & & & & & & & & & & & & \\
\hline & 4 & & & & & & & & & & & & \\
\hline & 3.9 & & & 36 & & & & & & & & & \\
\hline & 9.1 & & & & & & & & & & & & 3 \\
\hline-6453 & 6.6 & & & & & & & & & & & & \\
\hline & 6.5 & & & & & & & & & & & & \\
\hline & 5 & & & & & & & & & & & & \\
\hline & 3.6 & & & & & & & & & & & & \\
\hline & 7.6 & & & & & & & & & & & & \\
\hline & 6.7 & & & & & & & & & & & & 47 \\
\hline $43-3449$ & 7.1 & & & & & & & & & & & & 9.6 \\
\hline $43-4256$ & 5.8 & & & & & & & & & & & & \\
\hline $43-4937$ & 2.6 & & & & & & & & & & & & \\
\hline & 1.4 & & & & & & & & & & & & \\
\hline & 4 & & & & & & & & & & & & \\
\hline & 8.9 & & & & & & & & & & & & \\
\hline & 9.6 & & & & & & & & & & & & \\
\hline & 8.1 & & & & & & & & & & & & \\
\hline & 3 & & & & & & & & & 32 & & & 41. \\
\hline & 5 & & & & & & & & & & & & \\
\hline & 3 & & & & & & & & & & & & \\
\hline & 7.4 & & & & & & & & & & & & 50.4 \\
\hline & & & & & & & & & & & & & \\
\hline $45-3231$ & 0.8 & & & & & & & & & & & & 41.3 \\
\hline & & & & & & & & & & & & & \\
\hline & & & & & & & & & & & & & \\
\hline & & & & & & & & & & & & & \\
\hline & & & & & & & & & & & & & \\
\hline & 4. & & & & & & & & & & & & 44.8 \\
\hline & & & & & & & & & & & & & \\
\hline & 1.1 & & & & & & 37 & & & & & & \\
\hline & & & & & & & & & & & & & \\
\hline $0146-6646$ & 36.7 & & $0439-5327$ & 31.5 & & 3 & 44. & & & 53.0 & & 29 & 48.9 \\
\hline & 47.3 & & & 42. & & & 37. & & & & & & \\
\hline 20 & 38.2 & & & & & & 41. & & & 52 & & 55 & 49.2 \\
\hline & 51.6 & & & & & & & & & & & & \\
\hline HE $0148-1451$ & 46.0 & & HE $0440-2258$ & 37.8 & & HE $1155-0313$ & 48.3 & & HE $2140-5521$ & 35.1 & mpcb & HE2316-6954 & 43.1 \\
\hline
\end{tabular}


Tabela C.1 (Continuação)

\begin{tabular}{|c|c|c|c|c|c|c|c|c|c|c|c|c|c|}
\hline Nome & $\mathrm{PE}$ & Classe & Nome & $\mathrm{APE}$ & lasse & Nome & GPE & Classe & Nome & GPE & Classe & Nome & GPE \\
\hline HE0148-1745 & 36.4 & mpcc & HE0440-2440 & 44.4 & mpcc & $1155-0$ & 39.4 & mpcc & $21010-561$ & 43.1 & (DCC & 22317 & 413 \\
\hline HE0148-2324 & & & HE $0440-2505$ & & & E1155-0807 & & & & 43.7 & & & 60.0 \\
\hline E0148-3115 & 1.9 & & & 34.2 & & E1155-1550 & & & & 43.9 & & & 45.6 \\
\hline E0148-3659 & & & E0440-3937 & 55.1 & & E1155-2208 & & & E2141-0659 & 35.8 & & [E $2317-3207$ & \\
\hline [E0148-4735 & 4.6 & & & 43.8 & & & & & & & & & 38.6 \\
\hline [E0148-6044 & & & E0440-5525 & & & E1155-3109 & & & $\mathrm{HE} 2141-2113$ & & & HE $2317-5558$ & \\
\hline & 5.3 & & & 48.7 & & & & & & & & & \\
\hline E0148-6521 & 36.3 & & E0441+0148 & & & E1156-0448 & & & HE2141-3556 & 43.9 & & HE $2317-6532$ & 53.3 \\
\hline & 34.3 & & & 34.9 & & & 56.2 & & & 43.3 & & & \\
\hline HE0149-1159 & 42.7 & & E0441-0039 & & & E1156-1058 & & & E2141-4005 & & & & \\
\hline HE0149-2901 & & & -0223 & & & 13 & & & & & & & \\
\hline & & & & & & & & & & & & & \\
\hline $149-4111$ & & & E0441-1241 & 35.2 & & & & & & & & & \\
\hline & & & & & & & & & & & & & \\
\hline $149-4656$ & 30.7 & & E0441-3430 & & & & & & & 37.7 & & & \\
\hline & 55.8 & & & 45.8 & & & & & & & & & \\
\hline $50+0104$ & 1.5 & & & 42.8 & & & & & & & & & \\
\hline & 9.7 & & & 42.3 & & & & & & & & & \\
\hline & 46.3 & & & 51.9 & & & & & & & & & \\
\hline & 57.2 & & & 41.9 & & & & & & & & & \\
\hline & & & & & & & & & & & & & \\
\hline & & & & & & & & & & & & & \\
\hline & & & & & & & & & & & & & \\
\hline & & & & & & & & & & & & & \\
\hline & & & & & & & & & & & & & \\
\hline+0117 & 5.5 & & & & & & & & & 50 & & & \\
\hline & .5 & & & & & & & & & & & & \\
\hline & 2.9 & & & & & & & & & & & & \\
\hline & & & & & & & & & & & & & \\
\hline & & & & & & & & & & & & & \\
\hline & & & & & & & & & & & & & \\
\hline & & & & 37 & & & & & & & & & \\
\hline & 1.4 & & & & & & & & & 31 & & & \\
\hline $51-4735$ & & & & & & & & & & & & & \\
\hline $1-4926$ & & & & & & & & & & & & & \\
\hline & & & & & & & & & & & & & \\
\hline & & & & & & & & & & & & & \\
\hline & & & & & & & & & & & & & \\
\hline & & & & & & & & & & & & & \\
\hline & & & & & & & & & & & & & \\
\hline & & & & & & & & & & & & & \\
\hline & 7.2 & & & & & & & & & & & & \\
\hline-4210 & & & & & & & & & & & & & \\
\hline & 7.2 & & & & & & & & & 40 & & & 52 \\
\hline & & & & & & & & & & & & & \\
\hline-2247 & & & & & & & & & & & & & 44.8 \\
\hline & .6 & & & & & & & & & & & & \\
\hline $3-4816$ & & & & & & & & & & & & & \\
\hline & & & & & & & & & & & & & 8 \\
\hline & & & & & & & & & & & & & \\
\hline & & & & & & & & & & 4 & & & 35.5 \\
\hline 1919 & & & & & & & & & & & & & \\
\hline & & & & & & & & & & & & & 59 \\
\hline & & & & & & & & & & & & & \\
\hline & & & & & & & & & & & & & 41.3 \\
\hline & & & & & & & & & & & & & \\
\hline 7 & & & & & & & & & & 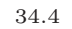 & & & 43.2 \\
\hline & & & & & & & & & & 3. & & & 44.6 \\
\hline 2918 & & & & & & & & & & & & & \\
\hline-5200 & & & 5 & & & & & & & & & 48 & 37.4 \\
\hline & & & & & & & & & & & & & \\
\hline & & & & & & & & & & & & & 6.8 \\
\hline & & & & & & & & & & & & & \\
\hline & & & & & & & & & & & & & 44.0 \\
\hline & & & & & & & & & & & & & \\
\hline 3 & & & & & & & & & & 36 & & & 44.9 \\
\hline & & & & & & & & & & & & & \\
\hline & & & & & & & & & & & & & \\
\hline & 1.3 & & & & & & & & & 4 & & & 42.0 \\
\hline & & & & & & & & & & & & & \\
\hline $8-5617$ & & & 18 & & & & & & & & & 16 & 38.2 \\
\hline & & & & & & & & & & & & & \\
\hline & & & & & & & & & & & & & 41.4 \\
\hline & & & & & & & & & & & & & \\
\hline & & & & & & & & & & & & & 818 \\
\hline & & & & & & & & & & & & & \\
\hline & & & & & & & & & & & & & \\
\hline & & & & & & & & & & & & & 46.1 \\
\hline & & & & & & & & & & & & & \\
\hline $\mathrm{H}$ & & & & & & & & & 32 & 32 . & & $\mathrm{E} 2328-3440$ & 40.4 \\
\hline & & & & & & & & & & & & & \\
\hline & & & & 45 & & & & & & & & & 46.3 \\
\hline & 40.3 & & & & & & & & & & & & \\
\hline HE $0200-1738$ & 37.6 & & HE0 $446-5049$ & 39.6 & & HE1215-1445 & 45.9 & & HE $2148-3057$ & 44.6 & & HE2329-2003 & 47.9 \\
\hline
\end{tabular}


Tabela C.1 (Continuação)

\begin{tabular}{|c|c|c|c|c|c|c|c|c|c|c|c|c|c|}
\hline Nome & $\mathrm{PE}$ & lasse & Nome & GPE & Classe & Nome & $\mathrm{PE}$ & Classe & Nome & GPE & Classe & Nome & GPE \\
\hline HE0200-2402 & 37.1 & mpcc & IE $0446-5052$ & 34.7 & mpcc & HE1215-1611 & 35.0 & pec & HE2148-3604 & 39.4 & $\mathrm{mpcc}$ & $2320-42$ & \\
\hline & 5.2 & & IE $0447-1751$ & 44.6 & & HE $1216-0036$ & 42.3 & & & & & & \\
\hline & 8.0 & & & 65.1 & & & & & & & & & \\
\hline HE $0201+0032$ & 4.8 & & E0447-3021 & 45.7 & & [E1216-2133 & 54.0 & & E2148-5145 & & & IE2329-6818 & \\
\hline & 5.4 & & & 39.7 & & & & & & & & & \\
\hline HE0201-1612 & 2.6 & & E0447-3334 & 32.5 & & HE $1216-2949$ & & & E2148-5939 & & & IE $2329-7620$ & \\
\hline & 6.5 & & & 45.1 & & & 51.6 & & & & & & \\
\hline & 1.0 & & $\mathrm{E} 0448+0024$ & 37.3 & & HE $1217-0046$ & & & HE2149-1 & & & & \\
\hline & 2.6 & & & 30.9 & & & 44.6 & & & & & & \\
\hline HE0201-5458 & 7.1 & & & & & HE $1217-0459$ & & & F2149-2 & & & & 45.8 \\
\hline HE0202-0153 & 0.9 & & & 50.8 & & & 8.3 & & 00 & & & & \\
\hline & 2.0 & & & & & & & & & & & & \\
\hline $2-0250$ & 8.4 & & & 44.5 & & & & & & & & & \\
\hline & & & & & & & & & & & & & \\
\hline $202-1005$ & 8.6 & & $8-51>$ & 33.1 & & & 35.5 & & & & & & \\
\hline & 55.2 & & & 36.4 & & & & & & & & & \\
\hline & 7.0 & & & 47.6 & & & 53.5 & & & & & & \\
\hline & 42.4 & & & 43.7 & & & & & & & & & \\
\hline-5539 & 7.8 & & & 45.6 & & & & & & & & & \\
\hline & 4.1 & & & 31.7 & & & 42.6 & & & & & & \\
\hline & 6.5 & & & & & & & & & & & & \\
\hline & 9.6 & & & & & & & & & & & & \\
\hline & 1.5 & & & & & & & & & & & & \\
\hline & 8.6 & & & 39.2 & & & & & & & & & \\
\hline & 3 & & & & & & & & & & & & \\
\hline $03-5910$ & 2.0 & & & 39.8 & & & 41 & & & & & & \\
\hline & 1.0 & & & 46. & & & & & & & & & \\
\hline & 2.6 & & & 50.8 & & & & & & & & & \\
\hline & 3.0 & & & 49 & & & & & & & & & \\
\hline & 7.9 & & & & & & & & & & & & \\
\hline & 2.7 & & & 47 & & & & & & & & & \\
\hline & 5.1 & & & & & & & & & & & & \\
\hline & 2.6 & & & 39.7 & & & 42 & & & 41 & & & \\
\hline $4-5716$ & 7.7 & & & 47.6 & & & & & & & & & \\
\hline & 3.1 & & & 30.4 & & & & & & & & & \\
\hline & 3 & & & & & & & & & & & & \\
\hline & 1.3 & & & 41. & & & & & & & & & \\
\hline & 4 & & & & & & & & & & & & \\
\hline & 4.5 & & & 49. & & & & & & & & & \\
\hline & 1.5 & & & 44. & & & & & & & & & \\
\hline & 4.4 & & & 43. & & & & & & & & & \\
\hline & 37.1 & & & 39. & & & & & & & & & \\
\hline & 6.1 & & & 45 & & & & & & & & & \\
\hline & 6.7 & & & 40. & & & & & & & & & \\
\hline & 0.8 & & & & & & & & & & & & \\
\hline-5251 & 1.7 & & & & & & & & & & & & \\
\hline & 8.2 & & & & & & & & & & & & \\
\hline & 7.1 & & & 30 & & & & & & & & & \\
\hline & 5 & & & & & & & & & & & & .1 \\
\hline-2341 & 1.1 & & & & & & & & & & & & \\
\hline & 9.2 & & & & & & & & & & & & 4 \\
\hline & 9.6 & & & & & & & & & & & & \\
\hline & 9.0 & & & & & & & & & & & & \\
\hline & & & & & & & & & & & & & \\
\hline & 7.3 & & & & & & & & & & & & \\
\hline & 1.4 & & & & & & & & & & & & \\
\hline & 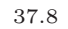 & & & & & & & & & & & & \\
\hline & 8.9 & & & 36. & & & & & & & & & 3 \\
\hline & 3 & & & 37 & & & & & & & & & \\
\hline & 8.4 & & & & & & & & & & & & 9.9 \\
\hline & 3.8 & & & & & & & & & & & & \\
\hline & 5.9 & & & & & & & & & & & & 4 \\
\hline & 2.7 & & & & & & & & & & & & \\
\hline & 3 & & & & & & & & & & & & 59.1 \\
\hline & 0.7 & & & & & & & & & & & & \\
\hline & 4 & & & & & & & & & 40 & & & 39.2 \\
\hline & 4 & & & & & & & & & & & & \\
\hline & & & & & & & & & & & & & \\
\hline & 6.5 & & & & & & & & & & & & .6 \\
\hline & & & & & & & & & & & & & \\
\hline $1-5511$ & 5.1 & & & & & & & & & 45.9 & & & 51.8 \\
\hline & & & & & & & & & & & & & \\
\hline & & & & & & & & & & & & & \\
\hline & 8. & & & & & & & & & & & & \\
\hline & & & & & & & & & & & & & \\
\hline & $1.8 \mathrm{r}=\mathrm{s}=\mathrm{s}$ & & & 49 & & & & & & & & & \\
\hline & & & & & & & & & & & & & \\
\hline & 4 & & & & & & 33 & & & & & & \\
\hline & & & & & & & & & & & & & \\
\hline 20213-0905 & 45.7 & & & 45.7 & & & 38. & & & 35.4 & & $37-6941$ & 56.1 \\
\hline & 36.6 & & & 43. & & & & & & & & & \\
\hline $3-3131$ & 45.7 & & & & & & 31 & & & 41 & & 14 & 53.2 \\
\hline & 48.8 & & & & & & & & & & & & \\
\hline HE $0213-5314$ & 51.9 & fhlc & HE $0458-4151$ & 35.3 & pcc & HE $1230-2638$ & 36.6 & mpcc & HE $2157-4428$ & 42.0 & mpcc & $\mathrm{HE} 2338+0032$ & 44.7 \\
\hline
\end{tabular}


Tabela C.1 (Continuação)

\begin{tabular}{|c|c|c|c|c|c|c|c|c|c|c|c|c|c|}
\hline Nome & $\mathrm{PE}$ & Classe & Nome & $\mathrm{APE}$ & lasse & Nome & GPE & Classe & Nome & GPE & Classe & Nome & GPE \\
\hline HE0213-5404 & 39.6 & mpcc & HE0 $458-4820$ & 39.3 & mpcb & E1231-0116 & 55.8 & mpcc & 2157 & 39.4 & mocc & $52328-20 \%$ & 39.9 \\
\hline HE0213-5707 & & & HE $0458-5306$ & & & E1231-1616 & & & HE $2157-5939$ & & & & 37.8 \\
\hline E0213-6140 & 7.7 & & & & & & & & E2158-1652 & 34.8 & & & 47.8 \\
\hline E0214+0013 & & & E0459-1647 & 47.1 & & E1231-2711 & & & E2158-1856 & 40.5 & & IE $2338-2908$ & 33.4 \\
\hline [E0214-0343 & 2.4 & & & 37.3 & & & & & & 39.6 & & & 39.8 \\
\hline [E0214-0818 & & & E0459-2051 & & & E1232-0337 & & & HE $2158-2643$ & 37.2 & & HE $2338-3739$ & \\
\hline & 1.7 & & & 39.9 & & & & & & 44.1 & & & \\
\hline E0214-2326 & 61.9 & & E0459-3850 & 37.7 & & E1232-3047 & & & HE $2158-4046$ & 35.2 & & HE $2338-5622$ & 46.3 \\
\hline & 35.8 & & & 44.8 & & & 40.6 & & & 31.3 & & & \\
\hline HE $0214-5145$ & 7.2 & & E0459-4822 & & & & & & IE $2158-5041$ & & & & 34.7 \\
\hline HE $0215-1648$ & .7 & & E0459-5650 & & & 54 & & & E2158-5731 & 50.7 & & & 39.3 \\
\hline & & & & & & & & & & & & & \\
\hline $215-5426$ & $\begin{array}{c}5.7 \\
\end{array}$ & & $\mathrm{E} 0500-4026$ & & & & & & & 43.2 & & & \\
\hline & & & & & & & & & & & & & \\
\hline $216-1204$ & & & E0500-5603 & & & & & & $50150 \quad 1$ & 37.1 & & & \\
\hline & 43.3 & lpcc & & 48.8 & & & & & & & & & 30.6 \\
\hline & 37.1 & & & 33.9 & & & & & & 46.7 & & & 52.7 \\
\hline & 43.2 & & & 31.3 & & & & & & & & & \\
\hline-2124 & 40.0 & & -3112 & & & & & & & 37.7 & & & 56.4 \\
\hline & 494 & & & 36.6 & & & & & & & & & \\
\hline & 34.9 & & & & & & & & & & & & 43.9 \\
\hline & 37.7 & & & & & & & & & & & & \\
\hline & & & & & & & & & & & & & \\
\hline & & & & & & & & & & & & & \\
\hline & & & & & & & & & & & & & \\
\hline & 0.7 & & & & & & & & & 3 & & & \\
\hline & 90 & & & 40. & & & & & & & & & \\
\hline & 4 & & & & & & & & & & & & \\
\hline & & & & & & & & & & & & & \\
\hline & & & & & & & & & & & & & \\
\hline & & & & & & & & & & 32 & & & \\
\hline & & & & & & & & & & & & & \\
\hline & 90 & & & & & & & & & 58.5 & & & \\
\hline & & & & & & & & & & & & & \\
\hline & & & & & & & & & & & & & \\
\hline & & & & & & & & & & & & & \\
\hline & & & & & & & & & & & & & \\
\hline & & & & & & & & & & & & & \\
\hline-0229 & & & & & & & & & & & & & \\
\hline & 7 & & & & & & & & & 6 & & & \\
\hline & & & & & & & & & & & & & 44 \\
\hline & 2.1 & & & & & & & & & 40 & & & 36 \\
\hline-4005 & & & & & & & & & & & & & \\
\hline & 4.1 & & & & & & & & & 42 & & & 56 \\
\hline & & & & & & & & & & & & & \\
\hline-1805 & & & & & & & & & & 1.4 & & & 56.3 \\
\hline & & & & & & & .6 & & & 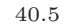 & & & \\
\hline & & & & & & & & & & & & & \\
\hline & & & & & & & & & & & & & \\
\hline-1604 & & & & & & & & & & & & & \\
\hline & & & & & & & & & & 4 & & & 51.4 \\
\hline & & & & & & & & & & & & & \\
\hline & & & & & & & & & & 55 & & & 35 \\
\hline & & & & & & & & & & & & & \\
\hline & & & & & & & & & & & & & 49 \\
\hline & & & & & & & & & & & & & \\
\hline & & & & & & & & & & 42.3 & & & 480 \\
\hline-1012 & .7 & & & & & & & & & 5.8 & & & 50.8 \\
\hline-1256 & & & & & & & & & & & & & \\
\hline $3-2804$ & & & & & & & & & & 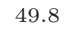 & & & 37.6 \\
\hline & & & & & & & & & & & & & \\
\hline & & & & & & & & & & & & & 42.1 \\
\hline & & & & & & & & & & & & & \\
\hline & & & & & & & & & & & & & 466 \\
\hline & & & & & & & & & & & & & \\
\hline & & & & & & & & & & & & & 34.5 \\
\hline & & & & & & & & & & 40 & & & \\
\hline & & & & & & & & & & & & & \\
\hline & & & & & & & & & & & & & 49.2 \\
\hline & & & & & & & & & & & & & \\
\hline-3616 & 1.5 & & & & & & & & 37 & 32.3 & & $45-6937$ & 56.0 \\
\hline & & & & & & & & & & & & & \\
\hline & & & & & & & & & & & & & \\
\hline & & & & & & & & & & & & & \\
\hline & & & & & & & & & & & & & 33 \\
\hline & & & & & & & & & & & & & 37.6 \\
\hline & & & & & & & & & & & & & \\
\hline & & & & & & & & & & 44 & & & 35.0 \\
\hline & & & & & & & & & & & & & \\
\hline $\mathrm{H}$ & & & E0509-1611 & 39 & & & & & $2205-5442$ & 51.7 & & HE $2346-6224$ & 33.1 \\
\hline & & & & & & & & & & 50. & & & \\
\hline & & & & & & & & & & 47. & & 59 & 46.8 \\
\hline & 51.1 & & & & & & & & & 42.1 & & & \\
\hline HE $0227-0811$ & 48.4 & & HE $0509-2042$ & 41.1 & & $\mathrm{HE} 1246-1644$ & 40.1 & npce & HE $2206+0132$ & 35.8 & & HE $2346-7147$ & 35.6 \\
\hline
\end{tabular}


Tabela C.1 (Continuação)

\begin{tabular}{|c|c|c|c|c|c|c|c|c|c|c|c|c|c|}
\hline Nome & $\mathrm{PE}$ & lasse & Nome & GPE & Classe & Nome & $\mathrm{PE}$ & Classe & Nome & GPE & Classe & Nome & GPE \\
\hline HE0227-1008 & 45.3 & mpcc & IE0509-2210 & 43.7 & mpcb & HE1247-0629 & 47.6 & mpcb & HE2206-1659 & 49.3 & $\mathrm{mpcc}$ & 2347 & \\
\hline & & & & 38.0 & & HE $1247-1944$ & & & & & & & \\
\hline HE $0227-1805$ & 4.4 & & & 45.2 & & & & & & & & & \\
\hline HE $0227-1805$ & 5.0 & & E0509-4255 & 41.6 & & [E1248-1116 & 8.5 & & E2206-2732 & 33.8 & & IE $2347-4449$ & \\
\hline HE $0227-3021$ & 2.7 & & & 32.7 & & & & & & & & & \\
\hline HE0227-3705 & 36.9 & & E0510-2227 & 61.0 & & HE $1249-1310$ & 43.3 & & E2206-2914 & & & IE2347-6839 & \\
\hline & 41.7 & & & 45.5 & & & 48.2 & & & & & & \\
\hline HE0227-4126 & 47.1 & & E0510-3428 & 41.3 & & HE $1249-2157$ & 35.0 & & HE2207-0912 & & & IE $2348-3140$ & \\
\hline & 40.2 & & & 35.9 & & & 57.5 & & & & & & \\
\hline & 36.4 & & & & & & & & & & & & \\
\hline $8-3524$ & 7.3 & & 50 & 66.5 & & & 4.6 & & & & & & \\
\hline & 48.1 & & & & & & & & & & & & \\
\hline $8-4357$ & 47.3 & & & 46.2 & & & 38.4 & & & & & & \\
\hline & 46.1 & & & & & & & & & & & & \\
\hline $29-0300$ & 47.6 & & 005112 & 33.1 & & & 36.0 & & & & & & \\
\hline & 32.6 & & & 42.2 & & & 41.4 & & & & & & \\
\hline & 47.3 & & & 33.0 & & & 38.6 & & & & & & \\
\hline & 46.8 & & & 38.8 & & & & & & & & & \\
\hline-4622 & 36.3 & & & 37.9 & & & 44.2 & & & & & & \\
\hline & 68.1 & & & 40.8 & & & 48.5 & & & & & & \\
\hline & 4.5 & & & & & & & & & & & & \\
\hline & 6.3 & & & & & & 37.6 & & & & & & \\
\hline & 6.1 & & & & & & & & & & & & \\
\hline & 41.4 & & & 40. & & & & & & & & & \\
\hline & 4.7 & & & & & & & & & & & & \\
\hline & 4.5 & & & 49. & & & 31 & & & & & & \\
\hline & 0.3 & & & & & & & & & & & & \\
\hline+0152 & 3.0 & & & 54. & & & 39 & & & & & & \\
\hline & 0.1 & & & 55. & & & & & & & & & \\
\hline & 4.1 & & & 49 & & & & & & & & & \\
\hline & 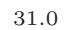 & & & 46. & & & & & & & & & \\
\hline & 2.9 & & & 43 & & & & & & & & & \\
\hline & 3.7 & & & 38. & & & & & & & & & \\
\hline & 5 & & & 42. & & & & & & & & & \\
\hline & 9.9 & & & & & & & & & & & & \\
\hline & 3 & & & & & & & & & & & & \\
\hline $2-3527$ & 4.5 & & & $34+2$ & & & & & & & & & \\
\hline & 0.6 & & & & & & & & & & & & \\
\hline $3+0155$ & 5.6 & & & & & & & & & & & & \\
\hline & 2.2 & & & 48. & & & & & & & & & \\
\hline & 0.3 & & & 36. & & & 52 & & & & & & \\
\hline & 6.9 & & & & & & & & & & & & \\
\hline & 4.9 & & & 49. & & & & & & & & & \\
\hline & 1.1 & & & 31. & & & 49. & & & & & & \\
\hline & 0.3 & & & 55. & & & & & & & & & \\
\hline 66 & 5.9 & & & & & & 51.4 & & & & & & \\
\hline & 4.3 & & & 41. & & & & & & & & & \\
\hline & 4.1 & & & 1 & & & & & & & & & \\
\hline & 41.3 & & & & & & & & & & & & \\
\hline & 47.9 & & & & & & & & & & & & \\
\hline & 3.8 & & & & & & & & & & & & 4 \\
\hline-1720 & 2.1 & & & & & & & & & & & & \\
\hline & 4.9 & & & & & & & & & & & & \\
\hline & 0.3 & & & & & & & & & & & & \\
\hline & 1.1 & & & & & & & & & & & & \\
\hline & 4 & & & & & & & & & & & & \\
\hline 5 & 6.0 & & & & & & & & & 39 & & & 52 \\
\hline & 7.1 & & & 45. & & & & & & & & & 8.2 \\
\hline $6-4218$ & 9. & & & & & & & & & & & & \\
\hline $7-1801$ & 6.4 & & & & & & & & & & & & 39.1 \\
\hline & 5.4 & & & & & & & & & & & & \\
\hline & 3.1 & & & & & & & & & & & & 46. \\
\hline & 5.4 & & & & & & & & & & & & \\
\hline & 3 & & & & & & & & & & & & \\
\hline & 5.3 & & & & & & & & & & & & \\
\hline & 6. & & & & & & & & & 43 & & & 58.3 \\
\hline & 8.6 & & & & & & & & & & & & \\
\hline & & & & & & & & & & & & & \\
\hline-4201 & 3.9 & & & & & & & & & & & & 50.9 \\
\hline & & & & & & & & & & & & & \\
\hline-0947 & 6.3 & & & 53. & & & & & & 31.2 & & & 44.9 \\
\hline & 6.7 & & & & & & & & & & & & \\
\hline & & & & & & & & & & & & & \\
\hline & & & & & & & & & & & & & \\
\hline & & & & & & & & & & & & & 42. \\
\hline & 6.2 .250 & & & & & & & & & & & & \\
\hline & 6. & & & & & & & & & & & & \\
\hline & 4 & & & & & & 46 & & & & & & \\
\hline & & & & & & & & & & & & & \\
\hline $40-2133$ & 45.8 & & $0521-3953$ & 45.5 & & 9 & 49. & & 49 & 36.2 & & IE $2354-5446$ & 42.0 \\
\hline & 6.7 & & & 41. & & & 40. & & & & & & \\
\hline-5115 & 48.0 & & & & & & & & & 39 & & 39 & 41.4 \\
\hline & 44.3 & & & & & & & & & & & & \\
\hline HE $0240-5833$ & 53.5 & mpcc & HE0522-4706 & 37.0 & & HE1306-2806 & 35.0 & mpcc & HE $2212-4127$ & 46.7 & mpcc & HE2355-3354 & 45.6 \\
\hline
\end{tabular}


Tabela C.1 (Continuação)

\begin{tabular}{|c|c|c|c|c|c|c|c|c|c|c|c|c|c|c|}
\hline Nome & GPE & Classe & Nome & GPE & Classe & Nome & GPE & Classe & Nome & GPE & Classe & Nome & GPE & Classe \\
\hline HE0241-0719 & 33.3 & $\mathrm{mpcc}$ & HE0522-5716 & 41.1 & mpcc & HE1307-0146 & 41.4 & $\mathrm{mpcc}$ & HE2212-4803 & 57.4 & macc & F $2355-30$ & 43.4 & mpcc \\
\hline HE0241-1927 & & & HE0523-2014 & & & HE1307-0529 & & & & 40.4 & & & 34.4 & \\
\hline E0241-3333 & 5.8 & & & 45.1 & & E1307-2509 & 41.7 & & E2212-6821 & 30.8 & & IE $2355-4007$ & 37.7 & \\
\hline E0241-3828 & 52.9 & mpcc & E0523-5019 & 52.1 & pcc & E1307-2906 & 36.8 & & E2213-1145 & 38.6 & & HE2355-4928 & 48.3 & \\
\hline E0241-4105 & 45.7 & fhlc & & 40.2 & & & 44.2 & & & 42.9 & mpcb & & 43.6 & \\
\hline E0241-4847 & 38.4 & $\mathrm{mpcc}$ & HE $0524-4106$ & 44.6 & & $\mathrm{E} 1308-2206$ & 37.3 & & HE $2213-1840$ & 34.3 & & HE $2355-6644$ & 48.8 & \\
\hline E0242-0849 & 42.8 & mpcc & HE0524-4134 & 45.2 & unid & E1308-2657 & 39.8 & unid & & 32.0 & & & 51.5 & \\
\hline E0242-1733 & 31.8 & & HE0524-4438 & 48.0 & & E1309-0258 & 45.5 & & HE $2213-2227$ & 33.0 & & HE $2356-1759$ & 50.1 & \\
\hline & 37.9 & & & 42.2 & & & & & & 45.6 & & & 49.3 & \\
\hline HE $0243+0129$ & 39.5 & & HE $0525-5332$ & 38.9 & & E1309-1739 & 33.8 & & HE $2213-3026$ & 41.3 & & HE $2356-2847$ & 35.2 & \\
\hline HE0243-1850 & & & & & & & & & & 61.1 & & & & \\
\hline $43-2741$ & 36.6 & & & & & & & & & & & & & \\
\hline $43-3433$ & 34.4 & & E0526-4734 & 36.6 & & $\mathrm{E} 1310+0112$ & & & & 42.7 & & & & \\
\hline $243-4154$ & 5.9 & & & 37.0 & & & & & & 42.1 & & & 61.2 & \\
\hline $243-5051$ & 37.2 & & E0528-4410 & 48.0 & & E1310-1407 & 30.2 & & $2214-0$ & 41.5 & & 47 & 44.0 & \\
\hline & 37.9 & & & 43.5 & & & & & & 40.1 & & & & \\
\hline-1806 & 8.6 & & -3745 & 46.1 & & & & & & 55.5 & & & 58.9 & \\
\hline & 6.2 & & & & & & & & & 43.5 & & & & \\
\hline & 5.5 & & & 38 & & & & & & 8 & & & 31.3 & \\
\hline & 48.2 & & & 51.3 & & & 54 & & & 35.2 & & & 43.9 & \\
\hline HE0244-3654 & 3 & $\mathrm{mpcc}$ & $529-5043$ & 50.7 & & 14 & 52.2 & & & 34.5 & $\mathrm{cb}$ & & 42.3 & \\
\hline-5148 & & & & & & & 36 & & & 34.3 & & & 48.6 & \\
\hline-1516 & & & & & & & & & & 7.2 & & & & \\
\hline $5-2237$ & 5.9 & & & 40.4 & & & 39.3 & & & 35.0 & & & 44.6 & \\
\hline & 3 & & & 43.4 & & & 53.9 & & & 47.9 & & & 31.8 & \\
\hline & & & & 42 & & & & & & 55.5 & & & & \\
\hline & 8.8 & & & & & & & & & 55. & & & 47.0 & \\
\hline & & & & & & & & & & & & & & \\
\hline 755 & 4.9 & & & 39.0 & & & 36. & & & 38.6 & & & 56.7 & \\
\hline & & & & & & & & & & & & & & \\
\hline & & & & & & & & & & 51.2 & & & 38.2 & \\
\hline & & & & 38 & & & 49 & & & 42.7 & & & 54.5 & \\
\hline & & & & & & & & & & 42.4 & & & 42.9 & \\
\hline $48-0740$ & 3.4 & & -5356 & 45.4 & & -3149 & 36.3 & & & 41.4 & & $59-0149$ & 41.8 & \\
\hline & & & & & & & & & & & & & & \\
\hline $48-1020$ & & & & & & & & & & 36.0 & & & 38.3 & \\
\hline & & & & & & & & & & & & & & \\
\hline & & & & & & & & & & 57.1 & & & 38.3 & \\
\hline & & & & & & & & & & 40 & & & 45 & \\
\hline & & & & & & & & & & & & & & \\
\hline & & & & 30 & & & & & & 40 & & & 33.8 & \\
\hline & & & & & & & & & & & & & & \\
\hline $48-3851$ & 4 & & HE0536-3825 & 40 & & E1318-0445 & 36.2 & & HE2216-51 & 34.1 & & HE2359-4030 & 41.6 & mpcc \\
\hline & & & & & & & & & & 37.5 & & & & \\
\hline $\mathrm{H}$ & & & 40 & & & 15 & & & & 44.7 & & 10 & 32.7 & \\
\hline & & & & & & & & & & 47.0 & & & 40.8 & \\
\hline $49-310$ & & & $\mathrm{H}$ & 41 & & 4 & & & 26 & 56.9 & & HE2359-6 & 54.6 & mpcc \\
\hline & & & & & & & & & & 36.7 & & $\ldots$ & & \\
\hline HE0250-3217 & & & & & & & & & & 41.7 & & . & & \\
\hline
\end{tabular}

